\title{
High Fumonisin Content in Maize: Search for Source of Infection and Biological Function
}

\author{
Dissertation \\ to obtain the $\mathrm{Ph}$. D. degree \\ in the International Ph.D. Program for Agricultural Sciences in Göttingen (IPAG) \\ at the Faculty of Agricultural Sciences, \\ Georg-August-University Göttingen, Germany
}

Presented by

Raana Dastjerdi

Born in Ghazvin, Iran

Göttingen, March 2014 
D7

1. Name of supervisor:

Prof. Dr. Petr Karlovsky

2. Name of co-supervisor:

Dr. Horst-Henning Steinmann

Date of dissertation:

May 8, 2014 
Life is not empty

Kindness, apples, faith

Aye, !

While there are peonies one can live on...

In my heart, there is something like a blaze of light, like a morning dream

And so restless am I that I feel like running

To the far end of the plains, up to the mountain top

A voice keeps calling me from afar........

"Sohrab Sepehri", Iran (1928-1980)

"I dedicate this thesis to my parents" 


\section{Contents}

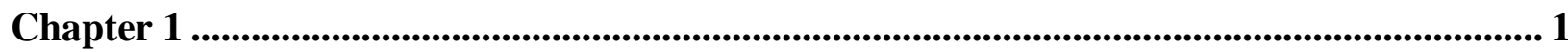

General Background........................................................................................................................................... 1

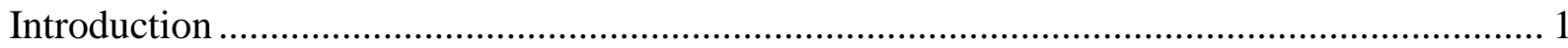

Epidemiology of Maize Fusarium Diseases .................................................................... 2

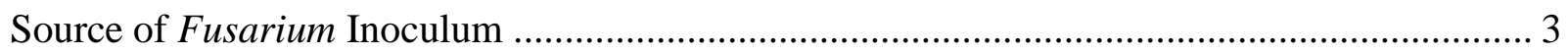

Weed Plants as Symptomless Alternative Hosts...................................................................... 4

Identification and Characterization of Fusarium Species ....................................................... 6

Detection and Quantification of Fungal Biomass .................................................................... 8

Role of Mycotoxins in Fusarium Diseases .................................................................... 9

Objectives of the Study …………………....................................................................... 12

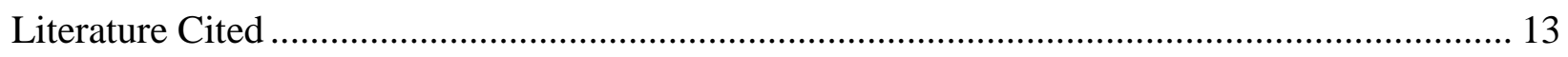

Chapter 2 ............................................................................................................................................................ 21

Real-time PCR (qPCR) for Simultaneous Quantification of Maize Pathogens: Fusarium avenaceum, $F$. culmorum, $F$. equiseti, $F$. graminearum, $F$. poae, $F$. proliferatum, F. subglutinans, F. tricinctum, and $F$. verticillioides in 4- $\mu \mathrm{l}$ Reactions...................................... 21

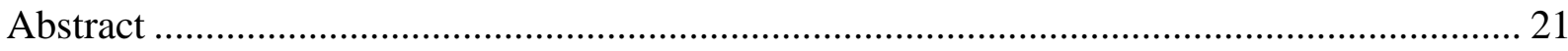

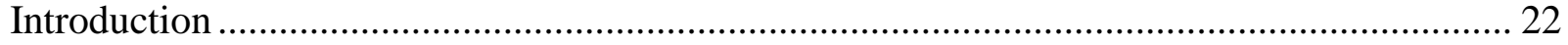

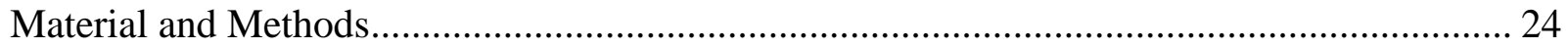

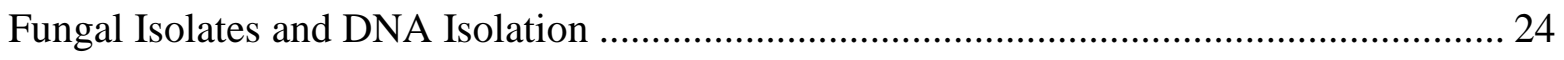

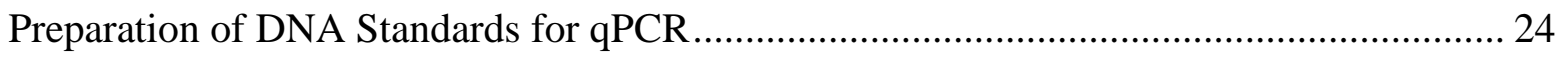

Selection of Primers and Evaluation of their Specificity .................................................... 27

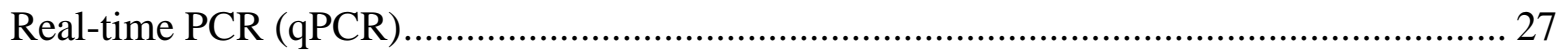

Determination of qPCR Sensitivity and Efficiency ……..................................................... 28 


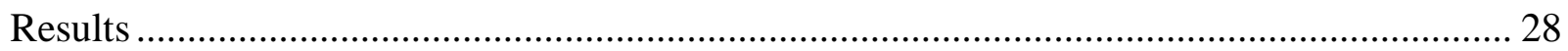

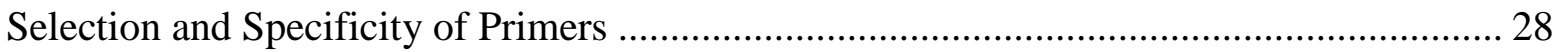

Optimization of a Protocol for Simultaneous Quantification of Nine Fusarium spp. in a Single Microplate ................................................................................................... 29

Optimization of the qPCR Assays for Individual Fusarium Species .............................. 31

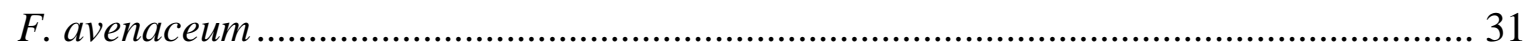

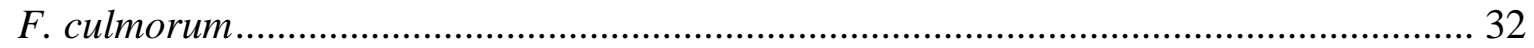

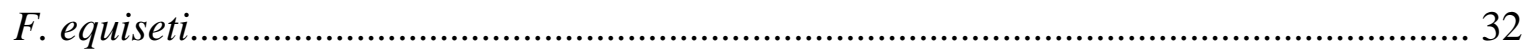

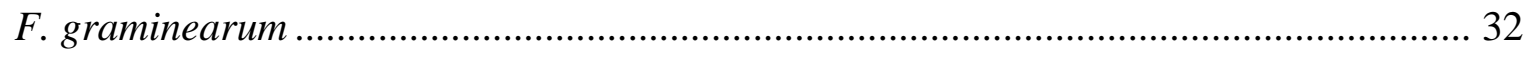

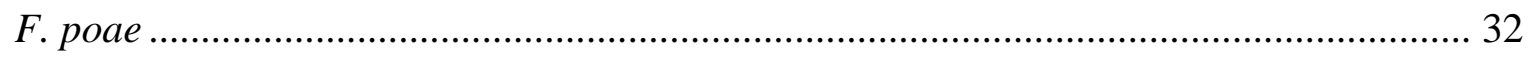

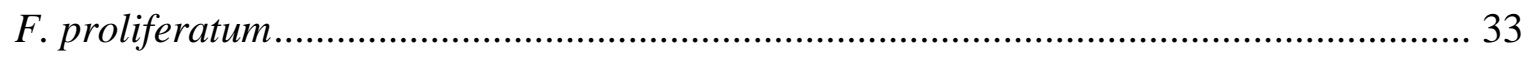

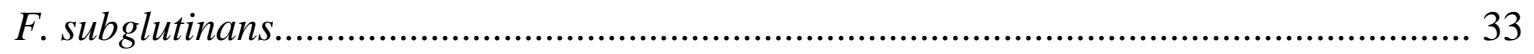

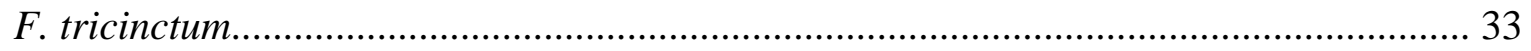

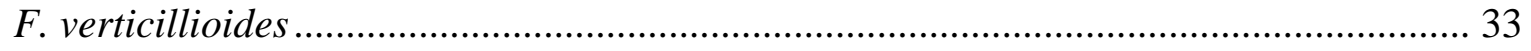

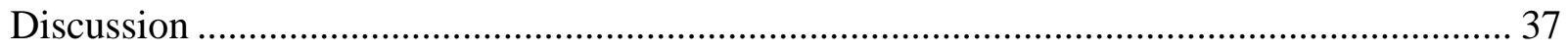

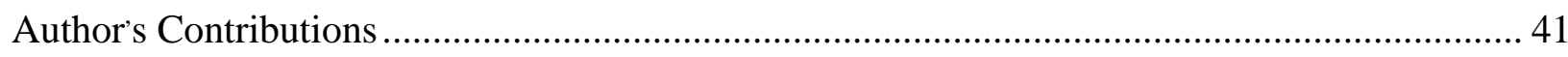

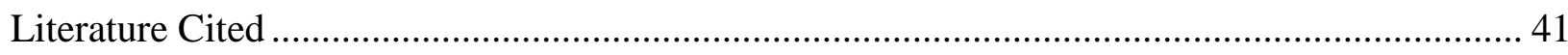

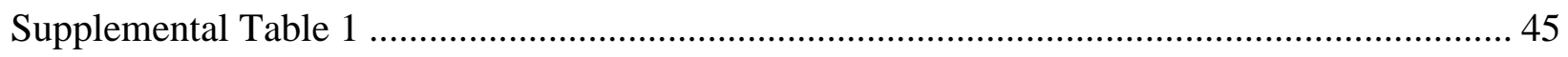

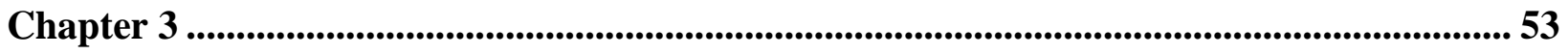

Colonization of Weed Species with Fusarium spp. in Maize Fields ........................................ 53

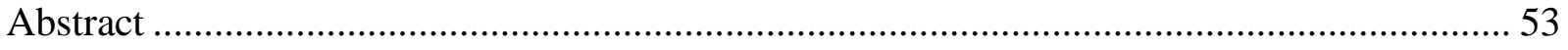

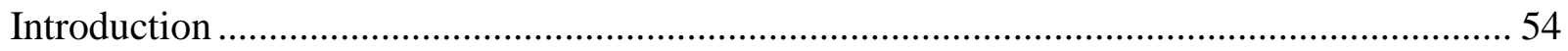

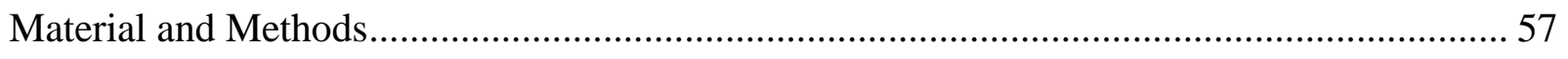

Collection and Processing of Weed Plants from Maize Fields ....................................... 57

Detection of Fusarium spp. in Weeds by Real-time PCR ............................................. 58 
Fungal Isolation and Morphological Identification of Fusarium spp................................ 58

Fusarium DNA Sequencing and Taxonomic Analysis ............................................. 59

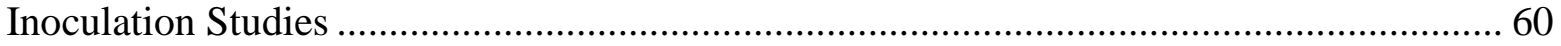

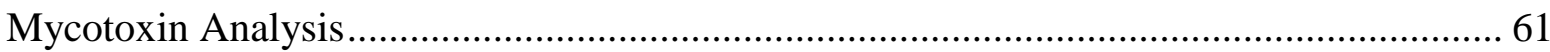

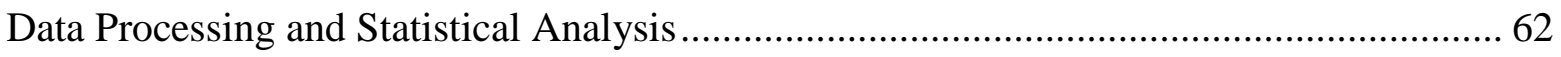

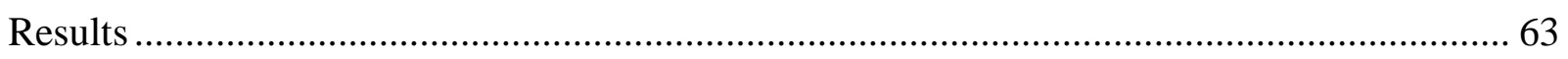

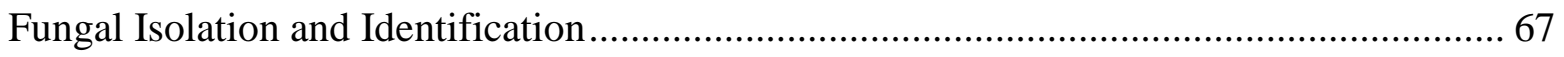

Fusarium DNA Sequencing and Phylogenetic Analysis............................................. 69

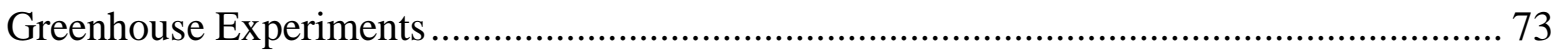

Determination of Mycotoxins Content ............................................................... 74

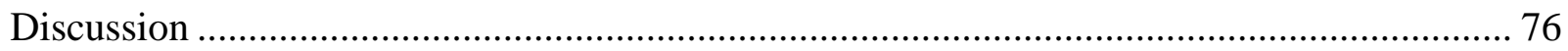

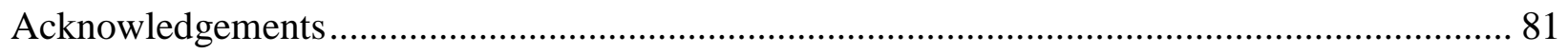

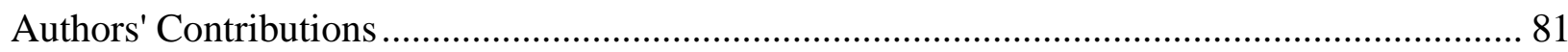

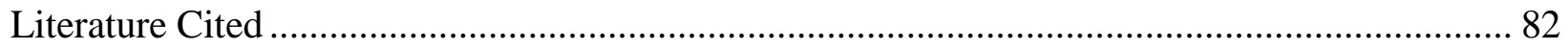

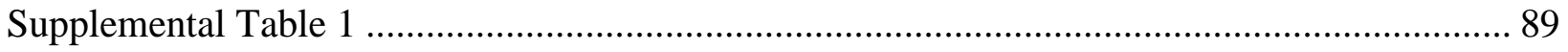

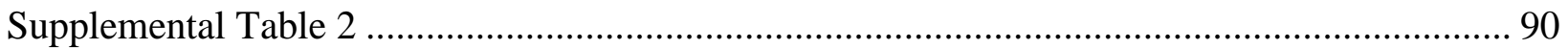

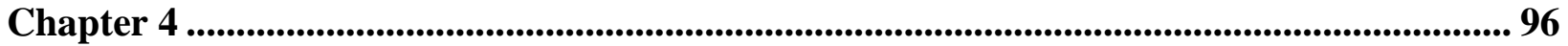

Aggressiveness of Fusarium verticillioides Strains Differing in Ability to Produce Fumonisin in Maize, Sorghum, Rice, and Beetroot Seedlings ................................................... 96

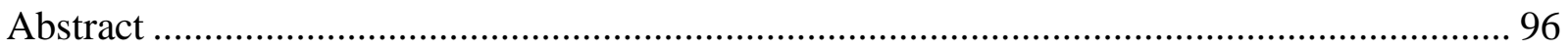

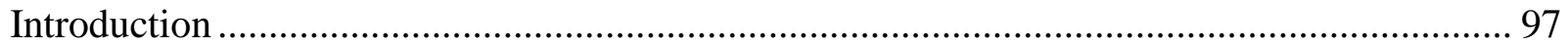

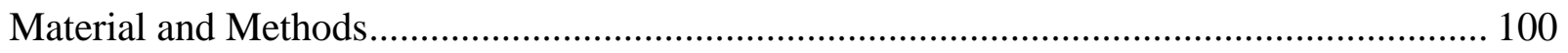

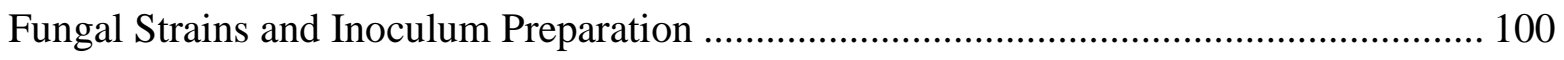

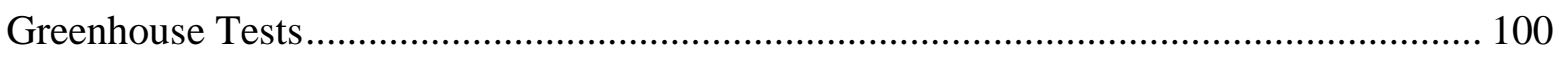

DNA Extraction and Determination of Matrix Effects .............................................. 102 
Molecular Quantification of Fungal DNA................................................................. 102

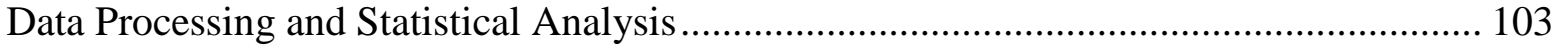

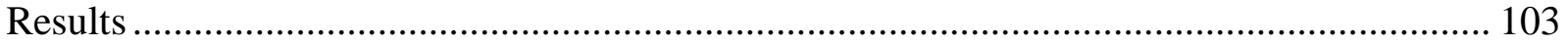

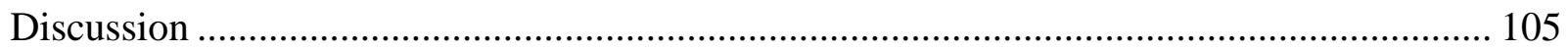

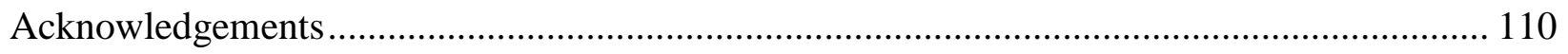

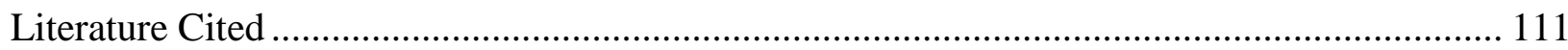

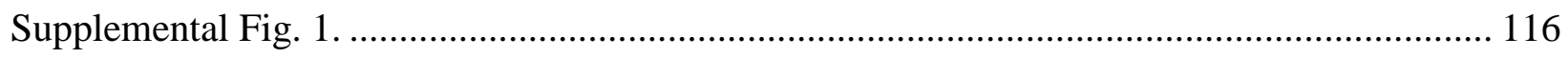

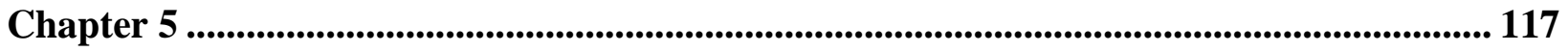

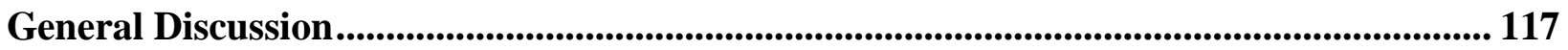

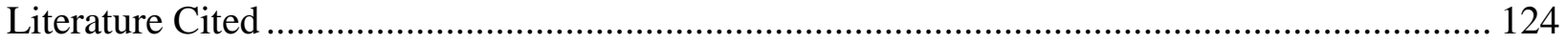

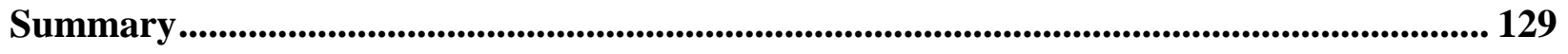

Acknowledgements ............................................................................................................... 131

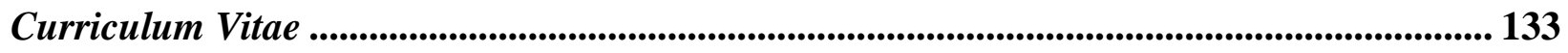

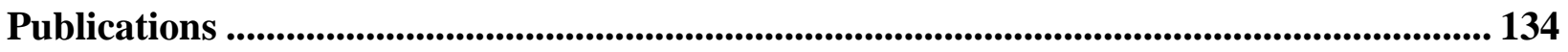




\section{Chapter 1}

\section{General Background}

\section{Introduction}

Maize (Zea mays) is one of the most important cereal crops in the world, and is widely grown in diverse climatic and ecological conditions. Worldwide production of maize is 690 million tons, of which 273 million tons (around 40\%) is grown by the United States (FAO, 2013). China and Brazil, with productions of 208 and 71 million tons respectively, are the next largest producers in the world. Maize plays an important role in the diet of both humans and animals. Therefore, the growing demand from a rising human population has been causing a steady increase in the global production of maize (Shiferaw et al., 2011; Nuss \& Tanumihardjo, 2010).

Fungi in the genus Fusarium are well known as economically important maize pathogens. They cause ear and kernel rot, stalk rot and seedling blight, with subsequent yield reductions of 10 to $30 \%$, while the quality of the products is also influenced (Logrieco et al., 2002; Gilbertson et al., 1985; Pintos Varela et al., 2013). Among the large number of Fusarium spp. reported from maize infected tissues, relatively few are considered to be of major significance. The main Fusarium pathogens associated with maize ear rot are divided into two groups. The members of the Gibberella fujikorui species complex, including Fusarium verticillioides (Sacc.) Nirenberg, F. proliferatum (Matsushima) Nirenberg, F. subglutinans (Wollenweb. \& Reinking) P. E. Nelson, T. A. Toussoun \& Marasas and F. temperatum are responsible for Fusarium ear rot or pink fusariosis. These species are representatives of Liseola section. Recently, F. temperatum has been separated from F. subglutinans (Scauflaire et al., 2011) and shown to be a pathogen of seedling blight and stalk rot of maize in Spain (Pintos Varela et al., 2013). The second group contains species of the Discolour section, mainly F. graminearum Schwabe and F.culmorum (W. G. Smith) Sacc, which cause red fusariosis or Gibberella ear rot (Munkvold, 2003). Although these Fusarium species are of the greatest overall significance, other toxigenic Fusarium spp. including F. avenaceum, F. poae, F. equiseti, F. tricinctum, F. cerealis, F. sporotrichioides and F. semitectum also contribute to the infection of maize ear tissue in particular situations. F. oxysporum has been found to be a less common 
species in maize and other cereal crops. $F$. venenatum is another species that sporadically has been isolated from maize tissues (Logrieco et al., 2002; Kosiak et al., 2003; Yli-Mattila, 2010). The distribution and prevalence of different Fusarium spp. largely depends on environmental conditions and agricultural practices (Arino \& Bullermann, 1994). Simultaneous occurrence of several species of Fusarium on maize kernels can affect the final level of infection and mycotoxin contamination (Munkvold, 2003).

Maize Fusarium diseases have received more attention because of their association with kernel mycotoxin contamination. Mycotoxins are secondary metabolites produced by fungi such as Fusarium spp. that are capable of contaminating food and feed products. Occurrence of mycotoxins in maize had always been a serious concern for both human and animal consumers. Low doses of mycotoxins could also be dangerous when consumed over prolonged periods of time (Pestka \& Smolinski, 2005). The main Fusarium mycotoxins, including trichothecenes, fumonisins, zearalenone, enniatins and moniliformin are usually reported from infected maize tissues (Glenn, 2007; Placinta et al., 1999). They are formed in rotted stalks (zearalenone, zearalenols) (Bottalico et al., 1985), infected leaves (nivalenol) and in entire plants (zearalenone) (reviewed in Logrieco et al., 2002). Many countries have established threshold values for Fusarium mycotoxin contamination in cereals and products and samples exceeding this limit are not allowed to be marketed (D'Mello et al., 1999).

\section{Epidemiology of Maize Fusarium Diseases}

F. verticillioides is the predominant Fusarium pathogen, known as causal agent of maize pink ear rot. It is a heterothallic species and forms fruiting structures less readily than homothallic ones. Therefore, it usually produces thickened hyphae to be able to survive the absence of host plants during the off season. Although sexual reproduction is considered important for the genetic recombination of the fungi, in epidemiology it does not play a major role. For this heterothallic Fusarium spp., formation of asexual spores on plant residues is considered as the main source of inoculum. Infection of the silk channel by airborne conidia leads to symptomless kernel infection. The primarily infectious propagules, thus, are microconidia, although dispersion of macroconidia by wind has been reported as well (Munkvold, 2003). 
In contrast, reports show F. graminearum isolates (teleomorph: Gibberella zeae (Schweinitz) Petch, which are a causal agent of both head blight (scab) of wheat and red ear rot of maize, are able to produce brownish perithecia in nature (Parry et al., 1995). In Europe, this species ( $F$. graminearum, lineage 7 sensu stricto) has been replacing the closely related F. culmorum (Yli-Mattila, 2010). The perithecia are formed on the surface of crop debris and the ascospores start the primary infection. The optimal temperature for releasing the ascospores is around $16^{\circ} \mathrm{C}$ (Tschantz et al., 1976). Reports show that the perithecial drying during the day followed by high relative humidity at night can stimulate discharging of spores, but ascospore release will be inhibited under heavy rainfall conditions (Paulitz, 1996). In addition to sexual spores as the principal inoculum source of fungus, asexual spores originating from sporodochia also are important for the infection of maize plants (Paul et al., 2004). Dispersal of ascospores is usually by air (Paulitz et al., 1999); while macroconidia are disseminated by water splashes or wind (Parry et al., 1995). No secondary infection by the fungus is demonstrated (Fernando et al., 1997). Since $F$. graminearum is primarily a monocyclic disease, the role of primary inoculum in disease epidemics is outstanding.

\section{Source of Fusarium Inoculum}

Fusarium species that invade cereals are able to survive saprophytically on crop residues (Parry et al., 1995). This residue in or on the soil where the crop is grown or in nearby fields, is considered to provide the primary source of inoculum for the infection of the plants during the growing season (Munkvold, 2003). Different reports show that the maize plant debris could be the principal source of inoculum for both maize and wheat crops when they are grown in rotation (Seaman, 1982; Clear \& Abramson, 1986; Teich \& Nelson, 1984). Further studies in Europe and North America confirmed that, compared to other debris, maize residues are more effective inoculum contributing to the incidence of fusarium head blight of wheat crop (Dill-Macky \& Jones, 2000; Schaafsma et al., 2001). In Uruguayan production systems, however, maize debris contributes a lower propotion of inoculum production for $F$. graminearum epidemics (Pereyra \& Dill-Macky, 2008). Maize debris provides a long-term reservoir of inoculum, particularly if they form a surface residue (Cotten \& Munkvold, 1998). Re-colonization of surface residue by airborne inoculum leads to long-term survival of fungus, production of new spores, and subsequently infection of new maize plants. In this case, survival of the fungus is affected by the 
size and residue depth (Cotten \& Munkvold, 1998). Infected debris generates different types of infectious propagules including sexual or asexual spores (Munkvold, 2003).

In addition to wheat, barley and maize debris, some weed species and wild plants have been demonstrated as inoculum source of $F$. graminearum (Jenkinson \& Parry, 1994); while lack of perithecia production by G. zeae on sunflower residues indicated this substrate could not contribute to the primary inoculum of the fungus (Pereyra \& Dill-Macky, 2008). On the other hand, the potential inoculum of Fusarium spp. in the soil is affected by the previous crop and the system of soil preparation, as well. Therefore, organic farming systems have indicated a significantly lower level of inoculum in the soil compared to the fields under integrated management (Meier et al., 2001).

Most of the Fusarium species in maize such as F. verticillioides, $F$. graminearum and $F$. subglutinans are seedborne pathogens. Therefore, seeds are another source of inoculum in the fields (reviewed in Munkvold, 2003). Symptomless systemic infection of maize by $F$. verticillioides has been reported. The fungus transmits from infected seeds to the upper parts of plants (Munkvold et al., 1997; Munkvold \& Carlton, 1997). Furthermore, Desjardins et al. (1998) also demonstrated symptomless systemic infection of maize kernels by spores originating from the root rhizosphere.

\section{Weed Plants as Symptomless Alternative Hosts}

Although weed plants provide suitable habitat conditions such as high humidity for the development of plant diseases, the role of weeds as hosts is probably more complex. For many years, wild plants, weeds as well as cultivated plants have been considered as bridges between seasons or between crops for the survival of fungal pathogens over the periods. These bridging hosts contribute to epidemics of plant diseases either as a source for production of additional inoculum or as a harbor for resting propagules of pathogens. Therefore, the pathogens will be able to remain active between seasons. On the other hand, with the presence of weeds and wild plants the possibility of potential danger of minor pathogens should not be ignored; even though the main cultivated crop has escaped from those (Dinoor, 1974). 
The involvement of weed plants in epidemics of plant pathogens is a delicate subject. It is claimed that in fields under suitable agricultural management, the causal organism may be present and contribute to the buildup of inoculum, but disease epidemics would not occur. The transition from a minor or moderate level of disease to a major problem will only happen when farmers do not employ suitable cultural practices such as tillage, residue management or rotation. In such situations, wild plants may be contaminated by the pathogen and the development of disease will occur in wild hosts (Dinoor, 1974). Weed plants and natural vegetation are thought to be a reservoir of Fusarium pathogens over the winter (Jenkinson \& Parry, 1994). The first report regarding weeds as Fusarium harbor indicated recovery of Fusarium spp. from 19 species of cereals and grasses as well as 24 species of common weeds (Gordon, 1959). In 1960, for the first time the importance of weed plants as a source of fungal inoculum was emphasized (Garrett, 1960). Garrett proposed that weed roots infected by soil-borne pathogens could directly act as a source of inoculum for the roots of susceptible plants. Viable and compatible inoculum is necessary to establish a destructive epidemic (Dinoor, 1974). It is believed the role of weed plants in the survival of Fusarium species such as $F$. poae which have no saprophytic growth on debris and no resting spore for overwintering is significantly important (Jenkinson \& Parry, 1994).

Alternative hosts have been generally considered as the bridges between crops that support the fungal inoculum source. They include any hosts such as grasses or broad-leaved weeds in addition to the main host. Alternative hosts harbor the pathogens during the off season, when the economically main host is absent and, then, serve as bridges in the main growing season (Dinoor, 1974; Parry et al., 1995). Therefore, a fungal pathogen may have an entirely different adaptation to a range of hosts that would be distinctly unrelated. Jenkinson \& Parry, (1994) demonstrated some new weed hosts for F. avenaceum, F. culmorum, F. graminearum, F. poae, and F. sambucinum. Studies in Southern Manitoba indicated some wild grasses such as Bromus intermis, Calamagrostis canadensis, and Agropyron trachycaulum were colonized more easily than others as symptomless carriers by Fusarium spp. (Inch \& Gilbert, 2003). The gramineous weeds of Digitaria sanguinalis, Setaria spp., Lolium multiflorum, and Cynodon dactylon as well as wheat, barley and maize debris have also been cited as the sources of F. graminearum inoculum; while white clover and birdsfoot trefoil (the perennial pastures in 
Uruguay) did not contribute to G. zeae inoculum (Pereyra \& Dill-Macky, 2008). Several weed species have been found to host 14 different Fusarium spp. in Croatian fields (Postic et al., 2012). Most of the studies on weeds as alternative hosts for fungal pathogens have concentrated on F. oxysporum (Katan, 1971; McDonald \& Leach, 1976; Haware \& Nene, 1982; Helbig \& Carroll, 1984; Altinok, 2013).

Studies have mostly revealed the symptomless colonization of weeds by different pathogenic fungi (Roy, 1982; Cerkauskas et al., 1983; Helbig \& Carrol, 1984; Roy et al., 1994; Jenkinson \& Parry, 1994; Postic et al., 2012; Altinok, 2013). Katan, (1971) reported that the contribution of a symptomless carrier for inoculum production of Fusarium tomato wilt is 1-4\% of the propagules developed on a susceptible host. The exhibition of no symptoms by weed plants infected with Fusarium species has been remained a contentious issue. Some reports have claimed that only less aggressive strains can invade weeds and produce a symptomless infection (Helbig \& Carroll, 1984). Lack of strong adaptation of Fusarium on alternative hosts showed that the passage through an alternative host causes the reduction of pathogenic fitness (aggressiveness); but increases overall fungal reproduction (saprophytic behavior). As a result of transition through an alternative host, a conversion of pathogen behavior may be occurred and colonization of primary host would be improved (Akinsanmi et al., 2007). Successful infection of weed plant tissues and lack of diseases symptoms on them would suggest that the contamination of weeds by Fusarium spp. may be endophytic (Jenkinson \& Parry., 1994). The endophytic growth of $F$. culmorum, $F$. graminearum as well as Microdochium nivale (syn. F. nivale) has been demonstrated (Sieber at al., 1988). All these studies conclude that effective weed management can be a useful approach for the reduction of inoculum of Fusarium diseases in maize fields (reviewed in Fandohan et al., 2003).

\section{Identification and Characterization of Fusarium Species}

The current estimated number of described Fusarium species is between 70 and 500 (Leslie \& Summerell, 2011), and the number is expected to increase in the coming years as more are discovered. The most common and widely applied method for identification of Fusarium species relies on morphological and other phenotypic traits. Typical criteria employed for traditional identification are the presence or absence of microconidia and chlamydospores, the 
size and shape of micro- and macroconidia, morphological characters of conidiogenous cells as well as colony morphology and growth rate (Leslie \& Summerell, 2006). However, the application of morphological characters alone for identification and differentiation of similar species may not be sufficient. The problem is clearly obvious when very closely related Fusarium species, such as members of the $F$. avenaceum/F. acuminatum/F. tricinctum species complex, are studied. Furthermore, description of species boundaries and subsequently detection of inter- and intra-specific variability by such classical methods is difficult or in some cases probably impossible (Harrow et al., 2010). Fortunately, alternative procedures have been introduced in recent years, in which DNA sequence analysis is used to evaluate and characterize the Fusarium species status. Performing these techniques as alternative or complementary approaches has reduced some of the disadvantages of conventional diagnostic methods.

As mentioned, the molecular techniques generally use the DNA sequences data to support classical phenotypic identification and to increase knowledge of the taxonomy of Fusarium. They provide the opportunity to distinguish unknown isolates and clarify the phylogenetic structure within closely related species. In addition, the DNA sequences of single-copy nuclear genes have successfully been used to determine the evolutionary history of secondary metabolites, and many toxin profiles have been mapped to the Fusarium species (O'Donnell et al., 1998b; Kristensen et al., 2005; Marín et al., 2012; Gräfenhan et al., 2013). In comparison with phenotypic variations, DNA sequence variations are more numerous and undergo fewer changes in culture collections (Leslie \& Summerell, 2011). Several gene sequences have successfully been used to differentiate species in the genus of Fusarium including the B-tubulin gene, the calmodulin gene (O'Donnell et al., 1998a; Yli-Mattila et al., 2002; Steenkamp et al., 2002), and the translation elongation factor 1-alpha (TEF-1 $\alpha$ ) gene sequence (O'Donnell et al., 1998b, 2000; Knutsen et al., 2004; Harrow et al., 2010; Marín et al., 2012; Gräfenhan et al., 2013).

The partial TEF- $1 \alpha$ gene is taxonomically most informative sequence in the Fusarium genus. It is constantly single-copy in Fusarium and, due to its high sequence polymorphism among closely related species, has been a useful genetic marker. It was, therefore, used as a single-locus identification tool to create the Fusarium-ID v.1.0 database (Geiser et al., 2004). The ef 1 and ef 2 primer pairs, which can amplify a 700 bp region of TEF, were first designed to 
evaluate the relationships within $F$. oxysporum species complex (O'Donnell et al., 1998b). Currently, these primers are used for a wide variety of filamentous ascomycetes. In some cases, the phylogenetically distinct species may show slight differences in the TEF-1 $\alpha$ gene, which are not sufficient for their differentiation by Fusarium-ID database. Classification should, therefore, be done cautiously and extra sequence data from other gene markers is necessary to establish the phylogenetic relationships within such groups. According to previous studies, for example, differentiation between $F$. avenaceum and $F$. arthrosporioides strains is possible only when the combined ATP Citrate Lyase (acl1) and TEF-1 $\alpha$ gene sequences are employed (Gräfenhan et al., 2013). One possible explanation would be the presence of a fair to poor representation of such species in the database (Geiser et al., 2004).

\section{Detection and Quantification of Fungal Biomass}

For many years, DNA-based methods, particularly real-time PCR (qPCR) have developed as potentially more reliable techniques for identification, detection and quantification of plant pathogens as well as studying plant systemic infections (McCartney et al., 2003). The qPCR assay allows the quantification of unknown samples, which means to determine the number of copies of the target gene present in a sample. Since monitoring of PCR products is possible either by fluorescent DNA-intercalating dye (such as SYBR Green I) or sequence-specific probe-based assays (Wittwer et al., 1997), measurement of the intensity of fluorescent signals during the exponential step of DNA amplification will lead to DNA quantification. For this purpose, standard curve needs to be constructed. It can be generated by running the qPCR for a serial dilution of pure genomic DNA of fungus. The average amount of threshold values $(\mathrm{Ct})$ should, then, be plotted against the logarithmic scale of starting DNA quantity (SQ). Afterwards, the initial number of copies of the target gene in an unknown sample is measured by interpolating its Ct value to the standard curve equation (McCartney et al., 2004).

Quantitative and species-specific determination of Fusarium spp. biomass in plant tissues is essential in disease etiology and epidemiology research, as well as in resistance breeding. Both absolute and relative qPCR assays have been used with success for detection and quantification of the pathogens such as $F$. solani f.sp. glycines in soybean that are slow growing fungi with variable phenotypic characteristics (Gao et al., 2004). Since several studies have shown a 
positive correlation between the fungal biomass and mycotoxin content (Waalwijk et al., 2004; Schnerr et al., 2002; Yli-Mattila et al., 2008; Fredlund et al., 2010), it is supposed that the qPCR can be used as a fast and cost-effective means to assess the risk of grain contamination. Although mycotoxin profile analysis should not be displaced by the qPCR procedure, it can be employed as a high throughput and low cost method in quarantine posts where batches and cargoes are initially inspected for the risk of mycotoxin contamination. This primitive process can help sorting the contaminated plant materials that likely exceed the legal thresholds, so they can undergo further chemical analysis. Simultaneous quantification of different target DNA in a single qPCR with small reaction volumes will make the assessments more applicable, faster and cost-effective.

\section{Role of Mycotoxins in Fusarium Diseases}

Possible involvement of toxins or other certain pathogen-produced molecules in plant diseases has always been of great interest for plant pathologists. Pathogenesis as a qualitative term has simply been defined as the ability of pathogen to cause disease; while virulence is a quantitative term which describes the amount or extent of disease caused. The economic or scientific importance of a virulence factor may be identical or even higher than the pathogenicity factor. Virulence factors should thus be regarded as significant as pathogenicity factors (Yoder, 1980). Fungal toxins may play a role in pathogenicity, virulence or no role in plant disease. To evaluate toxins as factors in pathogenesis, commonly used criteria include: i) Host specificity, ii) Present in infected plant, iii) Production at a key step in disease development, iv) Induction of typical disease symptoms (Yoder, 1980). A common and practical approach to find the toxin function is elimination of toxin from the biological system, leaving the rest of process the same and, then, monitoring how disease will be changed. For this purpose, several ways such as using metabolic inhibitors have been introduced (Yoder, 1980). For many years, genetic analysis was employed to evaluate toxins as pathogenicity factors by application of the toxin-producing strains against the natural variants that are unable to produce toxins. Such strains have different genetic backgrounds. They undoubtedly differ in many traits other than toxin production that may affect the virulence of the pathogen. Therefore, the results of research on this topic have been presented cautiously. In recent years, genetic manipulation via recombination or mutational 
analysis has generated identical amended strains differing only in a gene that confers toxin production (Desjardins et al., 2002).

Many of the Fusarium species are well known to be aggressive plant pathogens. Since the mycotoxins produced by these species are phytotoxic, it is speculated that Fusarium mycotoxins should have a role in the pathogenicity of fungus (Yang et al., 1996). Among the most important Fusarium associated with maize, most researches have been focused on species that are known as producers of trichothecenes and fumonisins. This is due primarily to their contribution in the human and animal food chain.

All trichothecene-producing Fusarium species are principal pathogens that can infect a range of the plant species and cause destructive diseases. Wet weather at harvesting time and high humidity during storage can increase the trichothecene level in maize and wheat kernels (Desjardins et al., 1993). Trichothecenes have been known to be the virulence factors in some Fusarium spp. pathogens (Yoder, 1980). They can damage the protein synthesis in plants and/or suppress or delay the plant defense reaction (Harris et al., 1999). According to the high correlation between levels of trichothecene production, sexual fertility and the original isolation of the strain from diseased plant materials in G. pulicaris (anamorph: F. sambucinum), it is suggested that trichothecene production may be implicated in both pathogenicity and fertility (Beremand et al., 1991). Other reports show trichothecenes are not necessary for fungal growth in vitro. The growth rate and morphology of non-trichothecene producing strains were not distinguishable from those of the progenitor strains (Hohn \& Desjardins, 1992). Since toxin production in vitro is affected by the physical environment and culture compounds, therefore, virulence may not be correlated with amount of toxin produced in culture (Yoder, 1980).

Trichothecenes act as virulence factors in some Fusarium spp. pathogens. They are able to produce different disease symptoms such as necrosis, chlorosis and wilting in a variety of plant species and affect the amount or extent of disease (Yoder, 1980; Desjardins et al., 1993). It has been shown that trichothecenes are host non-specific and different eukaryotic organisms such as plants are influenced through exposure even to the low concentrations of toxin (Desjardins et al., 1993). Although trichothecenes have been found in some Fusarium infected plant tissues (Snijders \& Perkowski, 1990; Desjardins et al., 1989; Desjardins \& Plattner, 1989), detection of 
toxin in the infected tissues, however, have not always been successful (Bean et al., 1984). Toxins may fail to establish in infected tissues, although the infection may have resulted from toxin action. In this case, the plant enzymes may be responsible for toxin inactivation or it is not detectable due to the complex plant matrix effects (Yoder, 1980; Mitchell, 1984). The results of disruption of the Tox5 gene in G. pulicaris, responsible for trichothecene synthase, suggested the role of trichothecenes in virulence may be different from one plant species to another. It has been clearly observed to be the virulence factor of $F$. sporotrichioides and G. pulicaris on parsnip roots, while infection of potato tubers by G. pulicaris is independent of trichothecene (reviewed in Desjardins et al., 1993). Similarly, although trichothecenes contribute to the virulence of F. graminearum to cause fusarium head blight on wheat (Desjardins et al., 1996), they are not essential for the infection of maize tissue. Trichothecenes may act as a virulence factor to enhance the spread of the fungus on maize plants (Harris et al., 1999).

The results for finding the importance of naphthazarin production on the virulence of F. solani var. martii (teleomorph: Nectria haematococca) indicated that this toxic compound would not be a significant virulence factor for the infection of pea plants (Holenstein \& Defago, 1983). Regarding the function of secondary metabolites in the infection process of $F$. avenaceum on potato tuber tissues, although the reports have suggested some additional pathogenicity factors, they obviously show the contribution of the enniatin toxin to the virulence of the pathogen (Herrmann et al., 1996).

Fumonisins as polyketide mycotoxins are produced by number of Fusarium spp. such as F. verticillioides. Toxicity of fumonisins to plants and field animals has been clearly demonstrated (Lamprecht et al., 1994); but there are controversial reports regarding the potential function of fumonisins in virulence on maize. In latest reports, fumonisin bioavailability to maize roots has been linked to the reduction in stalk weight and root mass, while the number of leaf lesions increased (Williams et al., 2006). These findings have supported the importance of fumonisins in plant pathogenesis. Recently studies have presented that the expression of foliar maize diseases is associated with fumonisin production, and this toxin can contribute to all aspects of F. verticillioides maize seedling diseases (Williams et al., 2007; Glenn et al., 2008). According to the field studies using $F$. verticillioides strains carrying gene disruptions, fumonisin production is not necessary for the fungus to cause maize ear rot (Desjardins et al., 2002). If 
fumonisins have no role in maize ear rot, they may be important in other ecological aspects of F. verticillioides. Furthermore, they may distribute to enhance the fungal virulence on plant species other than maize (Proctor et al., 2002).

\section{Objectives of the Study}

Develop a qPCR protocol for simultaneous quantification of the DNA of nine Fusarium species occurring in maize at a reaction volume of $4 \mu 1$. Furthermore, specific optimal conditions for each species should be established to maximize the performance of the analysis when a single pathogen is studied.

The second objective was to investigate the role of weeds in survival of Fusarium pathogens and assess their ability to produce mycotoxins. Motivation for this studey was an observation of rare occurrence of unusually high amounts of fumonisins and fungal colonization in well-controlled field trials, which was difficult to explain (Nutz \& Karlovsky, unpublished). There is a hypothesis that particular species of weed plants that host Fusarium spp. increase the infection pressure locally and account for the high levels of Fusarium mycotoxins in organic maize fields. The project should address the following questions: Do the weed plants play a role as alternative hosts for Fusarium species pathogenic to maize? Can they provide a significant source of inoculum for maize plants and thus increase mycotoxin accumulation?

In the third part of this study, the aim was to identify differences between the aggressiveness of $F$. verticillioides strains, differring in the production of fumonisins, towards maize, sorghum, rice and beetroot seedlings in vitro. These differences would define a biological function for fumonisins in the virulence of $F$. verticillioides for maize and other hosts. We hypothesize that fumonisin synthesis originated on hosts other than maize and in plant tissues other than silks/cobs. 


\section{Literature Cited}

- Akinsanmi, O. A., Chakraborty, S., Backhouse, D., and Simpfendorfer, S. 2007. Passage through alternative hosts changes the fitness of Fusarium graminearum and Fusarium pseudograminearum. Environ. Microbiol. 9:512-520.

- Altinok, H. H. 2013. Fusarium species isolated from common weeds in eggplant fields and symptomless hosts of Fusarium oxysporum f. sp. melongenae in Turkey. J. Phytopathol. 161:335-340.

- Arino, A., and Bullerman, L. B. 1994. Fungal colonization of corn grown in Nebraska in relation to year, genotype and growing conditions. J. Food Protect. 57:1084-1087.

- Bean, G. A., Fernando, T., Jaris, B. B., and Bruton, B. 1984. The isolation and identification of trichothecene metabolites from a plant pathogenic strain of Myrothecium roridum. J. Nat. Prod. 47:727-728.

- Beremand, M. N., Desjardins, A. E., Hohn, T. M., and VanMiddlesworth, F. L. 1991. Survey of Fusarium sambucinum (Gibberella pulicaris) for mating type, trichothecene production, and other selected traits. Phytopathology 81:1452-1458.

- Bottalico, A., Visconti, A., Logrieco, A., Solfrizzo, M., and Mirocha, C. J. 1985. Occurrence of zearalenols (diastereomeric mixture) in corn stalk rot and their production by associated Fusarium species. Appl. Environ. Microb. 49:547-551.

- Cerkauskas, R. F., Dhingra, O. D., Sinclair, G. B., and Asmus, G. 1983. Amaranthus spinosus, Leonotis nepetaefolia and Leonurus sibiricus: new hosts of Phomopsis spp. in Brazil. Plant Dis. 67:821-824.

- Clear, R. M., and Abramson, D. 1986. Occurrence of fusarium head blight and deoxynivalenol in two samples of Manitoba wheat in 1984. Can. Plant Dis. Surv. 66:9-11.

- Cotten, T. K., and Munkvold, G. P. 1998. Survival of Fusarium moniliforme, F. proliferatum and F. subglutinans in maize stalk residue. Phytopathology 88:550-555.

- Desjardins, A. E., Munkvold, G. P., Plattner, R. D., and Proctor, R. H. 2002. FUM1- A gene required for fumonisin biosynthesis but not for maize ear rot and ear infection by Gibberella moniliformis in field tests. Mol. Plant-Microbe Interact. 15:1157-1164.

- Desjardins, A. E., Plattner, R. D., Lu, M., and Claflin, L. E. 1998. Distribution of fumonisins in maize ears infected with strains of Fusarium moniliforme that differ in fumonisin production. Plant Dis. 82:953-958. 
- Desjardins, A. E., Proctor, R. H., Bai, G., McCormick, S. P., Shaner, G., Buechley, G., and Hohn, T. M. 1996. Reduced virulence of trichothecene-nonproducing mutants of Gibberella zeae in wheat field tests. Mol. Plant-Microbe Interact. 9:775-781.

- Desjardins, A. E., Hohn, T. M., and McCormick, S. P. 1993. Trichothecene biosynthesis in Fusarium species: chemistry, genetics, and significance. Microbiol. Rev. 57:595-604.

- Desjardins, A. E., Plattner, R. D. 1989. Trichothecene toxin production by strains of Gibberella pulicaris (Fusarium sambucinum) in liquid culture and in potato tubers. J. Agric. Food Chem. 37:388-392.

- Desjardins, A. E., Spencer, G. F., and Plattner, R. D. 1989. Tolerance and metabolism of furanocoumarins by the phytopathogenic fungus Gibberella pulicaris (Fusarium sambucinum. Phytochemistry 28:2963-2969.

- Dill-Macky, R., and Jones, R. K. 2000. The effect of previous crop residues and tillage on fusarium head blight of wheat. Plant Dis. 84:71-76.

- Dinoor, A. 1974. Role of wild and cultivated plants in the epidemiology of plant disease in Israel. Ann. Rev. Phytopathol. 12:413-436.

- D'Mello, J. P. F., Placinta, C. M., and Macdonald. A. M. C. 1999. Fusarium mycotoxins: a review of global implications for animal health, welfare and productivity. Anim. Feed Sci. Tech. 80:183-205.

- Fandohan, P., Hell, K., Marasas, W. F. O., and Wingfield, M. J. 2003. Infection of maize by Fusarium species and contamination with fumonisin in Africa. Afr. J. Biotechnol. 2:570-579.

- Fernando, W. G. D., Paulitz, T. C., Seaman, W. L., Dutilleul, P., and Miller, J. D. 1997. Head blight gradients caused by Gibberella zeae from area sources of inoculum in wheat field plots. Phytopathology 87:414-421.

- Fredlund, E., Gidlund, A., Pettersson, H., Olsen, M., and Börjesson, T. 2010. Real-time PCR detection of Fusarium species in Swedish oats and correlation to T-2 and HT-2 toxin content. World Mycotoxin Journal 3:77-88.

- Gao, X., Jackson, T. A., Lambert, K. N., Li, S., Hartman, G. L., and Niblack, T. L. 2004. Detection and quantification of Fusarium solani f.sp. glycines in Soybean roots with real-time quantitative polymerase chain reaction. Plant Dis. 88:1372-1380. 
- Garrett, S. D. 1960. Inoculum Potential in Plant Pathology. An Advanced Treatise. Vol. 3 (ed. J. G. Horsfall \& A. E. Dismond), p. 23-56. Academic press: New York.

- Geiser, D. M., Jime'nez-Gasco, M. D. M., Kang, S., Makalowska, I., Veeraraghavan, N., Ward, T. J., Zhang, N., Kuldau, G. A., and O'Donnell, K. 2004. FUSARIUM-ID v. 1.0: A DNA sequence database for identifying Fusarium. Eur. J. Plant Pathol. 110:473-479.

- Gilbertson, R. L., Brown, W. M. J. R., and Ruppel, E. G. 1985. Prevalence and virulence of Fusarium spp. associated with stalk rot of corn in Colorado. Plant Dis. 69:1065-1068.

- Glenn, A. E., Zitomer, N. C., Zimeri, A. M., Williams, L. D., Riley, R. T., and Proctor, R. H. 2008. Transformation-mediated complementation of a FUM gene cluster deletion in Fusarium verticillioides restores both fumonisin production and pathogenicity. Mol. Plant-Microbe Interact. 21:87-97.

- Glenn, A. E. 2007. Mycotoxigenic Fusarium species in animal feed. Anim. Feed Sci. Tech. 137:213-240.

- Gordon, W. L. 1959. The occurrence of Fusarium species in Canada. VI. Taxonomic and geographic distribution of Fusarium species on plants, insects and fungi. Can. J. Botany 37:257-290.

- Gräfenhan, T., Patrick, S. K., Roscoe, M., Trelka, R., Gaba, D., Chan, J. M., McKendry, T., Clear, R. M., and Tittlemier, S. A. 2013. Fusarium damage in cereal grains from western Canada. Phylogenetic analysis of moniliformin-producing Fusarium species and their natural occurrence in mycotoxin-contaminated. J. Agric. Food Chem. 61:5425-5437.

- Harris, L. J., Desjardins, A. E., Plattner, R. D., Nicholson, P., Butler, G., Young, J. C., Weston, G., Proctor, R. H., and Hohn, T. M. 1999. Possible role of trichothecene mycotoxins in virulence of Fusarium graminearum on maize. Plant Dis. 83:954-960.

- Harrow, S. A., Farrokhi-Nejad, R., Pitman, A. R., Scott, I. A. W., Bentley, A., Hide, C., and Cromey, M. G. 2010. Characterization of New Zealand Fusarium populations using a polyphasic approach differentiates the Fusarium avenaceum/ F. acuminatum/ F. tricinctum species complex in cereal and grassland systems. Fungal Biol. 114:293-311.

- Haware, M. P., and Nene, Y. L. 1982. Symptomless carriers of the chickpea wilt Fusarium. Plant Dis. 66:250-251.

- Helbig, J. B., and Carroll, A. B. 1984. Dicotyledonous weeds as a source of Fusarium oxysporum pathogenic on soybean. Plant Dis. 68:694-696. 
- Herrmann, M., Zocher, R., and Haese, A. 1996. Effect of disruption of the enniatin synthetase gene on the virulence of Fusarium avenaceum. Mol. Plant-Microbe Interact. 9:226-232.

- Hohn, T. M., and Desjardins, A. E. 1992. Isolation and gene disruption of the Tox5 gene incoding trichodiene synthase in Gibberella pulicaris. Mol. Plant-Microbe Interact. 5:249-256.

- Holenstein, J., and Defago, G. 1983. Inheritance of naphthazarin production and pathogenicity to pea in Nectria haematococca. J. Exp. Bot. 34:927-935.

- Inch, S., and Gilbert, J. 2003. The incidence of Fusarium species recovered from inflorescences of wild grasses in southern Manitoba. Can. J. Plant Pathol. 25:379-383.

- Jenkinson, P., and Parry, D. W. 1994. Isolation of Fusarium species from common broad-leaved weeds and their pathogenicity to winter wheat. Mycol. Res. 98:776-780.

- Katan, J. 1971. Symptomless carriers of the tomato Fusarium wilt pathogen. Phytopathology 61:1213-1217.

- Knutsen, A. K., Torp, M., and Holst-Jensen, A. 2004. Phylogenetic analyses of the Fusarium poae, Fusarium sporotrichioides and Fusarium langsethiae species complex based on partial sequences of the translation elongation factor-1 alpha gene. Int. J. Food Microbiolo. 95:287-295.

- Kosiak, B., Torp, M., Skjerve, E., and Thrane, U. 2003. The prevalence and distribution of Fusarium species in Norwegian cereals: a survey. Acta Agr. Scand. (Section B- Soil and Plant Science) 53:168-176.

- Kristensen, R., Torp, M., Kosiak, B., and Holst-Jensen, A. 2005. Phylogeny and toxigenic potential is correlated in Fusarium species as revealed by partial translation elongation factor 1 alpha gene sequences. Mycol. Res. 109:173-186.

- Lamprecht, S. C., Marasas, W. F. O., Alberts, J. F., Cawood, M. E., Gelderblom, W. C. A., Shephard, G. S., Thiel, P. G., and Calitz, F. J. 1994. Phytotoxicity of fumonisins and TA-toxin to corn and tomato. Phytopathology 84:383-391.

- Leslie, J. F., and Summerell, B. A. 2011. In search of new Fusarium species. Plant Breeding and Seed Science 63:93-101.

- Leslie, J. F., and Summerell, B. A. 2006. The Fusarium Laboratory Manual. Blackwell Publishing. 388 pp. 
- Logrieco, A., Mule, G., Moretti, A., and Bottalico, A. 2002. Toxigenic Fusarium species and mycotoxins associated with maize ear rot in Europe. Eur. J. Plant Pathol. 108: 597-609.

- MacDonald, J. D., and Leach, L. D. 1976. Evidence for an expanded host range of Fusarium oxysporum f. sp. betae. Phytopathology 66:822-827.

- Marín, P., Moretti, A., Ritieni, A., Jurado, M., Vázquez, C., and González-Jaén, M. T. 2012. Phylogenetic analyses and toxigenic profiles of Fusarium equiseti and Fusarium acuminatum isolated from cereals from Southern Europe. Food Microbiol. 31:229-237.

- McCartney, H. A., Foster, S. J., Fraaije, B. A., and Ward, E. 2003. Molecular diagnostics for fungal plant pathogens. Pest Manag. Sci. 59:129-142.

- Meier, A., Birzele, B., Oerke, E. C., Steiner, U., Krämer, J., and Dehne, H. W. 2001. Significance of different inoculum sources for the Fusarium infection of wheat ears. Mycotoxin Research 17:71-75.

- Mitchell, R. E. 1984. The relevance of non-host-specific toxins in the expression of virulence by pathogens. Annu. Rev. Phytopathol. 22:215-245.

- Munkvold, G. P. 2003. Epidemiology of Fusarium diseases and their mycotoxins in maize ears. Eur. J. Plant Pathol. 109:705-713.

- Munkvold, G. P., and Carlton, W. M. 1997. Influence of inoculation method on systemic Fusarium moniliforme infection of maize plants grown from infected seeds. Plant Dis. 81:211-216.

- Munkvold, G. P., McGee, D. C., and Carlton, W. M. 1997. Importance of different pathways for maize kernel infection by Fusarium moniliforme. Phytopathology 87: 209-217.

- Nuss, E. T., and Tanumihardjo, S. A. 2010. Maize: A paramount staple crop in the context of global nutrition. Comprehensive Reviews in Food Science and Food Safety 9:417-436.

- O'Donnell, K., Kistler, H. C., Tacke, B. K., and Casper, H. H. 2000. Gene genealogies reveal global phylogeographic structure and reproductive isolation among lineages of Fusarium graminearum, the fungus causing wheat scab. P. Natl. Acad. Sci. USA. 97:7905-7910. 
- O'Donnell, K., Cigelnik, E., and Nirenberg, H. I. 1998a. Molecular systematics and phylogeography of the Gibberella fujikuroi species complex. Mycologia 90:465-493.

- O'Donnell, K., Kistler, H. C., Cigelnik, E., and Ploetz, R. C. 1998b. Multiple evolutionary origins of the fungus causing Panama disease of banana: Concordant evidence from nuclear and mitochondrial gene genealogies. Proceedings of the National Academy of Sciences of the United States of America 95:2044-2049.

- Parry, D. W., Jenkinson, P., and McLeod, L. 1995. Fusarium ear blight (scab) in small grain cereals- A review. Plant Pathol. 44:207-238.

- Paul, P. A., El-Allaf, S. M., Lipps, P. E., and Madden, L. V. 2004. Rain splash dispersal of Gibberella zeae within wheat canopies in Ohio. Phytopathology 94:1342-1349.

- Paulitz, T., Dutilleul, P., Yamasaki, S. H., Fernando, W. D. G., and Seaman, W. L. 1999. A generalized two-dimensional Gaussian model of disease foci of head blight of wheat caused by Gibberella zeae. Phytopathology 89:74-83.

- Paulitz, T. 1996. Diurnal release of ascospores by Gibberella zeae in inoculated wheat plots. Plant Dis. 80:674-678.

- Pereyra, S. A., and Dill-Macky, R. 2008. Colonization of the residues of diverse plant species by Gibberella zeae and their contribution to fusarium head blight inoculum. Plant Dis. 92:800-807.

- Pestka, J. J., and Smolinski, A. T. 2005. Deoxynivalenol: toxicology and potential effects on humans. J. Toxicol. Environ. Health. B Crit. Rev. 8:39-69.

- Pintos Varela, C., Aguín Casal, O., Chaves Padin, M., Ferreiroa Martinez, V., Sainz Oses, M. J., Scauflaire, J., Munaut, F., Bande Castro, M. J., and Mansilla Vázquez, J. P. 2013. First report of Fusarium temperatum causing seedling blight and stalk rot on maize in Spain. Plant Dis. (Abstr.) 97:1252.

- Placinta, C. M., D'Mello, J. P. F., and Macdonald, A. M. C. 1999. A review of worldwide contamination of cereal grains and animal feed with Fusarium mycotoxins. Anim. Feed Sci. Technol. 78:21-37.

- Postic, J., Cosic, J., Vrandecic, K., Jurkovic, D., Saleh, A. A., and Leslie, J. F. 2012. Diversity of Fusarium species isolated from weeds and plant debris in Croatia. J. Phytopathol. 160:76-81. 
- Proctor, R. H., Desjardins, A. E., McCormick, S. P., Plattner, R. D., Alexander, N. J., and Brown, D. W. 2002. Genetic analysis of the role of trichothecene and fumonisin mycotoxins in the virulence of Fusarium. Eur. J. Plant Pathol. 108: 691-698.

- Roy, K. W. 1982. Cercospora kikuchii and other pigmented species: cultural and reproductive characteristics and pathogenicity to soybean. Can. J. Plant Pathol. 4: 226-232.

- Roy, K. W., Miller, W. A., and McLean, K. S. 1994. Survey of pathogenic genera on fungi on foliage of weeds in Mississippi. Can. J. Plant Pathol. 16:25-29.

- Scauflaire, J., Gourgue, M., and Munaut, F. 2011. Fusarium temperatum sp. nov. from maize, an emergent species closely related to F. subglutinans. Mycologia 103:586-597.

- Schaafsma, A. W., Tamburic-Ilinic, L., Miller, J. D., and Hooker, D. C. 2001. Agronomic considerations for reducing deoxynivalenol in wheat grain. Can. J. Plant Pathol. 23: 279-285.

- Schnerr, H., Vogel, R. F., and Niessen, L. 2002. Correlation between DNA of trichothecene-producing Fusarium species and deoxynivalenol concentrations in wheat-samples. Lett. Appl. Microbiol. 35:121-125.

- Seaman, W. L. 1982. Epidemiology and control of mycotoxigenic Fusaria on cereal grains. Can. J. Plant Pathol. 4:187-190.

- Shiferaw, B., Prasanna, B. M., Hellin, J., and Baenziger, M. 2011. Crops that feed the world 6. Past successes and future challenges to the role played by maize in global food security. Food Sec. 3:307-327.

- Sieber. T., Riesen, T. K., Müller, E., and Fried, P. M. 1988. Endophytic fungi in four winter wheat cultivars (Triticum aestivum L.) differing in resistance against Stagonospora nodorum (Berk.) Cast. \& Germ.=Septoria nodorum (Berk.) Berk. J. Phytopathol. 122:289-306.

- Snijders, C. H. A., and Perkowski, J. 1990. Effects of head blight caused by Fusanum culmorum on toxin content and weight of wheat kernels. Phytopathology 80:566-570.

- Steenkamp, E. T., Wingfield, B. D., Desjardins, A. E., Marasas, W. F. O., and Wingfield, M. J. 2002. Cryptic speciation in Fusarium subglutinans. Mycologia 94:1032-1043.

- Teich, A. H., and Nelson, k. 1984. Survey of fusarium head blight and possible effects of cultural practices in wheat fields in Lambton County in 1983. Can. Plant Dis. Surv. 64: 11-13. 
- Tschanz, A. T., Horst, R. K., and Nelson, P. E. 1976. The effect of environment on sexual reproduction of Gibberella zeae. Mycologia 68:327-340.

- Waalwijk, C., van der Heide, R., de Vries, I., van der Lee, T., Schoen, C., Costrel-de Corainville, G., Häuser-Hahn, I., Kastelein, P., Köhl, J., Lonnet, P., Demarquet, T., and Kema, G. H. J. 2004. Quantitative detection of Fusarium species in wheat using TaqMan. Eur. J. Plant Pathol. 110:481-494.

- Williams, L. D., Glenn, A. E., Zimeri, A. M., Bacon, C. W., Smith, M. A., and Riley, R. T. 2007. Fumonisin disruption of ceramide biosynthesis in maize roots and the effects on plant development and Fusarium verticillioides-induced seedling disease. J. Agric. Food Chem. 55:2937-2946.

- Williams, L. D., Glenn, A. E., Bacon, C. W., Smith, M. A., and Riley, R. T. 2006. Fumonisin production and bioavailability to maize seedlings grown from seeds inoculated with Fusarium verticillioides and grown in natural soils. J. Agric. Food Chem. 54:5694-5700.

- Wittwer, C. T., Herrmann, M. G., Moss, A. A., and Rasmussen, R. P. 1997. Continuous fluorescence monitoring of rapid cycle DNA amplification. BioTechniques 22:130-138.

- Yang, G., Rose, M. S., Turgeon, B. G., and Yoder, O. C. 1996. A Polyketide synthase is required for fungal virulence and production of the polyketide T-Toxin. The Plant Cell 8:2139-2150.

- Yli-Mattila, T. 2010. Ecology and evolution of toxigenic Fusarium species in cereals in Northern Europe and Asia. J. Plant Pathol. 92:7-18.

- Yli-Mattila, T., Paavanen-Huhtala, S., Jestoi, M., Parikka, P., Hietaniemi, V., Gagkaeva, T., Sarlin, T., Haikara, A., Laaksonen, S., and Rizzo, A. 2008. Real-time PCR detection and quantification of Fusarium poae, F. graminearum, F. sporotrichioides and F. langsethiae in cereal grains in Finland and Russia. Archives of Phytopathology and Plant Protection 41:243-260.

- Yli-Mattila, T., Paavaeen-Huhtala, S., Bulat, S. A., Alekhina, I. A., and Nirenberg, H. I. 2002. Molecular, morphological and phylogenetic analysis of the Fusarium avenaceum/ F. arthrosporioides/ F. tricinctum species complex- a polyphasic approach. Mycol. Res. 106:655-669.

- Yoder, O. C. 1980. Toxins in pathogenesis. Ann. Re. Phytopathol. 18:103-129. 


\title{
Chapter 2
}

\section{Real-time PCR (qPCR) for Simultaneous Quantification of Maize Pathogens: Fusarium avenaceum, F. culmorum, F. equiseti, F. graminearum, F. poae, $F$. proliferatum, $F$. subglutinans, $F$. tricinctum, and $F$. verticillioides in 4- $\mu 1$ Reactions}

\author{
Raana Dastjerdi, Eva-Maria Becker, Petr Karlovsky
}

Molecular Phytopathology and Mycotoxin Research, Georg-August-University Göttingen, Grisebachstr. 6, 37077 Göttingen, Germany

Corresponding author: P. Karlovsky; E-mail address: pkarlov@gwdg.de

\begin{abstract}
Fusarium avenaceum, F. culmorum, F. equiseti, F. graminearum, F. poae, $F$. proliferatum, F. subglutinans, F. tricinctum, and $F$. verticillioides are mycotoxin producing pathogens of maize and small-grain cereals. We developed a species-specific real-time PCR (qPCR) assay for simultaneous quantification of genomic DNA of these nine Fusarium species in plant tissues in 384-well microplates in a total volume of $4 \mu 1$. The reactions are set by combining $1 \mu \mathrm{l}$ sample DNA with $3 \mu \mathrm{l}$ master mix containing SYBR Green; the wells are sealed with mineral oil instead of adhesive foil to prevent concentration changes due to the evaporation. The thermocycler program was optimized to allow for simultaneous quantification of all nine Fusarium species in the same microplate. The sensitivity of method ranged from 0.05-1.52 pg DNA per well and repeatability ranged from $0.81 \%$ to $1.71 \%$ RSD (relative standard deviation). The PCR efficiency of $92.15 \%$ on the average was achieved. The assay was used for the analysis of several thousands field samples of maize grain, wheat grain and whole plants. It can easily be extended to simultaneous, low-cost quantification of further pathogens with a throughput of over a thousand assays per day and thermocycler.
\end{abstract}

Additional keywords: qPCR, 384-well microplate, Fusarium avenaceum, Fusarium culmorum, Fusarium equiseti, Fusarium graminearum, Fusarium poae, Fusarium proliferatum, Fusarium subglutinans, Fusarium tricinctum, Fusarium verticillioides 


\section{Introduction}

Real-time PCR (qPCR) has become the standard method for species-specific quantification of fungal biomass in plant tissues. The qPCR assays for major plant pathogens and decay fungi have been established and used extensively in the last decade. The majority of qPCR assays carried out in research laboratories and plant diagnostic services relied on real-time thermocyclers in 96-well format; both SYBR Green-based detection of PCR products and hybridization probes (e.g., TaqMan) were extensively used. In most published qPCR assays, thermocycler programs were optimized for each assay separately, making it necessary to carry out a separate thermocycler run for each template. The growing need for multiple qPCR assays and the availability of thermocyclers with 384-well blocks entailed the development of common thermocycler programs shared by several assays to be carried out simultaneously in the same microplate. 384-well blocks increased the throughput, permitting the analysis of over a thousand samples per day with a single-block machine. Special instrumentation allows reducing the reaction volume to several nanoliters (Brenan \& Morrison, 2005; Dahl et al., 2007). Most laboratories, however, still work with standard thermocyclers and set their qPCR assays in 15 to $25 \mu \mathrm{l}$ even when using 384-well thermocyclers.

Simultaneous quantification of several targets in a single qPCR, designated multiplexing, is not possible with low-cost assays based on intercalating dyes such as SYBR Green II. Several targets that occur in a mutually exclusive fashion can theoretically be quantified in a single reaction with SYBR Green II detection but only semi-quantitative data can be obtained for samples containing more than one target (Brandfass \& Karlovsky, 2006). Detection based on doubly labeled hybridization probes such as TaqMan allows limited multiplexing (up to four simultaneous assays). The comparatively high costs of doubly-labeled probes, however, as well as high demands on qPCR optimization in a multiplex set up and competition among templates have limited the use of the method. Small reaction volumes and large well densities of new thermocycler blocks dwarfed the advantages of multiplexing as compared to a set of parallel assays with intercalating dyes. We envision a new paradigm in which growing number of qPCR assays will be adapted to few shared thermocycler programs, allowing for simultaneous quantification of different targets in the same microplate. 
Genus Fusarium comprises economically important pathogens of crop plants, most of which are known to produce mycotoxins (Moretti, 2009). Maize (Zea mays L.) is a host of several Fusarium species that cause ear and kernel rot, stalk rot and seedling blight (Logrieco et al., 2002; Gilbertson et al., 1985; Pintos Varela et al., 2013). Some Fusarium species colonize maize without visible symptoms and can therefore be regarded as endophytes (Gelderblom et al., 1988). Major Fusarium pathogens reported to cause ear rot of maize can be divided into two groups. The first group contains members of Gibberella fujikuroi species complex, Fusarium verticillioides (Sacc.) Nirenberg, F. proliferatum (Matsushima) Nirenberg, F. subglutinans (Wollenweb. \& Reinking) P. E. Nelson, T. A. Toussoun \& Marasas and F. temperatum, the latter of which has recently been separated from F. subglutinans (Scauflaire et al., 2011). The second group consists of species of the Discolour section, most importantly F. graminearum Schwabe and F.culmorum (W. G. Smith) Sacc, which are responsible for red ear rot (Gibberella ear rot). A range of further Fusarium species have been reported to infect maize ears and cause tissue damage and mycotoxin accumulation, including $F$. avenaceum, F. poae, F. equiseti, and $F$. tricinctum. While the role of G. fujikuroi species complex and section Discolour in the accumulation of mycotoxins in maize grains is established, the relative importance of further species is the subject of ongoing research.

Quantitative and species-specific determination of Fusarium spp. biomass in plant tissue is indispensable in research on disease etiology and epidemiology as well as in resistance breeding. Because of positive correlation between fungal biomass and mycotoxin content in plant tissue (Waalwijk et al., 2004; Schnerr et al., 2002; Yli-Mattila et al., 2008; Fredlund et al., 2010), qPCR can be used as a fast and cost-effective means to assess the risk of grain contamination. In contrast to mycotoxin analysis, qPCR can be carried out with a high throughput and low costs. The assessment of mycotoxin risk based on fungal biomass does not replace mycotoxin analysis; but it may help identifying batches or cargoes in risk of exceeding legal thresholds, tagging them for chemical analysis of mycotoxin content or for exclusion from human consumption in growing areas where mycotoxin analysis is not available or bears prohibitive costs.

In this work we developed a protocol for the simultaneous quantification of DNA of nine Fusarium spp. occurring in maize by qPCR with SYBR Green detection in 384-well plates with 
a reaction volume of $4 \mu \mathrm{l}$. Furthermore, specific optimal conditions for each species were established to maximize performance of the analysis when a single pathogen is studied.

\section{Material and Methods}

\section{Fungal Isolates and DNA Isolation}

Fungal strains used in this study are listed in Table 1. The cultures were grown on potato dextrose broth (PDB) (Roth, Karlsruhe, Germany) in Erlenmeyer flasks in darkness at $25^{\circ} \mathrm{C}$ for 7 to 10 days. Mycelium was harvested by filtration onto sterile paper disks, frozen in $-70^{\circ} \mathrm{C}$, freeze-dried and stored at room temperature till extracting genomic DNA. Forty milligrams of lyophilized mycelium were ground in $2 \mathrm{ml}$ Eppendorf tubes with round bottom containing 4-5 wolfram carbide spheres (diameter $3 \mathrm{~mm}$, Retsch, Haan, Germany) in a reciprocal mill (Mixer Mill MM 200,Retsch, Haan, Germany). Genomic DNA was extracted by a CTAB method (Brandfass \& Karlovsky, 2008), further purified by phenol extraction, precipitated and dissolved in TE buffer. The DNA quality was checked and concentration determined using electrophoresis in $0.8 \%(w / v)$ agarose gels (Cambrex, Rockland, ME, USA).

\section{Preparation of DNA Standards for qPCR}

DNA quantification was carried out by densitometry of DNA bands after electrophoretic separation; because calculation of DNA concentration from absorbance of the solution in UV light is error-prone (Wilfinger et al., 1997). For this purpose, a range of dilutions of genomic DNA was separated electrophoretically on $1.2 \%(\mathrm{w} / \mathrm{v})$ agarose gels prepared in TAE buffer (40 mM Tris, $1 \mathrm{mM}$ EDTA, pH set to 8.5 with acetic acid, Riedel-de Haen, Hanover, Germany) along with a dilution series of lambda phage DNA of known concentration (methylated, from Escherichia coli host strain W3110). The electrophoresis was carried out at $4 \mathrm{~V} \mathrm{~cm}^{-1}$ for $60 \mathrm{~min}$. After staining with ethidium bromide $\left(0.5 \mu \mathrm{g} \mathrm{ml}^{-1}\right)$ and destaining in demineralized water, DNA bands were visualized in UV light using a CCD camera (Vilber Lourmat, Marne La Vallee, France). The electrophoretic bands within the linear range of the densitometry were used for quantification using Multi Analyst-Software (BioRad, Hercules, CA, USA). Standards for qPCR

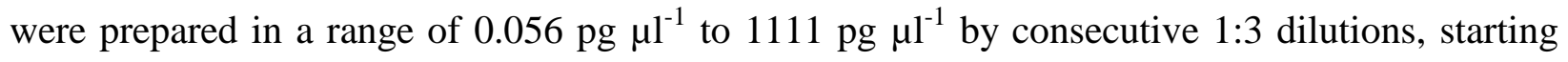
with the highest standard, in sterile distilled water. 
Table 1. Fungal isolates used in this research

\begin{tabular}{|c|c|c|}
\hline Fungal strain & Isolate code & Source \\
\hline Fusarium graminearum & DSM 62722 & $\begin{array}{l}\text { Deutsch Sammlung fon Mikroorganismen und Zellkulturen, Braaunschweig, } \\
\text { Germany }\end{array}$ \\
\hline Fusarium graminearum & DSM 67638 & $\begin{array}{l}\text { Deutsch Sammlung fon Mikroorganismen und Zellkulturen, Braaunschweig, } \\
\text { Germany }\end{array}$ \\
\hline Fusarium graminearum & BBA 62048 & H. Nirenberg (BBA, Berlin, Germany) via E. Möller \\
\hline Fusarium graminearum & Fg 5 & H. Nirenberg (BBA, Berlin, Germany) via E. Möller \\
\hline Fusarium graminearum & Fg 71 & T. Miedaner, University of Hohenheim, Germany \\
\hline Fusarium graminearum & Fg 210. $1 \mathrm{wt}$ & $\begin{array}{l}\text { Plant Pathological Strain Collection of the University of Göttingen, } \\
\text { Germany }\end{array}$ \\
\hline Fusarium proliferatum & FPRO 1 & A. Szecsi, Budapest, Hungary via E. Möller \\
\hline Fusarium proliferatum & FPRO 2 & A. Szecsi, Budapest, Hungary via E. Möller \\
\hline Fusarium proliferatum & FPRO 4 & A. Szecsi, Budapest, Hungary via E. Möller \\
\hline Fusarium proliferatum & FPRO 5 & A. Szecsi, Budapest, Hungary via E. Möller \\
\hline Fusarium proliferatum & FPRO 6 & A. Szecsi, Budapest, Hungary via E. Möller \\
\hline Fusarium proliferatum & FPRO 7 & A. Szecsi, Budapest, Hungary via E. Möller \\
\hline Fusarium proliferatum & FPRO 8 & A. Szecsi, Budapest, Hungary via E. Möller \\
\hline Fusarium proliferatum & FPRO 9 & A. Szecsi, Budapest, Hungary, via E. Möller \\
\hline Fusarium proliferatum & FPRO 11 & A. Szecsi, Budapest, Hungar,y via E. Möller \\
\hline Fusarium proliferatum & FPRO 12 & A. Szecsi, Budapest, Hungary, via E. Möller \\
\hline Fusarium avenaceum & $\mathrm{Fa} 95$ & E. Möller, University of Hohenheim, Germany \\
\hline Fusarium avenaceum & $\mathrm{Fa} 23$ & Department of Crop Sciences, University of Göttingen, Germany \\
\hline Fusarium avenaceum & $\mathrm{Fa} 5-2$ & Department of Crop Sciences, University of Göttingen, Germany \\
\hline Fusarium avenaceum & DSM 62161 & $\begin{array}{l}\text { Deutsche Sammlung von Mikroorganismen und Zellkulturen, Braunschweig, } \\
\text { Germany }\end{array}$ \\
\hline Fusarium culmorum & Fc 15 & $\begin{array}{l}\text { T. Miedaner, State Plant Breeding Institute, University of Hohenheim, } \\
\text { Stuttgart, Germany, via E. Möller }\end{array}$ \\
\hline Fusarium culmorum & $\mathrm{Fc} 2$ & H. Nirenberg (BBA, Berlin, Germany) via E. Möller \\
\hline Fusarium culmorum & Fc 22 & $\begin{array}{l}\text { T. Miedaner, State Plant Breeding Institute, University of Hohenheim, } \\
\text { Stuttgart, Germany, via E. Möller }\end{array}$ \\
\hline Fusarium culmorum & FCH 69 & Department of Crop Sciences, University of Göttingen, Germany \\
\hline Fusarium tricinctum & FT 2 & Department of Crop Sciences, University of Göttingen, Germany \\
\hline Fusarium tricinctum & FT 3 & Department of Crop Sciences, University of Göttingen, Germany \\
\hline Fusarium verticillioides & A00102 & J. F. Leslie, Kansas State University, Manhattan, KS, USA, via E. Möller \\
\hline Fusarium verticillioides & 1.34 & Mykothek FAP (W.Winter), via E. Möller \\
\hline Fusarium verticillioides & FV 234/1 & $\begin{array}{l}\text { P, Battilani, Faculty of Agriculture, UniversitaCattolica del SacroCoure, } \\
\text { Piacenza, Italy, via T. Miedaner }\end{array}$ \\
\hline Fusarium verticillioides & FM 8114 & Fusarium Research Center, Pennsylvania State University, USA \\
\hline Fusarium verticillioides & FV Ita 1 & A. Prodi, University of Bologna, Italy \\
\hline Fusarium oxysporum & Fo 125 & Department of Crop Sciences, University of Göttingen, Germany \\
\hline Fusarium oxysporum & Foxy 121 & Department of Crop Sciences, University of Göttingen, Germany \\
\hline Fusarium oxysporum & Foxy 436 & Department of Crop Sciences, University of Göttingen, Germany \\
\hline Fusarium oxysporum & Foxy 119 & Department of Crop Sciences, University of Göttingen, Germany \\
\hline Fusarium oxysporum & Foxy 6 & Department of Crop Sciences, University of Göttingen, Germany \\
\hline Fusarium oxysporum & Foxy 2 & Mykothek FAP (W.Winter), via E. Möller \\
\hline Fusarium poae & Fpoae 517 & Department of Crop Sciences, University of Göttingen, Germany \\
\hline Fusarium poae & Fpoae 369 & Department of Crop Sciences, University of Göttingen, Germany \\
\hline Fusarium poae & FP 2 & $\begin{array}{l}\text { T. Miedaner, State Plant Breeding Institute, University of Hohenheim, } \\
\text { Stuttgart, Germany, via E. Möller }\end{array}$ \\
\hline Fusarium poae & DSM 62376 & $\begin{array}{l}\text { Deutsche Sammlung von Mikroorganismen und Zellkulturen, Braunschweig, } \\
\text { Germany }\end{array}$ \\
\hline
\end{tabular}


Table 1: continued

\begin{tabular}{|c|c|c|}
\hline Fungal strain & Isolate code & Source \\
\hline Fusarium subglutinans & Fsub 2210 & E. Möller, Field isolates from Maize, Radzikow, Poland \\
\hline Fusarium subglutinans & Fsub 2209 & E. Möller, Field isolates from Maize, Radzikow, Poland \\
\hline Fusarium subglutinans & B 01722 & J. F. Leslie, Kansas State University, Manhattan, KS, USA, via E. Möller \\
\hline Fusarium subglutinans & В 00278 & J. F. Leslie, Kansas State University, Manhattan, KS, USA, via E. Möller \\
\hline Fusarium subglutinans & B $038 \mathrm{~J}$ & J. F. Leslie, Kansas State University, Manhattan, KS, USA, via E. Möller \\
\hline Fusarium subglutinans & B 03821 & J. F. Leslie, Kansas State University, Manhattan, KS, USA, via E. Möller \\
\hline Fusarium subglutinans & No. 43.92 & H. Lew and A. Adler, Linz, Austria \\
\hline Fusarium subglutinans & CBS 215.76 & CBS-KNAW Fungal Biodiversity Center, Utrecht, Netherland \\
\hline Fusarium subglutinans & Fsub 2-17 & P. Karlovsky, Shaam 6-39, China \\
\hline Fusarium subglutinans & Fsub 2215 & E. Möller, Field isolates from Maize, Radzikow, Poland \\
\hline Fusarium subglutinans & Fsub 2213 & E. Möller, Field isolates from Maize, Radzikow, Poland \\
\hline Fusarium subglutinans & Fsub 2220 & E. Möller, Field isolates from Maize, Radzikow, Poland \\
\hline Fusarium subglutinans & CBS 215.96 & CBS-KNAW Fungal Biodiversity Center, Utrecht, Netherland \\
\hline Fusarium sacchari & B 03853 & J. F. Leslie, Kansas State University, Manhattan, KS, USA, via E. Möller \\
\hline Fusarium sacchari & B 03852 & J. F. Leslie, Kansas State University, Manhattan, KS, USA, via E. Möller \\
\hline Fusarium crookwellense & FCKW1 & H. Nirenberg (BBA, Berlin, Germany) via E. Möller \\
\hline Fusarium crookwellens & BBA 64545 & H. Nirenberg (BBA, Berlin, Germany) via E. Möller \\
\hline Fusarium equiseti & ICARDA 93532 & International Center for Agricultural Research in the Dry Area, Aleppo, Syria \\
\hline Fusarium equiseti & ICARDA 93715 & International Center for Agricultural Research in the Dry Area, Aleppo, Syria \\
\hline Fusarium acuminatum & ICARDA 93803 & International Center for Agricultural Research in the Dry Area, Aleppo, Syria \\
\hline Fusarium acuminatum & ICARDA 92099 & International Center for Agricultural Research in the Dry Area, Aleppo, Syria \\
\hline Fusarium acuminatum & ICARDA 93682 & International Center for Agricultural Research in the Dry Area, Aleppo, Syria \\
\hline Fusarium acuminatum & ICARDA 93831 & International Center for Agricultural Research in the Dry Area, Aleppo, Syria \\
\hline Ustilago maydis & PL2 & $\begin{array}{l}\text { Deutsche Sammlung von Mikroorganismen und Zellkulturen, Braunschweig, } \\
\text { Germany }\end{array}$ \\
\hline Ustilago maydis & DSM 3121 & $\begin{array}{l}\text { Deutsche Sammlung von Mikroorganismen und Zellkulturen, Braunschweig, } \\
\text { Germany }\end{array}$ \\
\hline Ustlago maydis & PL4 & $\begin{array}{l}\text { Deutsche Sammlung von Mikroorganismen und Zellkulturen, Braunschweig, } \\
\text { Germany }\end{array}$ \\
\hline Acremonium longisporum & $\mathrm{AL}$ & Department of Crop Sciences, University of Göttingen, Germany \\
\hline Acremonium longisporum & $\mathrm{AC} 2$ & Department of Crop Sciences, University of Göttingen, Germany \\
\hline Microdochium nivale & GN25 & $\begin{array}{l}\text { T. Miedaner, State Plant Breeding Institute, University of Hohenheim, } \\
\text { Stuttgart, Germany, via E. Möller }\end{array}$ \\
\hline Cladosporium herbarum & $\mathrm{CH} 4$ & Department of Crop Sciences, University of Göttingen, Germany \\
\hline Rhizoctonia cerealis & SAGWJ7 & Department of Crop Sciences, University of Göttingen, Germany \\
\hline Alternaria alternata & A4.1.1 & Department of Crop Sciences, University of Göttingen, Germany \\
\hline
\end{tabular}




\section{Selection of Primers and Evaluation of their Specificity}

PCR primers selected for the work are shown in Table 2. Although the specificity of these primers was tested by the authors who designed them (rightmost column in Table 2), we carried out additional specificity tests for $F$. avenaceum, $F$. subglutinans and $F$. poae primers with DNA of a range of Fusarium species (64 isolates belonging to 13 species) and 9 isolates of other fungal species commonly associated with cereals (Table 1).

Table 2. Characteristics of primers used in this study for detecting of nine Fusarium spp.

\begin{tabular}{|c|c|c|c|c|}
\hline Primer name & Primer sequence $\left(5^{\prime}-3^{\prime}\right)$ & Target species & $\begin{array}{l}\text { Product size } \\
\text { (bp) }\end{array}$ & Reference \\
\hline $\begin{array}{l}\text { MGBF } \\
\text { MGBR }\end{array}$ & $\begin{array}{l}\text { CCATCGCCGTGGCTTTC } \\
\text { CAAGCCCACAGACACGTTGT }\end{array}$ & $F$. avenaceum & 58 & Waalwijk et al., 2004 \\
\hline $\begin{array}{l}\text { OPT18 F } \\
\text { OPT18 R }\end{array}$ & $\begin{array}{l}\text { GATGCCAGACCAAGACGAAG } \\
\text { GATGCCAGACGCACTAAGAT }\end{array}$ & F. culmorum & 472 & Schilling et al., 1996 \\
\hline $\begin{array}{l}198 \mathrm{~F} 2 \\
198 \mathrm{R} 1\end{array}$ & $\begin{array}{l}\text { GACAGCAAGATTGACCTTTTGG } \\
\text { GACATACTCTACAAGTGCCAA }\end{array}$ & F. equiseti & 96 & Wilson et al., 2004 \\
\hline $\begin{array}{l}\text { Fg16N F } \\
\text { Fg16N R }\end{array}$ & $\begin{array}{l}\text { ACAGATGACAAGATTCAGGCACA } \\
\text { TTCTTTGACATCTGTTCAACCCA }\end{array}$ & F. graminearum & 280 & Nicholson et al., 1998 \\
\hline $\begin{array}{l}\text { Fp82F } \\
\text { Fp82R }\end{array}$ & $\begin{array}{l}\text { CAAGCAAACAGGCTCTTCACC } \\
\text { TGTTCCACCTCAGTGACAGGTT }\end{array}$ & F. poae & 220 & Parry \& Nicholson, 1996 \\
\hline $\begin{array}{l}\text { Fp3-F } \\
\text { Fp4-R }\end{array}$ & $\begin{array}{l}\text { CGGCCACCAGAGGATGTG } \\
\text { CAACACGAATCGCTTCCTGAC }\end{array}$ & F. proliferatum & 230 & Jurado et al., 2006 \\
\hline $\begin{array}{l}\text { SUB } 1 \\
\text { SUB } 2\end{array}$ & $\begin{array}{l}\text { CTGTCGCTAACCTCTTTATCCA } \\
\text { CAGTATGGACGTTGGTATTATATCTAA }\end{array}$ & F. subglutinans & 631 & Mulè et al., 2004 \\
\hline $\begin{array}{l}\text { Tri1 } \\
\text { Tri2 }\end{array}$ & $\begin{array}{l}\text { CGTGTCCCTCTGTACAGCTTTGA } \\
\text { GTGGTTACCTCCCGATACTCTA }\end{array}$ & F. tricinctum & 215 & Kulik, 2008 \\
\hline $\begin{array}{l}\text { VER } 1 \\
\text { VER } 2\end{array}$ & $\begin{array}{l}\text { CTTCCTGCGATGTTTCTCC } \\
\text { AATTGGCCATTGGTATTATATATCTA }\end{array}$ & F. verticillioides & 578 & Mulè et al., 2004 \\
\hline
\end{tabular}

\section{Real-time PCR (qPCR)}

Thermocycler CFX384 (BioRad, Hercules, CA, USA) with 384-wells microplate (Kisker Biotech GmbH, Steinfurt, Germany) was used. The qPCR was performed in a total volume of $4 \mu 1$. Prior to distributing master mix, $5 \mu 1$ of mineral oil (SIGMA, Tauflcirchen, Germany) were pipetted into each well. Every reaction contained $1 \mu \mathrm{l}$ template DNA or $1 \mu 1$ sterile water for negative controls. The reaction mixture consisted of $16 \mathrm{mM}(\mathrm{NH} 4)_{2} \mathrm{SO}_{4}, 67 \mathrm{mM}$ Tris- $\mathrm{HCl}$, $0.01 \%(\mathrm{v} / \mathrm{v})$ Tween-20; $\mathrm{pH}$ was set to 8.8 at $25^{\circ} \mathrm{C}$. Varying concentrations of deoxynucleotide triphosphates and $\mathrm{MgCl}_{2}$ (Bioline, Lükenwalde, Germany) was used. Taq DNA polymerase (BIOTaq, Bioline, Lükenwalde, Germany) or hot start Taq DNA polymerase (Immolase DNA 
Pol., Lükenwalde, Germany) was employed in the activity $0.1 \mathrm{u} /$ reaction. $0.1 \mathrm{x}$ SYBR Green I (Invitrogen, Karlsruhe, Germany) and primers at a concentration of $0.3 \mu \mathrm{M}$ were used. Fluorescent data were obtained during the annealing phase to construct a melting curve at the end of each assay. The qPCR was completed by carrying out a melting curve analysis according to the following protocol: PCR products were denatured at $95^{\circ} \mathrm{C}$ for $1 \mathrm{~min}$, annealed at $55^{\circ} \mathrm{C}$ for $1 \mathrm{~min}$ and gradually heated from $55^{\circ} \mathrm{C}$ to $95^{\circ} \mathrm{C}$ at a rate of $0.05^{\circ} \mathrm{C} / \mathrm{s}$ while the fluorescence was continuously recorded.

\section{Determination of qPCR Sensitivity and Efficiency}

Sensitivity was defined as the lowest amount of standard DNA (see Preparation of DNA standards for $\mathbf{q P C R}$ ) that generated PCR products with the expected melting temperature in at least 7 out of 8 replicates. Each standard DNA was run in at least eight replicates on three different days (Supplemental Table 1). The PCR efficiency was calculated in a common way (Nutz et al., 2011).

\section{Results}

\section{Selection and Specificity of Primers}

The primers used in this work were designed and tested previously for species-specific detection of Fusarium spp. (Table 2). Apart from specificity tests carried out by the researchers who designed them, we conducted additional specificity tests for three primer pairs of F. subglutinans (Nicolaisen et al., 2009; Möller et al., 1999; Mulè et al., 2004), two primer pairs of $F$. avenaceum (Turner et al., 1998; Waalwijk et al., 2004) and one primer pair of $F$. poae (Parry \& Nicholson, 1996). We carried out these tests under conditions recommended in publications in which the primers were described but reduced the reaction volume to $10 \mu 1$ (F. subglutinans) or $4 \mu \mathrm{l}$ (F. avenaceum, F. poae).

In our thermocycler, primer pair Fsub565/Fsub622A described by Nicolaisen et al. (2009) as specific for $F$. subglutinans generated products with different melting temperatures for different $F$. subglutinans strains; moreover, DNA of the strains $F$. graminearum $\mathrm{Fg} 71$ and F. verticillioides Fv Ita 1 as template were amplified, too. The primer pair 61-2 F/61-2 R (Möller et al., 1999) turned out not to be specific for F. subglutinans because it generated products with 
the genomic DNA of strains F. graminearum Fg 71 and F. verticillioides Fv Ita 1 . The primers SUB 1/SUB 2 designed by Mulè et al. (2004) for F. subglutinans were specific and have, therefore, been selected.

For F. avenaceum we tested primers MGBF/R (Waalwijk et al., 2004) and JIAF/R (Turner et al., 1998). When pure fungal DNA was tested, both primer pairs were specific for $F$. avenaceum and exhibited the same sensitivity. When they tested on DNA extracted from infected plants, however, primers MGBF/R were more sensitive (data not shown). We, therefore, selected primers MGBF/R for the detection of $F$. avenaceum.

The qPCR with primer set Fp82F/R designed for F. poae (Parry \& Nicholson, 1996) was negative for all Fusarium strains described in Table 1 except for $F$. poae.

Optimization of a Protocol for Simultaneous Quantification of Nine Fusarium spp. in a Single Microplate

The PCR assays were carried out in a total volume of $4 \mu$ l overlaid with the mineral oil. Using adhesive foil instead of oil lead to the identical results. Loading small volumes in 384-well microplates can conveniently be carried out with pipetting robots. Because most plant pathology laboratories do not possess this equipment, we designed a simple loading scheme for manual loading with multichannel pipettes, consisting of three steps (Fig. 1). The composition of the reaction mixture and a thermocycler protocol suitable for all nine Fusarium species were designed based on the conditions optimized for individual assays (see below). For a convenient printout, these conditions are summarized on Fig. 2.

The performance of the method was tested on serial dilutions of pure genomic DNA for each Fusarium spp. Calibration curves are shown in Fig. 3. The coefficient of determination $\left(\mathrm{R}^{2}\right)$, ranging from 0.991 to 0.999 , indicated a high accuracy of three-fold dilution series of standard DNA. The sensitivity of qPCR assays ranged from $0.05 \mathrm{pg}$ ( $F$. proliferatum) to $1.5 \mathrm{pg}$ (F. equiseti and F. verticillioides) for pure fungal DNA (Table 3a). Melting curves of PCR products for all nine species showed single transition points at temperatures $81^{\circ} \mathrm{C}$ to $90^{\circ} \mathrm{C}$, indicating that a single product was amplified in each assay. PCR amplification efficiency of $92.15 \%$ on the average was accomplished. 


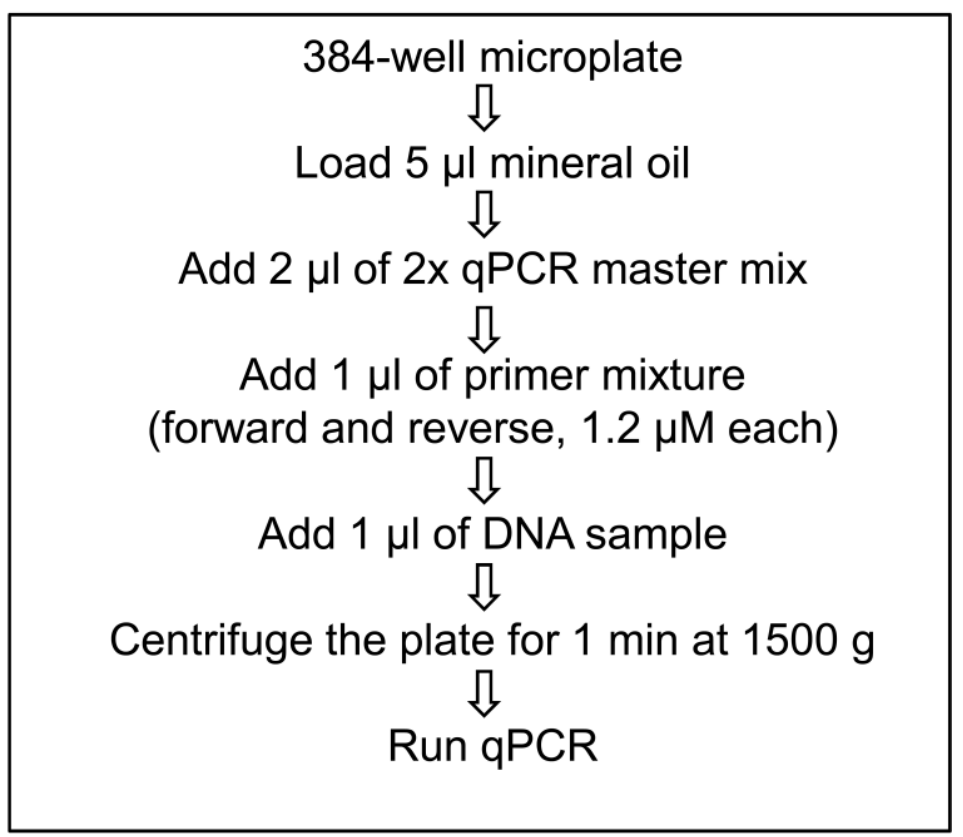

Fig. 1. Pipetting flowchart for multi-species qPCR detection of Fusarium spp. in a 384-well real-time thermocycler

Common PCR protocol for nine Fusarium spp.
Master mix (2x)
- $2 x \mathrm{PCR}$ buffer
- $2.5 \mathrm{mM} \mathrm{MgCl} 2$
- $150 \mu \mathrm{MMNTPs}$
- $0.025 \mathrm{u} / \mu \mathrm{hl}$ Taq polymerase
- $1 \mathrm{x} \mathrm{SYBR}$ Green
Thermocycler protocol
1. $2 \mathrm{~min} / 95^{\circ} \mathrm{C}$
2. $30 \mathrm{~s} / 94^{\circ} \mathrm{C}$
3. $30 \mathrm{~s} / 63^{\circ} \mathrm{C}$
4. $\left.35 \mathrm{~s} / 72^{\circ} \mathrm{C}\right]$
5. $5 \mathrm{~min} / 72^{\circ} \mathrm{C}$

Fig. 2. Scheme of common PCR protocol for the nine Fusarium spp. 


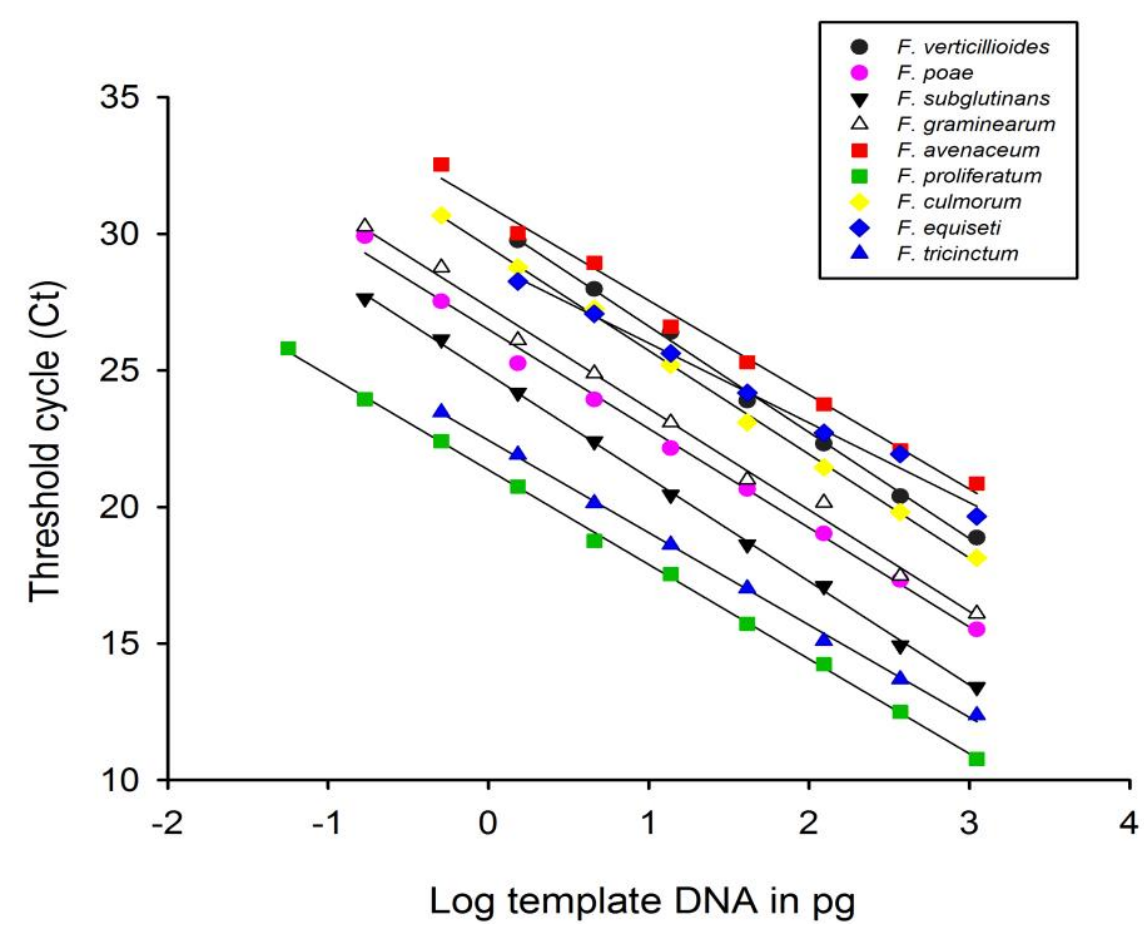

Fig. 3. Standard curves for simultaneous quantification of nine Fusarium spp.

\section{Optimization of the qPCR Assays for Individual Fusarium Species}

Similarly as in multiplex PCR assays, any protocol for parallel analysis of different species is a compromise among optimal conditions for the individual assays. In order to compare the performance of the multi-species assay with individual qPCR assays run under optimal conditions, we optimized the qPCR for each species, individually. Protocols for species-specific qPCR with SYBR Green detection, using the selected primers, were published for 4 out of the 9 Fusarium spp. (Brandfass \& Karlovsky 2006; Nutz et al., 2011). Because these protocols performed sub-optimally in $4 \mu \mathrm{l}$ reaction volumes (data not shown), we re-optimized the PCR conditions for all species in 384-well microplate. Simultaneous optimization of the annealing temperature and $\mathrm{MgCl}_{2}$ concentration was achieved with the help of a temperature gradient block of the thermocycler. The experiments were conducted in four different quantities of the template

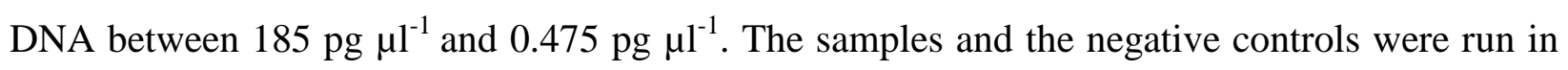
duplicate.

F. avenaceum. The qPCR assay was performed in the range $59-65^{\circ} \mathrm{C}$ of annealing temperature and $\mathrm{MgCl}_{2}$ concentrations $1.5,2.0$ and $2.5 \mathrm{mM}$. The optimal conditions were annealing 
temperature of $63^{\circ} \mathrm{C}$ and $2.5 \mathrm{mM} \mathrm{MgCl}$. The threshold values $(\mathrm{Ct})$ indicated a delicate fluctuation for annealing temperatures $60-63^{\circ} \mathrm{C}$ and $2.0-2.5 \mathrm{mM} \mathrm{MgCl}_{2}$ for standard DNA amounts higher than $10 \mathrm{pg}$. Therefore, considering the lowest amount of $\mathrm{Ct}$ in different quantities of template DNA, the suitable qPCR conditions were selected. The annealing time was lowered from the recommended time of $60 \mathrm{~s}$ (Waalwijk et al., 2004) to $25 \mathrm{~s}$. Considering the length of PCR amplicon, the best time for elongation step was $10 \mathrm{~s}$.

F. culmorum. Performance of annealing gradient qPCR assay between $58-66^{\circ} \mathrm{C}$ and $2.5,3.0,3.5$ $\mathrm{mM}$ of $\mathrm{Mg}^{++}$concentrations indicated that temperature of $62^{\circ} \mathrm{C}$ and $2.5 \mathrm{mM} \mathrm{MgCl}_{2}$ can produce suitable $\mathrm{Ct}$ values in all DNA quantities, in contrast to the annealing temperature of $64^{\circ} \mathrm{C}$ and 4 $\mathrm{mM}$ of $\mathrm{Mg}^{++}$concentration which are suggested by Brandfass \& Karlovsky (2008). The time for annealing and extension steps was $40 \mathrm{~s}$ and $45 \mathrm{~s}$, respectively.

F. equiseti. The qPCR assay was performed in range $58.2-66.8^{\circ} \mathrm{C}$ of annealing temperature and $\mathrm{MgCl}_{2}$ concentrations $1.5,2.0$ and $2.5 \mathrm{mM}$. Initial experiments showed that $63^{\circ} \mathrm{C}$ of annealing temperature and $2.5 \mathrm{mM} \mathrm{MgCl} 2$ would be the optimal qPCR conditions. But there was unspecific peak especially in low concentrations of DNA. Therefore the PCR condition was improved by using a high quality Taq DNA polymerase. In this case the optimal annealing temperature was increased to $65^{\circ} \mathrm{C}$ for $20 \mathrm{~s}$. The time for extension step was $20 \mathrm{~s}$.

F. graminearum. Annealing temperature in the range $59.0-66.5^{\circ} \mathrm{C}$ and $\mathrm{Mg}^{++}$concentrations 2.0 , 2.5 and $3.0 \mathrm{mM}$ were tested. The optimal conditions were annealing temperature of $61^{\circ} \mathrm{C}$ and $2.5 \mathrm{mM} \mathrm{MgCl}_{2}$, similar to Brandfass \& Karlovsky (2008) who found $64^{\circ} \mathrm{C}$ and $2.5 \mathrm{mM} \mathrm{MgCl}_{2}$ to be optimal for qPCR with the same primers in a reaction volume of $25 \mu 1$. We found no difference in the threshold cycle for annealing temperatures $60.0-62.5^{\circ} \mathrm{C}$ and $2.0-3.0 \mathrm{mM} \mathrm{MgCl}_{2}$ for standard DNA amounts higher than $40 \mathrm{pg}$. The time for annealing and elongation steps were reduced from 45 s recommended by Brandass \& Karlovsky (2008) to 30 s.

F. poae. Testing annealing temperature in the range $60-65^{\circ} \mathrm{C}$ and $1.5,2.0$ and $2.5 \mathrm{mM} \mathrm{Mg}^{++}$ concentration indicated that the qPCR could be operated in a wide range of annealing temperature and $\mathrm{MgCl}_{2}$. The amount of $\mathrm{Ct}$ value did not show a big fluctuation in different conditions. Therefore, the annealing temperature of $62.5^{\circ} \mathrm{C}$ and $2 \mathrm{mM}$ of $\mathrm{MgCl}_{2}$ were selected as 
the best qPCR conditions. Parry \& Nicholson (1996) had suggested the annealing temperature of $60^{\circ} \mathrm{C}$ for the primer set Fp82 F/R. Time for annealing and extension steps was optimized on $30 \mathrm{~s}$ and $35 \mathrm{~s}$, respectively.

F. proliferatum. The qPCR assay was carried out in the range $59-65^{\circ} \mathrm{C}$ of annealing temperature and 2.0, 2.5, $3.0 \mathrm{mM}$ of $\mathrm{Mg}^{++}$concentration. The optimal conditions were annealing temperature of $64^{\circ} \mathrm{C}$ and $2 \mathrm{mM} \mathrm{MgCl}_{2}$, similar to Brandfass \& Karlovsky (2008). There was no difference in threshold cycles for the annealing temperatures $60-65^{\circ} \mathrm{C}$ and $2.0-2.5 \mathrm{mM} \mathrm{MgCl} 2$ while standard DNA amounts were less than $20 \mathrm{pg}$. The best time for annealing and extension steps was $30 \mathrm{~s}$ and $35 \mathrm{~s}$, respectively.

F. subglutinans. Annealing temperature in the range $54-68^{\circ} \mathrm{C}$ and $\mathrm{Mg}^{++}$concentration 2.0-4.5 mM were tested. An annealing temperature of $65^{\circ} \mathrm{C}$ yielded specific products, in contrast to the annealing temperature of $56^{\circ} \mathrm{C}$ suggested by the primer designers (Mulè et al., 2004). The optimal concentration for $\mathrm{MgCl}_{2}$ was $3.0 \mathrm{mM}$. We found no difference in $\mathrm{Ct}$ values for $64-66^{\circ} \mathrm{C}$ and 2.5-3.5 $\mathrm{mM} \mathrm{MgCl}_{2}$. Considering the lowest $\mathrm{Ct}$ value and specificity for primer annealing, the best qPCR conditions were selected. Desired time for annealing and extension steps was $30 \mathrm{~s}$ and $40 \mathrm{~s}$, respectively.

F. tricinctum. Performance of annealing gradient qPCR assay between $58.2-66.8^{\circ} \mathrm{C}$ and $2.5,3.0$, $3.5 \mathrm{mM}$ of $\mathrm{Mg}^{++}$concentrations indicated that temperature of $65^{\circ} \mathrm{C}$ and $2.5 \mathrm{mM} \mathrm{MgCl}_{2}$ can produce suitable $\mathrm{Ct}$ values in all DNA quantities. The annealing conditions were similar to Kulik (2008); but the time for extension step was reduced of $55 \mathrm{~s}$ (Kulik, 2008) to $25 \mathrm{s.}$

F. verticillioides. Annealing temperature in the range $56-65^{\circ} \mathrm{C}$ and $\mathrm{Mg}^{++}$concentrations $2.0,2.5$ and $3.0 \mathrm{mM}$ were evaluated. The optimal conditions were annealing temperature of $62.5^{\circ} \mathrm{C}$ and $2.5 \mathrm{mM} \mathrm{MgCl}_{2}$. There was no difference in $\mathrm{Ct}$ values for annealing temperatures $60.0-62.5^{\circ} \mathrm{C}$ and 2.5-3.0 $\mathrm{mM} \mathrm{MgCl} 2$ for the standard DNA amounts higher than $10 \mathrm{pg}$, but the best qPCR conditions were selected considering the suitable conditions for lower DNA quantities. The time for annealing and elongation steps were lowered from the recommended time of $50 \mathrm{~s}$ and $60 \mathrm{~s}$ (Nutz et al., 2011) to $30 \mathrm{~s}$ and $40 \mathrm{~s}$, respectively. 
The optimal qPCR conditions were tested for the overall performance of assay by using the data generated from a serial dilution of pure genomic DNA for each Fusarium spp., individually. The average amount of $\mathrm{Ct}$ values was graphed versus the logarithm of the correspondent starting DNA quantity (SQ) to construct the standard curves. Comparing of $\mathrm{R}^{2}$ indicated the accuracy of the dilution series and the overall assay sensitivity. The coefficient of determination ranged from 0.990 to 0.999. Typical calibration curves generated for Fusarium spp. DNA are given in Fig. 4. The sensitivity of qPCR assays was estimated to be $0.05 \mathrm{pg}$ for pure DNA of $F$. proliferatum, $0.17 \mathrm{pg}$ for $F$. avenaceum, $F$. graminearum, $F$. poae, $F$. subglutinans and $0.50 \mathrm{pg}$ for F. culmorum, F. equiseti, F. tricinctum and F. verticillioides in a background free of plant tissue and other contamination. The average repeatability varied from $0.84 \%$ RSD (relative standard deviation) for $F$. verticillioides to $2.00 \%$ RSD for $F$. tricinctum (Table $3 b$ ). The main point in this protocol was the least possible number of samples which are included in each qPCR assay. Considering amount of Taq DNA polymerase, the master mix would be prepared at least for 50 samples to decrease the pipetting error.

As it is presented above, the qPCR optimization tests indicated flexibility in some cases. In such conditions, qPCR assay could be operated in a wide range of annealing temperature and $\mathrm{MgCl}_{2}$ concentrations. Nevertheless, concerning low $\mathrm{Ct}$ values and specificity of primer annealing, the best conditions were selected for each Fusarium spp. Optimized qPCR conditions for each Fusarium spp. are summarized in Table 3b. The performance of new optimized assays for nine species of Fusarium in $4 \mu \mathrm{l}$ volumes was gratified and low concentrations of genomic DNA were also detectable by qPCR assay without creating unspecific peak.

The results also show that the difference between qPCR efficiency in single species and multi-species detection of Fusarium spp. is not high and the $\mathrm{Ct}$ values did not change by more than approximately $1 \mathrm{Ct}$. Furthermore, we compared PCR sealing film and the mineral oil as a coating layer for qPCR microplate. There was no difference in $\mathrm{Ct}$ values and efficiency of assay. Therefore, we would suggest using the mineral oil instead of other sealing film. 
Table 3a. PCR conditions and performance parameters of multi-species qPCR assay

\begin{tabular}{|c|c|c|c|c|c|c|c|c|c|c|}
\hline Fusarium spp. & $\begin{array}{l}\mathrm{MgCl}_{2} \\
(\mathrm{mM})\end{array}$ & $\begin{array}{r}\mathrm{dNTP}_{\mathrm{s}} \\
(\mu \mathrm{M})\end{array}$ & $\mathrm{Ta}$ & $\begin{array}{c}\text { Ann. time } \\
\text { (s) }\end{array}$ & $\begin{array}{l}\text { Ext. time } \\
\text { (s) }\end{array}$ & $\begin{array}{c}\text { PCR } \\
\text { Efficiency } \\
(\%)\end{array}$ & $\begin{array}{l}\text { Sens. }^{1} \\
(\mathrm{pg})\end{array}$ & $\begin{array}{c}\mathrm{Ct} \text { for } 1 \\
\mathrm{pg}\end{array}$ & $\begin{array}{l}\text { Ave of } \\
\% \text { RSD }^{2}\end{array}$ & $\begin{array}{l}\mathrm{Tm}^{3} \\
\left({ }^{\circ} \mathrm{C}\right)\end{array}$ \\
\hline F. avenaceum & & & & & & 94.8 & 0.508 & 31.01 & 1.57 & 81 \\
\hline F. culmorum & & & & & & 83.4 & 0.508 & 29.52 & 1.71 & 87 \\
\hline F. equiseti & & & & & & 120.1 & 1.524 & 28.91 & 1.00 & 86 \\
\hline F. graminearum & & & & & & 85.9 & 0.169 & 27.31 & 1.40 & 82 \\
\hline F. poae & 2.5 & 150 & 63 & 30 & 35 & 88.5 & 0.169 & 26.49 & 1.69 & 83 \\
\hline$F$. proliferatum & & & & & & 94.4 & 0.056 & 21.35 & 1.58 & 89 \\
\hline F. subglutinans & & & & & & 83.5 & 0.169 & 24.85 & 1.50 & 88 \\
\hline F. tricinctum & & & & & & 97.6 & 0.508 & 22.44 & 0.81 & 90 \\
\hline F. verticillioides & & & & & & 81.0 & 1.524 & 30.05 & 1.62 & 88 \\
\hline
\end{tabular}

Table 3b. PCR conditions and performance parameters of single species qPCR assays

\begin{tabular}{|c|c|c|c|c|c|c|c|c|c|c|}
\hline Fusarium spp. & $\begin{array}{l}\mathrm{MgCl}_{2} \\
(\mathrm{mM})\end{array}$ & $\begin{array}{l}\mathrm{dNTP}_{\mathrm{s}} \\
(\mu \mathrm{M})\end{array}$ & $\begin{array}{c}\mathrm{Ta} \\
\left({ }^{\circ} \mathrm{C}\right)\end{array}$ & $\begin{array}{c}\text { Ann. time } \\
\text { (s) }\end{array}$ & $\begin{array}{l}\text { Ext. time } \\
\text { (s) }\end{array}$ & $\begin{array}{c}\text { PCR } \\
\text { Efficiency } \\
(\%)\end{array}$ & $\begin{array}{l}\text { Sens. }^{1} \\
(\mathrm{pg})\end{array}$ & $\begin{array}{c}\mathrm{Ct} \text { for } 1 \\
\mathrm{pg}\end{array}$ & $\begin{array}{l}\text { Ave of } \\
\% \text { RSD }^{2}\end{array}$ & $\begin{array}{l}\mathrm{Tm}^{3} \\
\left({ }^{\circ} \mathrm{C}\right)\end{array}$ \\
\hline F. avenaceum & 2.5 & 150 & 63.0 & 25 & 10 & 98.19 & 0.169 & 30.15 & 1.42 & 81 \\
\hline F. culmorum & 2.5 & 150 & 62.0 & 40 & 45 & 94.28 & 0.508 & 28.27 & 1.11 & 87 \\
\hline F. equiseti & 2.5 & 150 & 65 & 20 & 10 & 110.1 & 0.508 & 29.18 & 0.96 & 86 \\
\hline F. graminearum & 2.5 & 150 & 61.0 & 30 & 30 & 100.3 & 0.169 & 28.09 & 1.79 & 82 \\
\hline F. poae & 2.0 & 100 & 62.5 & 30 & 35 & 99.83 & 0.169 & 25.93 & 1.47 & 83 \\
\hline F. proliferayum & 2.0 & 150 & 64.0 & 30 & 35 & 98.64 & 0.056 & 21.53 & 1.56 & 89 \\
\hline F. subglutinans & 3.0 & 100 & 65.0 & 30 & 40 & 97.75 & 0.169 & 24.49 & 1.56 & 88 \\
\hline F. tricinctum & 2.5 & 150 & 65 & 25 & 30 & 106.0 & 0.508 & 21.62 & 2.00 & 90 \\
\hline F. verticillioides & 2.5 & 100 & 62.5 & 30 & 40 & 96.37 & 0.508 & 29.40 & 0.84 & 88 \\
\hline
\end{tabular}

${ }^{1 .}$ Sensitivity ("Sens."): The lowest standard in a 3-fold dilution series starting with 1111 pg that was amplified in at least 7 out of 8 replicates

2. Average percent of relative standard deviation ("Ave \%RSD") for all detectable qPCR standards

${ }^{3 .}$ Melting temperature ("Tm") determined with accuracy of $0.5^{\circ} \mathrm{C}$ 

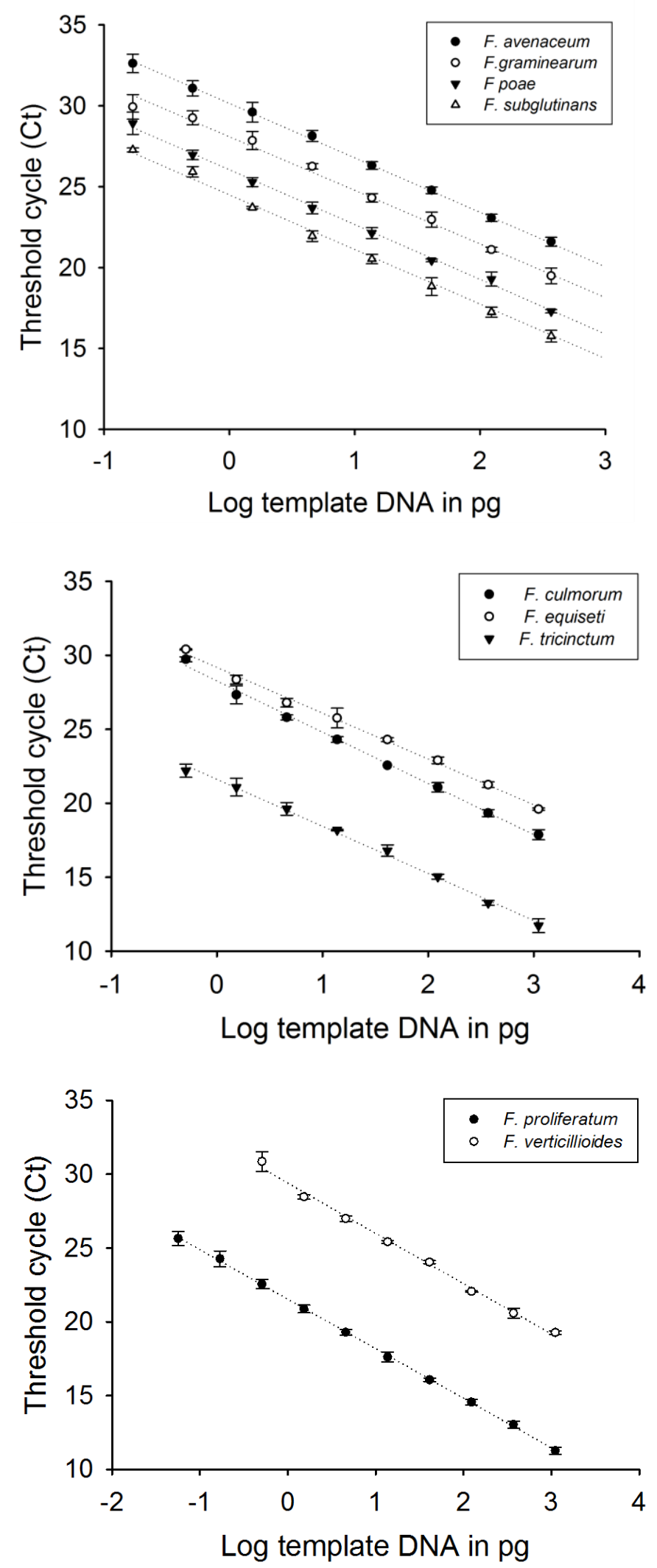

Fig. 4. Standard curves for Fusarium spp. qPCR assays 


\section{Discussion}

Cereals are contaminated with a wide range of Fusarium spp., most of which produce mycotoxins (Jurado et al., 2005). Quantitative determination of fungal biomass in plant tissue is invaluable in studies of plant diseases. Furthermore, quantitative data on fungal biomass can be used for the prediction of mycotoxin content; the biomass of a Fusarium species and the concentration of its mycotoxin in the infected tissue often tightly correlate (Waalwijk et al., 2004; Schnerr et al., 2002; Yli-Mattila et al., 2008). Therefore, quantitative diagnosis of pathogenic Fusaria in plant tissues is an essential and powerful tool in both research and diagnostic laboratories. Sensitive and fast diagnostic methods are also important in assaying crop propagules for quarantine pathogens (Waalwijk et al., 2004). Since the range of Fusarium species associated with cereals is quite extensive, to facilitate fusarium diseases investigation while testing some samples for more than one species of Fusarium, we developed a multi-species qPCR assay in $4 \mu 1$ volume reactions by using a 384-well thermocycler. The qPCR assays for all nine species, studied in this work, can be carried out in the same microplate, because they utilize the same thermocycle profile. Multi-species qPCR protocol is particularly useful when user have a few samples, but wants to check them for more than one Fusarium spp. In this case, we will likely have less labor intensive if we can run the samples in 384-well qPCR plate and the time of qPCR analysis could be reduced intensely to a single day. Simultaneous quantification approach allows maximum amount of data to be generated from each qPCR assay. Nine species of Fusarium evaluated in this study, cause important diseases on maize and small grain cereals. The qPCR optimization tests which quantified Fusarium spp. individually, had revealed that some of the qPCR variables can work in a wide range of PCR conditions. Therefore, concerning the low $\mathrm{Ct}$ values and specificity of primer annealing, the most suitable conditions were selected. On the other hand, in our experiments, assessment of common domains of qPCR variables helped us for designing a multi-species qPCR assay. Eventually, owing to applicable common range in qPCR variables we concluded on specific PCR profiling for the nine species of Fusarium.

Sensitivity and robustness of qPCR assay are known as the crucial factors. Standard performance parameters of analytical methods are the limit of detection (LOD) and limit of quantification (LOQ). Standard methods for the determination of LOD and LOQ, based on the 
noise of the background are not suitable for qPCR. Several authors suggested alternative definitions of LOD and LOQ in qPCR (Bustin et al., 2009; Mattarucchi et al., 2005; Vaerman et al., 2004; Gao et al., 2004); but none of these procedures was accepted by the community. The use of receiver operating curve analysis is the most recent suggestion for the determination of LOQ in qPCR (Nutz et al., 2011); but the method requires the analysis of large field data sets which was not available for our assays. We, therefore, used a simple sensitivity parameter defined as the lowest amount of template DNA that generated products with the expected melting temperature in at least seven out of eight replicates. The sensitivity determined in this way depends on DNA quantities of the standards; because we used a 3-fold dilution series, sensitivity value of $\mathrm{S}$ specifies a confidence interval for LOD as follows: $\mathrm{S}>\mathrm{LOD}>\mathrm{S} / 3$. According this definition, the real-time PCR assay was sensitive with consistent detection of

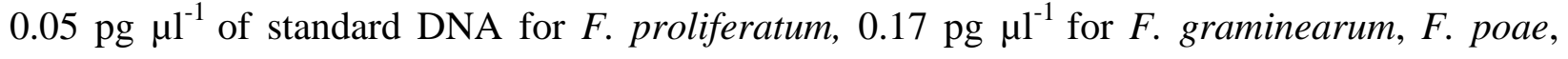

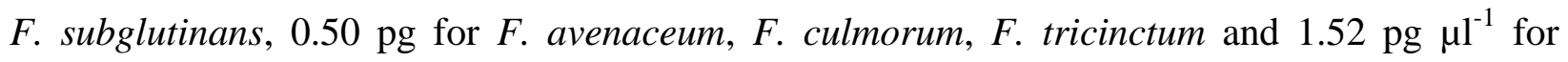
$F$. equiseti and $F$. verticillioides. Lack of adequate sensitivity for quantifying of $F$. equiseti and F. verticillioides in multi-species qPCR protocol indicates the importance of using the single species detection method in the precise quantification researches of these two species of Fusarium.

The previous published qPCR conditions for F. culmorum, F. graminearum, F. proliferatum and F. verticillioides (Brandfass \& Karlovsky, 2006; Nutz et al., 2011) for $25 \mu 1$ volumes were not fit when used in $4 \mu \mathrm{l}$ reactions. In most cases, especially in low concentrations of DNA, a second peak prior to specific melting point made disorders for the qPCR dissociation curve. This wide shape peaks would be generated from primer-dimmers or unspecific amplification products and should be discarded after enhancing of qPCR conditions. Therefore, for all of those species, we re-optimized the qPCR conditions to find the best options for running a single species qPCR. The main changes for the thermal cycling parameters were involved annealing and elongation steps. Considering threshold cycle and specificity of primer annealing, the optimal concentration of PCR reagents was selected for the nine species of Fusarium.

The single species qPCR protocol showed high sensitivity for $F$. proliferatum $(0.05 \mathrm{pg}$ DNA $\left.\mu 1^{-1}\right), F$. avenaceum, $F$. graminearum, F.poae, $F$. subglutinans $\left(0.17\right.$ pg DNA $\left.\mu 1^{-1}\right)$ and it was $0.50 \mathrm{pg}$ DNA $\mu 1^{-1}$ for $F$. culmorum, F. equiseti, $F$. tricinctum and $F$. verticillioides. Further 
experiments indicated a constant higher sensitivity for $F$. proliferatum $\left(2 \mathrm{fg}\right.$ DNA $\left.\mu 1^{-1}\right)$ while the average of the Ct value was 29.8 (data not shown). Using the hot start Taq DNA polymerase could enhance the amplification of $F$. equiseti strains. Due to the results, the correspondence among single-species and multi-species qPCR assays demonstrated in this work, was optimal and the $\mathrm{Ct}$ values did not change by more than approximately $1 \mathrm{Ct}$ in two reported protocols. The DNA samples of plant tissues often need to be diluted prior to PCR; because of the presence of different inhibitors in DNA extracts which can affect the target amplification. The PCR inhibitors are particularly known to attend in the DNA prepared from senescing plant tissues (Turner et al., 1998) and also the DNA extracts from the soil or plant roots (Van de Graaf et al., 2003; Gao et al., 2004).

The $\mathrm{Ct}$ value for $1 \mathrm{pg}$ DNA $\mu \mathrm{l}^{-1}$ was between $24-30$ cycles for all nine Fusarium spp. except $F$. proliferatum and $F$. tricinctum, which have a threshold cycle of 21 for this amount of the pure genomic DNA. The reason is that the primers used for these two Fusarium species were derived from the IGS (Intergenic Spacer) rDNA region which is a multi-copy domain in the genome and fungal detection is more sensitive for multi-copy IGS-based PCR assay (Jurado et al., 2006).

The set of species-specific primers used in this work allowed amplifying the considering specific fragments by qPCR assay. Some of the primer pairs indicated specificity problems and excluded from the further experiments. For F. subglutinans, Primer Fsub565/Fsub622A (Nicolaisen et al., 2009) produced non-specific PCR products for $F$. subglutinans DNA samples, Fg 71 and Fv Ita 1 isolates. Furthermore, primer 61-2 F/61-2 R published by Möller et al. (1999), generated specific melting temperature for some of the reference DNA. Zheng \& Ploetz (2002), demonstrated primer pairs 61-2 F/61-2 R were not useful for identifying the $F$. subglutinans-like isolates such as $F$. sacchari and $F$. circinatum. As a result in our work the primer pair SUB 1/SUB 2, designed based on the calmodulin partial gene (Mulè et al., 2004) considered as the species-specific primer in real-time PCR for $F$. subglutinans. There was no cross-reaction with other Fusarium spp. and the fungal DNA tested. Therefore, F. subglutinans optimization was continued with SUB 1/SUB 2 primers. Regarding to $F$. avenaceum, Turner et al. (1998), designed primer JIAF/R based on the nuclear 5.8s rDNA ITS sequence and demonstrated to be specific for $F$. avenaceum with no cross reactivity with $F$. tricinctum or any other wheat 
pathogens. Furthermore, primer $\mathrm{MGBF} / \mathrm{R}$ which is a set of novel oligonucleotides including "Minor Groove Binder" (MGB) ligands has been designed by Waalwijk et al. (2004). These scientists produced this primer based on the sequencing of a $920 \mathrm{bp}$ amplified DNA fragment generated by $\mathrm{Fa}$ F/R primer. The primer $\mathrm{Fa} F / \mathrm{R}$ was reported to be specific to $F$. avenaceum (Doohan et al., 1998). In our experiments both of these primers (JIAF/R and avenaceum MGBF/R) produced specific peak only in $F$. avenaceum wells; but more sensitivity of primer $\mathrm{MGBF} / \mathrm{R}$ with field samples led to its selection as the specific primer for $F$. avenaceum. Higher specificity of MGB ligands primers compared to the classical primers is for the nature of ligands (Afonia et al., 2002). Primer set Fp82F/R for F. poae was created from clone T161 by Parry and Nicholson (1996). They had presented this primer as a monomorphic marker which is able to detect $F$. poae in wheat samples; but another primer pair designed for $F$. poae (Fp8F/R) had shown polymorphic bands and, therefore, did not develop further. In our experiments primer Fp82F/R, amplified the target DNA while no amplification occurred in the reference fungal DNA nor for the negative control. Consequently, the ability of primer pairs SUB 1/SUB 2, $\mathrm{MGBF} / \mathrm{R}$ and Fp82F/R was confirmed to detect corresponding Fusarium species in the extracts from maize plant tissue samples by qPCR. Primer pair 198F2/198R1 designed by Wilson et al. (2004) for $F$. equiseti was tested against isolates of the target species and a variety of other Fusarium species and other fungi associated with diseases of cereals (Wilson et al., 2004; Nicholson et al., 2004). Kulik (2008) evaluated the specificity of Tri1/Tri2 primers on genomic DNA extracted from 56 isolates representing 20 Fusarium species and also 12 F. tricinctum isolates. He found unexpected amplicons which were amplified from one isolate of F. acuminatum and one from F. nurragi. Further sequencing experiments indicated 100\% identity of $F$. acuminatum isolate to $F$. tricinctum while $F$. nurragi had $99 \%$ of similarity to CBS 261.51 (F. tricinctum).

In conclusion it is believed that the real-time PCR protocols described in this study are specific, reliable and sensitive for singly detection and quantification of nine Fusarium spp. genomic DNA. Furthermore, the established multi-species qPCR method is also robust, precise, cost effective, quick and applicable for monitoring and quantifying of nine Fusarium spp. These protocols are widely used in our department for detection and quantification of Fusarium spp. in cereal crops including maize, wheat, sorghum, rice, and different other plants such as weeds 
which naturally or artificially have single or multiple infection of Fusarium spp. It is anticipated that the reported protocols would be applicable for other crops, as well.

\section{Author's Contributions}

In this work, the specificity test for $F$. subglutinans primer sets was performed by Dr. Eva-Maria Becker.

\section{Literature Cited}

- Afonia, I. A., Reed, M. W., Lusby. E., Shishkina. I. G., and Belousov, Y. S. 2002. Minor Groove Binder-conjugated DNA probes for quantitative DNA detection by hybridization-triggered fluorescence. Biotechniques 32:940-949.

- Brandfass, C., and Karlovsky, P. 2008. Upscaled CTAB-based DNA extraction and real-time PCR assays for Fusarium culmorum and $F$. graminearum DNA in plant material with reduced sampling error. Int. J. Mol. Sci. 9:2306-2321.

- Brandfass, C., and Karlovsky, P. 2006. Simultaneous detection of Fusarium culmorum and $F$. graminearum in plant material by duplex PCR with melting curve analysis. BMC Microbiol. 6 (4). Available from: http://www.biomedcentral.com/1471-2180/6/4 : URL. DOI.

- Brenan, C., and Morrison, T. 2005. High throughput, nanoliter quantitative PCR. Drug Discovery Today: Technologies 2:247-253.

- Bustin, S. A., Benes, V.,Garson, J. A., Hellemans, J., Huggett, J., Kubista, M., Mueller, R., Nolan, T., Pfaffl, M. W., Shipley, G. L., Vandesompele, J., and Wittwer, C. T. 2009. The MIQE guidelines: minimum information for publication of quantitative real-time PCR experiments. Clin. Chem. 55:611-622.

- Dahl, A., Sultan, M., Jung, A., Schwartz, R., Lange, M., Steinwand, M., Livak, K. J., Lehrach, H., and Nyarsik, L. 2007. Quantitative PCR based expression analysis on a nanoliter scale using polymer nano-well chips. Biomed. Microdevices 9:307-314.

- Doohan, F. M., Parry, D. W., Jenkinson, P., and Nicholson, P. 1998. The use of speciesspecific PCR-based assays to analyse Fusarium ear blight of wheat. Plant Pathol. 47: 197-205. 
- Fredlund, E., Gidlund, A., Pettersson, H., Olsen, M., and Börjesson, T. 2010. Real-time PCR detection of Fusarium species in Swedish oats and correlation to T-2 and HT-2 toxin content. World Mycotoxin Journal 3:77-88.

- Gao, X., Jackson, T. A., Lambert, K. N., Li, S., Hartman, G. L., and Niblack, T. L. 2004. Detection and quantification of Fusarium solani f.sp. glycines in soybean roots with real-time quantitative polymerase chain reaction. Plant Dis. 88:1372-1380.

- Gelderblom, W. C. A., Jaskiewicz, K., Marasas, W. F. O., Thiel, P. G., Horak, R. M., Vleggaar, R., and Kriek, N. P. J. 1988. Fumonisins-novel mycotoxins with cancer-promoting activity produced by Fusarium moniliforme. Appl. Environ. Microb. 54:1806-1811.

- Gilbertson, R. L., Brown, W. M. Jr., and Ruppel, E. G. 1985. Prevalence and virulence of Fusarium spp. associated with stalk rot of corn in Colorado. Plant Dis. 69:1065-1068.

- Jurado, M., Vazquez, C., Patino, B., and González-Jaén, M. T. 2005. PCR detection assays for the trichothecene-producing species Fusarium graminearum, Fusarium culmorum, Fusarium poae, Fusarium equiseti and Fusarium sporotrichioides. Syst. Appl. Microbiol. 28:562-568.

- Jurado, M., Vazquez, C., Marin, S., Sanchis, V., and González-Jaén, M. T. 2006. PCR-based strategy contamination with mycotoxicogenic Fusarium species in maize. Syst. Appl. Microbiol. 29:681-689.

- Kulik, T. 2008. Detection of Fusarium tricinctum from cereal grain using PCR assay. J. Appl. Genet. 49:305-311.

- Logrieco, A., Mulè, G., Moretti, A., and Bottalico, A. 2002. Toxigenic Fusarium species and mycotoxins associated with maize ear rot in Europe. Eur. J. Plant Pathol. 108: 597-609.

- Mattarucchi, E., Marsoni, M., Binelli, G., Passi, A., Curto, F. L., Pasquali, F., and Porta, G. 2005. Different real time PCR approaches for the fine quantification of SNP's alleles in DNA pools: assays development, characterization and pre-validation. J. Biochem. Mol. Biol. 38:555-562.

- Moretti, A. N. 2009. Taxonomy of Fusarium genus, a continous fight between lumpers and splitters. Proc. Nat. Sci, Matica Srpska Novi Sad. 117:7-13. 
- Mulè, G., Susca, A., Stea, G., and Moretti, A. 2004. A species-specific PCR assay based on the calmodulin partial gene for identification of Fusarium verticillioides, $F$. proliferatum and F. subglutinans. Eur. J. Plant Pathol. 110:495-502.

- Möller, E. M., Chełkowski, J., and Geiger, H. H. 1999. Species-specific PCR assays for the fungal pathogens Fusarium moniliforme and Fusarium subglutinans and their application to diagnose maize ear rot disease. J. Phytopathol. 147:497-508.

- Nicholson, P., Simpson, D. R., Weston, G., Rezanoor, H. N., Lees, A. K., Parry, D. W., and Joyce, D. 1998. Detection and quantification of Fusarium culmorum and Fusarium graminearum in cereals using PCR assays. Physiol. Mol. Plant Pathol. 53:17-37.

- Nicholson, P., Simpson, D. R., Wilson, A. H., Chandler, E., and Thomsett, M. 2004. Detection and differentiation of trichothecene and enniatin-producing Fusarium species on small-grain cereals. Eur. J. Plant Pathol. 110:503-514.

- Nicolaisen, M., Supronienè, S., Nielsen, L. K., Lazzaro, I., Spliid, N. H., and Justesen, A. F. 2009. Real-time PCR for quantification of eleven individual Fusarium species in cereals. J. Microbial. Methods. 76:234-240.

- Nutz, S., Döll, K., and Karlovsky, P. 2011. Determination of the LOQ in real-time PCR by receiver operating characteristic curve analysis: application to qPCR assays for Fusarium verticillioides and F. proliferatum. Anal. Bioanal. Chem. 401:717-726.

- Parry, D. W., and Nicholson, P. 1996. Development of a PCR assay to detect Fusarium poae in wheat. Plant Pathol. 45:383-391.

- Pintos Varela, C., Aguín Casal, O., Chaves Padin, M., Ferreiroa Martinez, V., Sainz Oses, M. J., Scauflaire, J., Munaut, F., Bande Castro, M. J., and Mansilla Vázquez, J. P. 2013. First report of Fusarium temperatum causing seedling blight and stalk rot on maize in Spain. Plant Dis. (Abstr.) 97:1252.

- Scauflaire, J., Gourgue, M., and Munaut, F. 2011. Fusarium temperatum sp. nov. from maize, an emergent species closely related to F. subglutinans. Mycologia 103:586-597.

- Schilling, A. G., Möller, E. M., and Geiger, H. H. 1996. Polymerase chain reaction-based assays for species-specific detection of Fusarium culmorum, F. graminearum, and F. avenaceum. Phytopathology 86:515-522.

- Schnerr, H., Vogel, R. F., and Niessen, L. 2002. Correlation between DNA of trichothecene-producing Fusarium species and deoxynivalenol concentrations in wheat-samples. Lett. Appl. Microbiol. 35:121-125. 
- Turner, A. S., Lees, A. K., Rezanoor, H. N., and Nicholson, P. 1998. Refinement of PCR-detection of Fusarium avenaceum and evidence from DNA marker studies for phonetic relatedness to Fusarium tricinctum. Plant Pathol. 47:278-288.

- Vaerman, J. L., Saussoy, P., and Ingargiola, I. 2004. Evaluation of real-time PCR data. J. Biol. Regul. Homeost. Agents. 18:212-214.

- Van de Graaf, P., Lees, A. K., Cullen, D. W., and Duncan, J. M. 2003. Detection and quantification of Spongospora subterranea in soil, water and plant tissue samples using real-time PCR. Eur. J. Plant Pathol. 109:589-597.

- Waalwijk, C., van der Heide, R., de Vries, I., van der Lee, T., Schoen, C., Costrel-de Corainville, G., Häuser-Hahn, I., Kastelein, P., Köhl, J., Lonnet, P., Demarquet, T., and Kema, G. H. J. 2004. Quantitative detection of Fusarium species in wheat using TaqMan. Eur. J. Plant Pathol. 110:481-494.

- Wilfinger, W. W., Mackey, K., and Chomczynski, P. 1997. Effect of pH and ionic strength on the spectrophotometric assessment of nucleic acid purity. Biotechniques $22: 474-481$.

- Wilson, A., Simpson, D., Chandler, E., Jennings, P., and Nicholson, P. 2004. Development of PCR assays for the detection and differentiation of $F$. sporotrichoides and F. longsethiae. FEMS Microbiol. Lett. 233:69-76.

- Yli-Mattila, T., Paavanen-Huhtala, S., Jestoi, M., Parikka, P., Hietaniemi, V., Gagkaeva, T., Sarlin, T., Haikara, A., Laaksonen, S., and Rizzo, A. 2008. Real-time PCR detection and quantification of Fusarium poae, $F$. graminearum, $F$. sporotrichioides and F. langsethiae in cereal grains in Finland and Russia. Archives of Phytopathology and Plant Protection 41:243-260.

- Zheng, Q., and Ploetz, R. 2002. Genetic diversity in the mango malformation pathogen and development of a PCR assay. Plant Pathol. 51:208-216. 
Supplemental Table 1. Standard curves and determination of LOQ of qPCR for the nine Fusarium species with a common thermocycler program

\begin{tabular}{|c|c|c|}
\hline \multicolumn{3}{|c|}{ F. avenaceum } \\
\hline DNA (pg) & $\mathrm{Ct}$ & $\operatorname{Tm}\left({ }^{\circ} \mathrm{C}\right)^{1}$ \\
\hline 1111 & 18.99 & 82 \\
\hline 1111 & 19.05 & 82 \\
\hline 1111 & 19.34 & 82 \\
\hline 370.37 & 21.57 & 81.5 \\
\hline 370.37 & 21.39 & 82 \\
\hline 370.37 & 21.25 & 82 \\
\hline 123.45 & 22.60 & 82 \\
\hline 123.45 & 23.37 & 81.5 \\
\hline 123.45 & Failed & \\
\hline 41.15 & 23.28 & 82 \\
\hline 41.15 & 25.38 & 81.5 \\
\hline 41.15 & 25.11 & 81.5 \\
\hline 13.71 & 26.74 & 81.5 \\
\hline 13.71 & 26.33 & 82 \\
\hline 13.71 & 25.82 & 82 \\
\hline 4.57 & 28.33 & 81.5 \\
\hline 4.57 & 28.12 & 81.5 \\
\hline 4.57 & 28.15 & 82 \\
\hline 1.52 & 29.37 & 81.5 \\
\hline 1.52 & 29.94 & 81.5 \\
\hline 1.52 & 29.26 & 81.5 \\
\hline 0.508 & 31.41 & 81.5 \\
\hline 0.508 & 31.29 & 81.5 \\
\hline 0.508 & 31.79 & 82 \\
\hline 0.169 & 32.02 & 81.5 \\
\hline 0.169 & 33.30 & 81.5 \\
\hline 0.169 & 32.61 & 81.5 \\
\hline 1111 & 18.97 & 82 \\
\hline 1111 & 19.73 & 82 \\
\hline 370.37 & 21.62 & 82 \\
\hline 370.37 & 21.26 & 82 \\
\hline 123.45 & 23.15 & 82 \\
\hline 123.45 & 22.91 & 82 \\
\hline 41.15 & 24.80 & 82 \\
\hline 41.15 & 24.36 & 82 \\
\hline 13.71 & 26.64 & 81.5 \\
\hline 13.71 & 26.35 & 82 \\
\hline 4.57 & 29.40 & 81.5 \\
\hline 4.57 & 28.07 & 81.5 \\
\hline 1.52 & 29.97 & 81 \\
\hline 1.52 & 29.10 & 81.5 \\
\hline 0.508 & 31.85 & 81.5 \\
\hline 0.508 & 31.35 & 81.5 \\
\hline 0.169 & 32.34 & 81.5 \\
\hline 0.169 & Failed & \\
\hline 1111 & 19.24 & 82 \\
\hline 1111 & 20.03 & 82 \\
\hline 1111 & 19.96 & 82 \\
\hline
\end{tabular}

\begin{tabular}{lcl}
\hline \multicolumn{3}{c}{ F. culmorum } \\
\hline DNA $(\mathrm{pg})$ & $\mathrm{Ct}$ & $\mathrm{Tm}\left({ }^{\circ} \mathrm{C}\right)$ \\
\hline 1111 & 17.42 & 87 \\
1111 & 17.73 & 87.5 \\
1111 & 18.15 & 87 \\
370.37 & 18.99 & 87 \\
370.37 & 19.26 & 87 \\
370.37 & 19.38 & 87 \\
123.45 & 21.07 & 87 \\
123.45 & 21.17 & 87 \\
123.45 & 21.08 & 87 \\
41.15 & 22.44 & 87 \\
41.15 & 22.77 & 87 \\
41.15 & 22.68 & 87 \\
13.71 & 24.54 & 87 \\
13.71 & 24.13 & 87 \\
13.71 & 24.32 & 87 \\
4.57 & 25.69 & 87 \\
4.57 & 26.68 & 87 \\
4.57 & 26.02 & 87 \\
1.52 & 27.29 & 87 \\
1.52 & 27.51 & 87 \\
1.52 & Failed & \\
0.508 & 30.45 & 87 \\
0.508 & 28.96 & 87 \\
0.508 & 28.35 & 87 \\
\hline 1111 & 17.89 & 87 \\
1111 & 18.18 & 87 \\
370.37 & 20.08 & 87 \\
370.37 & 19.68 & 87.5 \\
123.45 & 21.23 & 87 \\
123.45 & 21.97 & 87 \\
41.15 & 23.01 & 87 \\
41.15 & 22.84 & 87 \\
13.71 & 24.91 & 87 \\
13.71 & 24.98 & 87.5 \\
4.57 & 26.24 & 87.5 \\
4.57 & 26.13 & 87 \\
1.52 & 27.41 & 87 \\
1.52 & 26.91 & 87.5 \\
0.508 & 29.31 & 87.5 \\
0.508 & Failed & \\
\hline 1111 & 17.49 & 87 \\
1111 & 17.98 & 87 \\
1111 & 18.14 & 87 \\
370.37 & 19.06 & 87 \\
370.37 & 19.46 & 87 \\
370.37 & 19.48 & 87 \\
123.45 & 21.13 & 87.5 \\
123.45 & 21.37 & 87.5 \\
& & \\
115 \\
115 \\
115
\end{tabular}

\begin{tabular}{|c|c|c|}
\hline \multicolumn{3}{|c|}{ F. equiseti } \\
\hline DNA (pg) & $\mathrm{Ct}$ & $\operatorname{Tm}\left({ }^{\circ} \mathrm{C}\right)$ \\
\hline 1111 & 19.54 & 86.5 \\
\hline 1111 & 20.04 & 86.5 \\
\hline 1111 & 19.77 & 86.5 \\
\hline 370.37 & 21.10 & 86.5 \\
\hline 370.37 & 21.50 & 86.5 \\
\hline 370.37 & 21.20 & 86.5 \\
\hline 123.45 & 22.98 & 86.5 \\
\hline 123.45 & 23.16 & 86.5 \\
\hline 123.45 & 22.87 & 86.5 \\
\hline 41.15 & 24.75 & 86.5 \\
\hline 41.15 & 24.42 & 86.5 \\
\hline 41.15 & 24.25 & 86.5 \\
\hline 13.71 & 26.44 & 86 \\
\hline 13.71 & 25.75 & 86 \\
\hline 13.71 & Failed & \\
\hline 4.57 & 25.89 & 86 \\
\hline 4.57 & Failed & \\
\hline 4.57 & 27.63 & 86 \\
\hline 1.52 & 28.15 & 86 \\
\hline 1.52 & 27.30 & 86 \\
\hline 1.52 & 27.72 & 86 \\
\hline 0.508 & 29.89 & 86 \\
\hline 0.508 & 30.01 & 86 \\
\hline 0.508 & Failed & \\
\hline 1111 & 19.51 & 86.5 \\
\hline 1111 & 19.63 & 86.5 \\
\hline 1111 & 19.65 & 86.5 \\
\hline 370.37 & 21.05 & 86.5 \\
\hline 370.37 & 21.42 & 86.5 \\
\hline 370.37 & 21.30 & 86.5 \\
\hline 123.45 & 22.96 & 86.5 \\
\hline 123.45 & 23.10 & 86.5 \\
\hline 123.45 & 22.66 & 86.5 \\
\hline 41.15 & 24.28 & 86.5 \\
\hline 41.15 & 24.44 & 86.5 \\
\hline 41.15 & 24.19 & 86 \\
\hline 13.71 & 26.44 & 86 \\
\hline 13.71 & 25.75 & 86 \\
\hline 13.71 & 25.10 & 86 \\
\hline 4.57 & 27.03 & 86 \\
\hline 4.57 & 26.89 & 86 \\
\hline 4.57 & 26.47 & 86 \\
\hline 1.52 & 28.48 & 86 \\
\hline 1.52 & 28.59 & 86 \\
\hline 1.52 & 28.03 & 86 \\
\hline 0.508 & 30.43 & 86 \\
\hline 0.508 & 29.85 & 86 \\
\hline 0.508 & 30.37 & 86.5 \\
\hline
\end{tabular}


Supplemental Table 1: continued

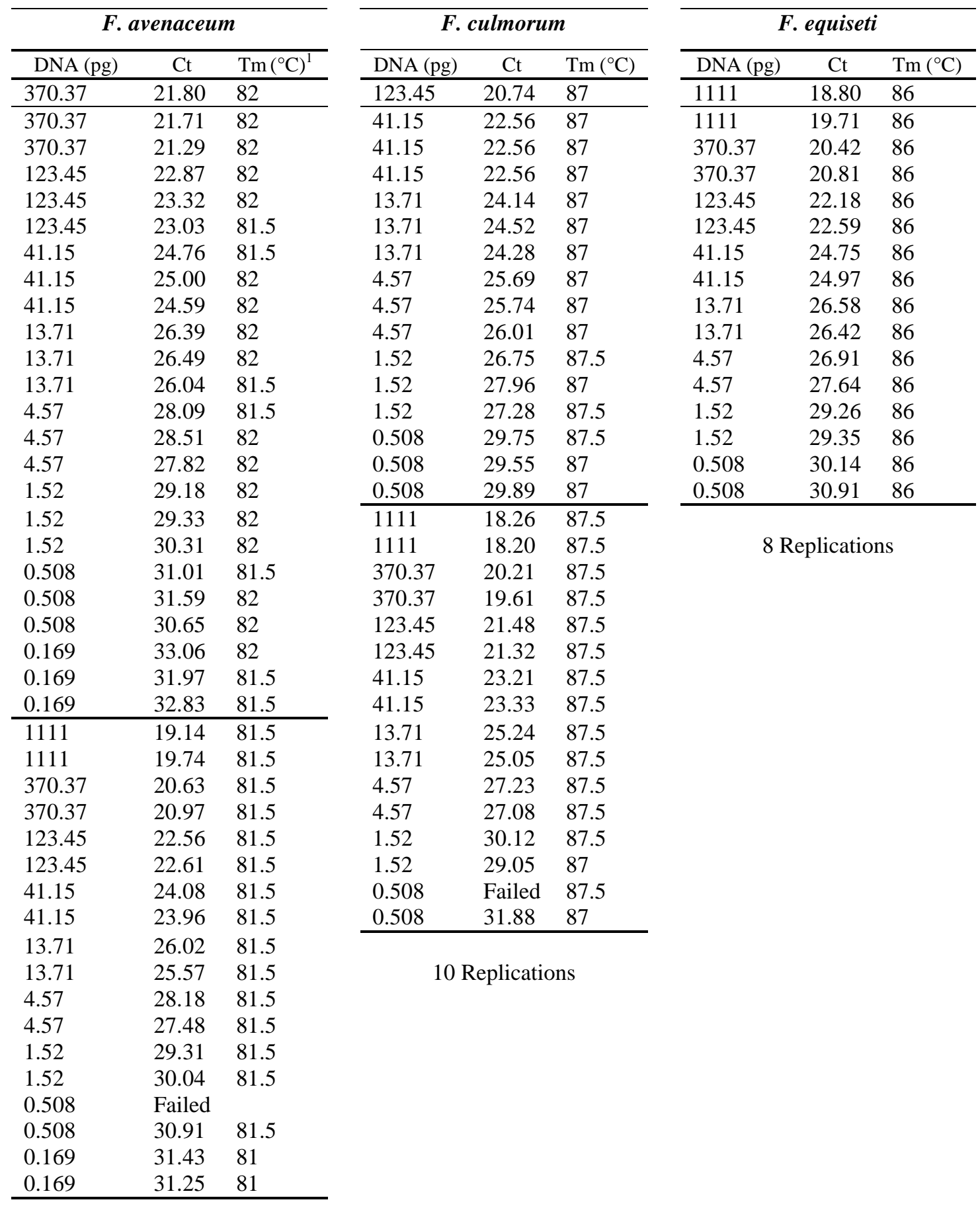

10 Replications 
Supplemental Table 1: continued

\begin{tabular}{|c|c|c|c|c|c|c|c|c|}
\hline \multicolumn{3}{|c|}{ F. graminearum } & \multicolumn{3}{|c|}{ F.poae } & \multicolumn{3}{|c|}{$F$. proliferatum } \\
\hline DNA (pg) & $\mathrm{Ct}$ & $\operatorname{Tm}\left({ }^{\circ} \mathrm{C}\right)^{1}$ & DNA (pg) & $\mathrm{Ct}$ & $\operatorname{Tm}\left({ }^{\circ} \mathrm{C}\right)$ & DNA (pg) & $\mathrm{Ct}$ & $\operatorname{Tm}\left({ }^{\circ} \mathrm{C}\right)$ \\
\hline 1111 & 17.76 & 82.5 & 1111 & 15.56 & 83 & 1111 & 12.02 & 89 \\
\hline 1111 & 17.91 & 82.5 & 1111 & 16.16 & 83 & 1111 & 11.89 & 89 \\
\hline 1111 & 17.89 & 82.5 & 1111 & 15.53 & 83 & 370.37 & 12.34 & 89 \\
\hline 370.37 & 19.40 & 82.5 & 370.37 & 17.30 & 83 & 370.37 & 12.92 & 89 \\
\hline 370.37 & 19.87 & 82.5 & 370.37 & 17.40 & 83 & 123.45 & 14.04 & 89 \\
\hline 370.37 & 19.63 & 82.5 & 370.37 & 17.19 & 83 & 123.45 & 14.52 & 89 \\
\hline 123.45 & 21.31 & 82.5 & 123.45 & 18.80 & 83 & 41.15 & 15.85 & 89 \\
\hline 123.45 & 21.32 & 82.5 & 123.45 & 19.67 & 83 & 41.15 & 16.07 & 89 \\
\hline 123.45 & 21.49 & 82.5 & 123.45 & 19.40 & 83 & 13.71 & 17.26 & 88.5 \\
\hline 41.15 & 22.91 & 82.5 & 41.15 & 20.43 & 83 & 13.71 & 17.81 & 89 \\
\hline 41.15 & 23.39 & 82.5 & 41.15 & 20.37 & 83 & 4.57 & 19.25 & 89 \\
\hline 41.15 & 23.24 & 82 & 41.15 & 20.55 & 83 & 4.57 & 19.3 & 89 \\
\hline 13.71 & 24.00 & 82.5 & 13.71 & 22.06 & 83 & 1.52 & 21.49 & 89 \\
\hline 13.71 & 23.94 & 82.5 & 13.71 & 22.51 & 83 & 1.52 & 22.21 & 89 \\
\hline 13.71 & 24.75 & 82.5 & 13.71 & 21.85 & 83 & 0.508 & 22.93 & 88.5 \\
\hline 4.57 & 26.46 & 82.5 & 4.57 & 23.41 & 83 & 0.508 & 23.05 & 89 \\
\hline 4.57 & 25.76 & 82.5 & 4.57 & 24.10 & 83 & 0.169 & 23.8 & 89 \\
\hline 4.57 & 25.90 & 82.5 & 4.57 & 23.55 & 83 & 0.169 & 24.5 & 89 \\
\hline 1.52 & 27.86 & 82.5 & 1.52 & 24.89 & 83 & 0.056 & 26.00 & 88.5 \\
\hline 1.52 & 26.89 & 82.5 & 1.52 & 25.52 & 83 & 0.056 & 25.83 & 88.5 \\
\hline 1.52 & 26.62 & 82.5 & 1.52 & 25.37 & 83 & 1111 & 11.91 & 89 \\
\hline 0.508 & 28.72 & 82.5 & 0.508 & 27.14 & 83 & 1111 & 12.04 & 89 \\
\hline 0.508 & 28.75 & 82.5 & 0.508 & 27.13 & 83 & 1111 & 11.68 & 89 \\
\hline 0.508 & 29.18 & 82.5 & 0.508 & 26.62 & 82.5 & 370.37 & 12.39 & 89 \\
\hline 0.169 & 30.17 & 82.5 & 0.169 & 28.58 & 82.5 & 370.37 & 13.49 & 89 \\
\hline 0.169 & Failed & & 0.169 & 28.90 & 83 & 370.37 & 12.97 & 89 \\
\hline 0.169 & 29.89 & 82.5 & 0.169 & 28.6 & 82.5 & 123.45 & 14.75 & 89 \\
\hline 1111 & 17.55 & 82.5 & 1111 & 16.28 & 83 & 123.45 & 13.82 & 89 \\
\hline 1111 & 17.93 & 83 & 1111 & 16.15 & 83 & 123.45 & 14.25 & 89 \\
\hline 370.37 & 19.66 & 82.5 & 1111 & 15.81 & 83 & 41.15 & 15.69 & 89 \\
\hline 370.37 & 19.76 & 82.5 & 370.37 & 17.17 & 83 & 41.15 & 15.93 & 89 \\
\hline 123.45 & 21.61 & 82.5 & 370.37 & 17.97 & 83 & 41.15 & 15.57 & 89 \\
\hline 123.45 & 22.20 & 82.5 & 370.37 & 17.37 & 82.5 & 13.71 & 17.34 & 89 \\
\hline 41.15 & 22.96 & 82.5 & 123.45 & 19.41 & 82.5 & 13.71 & 17.20 & 89 \\
\hline 41.15 & 23.81 & 82.5 & 123.45 & 19.75 & 82.5 & 13.71 & 18.02 & 89 \\
\hline 13.71 & 24.09 & 82.5 & 123.45 & 19.33 & 82.5 & 4.57 & 19.19 & 89 \\
\hline 13.71 & 25.97 & 82.5 & 41.15 & 21.08 & 83 & 4.57 & 18.62 & 89 \\
\hline 4.57 & Failed & & 41.15 & 21.69 & 82.5 & 4.57 & 19.13 & 89 \\
\hline 4.57 & 26.59 & 82.5 & 41.15 & 21.27 & 83 & 1.52 & 20.75 & 89 \\
\hline 1.52 & 27.17 & 82.5 & 13.71 & 22.88 & 83 & 1.52 & 20.59 & 89 \\
\hline 1.52 & 28.41 & 82.5 & 13.71 & 23.48 & 83 & 1.52 & 20.95 & 89 \\
\hline 0.508 & 29.85 & 82.5 & 13.71 & 22.63 & 82.5 & 0.508 & 22.06 & 89 \\
\hline 0.508 & 29.36 & 82.5 & 4.57 & 24.96 & 82.5 & 0.508 & 21.79 & 89 \\
\hline 0.169 & Failed & & 4.57 & 25.39 & 82.5 & 0.508 & 22.21 & 89 \\
\hline 0.169 & 30.66 & 82.5 & 4.57 & 24.87 & 82.5 & 0.169 & 23.90 & 88.5 \\
\hline 1111 & 16.85 & 82.5 & 1.52 & 26.97 & 83 & 0.169 & 24.08 & 89 \\
\hline 1111 & 17.30 & 82.5 & 1.52 & 26.04 & 83 & 0.169 & 24.06 & 89 \\
\hline 370.37 & 20.01 & 82 & 1.52 & 26.16 & 83 & 0.056 & 26.00 & 89 \\
\hline 370.37 & 19.11 & 82.5 & 0.508 & 28.20 & 83 & 0.056 & 25.03 & 89 \\
\hline 123.45 & 21.28 & 82 & 0.508 & 29.11 & 83 & 0.056 & Failed & \\
\hline
\end{tabular}


Supplemental Table 1: continued

\begin{tabular}{|c|c|c|c|c|c|c|c|c|}
\hline \multicolumn{3}{|c|}{ F. graminearum } & \multicolumn{3}{|c|}{$F$.poae } & \multicolumn{3}{|c|}{ F.proliferatum } \\
\hline DNA (pg) & $\mathrm{Ct}$ & $\operatorname{Tm}\left({ }^{\circ} \mathrm{C}\right)^{1}$ & DNA (pg) & $\mathrm{Ct}$ & $\operatorname{Tm}\left({ }^{\circ} \mathrm{C}\right)$ & DNA (pg) & $\mathrm{Ct}$ & $\operatorname{Tm}\left({ }^{\circ} \mathrm{C}\right)$ \\
\hline 123.45 & 21.45 & 82 & 0.508 & 27.97 & 83 & 1111 & 12.27 & 89 \\
\hline 41.15 & 23.61 & 82 & 0.169 & 27.61 & 83 & 1111 & 12.20 & 89 \\
\hline 41.15 & 23.19 & 82 & 0.169 & 29.30 & 82.5 & 370.37 & 13.52 & 89 \\
\hline 13.71 & 24.06 & 82 & 0.169 & 27.14 & 82.5 & 370.37 & 13.73 & 89.5 \\
\hline 13.71 & 24.88 & 82 & 1111 & 14.56 & 83 & 123.45 & 15.06 & 89 \\
\hline 4.57 & 25.64 & 82 & 1111 & 14.93 & 83 & 123.45 & 14.93 & 89 \\
\hline 4.57 & 26.11 & 82 & 370.37 & 16.39 & 83 & 41.15 & 16.71 & 89 \\
\hline 1.52 & 27.20 & 82 & 370.37 & 16.65 & 83 & 41.15 & 16.87 & 89 \\
\hline 1.52 & 27.62 & 82 & 123.45 & 19.28 & 83 & 13.71 & 18.05 & 89 \\
\hline 0.508 & 29.53 & 82.5 & 123.45 & 18.69 & 83 & 13.71 & 17.93 & 89 \\
\hline 0.508 & 28.73 & 82 & 41.15 & 20.42 & 83 & 4.57 & 20.21 & 89 \\
\hline 0.169 & 30.48 & 82.5 & 41.15 & 19.99 & 83 & 4.57 & 19.31 & 89 \\
\hline 0.169 & 30.74 & 82.5 & 13.71 & 22.11 & 83 & 1.52 & 21.66 & 89 \\
\hline 1111 & 17.45 & 82 & 13.71 & 21.51 & 83 & 1.52 & 21.96 & 89.5 \\
\hline 1111 & 17.34 & 82 & 4.57 & 23.47 & 83 & 0.508 & 23.54 & 89 \\
\hline 1111 & 18.38 & 82 & 4.57 & 23.81 & 83 & 0.508 & 22.56 & 89 \\
\hline 370.37 & 19.22 & 82 & 1.52 & 24.78 & 83 & 0.169 & 24.44 & 89 \\
\hline 370.37 & 19.20 & 82 & 1.52 & 25.10 & 83 & 0.169 & 23.89 & 89 \\
\hline 370.37 & 20.05 & 82 & 0.508 & 26.49 & 83.00 & 0.056 & 25.93 & 89 \\
\hline 123.45 & 21.07 & 82 & 0.508 & 26.52 & 83 & 0.056 & 25.09 & 89 \\
\hline 123.45 & 21.00 & 82 & 0.169 & 27.71 & 83 & 1111 & 11.03 & 89 \\
\hline 123.45 & 21.27 & 82 & 0.169 & 28.01 & 83 & 1111 & 11.25 & 89 \\
\hline 41.15 & 22.67 & 82 & 1111 & 15.62 & 83.5 & 1111 & 11.5 & 89 \\
\hline 41.15 & 22.73 & 82 & 1111 & 16.13 & 83.5 & 370.37 & 12.82 & 89 \\
\hline 41.15 & 23.51 & 82 & 370.37 & 18.05 & 83.5 & 370.37 & 13.29 & 89 \\
\hline 13.71 & 24.01 & 82 & 370.37 & 17.74 & 83.5 & 370.37 & 13.01 & 89 \\
\hline 13.71 & 24.47 & 82.5 & 123.45 & 19.72 & 83.5 & 123.45 & 14.34 & 89 \\
\hline 13.71 & 24.45 & 82 & 123.45 & 19.20 & 83.5 & 123.45 & 14.61 & 89 \\
\hline 4.57 & 26.14 & 82 & 41.15 & 21.11 & 83.5 & 123.45 & 14.72 & 89 \\
\hline 4.57 & 26.18 & 82 & 41.15 & 20.74 & 83.5 & 41.15 & 16.02 & 89 \\
\hline 4.57 & 26.45 & 82 & 13.71 & 21.90 & 83.5 & 41.15 & 16.20 & 89 \\
\hline 1.52 & 27.21 & 82 & 13.71 & 23.40 & 83.5 & 41.15 & 15.98 & 89 \\
\hline 1.52 & 28.18 & 82 & 4.57 & 25.45 & 83.5 & 13.71 & 17.45 & 89 \\
\hline 1.52 & 28.17 & 82.5 & 4.57 & 24.27 & 83.5 & 13.71 & 18.00 & 89 \\
\hline 0.508 & 28.87 & 82.5 & 1.52 & 25.63 & 83.5 & 13.71 & 17.38 & 89 \\
\hline 0.508 & 29.18 & 82 & 1.52 & Failed & & 4.57 & 19.19 & 89 \\
\hline 0.508 & 29.72 & 82 & 0.508 & 26.60 & 83.5 & 4.57 & 19.49 & 89 \\
\hline 0.169 & 29.12 & 82 & 0.508 & 27.01 & 83.5 & 4.57 & 19.16 & 89 \\
\hline 0.169 & 30.06 & 82 & 0.169 & 28.01 & 83.50 & 1.52 & 20.76 & 89 \\
\hline 0.169 & 30.63 & 82.5 & 0.169 & Failed & & 1.52 & 21.18 & 89 \\
\hline 1111 & 16.30 & 82 & 1111 & 15.65 & 83 & 1.52 & 20.69 & 89 \\
\hline 1111 & 16.46 & 82 & 1111 & 15.50 & 83 & 0.508 & 22.33 & 89 \\
\hline 370.37 & 17.99 & 82.5 & 370.37 & 16.79 & 83 & 0.508 & 22.91 & 89 \\
\hline 370.37 & 18.31 & 82.5 & 370.37 & 17.25 & 83 & 0.508 & 22.41 & 89 \\
\hline 123.45 & 19.11 & 82.5 & 123.45 & 19.10 & 83 & 0.169 & 23.68 & 89 \\
\hline 123.45 & 20.31 & 82.5 & 123.45 & 19.11 & 83 & 0.169 & 24.72 & 89 \\
\hline 41.15 & 21.42 & 82.5 & 41.15 & 21.04 & 83 & 0.169 & 24.43 & 89 \\
\hline 41.15 & 21.60 & 82.5 & 41.15 & 20.91 & 83 & 0.056 & 25.17 & 89.5 \\
\hline 13.71 & 23.29 & 82.5 & 13.71 & 22.17 & 83 & 0.056 & 26.14 & 89 \\
\hline 13.71 & 23.02 & 82.5 & 13.71 & 22.52 & 83 & 0.056 & 25.64 & 89 \\
\hline 4.57 & 25.14 & 82.5 & 4.57 & 23.95 & 83 & 1111 & 10.59 & 89 \\
\hline
\end{tabular}


Supplemental Table 1: continued

\begin{tabular}{lcl}
\hline \multicolumn{3}{c}{ F. graminearum } \\
\hline DNA $(\mathrm{pg})$ & $\mathrm{Ct}$ & $\mathrm{Tm}\left({ }^{\circ} \mathrm{C}\right)$ \\
\hline 4.57 & 25.13 & 82.5 \\
1.52 & 27.10 & 82.5 \\
1.52 & 26.72 & 82.5 \\
0.508 & 28.99 & 82.5 \\
0.508 & 27.92 & 82.5 \\
0.169 & 31.27 & 82 \\
0.169 & 30.52 & 82 \\
\hline
\end{tabular}

\begin{tabular}{lrl}
\multicolumn{3}{c}{ F. poae } \\
\hline DNA $(\mathrm{pg})$ & $\mathrm{Ct}$ & $\mathrm{Tm}\left({ }^{\circ} \mathrm{C}\right)$ \\
\hline 4.57 & 24.29 & 83 \\
1.52 & 25.75 & 83 \\
1.52 & 26.17 & 83 \\
0.508 & 26.76 & 83 \\
0.508 & 27.39 & 83 \\
0.169 & 28.99 & 83 \\
0.169 & 29.73 & 83 \\
\hline
\end{tabular}

12 Replications

12 Replications

F. proliferatum

\begin{tabular}{lcl}
\hline \multicolumn{1}{c}{ DNA $(\mathrm{pg})$} & $\mathrm{Ct}$ & $\mathrm{Tm}\left({ }^{\circ} \mathrm{C}\right)$ \\
\hline 1111 & 10.35 & 89 \\
370.37 & 12.09 & 89 \\
370.37 & 12.02 & 89 \\
123.45 & 12.90 & 89 \\
123.45 & 13.43 & 89 \\
41.15 & 15.10 & 89 \\
41.15 & 15.79 & 89 \\
13.71 & 16.52 & 89 \\
13.71 & 16.59 & 89 \\
4.57 & 19.34 & 89 \\
4.57 & 18.76 & 89 \\
1.52 & 19.94 & 89 \\
1.52 & 20.25 & 89 \\
0.508 & 23.31 & 89 \\
0.508 & 21.90 & 89 \\
0.169 & 23.83 & 89 \\
0.169 & 23.95 & 89 \\
0.056 & Failed & \\
0.056 & 24.99 & 89.5 \\
\hline
\end{tabular}

12 Replications 
Supplemental Table 1: continued

\begin{tabular}{|c|c|c|c|c|c|c|c|c|}
\hline \multicolumn{3}{|c|}{ F. subglutinans } & \multicolumn{3}{|c|}{ F. tricinctum } & \multicolumn{3}{|c|}{ F. verticillioides } \\
\hline DNA (pg) & $\mathrm{Ct}$ & $\operatorname{Tm}\left({ }^{\circ} \mathrm{C}\right)^{1}$ & DNA (pg) & $\mathrm{Ct}$ & $\operatorname{Tm}\left({ }^{\circ} \mathrm{C}\right)$ & DNA (pg) & $\mathrm{Ct}$ & $\operatorname{Tm}\left({ }^{\circ} \mathrm{C}\right)$ \\
\hline 1111 & 14.92 & 88.5 & 1111 & 11.19 & 90.5 & 1111 & 20.28 & 88 \\
\hline 1111 & 14.89 & 88.5 & 1111 & 11.90 & 90.5 & 1111 & 19.49 & 88 \\
\hline 1111 & 14.38 & 88.5 & 1111 & 12.08 & 91 & 370.37 & 21.08 & 88 \\
\hline 370.37 & 15.37 & 88.5 & 370.37 & 13.45 & 90.5 & 370.37 & 20.70 & 88 \\
\hline 370.37 & 16.09 & 88.5 & 370.37 & 13.18 & 90.5 & 123.45 & 22.94 & 88 \\
\hline 370.37 & 15.81 & 88.5 & 370.37 & 13.15 & 90.5 & 123.45 & 22.66 & 88 \\
\hline 123.45 & 16.94 & 88.5 & 123.45 & 14.87 & 90.5 & 41.15 & 24.44 & 88 \\
\hline 123.45 & 17.56 & 88.5 & 123.45 & 15.19 & 90.5 & 41.15 & 24.67 & 88 \\
\hline 123.45 & 17.22 & 88.5 & 123.45 & 15.03 & 91 & 13.71 & 24.98 & 88 \\
\hline 41.15 & 18.27 & 88.5 & 41.15 & 17.08 & 90.5 & 13.71 & 25.60 & 88 \\
\hline 41.15 & 18.84 & 88.5 & 41.15 & 16.95 & 90.5 & 4.57 & 27.12 & 88 \\
\hline 41.15 & 19.37 & 88.5 & 41.15 & 16.35 & 90.5 & 4.57 & Failed & \\
\hline 13.71 & 20.85 & 88.5 & 13.71 & 18.17 & 90.5 & 1.52 & 28.67 & 88 \\
\hline 13.71 & 20.27 & 88.5 & 13.71 & 18.15 & 90.5 & 1.52 & 29.24 & 88 \\
\hline 13.71 & 20.47 & 88.5 & 13.71 & 18.24 & 91.5 & 0.508 & 30.60 & 88 \\
\hline 4.57 & 22.20 & 88.5 & 4.57 & 19.26 & 90.5 & 0.508 & 29.24 & 88 \\
\hline 4.57 & 22.06 & 88.5 & 4.57 & 20.09 & 90.5 & 1111 & 18.79 & 88 \\
\hline 4.57 & 21.58 & 88.5 & 4.57 & 19.50 & 90.5 & 1111 & 19.02 & 88 \\
\hline 1.52 & 23.76 & 88.5 & 1.52 & 20.47 & 90.5 & 370.37 & 19.88 & 88.5 \\
\hline 1.52 & 23.73 & 88.5 & 1.52 & 21.12 & 91 & 370.37 & 19.97 & 88.5 \\
\hline 1.52 & 23.62 & 88.5 & 1.52 & 21.68 & 91.5 & 123.45 & 22.98 & 88.5 \\
\hline 0.508 & 25.60 & 88.5 & 0.508 & 21.70 & 90.5 & 123.45 & 22.59 & 88 \\
\hline 0.508 & 25.91 & 88.5 & 0.508 & Failed & & 41.15 & 24.00 & 88 \\
\hline 0.508 & 26.26 & 88.5 & 0.508 & Failed & & 41.15 & 24.18 & 88.5 \\
\hline 0.169 & 27.19 & 88.5 & 1111 & 11.20 & 91 & 13.71 & 24.79 & 88 \\
\hline 0.169 & 27.20 & 88.5 & 1111 & 11.83 & 91 & 13.71 & 25.63 & 88 \\
\hline 0.169 & 27.41 & 88.5 & 370.37 & 13.20 & 91 & 4.57 & Failed & \\
\hline 1111 & 15.20 & 88.5 & 370.37 & 13.53 & 91.5 & 4.57 & 27.24 & 88.5 \\
\hline 1111 & 15.18 & 88.5 & 123.45 & 14.93 & 91 & 1.52 & 28.45 & 88 \\
\hline 1111 & 14.89 & 88.5 & 123.45 & 15.31 & 91 & 1.52 & 29.49 & 88 \\
\hline 370.37 & 15.74 & 88.5 & 41.15 & 16.29 & 91 & 0.508 & Failed & \\
\hline 370.37 & 16.44 & 88.5 & 41.15 & 17.42 & 91 & 0.508 & 30.46 & 88 \\
\hline 370.37 & 15.87 & 88.5 & 13.71 & 17.75 & 91 & 1111 & 18.84 & 88.5 \\
\hline 123.45 & 19.69 & 88.5 & 13.71 & 18.37 & 91 & 1111 & 18.63 & 88 \\
\hline 123.45 & 18.47 & 88.5 & 4.57 & 19.43 & 91 & 370.37 & 20.46 & 88.5 \\
\hline 123.45 & 16.79 & 88.5 & 4.57 & 20.01 & 91 & 370.37 & 20.77 & 88.5 \\
\hline 41.15 & 19.33 & 88.5 & 1.52 & 20.70 & 91 & 123.45 & 22.29 & 88.5 \\
\hline 41.15 & 18.33 & 88.5 & 1.52 & 20.99 & 91 & 123.45 & 21.82 & 88.5 \\
\hline 41.15 & 19.48 & 88.5 & 0.508 & 22.34 & 90.5 & 41.15 & 23.93 & 88 \\
\hline 13.71 & 20.29 & 88.5 & 0.508 & 22.57 & 91 & 41.15 & 23.82 & 88.5 \\
\hline 13.71 & 20.33 & 88.5 & 1111 & 11.54 & 91 & 13.71 & 25.87 & 88 \\
\hline 13.71 & 20.61 & 88.5 & 1111 & 11.84 & 91 & 13.71 & 25.69 & 88 \\
\hline 4.57 & 23.28 & 88.5 & 1111 & 11.03 & 91 & 4.57 & 27.29 & 88 \\
\hline 4.57 & 21.99 & 88.5 & 1111 & 11.00 & 91 & 4.57 & 28.09 & 88.5 \\
\hline 4.57 & Failed & & 1111 & 11.61 & 91 & 1.52 & 28.55 & 88.5 \\
\hline 1.52 & 21.69 & 88.5 & 370.37 & 13.0 & 91 & 1.52 & 29.14 & 88 \\
\hline 1.52 & 25.20 & 88.5 & 370.37 & 13.79 & 91 & 0.508 & 30.55 & 88.5 \\
\hline 1.52 & 24.41 & 88.5 & 370.37 & 13.4 & 91 & 0.508 & 29.74 & 88 \\
\hline 0.508 & 25.71 & 88.5 & 370.37 & 13.05 & 91 & 1111 & 18.61 & 88.5 \\
\hline 0.508 & 26.13 & 88.5 & 370.37 & 13.36 & 91.5 & 1111 & 18.28 & 88.5 \\
\hline
\end{tabular}


Supplemental Table 1: continued

\begin{tabular}{|c|c|c|c|c|c|c|c|c|}
\hline \multicolumn{3}{|c|}{ F. subglutinans } & \multicolumn{3}{|c|}{ F. tricinctum } & \multicolumn{3}{|c|}{ F. verticillioides } \\
\hline DNA (pg) & $\mathrm{Ct}$ & $\operatorname{Tm}\left({ }^{\circ} \mathrm{C}\right)^{1}$ & DNA (pg) & $\mathrm{Ct}$ & $\operatorname{Tm}\left({ }^{\circ} \mathrm{C}\right)$ & DNA (pg) & $\mathrm{Ct}$ & $\operatorname{Tm}\left({ }^{\circ} \mathrm{C}\right)$ \\
\hline 0.508 & 26.41 & 88.5 & 123.45 & 14.75 & 91 & 370.37 & 20.33 & 88.5 \\
\hline 0.169 & 29.54 & 88.5 & 123.45 & 15.09 & 91 & 370.37 & 20.16 & 88 \\
\hline 0.169 & 27.74 & 88.5 & 123.45 & 14.84 & 91 & 123.45 & 22.12 & 88 \\
\hline 0.169 & 27.60 & 88.5 & 123.45 & 14.69 & 91 & 123.45 & 22.28 & 88 \\
\hline 1111 & 14.01 & 88.5 & 123.45 & 15.17 & 91 & 41.15 & 23.69 & 88 \\
\hline 1111 & 15.32 & 88.5 & 41.15 & 16.47 & 91 & 41.15 & 23.56 & 88 \\
\hline 370.37 & 16.74 & 88.5 & 41.15 & 16.63 & 91 & 13.71 & 25.90 & 88 \\
\hline 370.37 & 15.93 & 88.5 & 41.15 & 16.30 & 91 & 13.71 & 25.50 & 88 \\
\hline 123.45 & 17.01 & 88.5 & 41.15 & 16.11 & 91 & 4.57 & 27.50 & 88.5 \\
\hline 123.45 & 17.39 & 88.5 & 41.15 & 17.27 & 91 & 4.57 & 27.44 & 88.5 \\
\hline 41.15 & 18.22 & 88.5 & 13.71 & 18.06 & 91 & 1.52 & 28.72 & 88 \\
\hline 41.15 & 18.00 & 88.5 & 13.71 & 18.04 & 91 & 1.52 & 29.20 & 88 \\
\hline 13.71 & 19.81 & 88.5 & 13.71 & 18.11 & 91 & 0.508 & 30.56 & 88 \\
\hline 13.71 & 20.01 & 88.5 & 13.71 & 17.55 & 91 & 0.508 & 30.38 & 88 \\
\hline 4.57 & 21.51 & 88.5 & 13.71 & 18.21 & 91 & 1111 & 18.95 & 88.5 \\
\hline 4.57 & 21.68 & 88.5 & 4.57 & 19.45 & 91 & 1111 & 18.19 & 88.5 \\
\hline 1.52 & 23.04 & 88.5 & 4.57 & 20.00 & 91 & 370.37 & 19.84 & 88.5 \\
\hline 1.52 & Failed & & 4.57 & 19.47 & 91 & 370.37 & 19.65 & 88 \\
\hline 0.508 & 24.63 & 88.5 & 4.57 & 19.24 & 91 & 123.45 & 22.24 & 88 \\
\hline 0.508 & 25.21 & 88 & 4.57 & 19.79 & 91 & 123.45 & 22.20 & 88 \\
\hline 0.169 & 26.66 & 88.5 & 1.52 & 20.77 & 91 & 41.15 & 23.98 & 88 \\
\hline 0.169 & 26.93 & 88.5 & 1.52 & 21.09 & 91 & 41.15 & 23.62 & 88 \\
\hline \multirow{29}{*}{\multicolumn{3}{|c|}{8 Replications }} & 1.52 & 20.82 & 91 & 13.71 & 25.02 & 88.5 \\
\hline & & & 1.52 & 20.51 & 91 & 13.71 & 24.81 & 88 \\
\hline & & & 1.52 & 20.76 & 91 & 4.57 & 27.66 & 88 \\
\hline & & & 0.508 & 21.70 & 90.5 & 4.57 & 27.14 & 88 \\
\hline & & & 0.508 & 21.72 & 91 & 1.52 & 27.93 & 88 \\
\hline & & & 0.508 & 21.41 & 90.5 & 1.52 & Failed & \\
\hline & & & 0.508 & 22.19 & 90.5 & 0.508 & 29.62 & 88.5 \\
\hline & & & 0.508 & 22.35 & 91 & 0.508 & 30.07 & 88 \\
\hline & & & 1111 & 11.92 & 91.5 & 1111 & 18.85 & 88.5 \\
\hline & & & 1111 & 12.48 & 91.5 & 1111 & 18.78 & 88.5 \\
\hline & & & 370.37 & 13.47 & 91.5 & 1111 & 18.68 & 88 \\
\hline & & & 370.37 & 13.41 & 91.5 & 370.37 & 20.82 & 88.5 \\
\hline & & & 123.45 & 15.29 & 91.5 & 370.37 & 20.51 & 88 \\
\hline & & & 123.45 & 15.39 & 91.5 & 370.37 & 20.52 & 88.5 \\
\hline & & & 41.15 & 17.08 & 91.5 & 123.45 & 22.32 & 88.5 \\
\hline & & & 41.15 & 17.24 & 91.5 & 123.45 & 22.14 & 88.5 \\
\hline & & & 13.71 & 18.67 & 91.5 & 123.45 & 22.15 & 88 \\
\hline & & & 13.71 & 18.98 & 91.5 & 41.15 & 24.16 & 88.5 \\
\hline & & & 4.57 & 20.38 & 91.5 & 41.15 & 23.96 & 88.5 \\
\hline & & & 4.57 & 20.58 & 91.5 & 41.15 & 24.00 & 88 \\
\hline & & & 1.52 & 21.97 & 91.5 & 13.71 & 27.17 & 88.5 \\
\hline & & & 1.52 & 21.95 & 91.5 & 13.71 & 25.20 & 88.5 \\
\hline & & & 0.508 & 22.26 & 91.5 & 13.71 & 26.22 & 82 \\
\hline & & & 0.508 & 22.47 & 91.5 & 4.57 & 28.07 & 88.5 \\
\hline & & & \multirow{5}{*}{\multicolumn{3}{|c|}{12 Replications }} & 4.57 & Failed & \\
\hline & & & & & & 4.57 & 27.11 & 88.5 \\
\hline & & & & & & 1.52 & 28.96 & 88.5 \\
\hline & & & & & & 1.52 & 27.93 & 88.5 \\
\hline & & & & & & 1.52 & 29.04 & 88 \\
\hline
\end{tabular}


Supplemental Table 1: continued

\begin{tabular}{|c|c|c|c|c|c|c|c|c|}
\hline \multicolumn{3}{|c|}{ F. subglutinans } & \multicolumn{3}{|c|}{ F.tricinctum } & \multicolumn{3}{|c|}{ F. verticillioides } \\
\hline DNA (pg) & $\mathrm{Ct}$ & $\operatorname{Tm}\left({ }^{\circ} \mathrm{C}\right)^{1}$ & DNA (pg) & $\mathrm{Ct}$ & $\operatorname{Tm}\left({ }^{\circ} \mathrm{C}\right)$ & DNA (pg) & $\mathrm{Ct}$ & $\operatorname{Tm}\left({ }^{\circ} \mathrm{C}\right)$ \\
\hline & & & & & & 0.508 & 30.73 & 88.5 \\
\hline & & & & & & 0.508 & 31.08 & 88.5 \\
\hline & & & & & & 0.508 & 31.15 & 88.5 \\
\hline & & & & & & 1111 & 19.26 & 88.5 \\
\hline & & & & & & 1111 & 19.16 & 88.5 \\
\hline & & & & & & 1111 & 19.38 & 88.5 \\
\hline & & & & & & 370.37 & 20.88 & 88.5 \\
\hline & & & & & & 370.37 & 20.21 & 88.5 \\
\hline & & & & & & 370.37 & 20.66 & 88.5 \\
\hline & & & & & & 123.45 & 22.04 & 88.5 \\
\hline & & & & & & 123.45 & 22.01 & 88.5 \\
\hline & & & & & & 123.45 & 22.14 & 88.5 \\
\hline & & & & & & 41.15 & 24.15 & 88.5 \\
\hline & & & & & & 41.15 & 24.04 & 88.5 \\
\hline & & & & & & 41.15 & 23.95 & 88.5 \\
\hline & & & & & & 13.71 & 25.33 & 88.5 \\
\hline & & & & & & 13.71 & 25.43 & 88.5 \\
\hline & & & & & & 13.71 & 25.51 & 88.5 \\
\hline & & & & & & 4.57 & 26.78 & 88.5 \\
\hline & & & & & & 4.57 & 27.12 & 88 \\
\hline & & & & & & 4.57 & 27.09 & 88.5 \\
\hline & & & & & & 1.52 & 28.49 & 88.5 \\
\hline & & & & & & 1.52 & 28.31 & 88.5 \\
\hline & & & & & & 1.52 & 28.61 & 88 \\
\hline & & & & & & 0.508 & 31.44 & 88.5 \\
\hline & & & & & & 0.508 & 31.00 & 88.5 \\
\hline & & & & & & 0.508 & 30.14 & 88 \\
\hline & & & & & & 1111 & 18.05 & 88 \\
\hline & & & & & & 1111 & 18.87 & 88 \\
\hline & & & & & & 370.37 & 19.64 & 88 \\
\hline & & & & & & 370.37 & 19.89 & 88 \\
\hline & & & & & & 123.45 & 21.31 & 88 \\
\hline & & & & & & 123.45 & 22.00 & 88 \\
\hline & & & & & & 41.15 & 23.47 & 88 \\
\hline & & & & & & 41.15 & 23.77 & 88 \\
\hline & & & & & & 13.71 & 26.05 & 88 \\
\hline & & & & & & 13.71 & 25.54 & 88 \\
\hline & & & & & & 4.57 & 26.68 & 88 \\
\hline & & & & & & 4.57 & 27.83 & 88 \\
\hline & & & & & & 1.52 & Failed & \\
\hline & & & & & & 1.52 & 29.02 & 88 \\
\hline & & & & & & 0.508 & 29.93 & 88 \\
\hline & & & & & & 0.508 & 29.99 & 88 \\
\hline
\end{tabular}

18 Replications

For each species, the standard curves generated on different days are separated by a horizontal bar.

LOQ was defined as the lowest standard concentration which generated specific products on at least seven out of eight replicates.

1. Tm: melting temperature 


\title{
Chapter 3
}

\section{Colonization of Weed Species with Fusarium spp. in Maize Fields}

\author{
Raana Dastjerdi ${ }^{1}$, Katharina Döll ${ }^{1}$, Horst-Henning Steinmann ${ }^{2}$, Bärbel Gerowitt ${ }^{3}$, Petr Karlovsky ${ }^{1}$ \\ ${ }^{1-}$ Molecular Phytopathology and Mycotoxin Research, Georg-August-University Göttingen, Grisebachstr. 6, 37077 \\ Göttingen, Germany \\ 2- Centre of Biodiversity and Sustainable Land Use, Georg-August-University Göttingen, Grisebachstr. 6, 37077 \\ Göttingen, Germany \\ 3- Working Group Crop Health, Faculty of Agricultural and Environmental Sciences, University of Rostock, \\ Satowerstr. 48, 18051 Rostock, Germany
}

Corresponding author: P. Karlovsky; E-mail address: pkarlov@gwdg.de

\begin{abstract}
The qPCR assay detected eight Fusarium species in 201 weed samples representing 36 weed species collected from maize fields. The highest frequency was observed for $F$. equiseti (49\%) and F. avenaceum (34.7\%). It was followed by F. tricinctum, F. culmorum (each 18\%), $F$. proliferatum (11\%) and $F$. graminearum (8\%). The diversity of Fusarium spp. in comparison between organic and conventional farming was similar. Isolations were made from 66 plants belonging to 12 common weed species. Strains were identified based on morphology and translation elongation factor 1-alpha (TEF-1 $\alpha)$ gene sequence. The recovery rate was high for $F$. equiseti $(32.7 \%)$ and $F$. avenaceum $(21 \%)$. We could not isolate $F$. poae and $F$. subglutinans which were detected in low incidence rates (3\% and 1\%) in qPCR assessments. In contrast, F. oxysporum (16\%) and F. venenatum (8.5\%) were obtained from 10 weed species except Matricaria inodora and Galium aparine. None of the field samples as well as weed plants tested in inoculation studies show obvious symptoms of Fusarium infection. Re-isolation of the strains confirmed endophytic infection of weeds by Fusarium spp. The present study identified six new alternative hosts for Fusarium species in maize fields. High incidence rates of beauvericin and enniatins contamination were obtained in weed samples while trichothecenes, fumonisins and zearalenone were not detected in any of the weeds studied.
\end{abstract}

Additional keywords: weed hosts, Fusarium spp., mycotoxins, maize 


\section{Introduction}

Genus Fusarium comprises phytopathogenic species causing important diseases of cereals wherever corn (Zea mays L.), wheat (Triticum aestivum L.), barley (Hordeum vulgare L.) or other small-grain cereals are grown. The most commonly reported Fusarium spp. associated with maize plants include Fusarium avenaceum (Fr.) Sacc., F. culmorum (W.G. Smith) Sacc., F. graminearum Schwabe, $F$. proliferatum (Matsushima) Nirenberg, $F$. subglutinans (Wollenweber \& Reinking) P. E. Nelson, Toussoun \& Marasas and F. verticillioides (Sacc.) Nirenberg (Dornet al., 2009; Logrieco et al., 2002). Other Fusarium species also encounter maize tissues and have a distinct effect on the level of infection (Munkvold, 2003). Since Fusarium spp. have the potential to produce different mycotoxins, they had always been a serious concern for human and animal health. The quality and quantity of crops are affected when the Fusarium species colonize the ears and the kernels of wheat or corn produced for food or feed. Main Fusarium mycotoxins usually reported from infected maize tissues include trichothecenes, fumonisins, zearalenone, enniatins and moniliformin (Glenn, 2007; Placinta et al., 1999).

Although several sources of inoculum are considered for the survival of Fusarium pathogens, the primary source of inoculum in most fields is a remnant of plant residues. All cereal-related Fusarium spp. can survive saprophytically on the crop residues that remain in the field after harvesting (Parry et al., 1995). In maize fields, Fusarium species survive as mycelium or other survival structures on maize crop debris (Sutton, 1982; Cotten \& Munkvold, 1998; Naef \& De'fago, 2006). This crop debris is then the major reservoir for the infection of kernels of the subsequent maize crop (reviewed in Munkvold, 2003). More recent studies in Europe and North America have approved that in comparison with wheat residue, the maize residue has much more effect as a source of inoculum for the infection of wheat to fusarium head blight (Dill-Macky \& Jones, 2000; Schaafsma et al., 2001). In Uruguayan cultivation systems, a lower contribution of F. graminearum inoculum is allocated to corn (Pereyra \& Dill-Macky, 2008).

In spite of many research on biology, pathology and toxicology of Fusarium species, there is still need for improvement of the effective management of Fusarium diseases occurred in maize crop. Current management protocols for maize Fusarium diseases mostly involve the 
avoidance of crop residues (Maiorano et al., 2008; Naef \& Défago, 2006) to reduce fungal inoculum; but rarely consider weed hosts as a source for crop infection. Weed plants are mostly considered as organisms which can provide favorable conditions such as humidity for developing of Fusarium maize diseases. However, the role of weeds could be likely more. Weed and wild plants can be hosts which provide an important source of inoculum (Parry et al., 1995). Although the importance of weeds as a reservoir of fungal pathogens in fields was identified by Garrett in 1960, but still little literary work has been carried out on weeds as alternative hosts for fungal pathogens and mostly has been concentrated on $F$. oxysporum. There are contradictory reports for the interaction between weed plants density and fusarium head blight severity in different experimental investigations (Teich \& Nelson, 1984). It has been demonstrated that Fusarium populations in the soil can colonize senescent tissues of weed plants as well as maize tissues and produce different types of infectious propagules such as perithecia and ascospores or asexual spores of microconidia and macroconidia (Parry et al., 1995; Munkvold, 2003). Recovery of Fusarium spp. from 19 species of cereals and grasses and 24 species of common weed plants is one of the first reports that introduce weeds as a harbor for Fusarium species (Gordon, 1959). The reports from sugar beet, tomato, soybean and eggplant fields also show that $F$. oxysporum pathogenic on these crops has survival capability on several common weed plants (McDonald \& Leach, 1976; Haware \& Nene, 1982; Helbig \& Carroll, 1984; Altinok, 2013).

Some Fusarium strains are weed pathogens and, therefore, have been used as biocontrol agents. They are also used in the development of mycoherbicides and fungal phytotoxins for control of weeds (Boyette \& Walker, 1985; Abbas et al., 1991; Abbas \& Boyette, 1992; Roy et al., 1994). On the other hand, there are Fusarium strains that are not pathogenic to weeds. One reason for the absence of pathogenicity would be the ectosymbiotic bacteria complexes that are able to modulate the expression of pathogenicity genes in interaction with Fusarium strains (Minerdi et al., 2008). The pathogenic Fusarium strains show protective behavior against other antagonists while they harbor on non-host plants such as weeds. Subsequently, weed plants occupied by such endophytic Fusarium strains act as symptomless hosts to increase inoculum potential (Altinok, 2013). There is growing evidence that reveal weed plants are colonized by pathogenic fungi as symptomless hosts (Roy, 1982; Cerkauskas et al., 1983; Helbig \& Carrol, 1984; Roy et al., 1994; Jenkinson \& Parry, 1994; Postic et al., 2012; Altinok, 2013). Exhibition 
no symptoms on weed plants by Fusarium species has always been a question. Some reports assigned that only less aggressive strains can invade weeds and produce infection without symptoms (Helbig \& Carroll, 1984). Furthermore, lack of strong adaption performance of Fusarium on alternative hosts could also explain the symptomless infection of weeds. The reports show passage through alternative host causes reduction of the pathogenic fitness (aggressiveness) but increment of the overall fungal reproductivity (saprophytic behavior). As a result of transition through an alternative host, a conversion of pathogen behavior may be occurred and colonization of primary host would be improved (Akinsanmi et al., 2007). All these studies conclude that effective weed management can be a useful approach for reduction of Fusarium diseases inoculum in maize fields (reviewed in Fandohan et al., 2003).

On the average, organically grown maize is to the same extent or even less contaminated with mycotoxins than conventionally grown maize; but extremely high mycotoxin levels have been occasionally reported for organic maize products over the years. Low frequency but regular occurrence of unusually high mycotoxin values and fungal colonization has been observed in well-controlled field trials too which is difficult to explain (Nutz \& Karlovsky, unpublished). There is a hypothesis that particular species of weed plants that host Fusarium spp. maybe increase the infection pressure locally and account for high levels of Fusarium mycotoxins in organic maize fields. International developments in mycotoxin regulation make high pressure for finding novel strategies to manage the contamination of maize products by Fusarium mycotoxins. Therefore, understanding of Fusarium spp. survival and the sources of Fusarium inoculum potential as well as the factors influencing this potential is a prerequisite for plant pathologists to prevent the build-up of inoculum sources and, subsequently, management of the Fusarium diseases in maize fields.

This study was carried out to investigate the role of weed plants in the survival and inoculum production of maize Fusarium pathogens and to assess their ability for producing of the main mycotoxins. The question is if weed plants play a role as alternative hosts for Fusarium species pathogenic to maize and if they can provide a significant source of inoculum that help to increase maize mycotoxin contamination? 


\section{Material and Methods}

\section{Collection and Processing of Weed Plants from Maize Fields}

In 2010 and 2011, weed plants were sampled from 11 maize fields located in Germany (Table 1). Five fields were managed organically while the remaining six were conventionally cultured. In latter farming system chemical herbicides were used for the weed control. The plants were collected at random from five areas in each field during they were growing, fully developed but prior to senescence. All weed plants were identified and dried for around four days at $30^{\circ} \mathrm{C}$ (Westerman \& Gerowitt, 2012). Samples were inspected for visible symptoms and no obvious symptoms of Fusarium infection was observed on any of the plants sampled. The experiments, therefore, were continued with anticipation of endophytic growth of Fusarium spp. in weed plants. For this purpose, the whole dried plant sample including root, stem, leaf and flowers or seeds were initially crushed by a mixer. Then a subsample was taken and ground more by using a reciprocal mill (Retsch, Haan, Germany).

Total genomic DNA was extracted by using $40 \mathrm{mg}$ of the fine powder plant material based on the CTAB method according to Brandfass \& Karlovsky (2008). DNA quality and concentration was estimated by electrophoresis in $0.8 \%(\mathrm{w} / \mathrm{v})$ agarose gel (Cambrex, Rockland, ME, USA), prepared in TAE buffer (40 mM Tris, $1 \mathrm{mM}$ EDTA (ethylene diamine tetra acetic acid), $\mathrm{pH}$ set to 8.5) (both substances were obtained from Carl Roth, Karlsruhe, Germany). DNA was stained with ethidium bromide $\left(0.5 \mu \mathrm{g} \mathrm{ml}{ }^{-1}\right)$ (Applichem, Darmstadt, Germany) and visualized using a digital imaging system (VilberLourmat, Marne La Vallee, France). Prior to PCR, genomic DNA was diluted hundred or fifty times (v/v) with double distilled water for inhibitors reduction.

Table 1. Maize fields sampled for weed plants

\begin{tabular}{llll}
\hline Field & Location & Farming type & No. of assessed plants \\
\hline 1 & Kremlin & Organic & 17 \\
2 & Püggen & Organic & 49 \\
3 & Sallahn & Organic & 28 \\
4 & Rusch-Raduhn & Organic & 30 \\
5 & Koblentz & Organic & 23 \\
6 & Kritzmow & Conventional & 11 \\
7 & Niendorf & Conventional & 19 \\
\hline
\end{tabular}


Table 1: continued

\begin{tabular}{llll}
\hline Field & Location & Farming type & No. of assessed plants \\
\hline 8 & Dummers-torf & Conventional & 39 \\
9 & Niex & Conventional & 34 \\
10 & Göttingen & Conventional & 27 \\
11 & Göttingen & Conventional & 17 \\
\hline
\end{tabular}

\section{Detection of Fusarium spp. in Weeds by Real-time PCR}

Fusarium species were detected in weed samples based on a previously developed low-volume qPCR assay (see Chapter 2). The qPCR primers, specific conditions and thermal parameters for single or simultaneous detection of the nine Fusarium species are presented in Table 2, 3a and $3 \mathrm{~b}$ of Chapter 2.

\section{Fungal Isolation and Morphological Identification of Fusarium spp.}

Fusarium spp. were isolated from some of the symptom-free weed plant materials of mostly three weed species including Chenopodium album L., Echinochloa crus-galli (L.) Beauv and Polygonum convolvulus L. Other weed species used for Fusarium isolation are listed in Table 5. Plant tissue pieces $\left(5-10 \mathrm{~mm}^{2}\right)$ were surface disinfested in $1 \%(\mathrm{v} / \mathrm{v})$ sodium hypochlorite $(\mathrm{NaClO})$ solution for $1 \mathrm{~min}$. After rinsing three times with sterile distilled water, the samples were dried on filter paper for a few minutes. Five to six small plant segments were placed in 9-cm petri dishes containing Pepton PCNB Agar (PPA) (15 g Pepton, $1 \mathrm{~g} \mathrm{KH}_{2} \mathrm{PO}_{4}, 0.5 \mathrm{~g} \mathrm{MgSO}_{4}$ $7 \mathrm{H}_{2} \mathrm{O}, 750 \mathrm{mg} \mathrm{PCNB}, 15 \mathrm{~g}$ agar/liter distilled water; $\mathrm{pH}$ : 5.5-6.5) also called Nash Snyder as a selective medium with streptomycin sulphate $\left(100 \mathrm{mg} \mathrm{ml}^{-1}\right)$ and neomycin sulphate $\left(12 \mathrm{mg} \mathrm{ml}^{-1}\right)$ antibiotics (Nelson et al., 1983). Plates were incubated at $25^{\circ} \mathrm{C}$ for $7-10$ days. Distinct fungal colonies temporarily identified as Fusarium were transferred on Potato Dextrose Agar (PDA) (Roth, Karlsruhe, Germany) and recorded for colony morphology and pigmentation based on the visual inspection of the plates. Since Fusarium isolates produce uniform spores on SNA (Synthetic Nutrient Agar) medium ( $1 \mathrm{~g} \mathrm{KH}_{2} \mathrm{PO}_{4}, 1 \mathrm{~g} \mathrm{KNO}{ }_{3}, 0.5 \mathrm{~g} \mathrm{MgSO}_{4} 7 \mathrm{H}_{2} \mathrm{O}, 0.5 \mathrm{~g} \mathrm{KCl}, 0.2 \mathrm{~g}$ glucose, $0.2 \mathrm{~g}$ sucrose and $15 \mathrm{~g}$ agar/liter distilled water) (Nirenberg, 1976), all single spores isolates were transferred to SNA plates and incubated at $25^{\circ} \mathrm{C}$ under near UV light for 4-7 days. Small pieces of sterile filter paper were placed on the surface of cooled agar to induce fungal sporulation. Identification was carried out at species level based on the morphological 
descriptions of spores and conidiogenous cells according to Leslie \& Summerell (2006). Fusarium strains were stored as spore suspension in 15\% (v/v) glycerol (Carl Roth, Karlsruhe, Germany) at $-70^{\circ} \mathrm{C}$.

\section{Fusarium DNA Sequencing and Taxonomic Analysis}

Identification of recovered Fusarium isolates was performed according to the combination of morphological and molecular characters. Typical Fusarium structures were employed for morphological identification. Afterward, identification at species level was confirmed by the results of DNA sequence of the "Translaton Elongation Factor 1-alpha" (TEF-1 $\alpha$ ) gene, which is taxonomically most informative part in this fungal genus. For this purpose, representatives of each Fusarium group (totally 61 isolates) have been employed. Single spore cultures were cultivated in Potato Dextrose Broth (PDB) (Carl Roth, Karlsruhe, Germany) for 5 to 7 days at $25^{\circ} \mathrm{C}$. The mycelia were collected by filtration on sterile filter paper and freeze-dried. Lyophilized mycelium was ground to a fine powder by using a reciprocal mill in $2 \mathrm{ml}$ Eppendorf tubes with 4-5 wolfram carbide spheres (diameter $3 \mathrm{~mm}$, Retsch, Haan, Germany). DNA was extracted as described by Brandfass \& Karlovsky (2008).

Hot start PCR protocol was used to amplify the TEF-1 $\alpha$ gene region using the fungal specific primer set: ef1 (5'-ATGGGTAAGGA(A/G)GACAAGAC-3') and ef2 (5'-GA(G/A)GTACCAGT(G/C)ATCATGTT-3') described by O'Donnell et al. (1998). The reaction mixture consisted of reaction buffer $\left(16 \mathrm{mM}(\mathrm{NH} 4)_{2} \mathrm{SO}_{4} ; 67 \mathrm{mM}\right.$ Tris-HCl; 0.01\% (v/v) Tween-20, pH: 8.8 at $25^{\circ} \mathrm{C}$ ), $0.1 \mathrm{mM}$ concentration of each of the four deoxynucleoside triphosphates (Bioline, Lükenwalde, Germany), $2 \mathrm{mM}$ of $\mathrm{MgCl}_{2}, 1.75 \mathrm{U}$ of hot-start DNA polymerase (Immolase DNA Pol, Lükenwalde, Germany), $0.3 \mu \mathrm{M}$ concentration of each primer. Every reaction contained $1 \mu \mathrm{l}$ template DNA or $1 \mu \mathrm{l}$ sterile water as negative control. The PCR reactions were performed in a total volume of $25 \mu \mathrm{l}$ reactions with a peQ STAR Thermocycler (96 Universal Gradient). The cycling conditions were as follows: 1 cycle of $10 \mathrm{~min}$ at $95^{\circ} \mathrm{C}, 30$ cycles of $60 \mathrm{~s}$ at $94^{\circ} \mathrm{C}$ (denaturalization), $45 \mathrm{~s}$ at $58.5^{\circ} \mathrm{C}$ (annealing), $60 \mathrm{~s}$ at $72^{\circ} \mathrm{C}$ (extension) and followed by a final extension cycle at $72^{\circ} \mathrm{C}$ for $5 \mathrm{~min}$. Fungal amplified DNA fragments were sequenced (LGC Genomics, Berlin, Germany) by Sanger method in one direction using ef1 primer. The chromatogram of TEF-1 $\alpha$ sequence for each Fusarium species has been inspected 
visually and sequence reads edited when necessary. The sequences were, then, used as queries for Fusarium-ID v. 1.0 database (Geiser et al., 2004). In order to construct a phylogenetic tree sequences with the highest similarity to the query, together with some sequences retrieved from the GenBank database (Supplemental Table 1) were aligned. The distance matrix was constructed from pairwise similarities expressed as fractions of identical nucleotides with Jukes-Cantor nucleotide distance measure model for multiple substitutions, and an UPGMA (Un-weighted Pair Group Method with Averages) dendrogram was generated by using the program CLC Main Workbench 6.9. The reliability of analysis was estimated by bootstrap method with 1000 replications.

\section{Inoculation Studies}

Inoculation tests were conducted with six arbitrary selected Fusarium isolates belonging to four species (RD22, RD98 for F. avenaceum; RD100, RD102 for F. culmorum; RD92 for $F$. graminearum, and RD94 for $F$. proliferatum). The Fusarium strains had previously been recovered from weed plants. The isolates were tested to young seedlings of 11 weed species (Table 4) and also maize plants. The seeds of selected weed species were prepared from the Herbiseed Company at UK and also from the Botanical Garden Department, Göttingen, Germany. Mini maize cultivar (Gaspe Flint landrace, originally collected in Quebec, Canada, provided by Prof. Dr. J. Schirawski, Department of Molecular Biology of Plant-Microbe Interaction, University of Göttingen, Germany) was also used in this study. The seeds were sown in plastic multi-pots containing sterile fine sand $(<2 \mathrm{~mm}$ granularity) and irrigated as required. Seven to ten seeds of each weed species were planted per cavity and thinned to five plants when seedlings appeared. For some of the weed species including Galium aparine L., Polygonum convolvulus L., Polygonum persicaria L. and Amaranthus retroflexus L. vernalization at $4^{\circ} \mathrm{C}$ under dark conditions for 3-4 weeks was necessary.

Two or three weeks after germination, the seedlings were inoculated with conidial spore suspension of each species of Fusarium. Conidial inoculum was produced in liquid mung bean media (Bai \& Shaner, 1996) and has been stored in $15 \%(\mathrm{v} / \mathrm{v})$ glycerol at $-70^{\circ} \mathrm{C}$ till inoculation time. Prior to plant inoculation, spore germination test was carried out on PDA plates to assess the viability and rate of spore germination. The concentration of each conidial suspension was, 
then, determined using a Thoma Chamber $\left(0.0025 \mathrm{~mm}^{2}\right)$ and adjusted to $1 \times 10^{6}$ spore $\mathrm{ml}^{-1}$ of sterile tap water. Inoculum was contained $0.1 \%$ (v/v) Tween ${ }^{\circledR} 20$ (Applichem, Darmstadt, Germany) as a surfactant. Spore suspensions were kept on ice during inoculation and homogenized well before using.

Root-dip inoculation method was employed for artificial inoculation in the greenhouse by soaking the roots of individual plant in spore suspension for $30 \mathrm{~min}$. Inoculations were carried out in early morning. After inoculation the seedlings were transferred to new pots $(9 \times 9 \times$ $9.5 \mathrm{~cm}$ ) including mixed soil consisting of commercial plant substrate (Fruhstorfer Erde, Typ T25, HAWITA Group, Vechta, Germany) and sand (1:1). All pots were arranged according to a completely randomized design on the greenhouse benches. The plants were maintained at $25 \pm 5^{\circ} \mathrm{C}$ with alternating 12-h light (mercury vapour lamps, 6600 lux at ear height) and dark periods. During the experiment, relative humidity was $34-86 \%$. Five replicate pots were set up for each species of Fusarium and each pot included two plants. Control treatments were inoculated with autoclaved tap water mixed with adhesion detergent of Tween ${ }^{\circledR} 20$. Visual symptoms were determined on a weekly basis and six weeks after inoculation the plants were harvested. In order to verify the presence of fungus in artificial inoculated plants, subsequent detection of Fusarium spp. in plant tissue was performed by qPCR assay. For a few inoculated samples, fungal re-isolation was carried out from surface sterilized stem tissues.

\section{Mycotoxin Analysis}

The field weed samples which indicated a positive signal in qPCR experiments were analyzed for a number of Fusarium related mycotoxins including deoxynivalenol (DON), 3ADON, 15ADON, nivalenol (NIV), zearalenone (ZEN), fumonisin B1 (FB1), beauvericin (BEA), enniatins (B, B1, A, A1) by HPLC-MS/MS. Mycotoxin extraction was performed by adding $1 \mathrm{ml}$ acetonitrile-water (84:16) to $100 \mathrm{mg}$ fine powder of weed plant tissues. The extract (600 $\mu \mathrm{l})$ was dried in a rotational-Vacuum-Concentrator RVC 2-25 (Martin Christ Gefriertrocknungsanlagen $\mathrm{GmbH}$, Osterode am Harz, Germany) at $40^{\circ} \mathrm{C}$. The raw organic extract was resuspended in $600 \mu \mathrm{l}$ of methanol-water $(85: 15)$ and defatted with the same volume of cyclohexane. After centrigfugation the lower phase was taken for analysis. 
HPLC separation was carried out on a reverse-phase Polaris C18-ether column $\left(100 \times 2 \mathrm{~mm}, 3 \mu \mathrm{m}\right.$ particle size; Agilent, Darmstadt, Germany) at $40^{\circ} \mathrm{C}$ and trichothecenes $\mathrm{B}$ and zearalenone were detected by tandem mass spectrometry using triple quadrupol $1200 \mathrm{~L}$ (Varian, Darmstadt, Germany) according to Adejumo et al. (2007a) and Adejumo et al. (2007b), but two mass transitions were used for each mycotoxin. Beauvericin, fumonisin B1 and enniatins were separated on a reverse phase Kinetex C18 column $(50.0 \times 2.1 \mathrm{~mm}, 2.6 \mu \mathrm{m}$ particle size; Phenomenex (Aschaffenburg, Germany) and detected using ion trap 500MS (Varian, Darmstadt, Germany) as described by Nutz et al. (2011). For these mycotoxins three mass transitions were used. Pure analytical standards in methanol/water (1:1) were used to construct calibration curves.

\section{Data Processing and Statistical Analysis}

SigmaPlot 12.3 Notebook was used for statistical analysis. Non-parametric tests were performed while data distribution was not normal. The qPCR data were assessed for finding the positive samples based on the melting temperature (Tm), starting quantity (SQ) and threshold cycle $(\mathrm{Ct})$ value. The lowest standard DNA for each Fusarium spp. employed in the qPCR assays was considered as the limit of quantification (LOQ). According to the qPCR data, the quantity of fungal biomass ( $\mathrm{pg} \mathrm{mg}^{-1}$ ) for the positive samples was calculated. DNA quantity for the samples containing values lower than LOQ was substituted as LOQ/2 (Hornunga \& Reeda, 1990). These samples indicated the species-specific melting temperature in the PCR cycles lower than 30 . 


\section{Results}

A total of 294 plants (147 samples from each farming type) representing 55 weed species were collected from 11 maize fields in Germany. The qPCR Fusarium spp. monitoring indicated that 201 weed samples belonging to 36 weed species (3 monocotyledonous and 33 dicotyledonous) were infected with 8 species of Fusarium (Fig. 1). In total, 421 Fusarium infections were detected by species-specific real time PCR assay. In most cases, individual weed species appeared to be harbor of several species of Fusarium, although not necessarily in the same plant (see Table 3). Sometimes one sample was infected with two, three or more Fusarium species at the same time. The final results showed that 144 weed samples, which are $49 \%$ of total assessed weeds, were infected with $F$. equiseti. $F$. avenaceum had the second grade of infection with around $34.7 \%$. Rate of infection for F. culmorum and F. tricinctum (18\%) was equal across the experiments. For F. proliferatum, around $11 \%$ of total assessed samples were infected while the infection rate for $F$. graminearum was $8 \%$. Further assessment revealed insignificant rate of infection for $F$. poae and $F$. subglutinans (3\% and $1.0 \%$, respectively) in different weed samples.

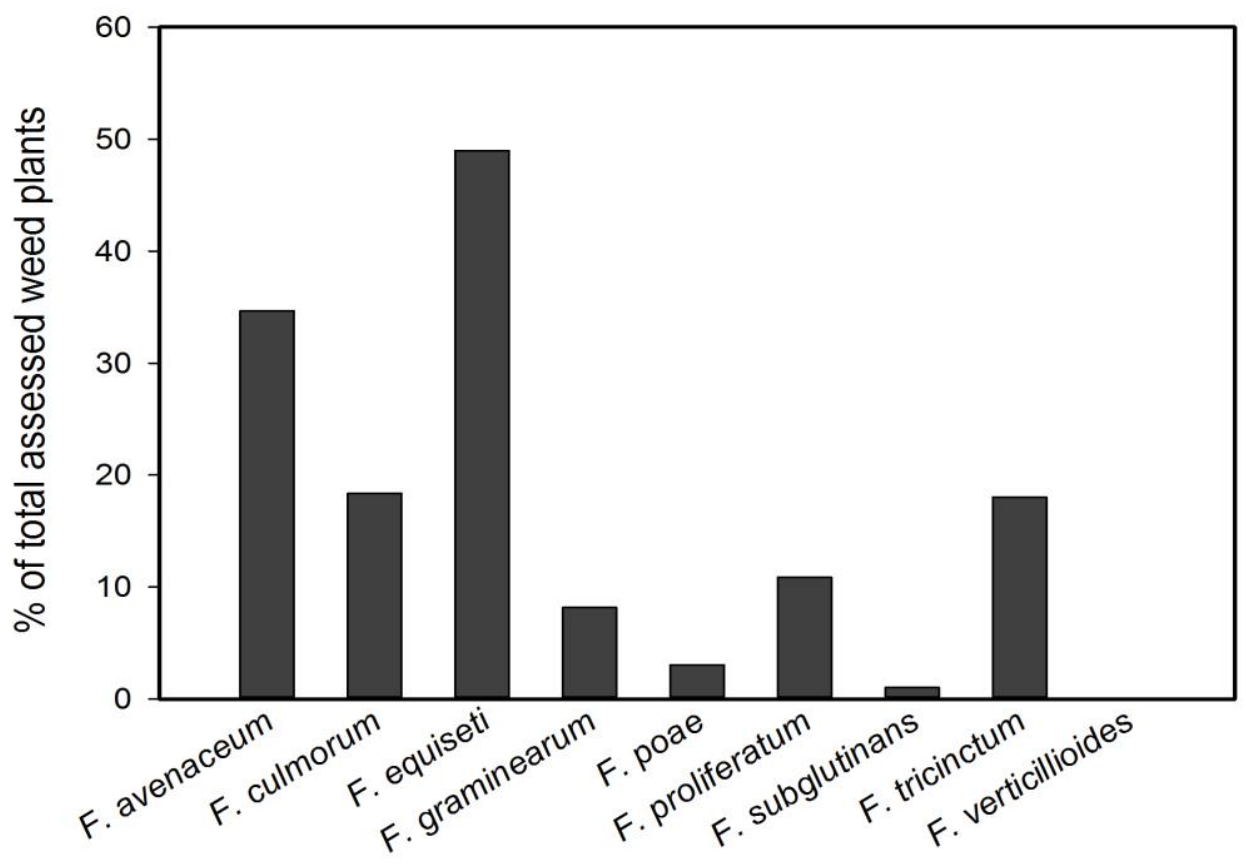

Fig. 1. Colonization of weed plants in maize fields by Fusarium spp.

The incidence of Fusarium species in Echinochloa crus-galli, Polygonum convolvulus, and Chenopodium album was higher than in other weed plants, respectively. F. equiseti and 
F. avenaceum were detected in almost all common studied weed species (Table 2). All species of weeds displayed in Table 2, except Polygonum persicaria, were infected with $F$. tricinctum and F. culmorum. Arabidopsis thaliana L. which is also a popular model organism in plant biology indicated infection with four Fusarium spp. In this assessment, F. verticillioides was the only species that failed to be detected.

No discrepancy for infection frequency appeared in the study of Fusarium spp. population in organic and conventional maize farming concerning to $F$. poae and also F. proliferatum (Fig. 2). F. subglutinans was not detected in the conventional farming, while only three infected weed samples were discovered in the maize fields under organic system. In ecological farms the frequency of $F$. equiseti and $F$. graminearum was higher than in the conventional ones (62.6\% and $11.6 \%$ comparing to $35.4 \%$ and $4.8 \%$, respectively). In contrast, the conventional fields indicated a higher rate of infection for $F$. avenaceum, $F$. culmorum, and F. tricinctum. Comparisons between the amounts of fungal biomass in two cultivation systems revealed a significant difference for $F$. equiseti and also for $F$. tricinctum $(P=0.05)$. No statistical difference in fungal biomass was found for other Fusarium spp. between organic and conventional fields (Fig. 3).

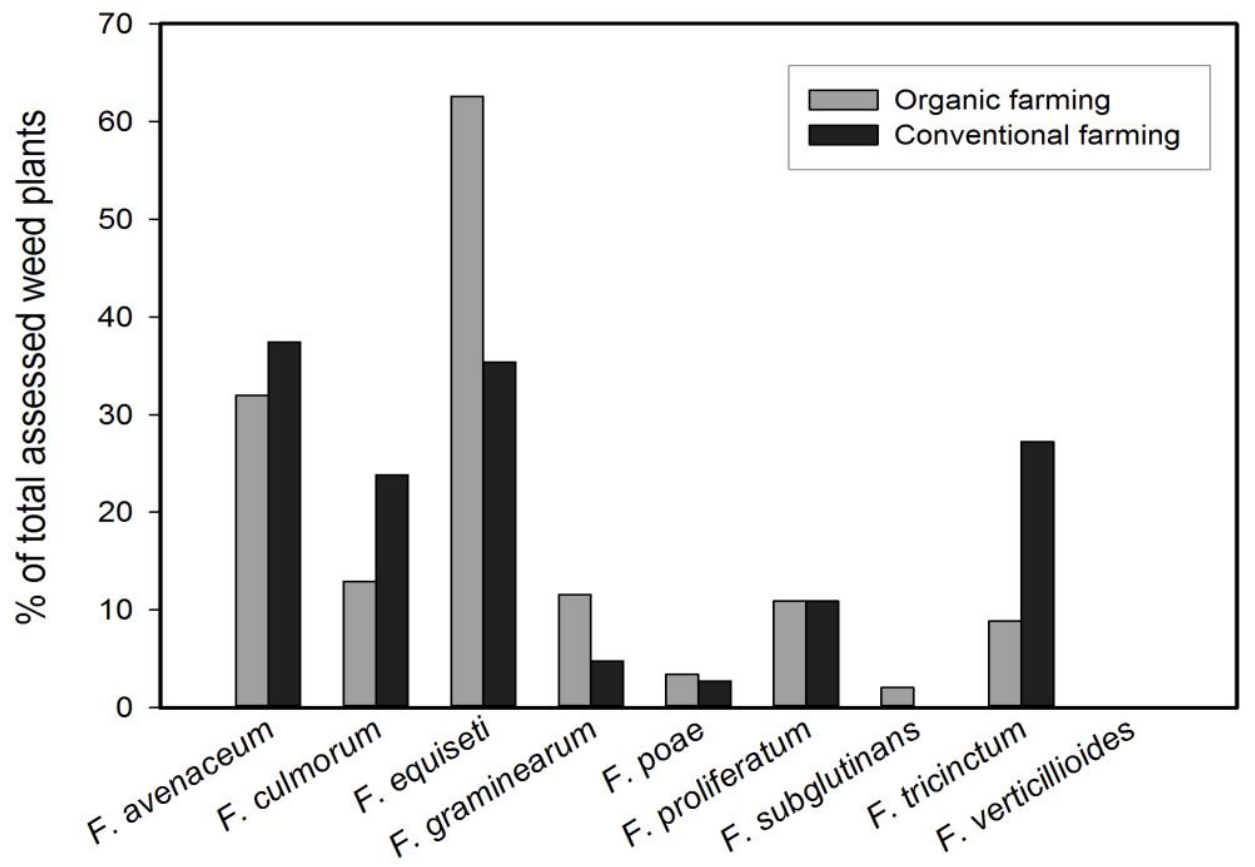

Fig. 2. Infection rate of weed plants by Fusarium spp. in organic and conventional maize fields 
Table 2. Overview of the incidence of Fusarium spp. detected in 294 weeds by qPCR assay

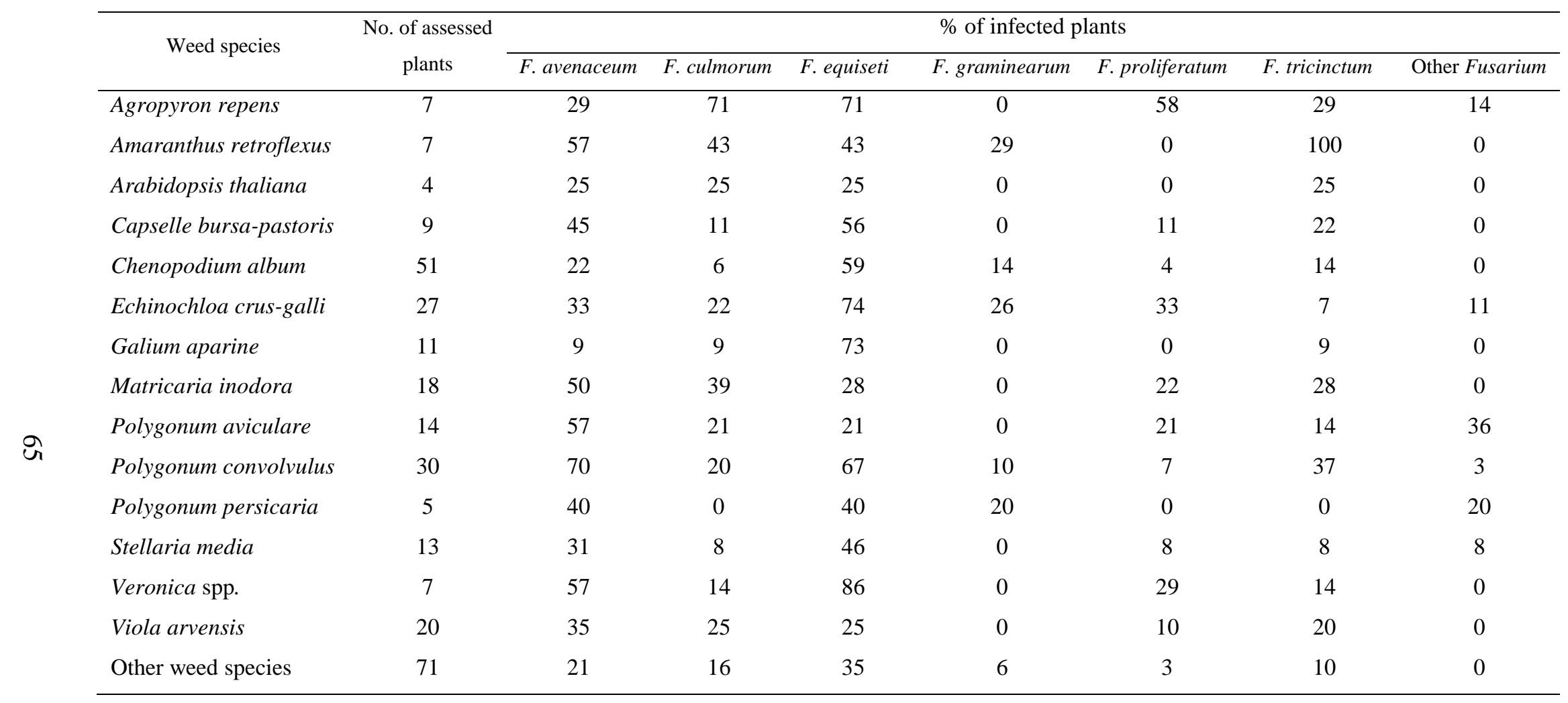



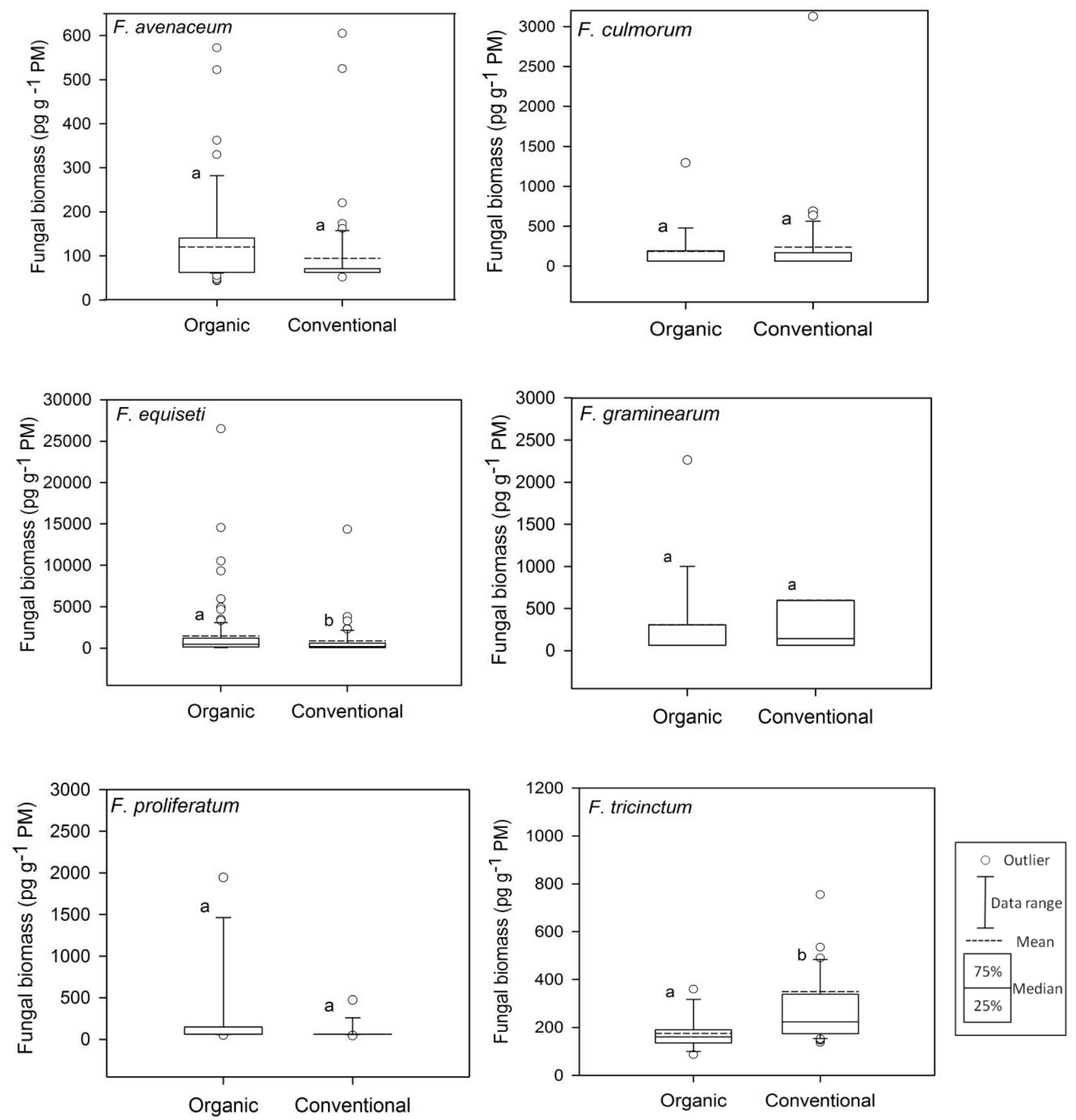

Fig. 3. Fungal biomass in weeds sampled from organic and conventional maize fields. Statistical differences within two cropping systems (Mann-Whitney $U$ test, $P=0.05$ ) are labeled with letters ("a" and "b"). PM= Plant material. F. poae and F. subglutinans are not constructed; because of low numbers of infected weed plants. 


\section{Fungal Isolation and Identification}

146 isolates recovered from different weed species were distributed to nine species of Fusarium, based on the morphological and molecular identification. Seven isolates were only identified to genus Fusarium level and excluded from further experiments. Distribution of isolated Fusarium spp. from common weed species of maize farms is presented in Table 3. Occasionally, more than one species were isolated from an identical weed sample. 50 (32.7\%) isolates of 153 Fusarium isolates were identified as F. equiseti. F. avenaceum included 31 isolates which was about $21 \%$ of total isolation. This was followed by F. oxysporum (16.3\%), F. venenatum (8.5\%), F. culmorum (7.8\%) and F. tricinctum (5.2\%). Less prevalently recovered species comprise $F$. graminearum $(3.3 \%)$ and $F$. proliferatum $(1.3 \%)$. We could not obtain $F$. poae and $F$. subglutinans from the few infected weed plants. Among recovered isolates, the strains of $F$. avenaceum RD22 and RD98, F. culmorum RD100 and RD102, F. graminearum RD92 and $F$. proliferatum RD94 were selected for further experiments in the greenhouse.

Table 3. Distribution of Fusarium spp. isolated from common weeds of maize fields studied

\begin{tabular}{llll}
\hline Weed species & Plant & Detected by qPCR & Additional recovered species \\
\hline Amaranthus retroflexus & 1 & ave, cul, tri, equ & oxy \\
& 2 & tri, equ & \\
Capsella bursa-pastoris & 3 & ave, tri & ven \\
& 1 & equ & \\
Chenopodium album & 3 & ave & oxu \\
& 1 & cul & oxy \\
& 2 & ave, tri, equ & \\
& 3 & pro, ave, equ & oxy \\
& 4 & ave, equ & oxy \\
& 5 & equ & oxy, ven \\
& 6 & gra, equ & oxy \\
& 7 & boothii, equ & \\
& 8 & ave, equ & oxy, ven \\
& 9 & ave & \\
& 10 & equ & oxy \\
& 11 & equ & ven \\
& 12 & gra, equ & oxy, ven \\
& 13 & equ & \\
& 14 & equ & oxy \\
& 15 & gra, equ & \\
16 & ave, tri, equ & oxy \\
17 & ave, tri & ven \\
\hline
\end{tabular}


Table 3: continued

\begin{tabular}{|c|c|c|c|}
\hline Weed species & Plant & Detected by qPCR & Additional recovered species \\
\hline & 4 & gra, cul, poa, equ & \\
\hline & 5 & cul, equ & oxy \\
\hline & 6 & pro, equ & \\
\hline & 7 & ave, equ & \\
\hline & 8 & ave, equ & oxy, ven \\
\hline & 9 & cul, pro & ven \\
\hline \multirow[t]{5}{*}{ Elymus repens } & 1 & pro, cul, ave & oxy \\
\hline & 2 & pro, equ & \\
\hline & 3 & pro, cul, equ & ven \\
\hline & 4 & cul, equ & \\
\hline & 5 & cul, ave, poa, equ, tri & ven \\
\hline \multirow[t]{2}{*}{ Galium aparinae } & 1 & ave, equ & \\
\hline & 2 & cul, tri, equ & \\
\hline \multirow{5}{*}{ Matricaria inodora } & 1 & cul, ave, tri & \\
\hline & 2 & ave & \\
\hline & 3 & cul, ave & \\
\hline & 4 & ave, equ & \\
\hline & 5 & cul & \\
\hline \multirow[t]{10}{*}{ Polygonum convolvulus } & 1 & cul, ave, tri, equ & ven \\
\hline & 2 & cul, ave, tri, equ & oxy, ven \\
\hline & 3 & ave & oxy \\
\hline & 4 & ave, equ & \\
\hline & 5 & ave, equ & \\
\hline & 6 & gra, equ & \\
\hline & 7 & ave, equ & \\
\hline & 8 & pro, equ & \\
\hline & 9 & cul, ave, equ & oxy \\
\hline & 10 & cul, ave, tri, equ & oxy \\
\hline \multirow[t]{2}{*}{ Polygonum persicaria } & 1 & ave, equ & oxy \\
\hline & 2 & ave, equ & oxy \\
\hline \multirow[t]{3}{*}{ Stellaria media } & 1 & ave, equ, sub, tri & oxy \\
\hline & 2 & pro, equ & \\
\hline & 3 & ave, equ & \\
\hline \multirow[t]{3}{*}{ Veronica spp. } & 1 & ave, equ & oxy \\
\hline & 2 & equ & \\
\hline & 3 & ave, equ & oxy \\
\hline \multirow{4}{*}{ Viola arvensis } & 1 & ave, equ & oxy, ven \\
\hline & 2 & ave, equ & \\
\hline & 3 & ave & \\
\hline & 4 & equ & \\
\hline
\end{tabular}

Bold letters indicate the recovered Fusarium species

The plant column shows number of plant samples employed for Fusarium isolation. It is not equal with the total number of plants sampled in this study

Abbreviations: ave: F. avenaceum; cul: F. culmorum; gra: $F$. graminearum; equ: $F$. equiseti; oxy: $F$. oxysporum; poa: F. poae; pro: F. proliferatum; sub: F. subglutinans; tri: F. tricinctum; ven: $F$. venenatum 


\section{Fusarium DNA Sequencing and Phylogenetic Analysis}

To confirm morphological identification, 62 representative isolates were sequenced based on the TEF-1 $\alpha$ gene which has been widely used for species identification. Thermal PCR conditions suggested by Geiser et al. (2004), lead to a mixture of specific and non-specific products. The situations were achieved by running a gradient PCR in the range of $53-63^{\circ} \mathrm{C}$ under "Hot start PCR". At the annealing temperature of $58.5^{\circ} \mathrm{C}$, a single band in the size range of 610 to $653 \mathrm{bp}$ was successfully amplified from all isolates. After DNA sequencing, each unknown Fusarium strain was identified according to the deposited sequences in Fusarium-ID database which had a high homology $(\geq 99 \%)$ with them. The first three hits for the sequence of each isolate have been assigned in Supplemental Table 2. The studied sequences were, then, aligned with TEF-1 $\alpha$ sequences of $F$. acuminatum, $F$. arthrosporioides, $F$. avenaceum, $F$. culmorum, F. flocciferum, F. graminearum, F. torulosum, F. tricinctum, and $F$. venenatum retrieved from sequence database (Supplemental Table 1) and exposed to phylogenetic analysis (Fig. 4, 5, 6). The UPGMA dendrogram clearly clustered distinct clades regarding to Fusarium spp. studied. Identification was well supported with bootstrap values. The studied strains, therefore, were placed into groups matching with those determined by Fusarium-ID database. The strain RD99 which was identified morphologically as $F$. graminearum, made a distinct branch close to F. graminearum. Fusarium-ID database identified this strain as F. boothii. Furthermore, the isolates morphologically identified as $F$. equiseti were grouped in three different haplotypes of Fusarium incarnatum-equiseti species complex (FIESC) based on the molecular identification. Similarly, isolates identified morphologically as $F$. oxysporum placed in three different sub-clades of Fusarium oxysporum species complex (FOSC). 


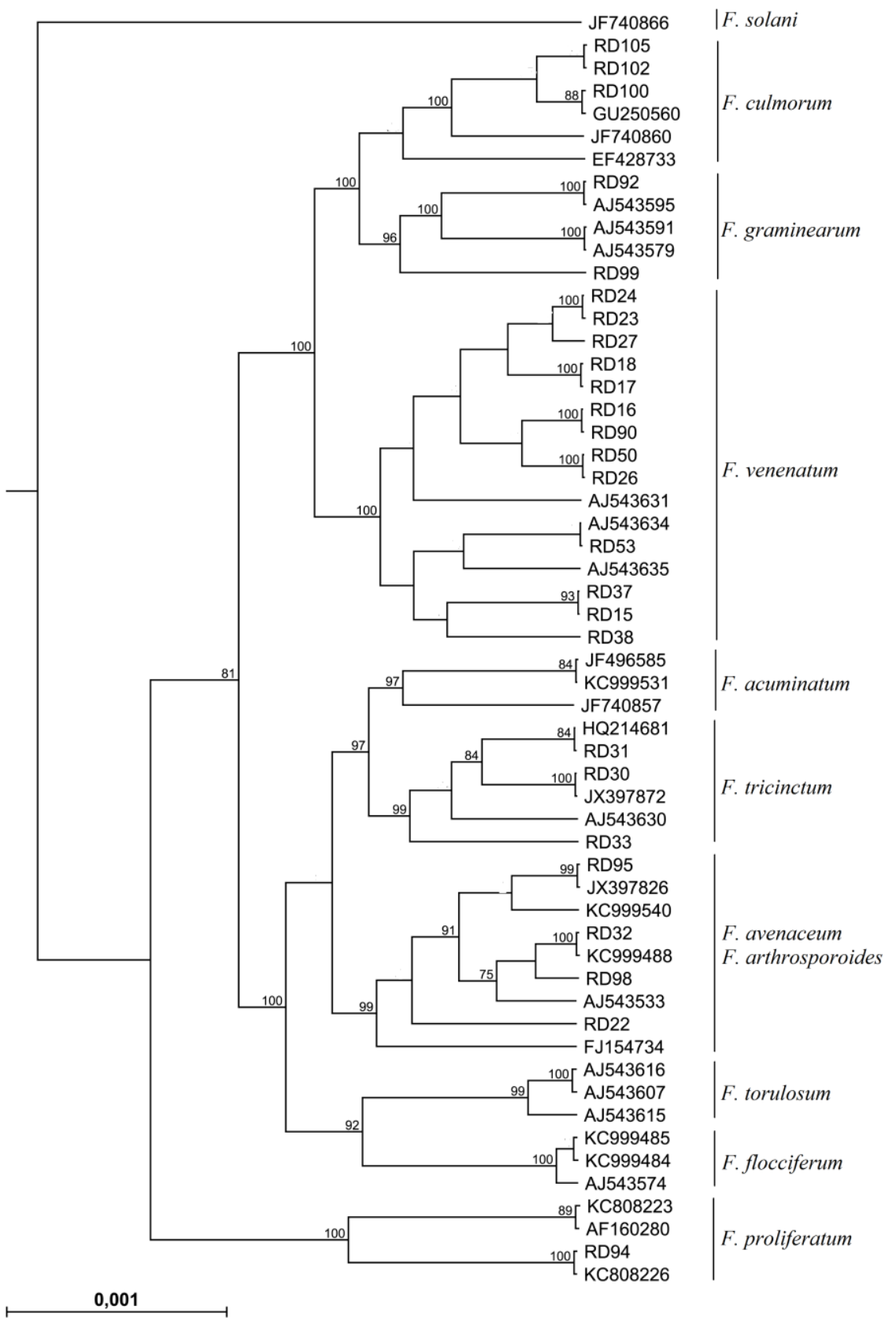

Fig. 4. UPGMA tree showing the relationship of Fusarium isolates inferred from TEF-1 $\alpha$ gene using Juckes-Cantor method. Numbers associated with each node indicate the proportion of 1000 bootstrap samples in which the certain clade was found. Only percentages $\geq 75 \%$ are shown. F. solani JF740866 is used as outgroup to root the tree. Isolates with RD label have been identified in this study and the rest have been retrieved from the GenBank. 


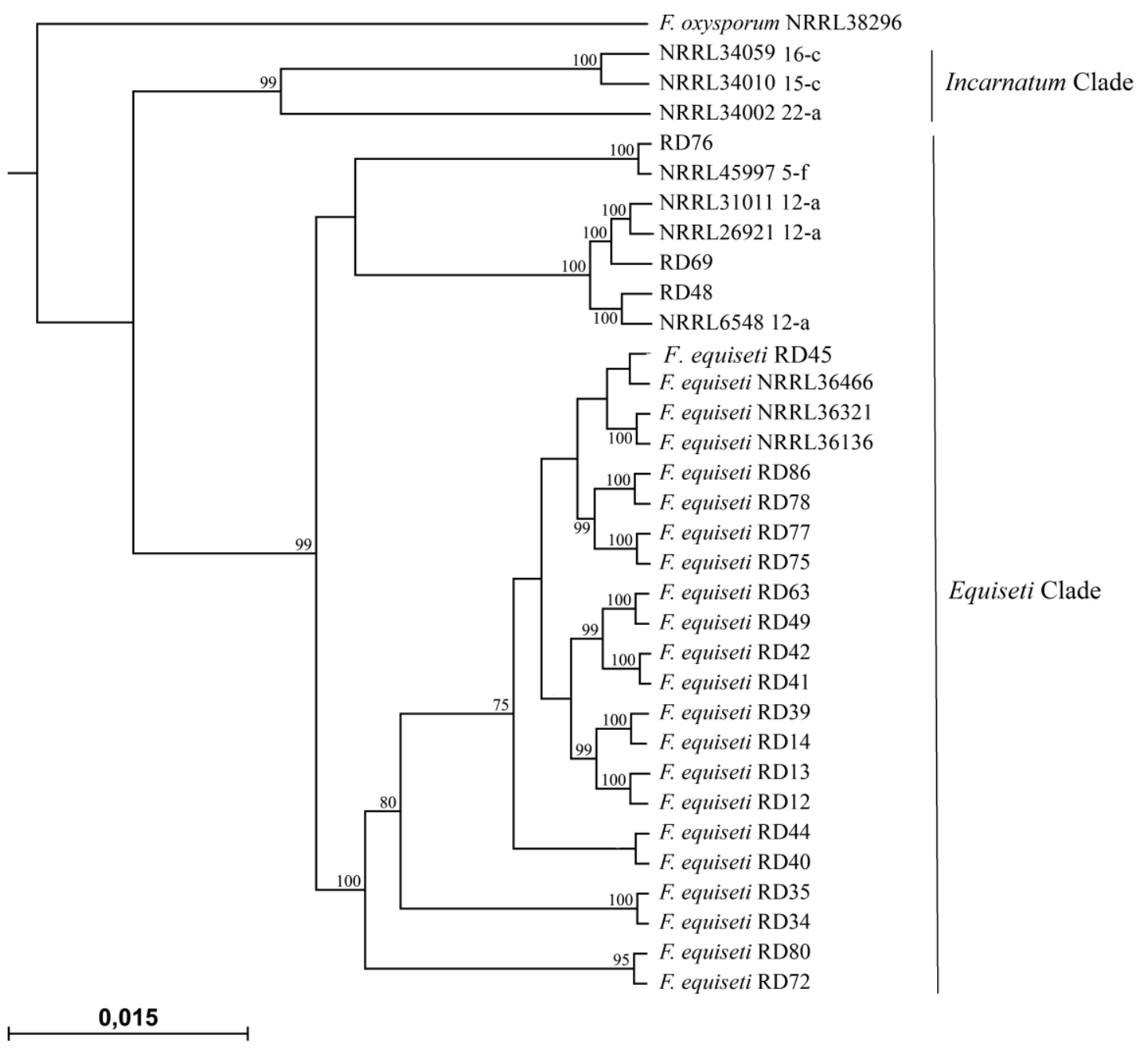

Fig. 5. UPGMA dendrogram for Fusarium incarnatum-equiseti species complex (FIESC) based on the nucleotide sequence of TEF-1 $\alpha$ gene. Only bootstrap values $\geq 75 \%$ are presented. F. oxysporum is used as outgroup. Isolates with $\mathrm{RD}$ label have been identified in this study and the rest have been retrieved from the Fusarium-ID database. 


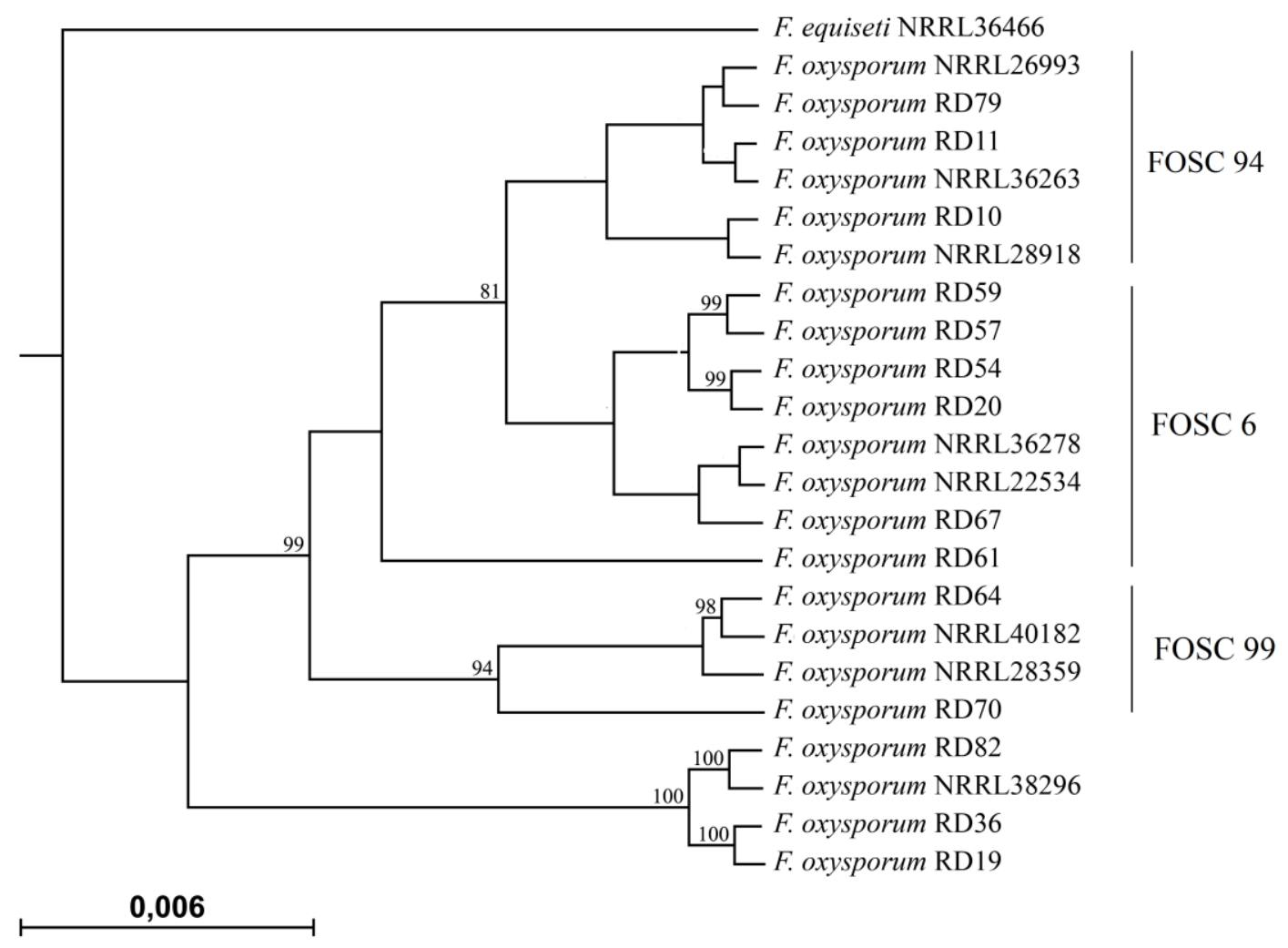

Fig. 6. Phylogenetic tree for isolates identified as Fusarium oxysporum species complex (FOSC) based on the nucleotide sequence of TEF- $1 \alpha$ gene. The bootstrap values $\geq 75 \%$ are indicated next to the branches. F. equiseti is used as outgroup. Isolates with RD label have been identified in this study and the rest have been retrieved from the Fusarium-ID database. 


\section{Greenhouse Experiments}

Inoculation of recovered Fusarium spp. on common weed species and also maize plant was performed under greenhouse conditions. No obvious symptom was observed on any of the weeds or maize plants. Therefore, quantity of fungal DNA in plant tissues was considered as a marker for finding of Fusarium presence in samples tested. Attendance of Fusarium in tissues was checked by real time PCR. The results of fungal biomass measurement in inoculated plant materials are demonstrated in Table 4. The Fusarium spp. were not detected in any of the control plants. Routine pathogen re-isolation from different parts of some samples confirmed the plant systemic infection. Table 4 shows the weeds that were identified as the host plants for Fusarium spp. in maize fields.

Table 4. Determination of fungal biomass $\left(\mathrm{pg} \mathrm{mg}^{-1}\right)$ of inoculated weeds and maize plants

\begin{tabular}{llllllllc}
\hline Weed species & F. avenaceum & $\mathrm{P} / \mathrm{R}$ & F. culmorum & $\mathrm{P} / \mathrm{R}$ & F. graminearum & $\mathrm{P} / \mathrm{R}$ & F. proliferatum & $\mathrm{P} / \mathrm{R}$ \\
\hline Amaranthus retroflexus & $\mathrm{nd}$ & $0 / 5$ & $\mathrm{nd}$ & $0 / 5$ & $189 \pm 88$ & $5 / 5$ & $\mathrm{nd}$ & $0 / 5$ \\
Beta vulgaris & $\mathrm{nd}$ & $0 / 5$ & $181 \pm 120$ & $3 / 4$ & $171 \pm 50$ & $4 / 5$ & $\mathrm{nd}$ & $0 / 5$ \\
Capselle bursa pastoris & $70 \pm 62$ & $5 / 5$ & $182 \pm 124$ & $4 / 5$ & $\mathrm{nd}$ & $0 / 5$ & $<\mathrm{LOQ}$ & $3 / 5$ \\
Chenopodium album & $290 \pm 542$ & $5 / 5$ & $183 \pm 126$ & $4 / 5$ & $157 \pm 102$ & $5 / 5$ & $55 \pm 31$ & $4 / 5$ \\
Echinochloa crus-galli & $90 \pm 78 *$ & $4 / 5$ & $190 \pm 45 *$ & $4 / 5$ & $151 \pm 58$ & $4 / 5$ & $51 \pm 20$ & $4 / 5$ \\
Galium aparine & $160 \pm 31 *$ & $3 / 3$ & $<\mathrm{LOQ}$ & $3 / 3$ & $\mathrm{nd}$ & $0 / 3$ & $\mathrm{nd}$ & $0 / 3$ \\
Matricaria inodora & $108 \pm 59$ & $4 / 5$ & $371 \pm 40$ & $3 / 5$ & $\mathrm{nd}$ & $0 / 5$ & $17 \pm 4 *$ & $4 / 5$ \\
Polygonum convolvulus & $86 \pm 83$ & $3 / 3$ & $\mathrm{nd}$ & $0 / 1$ & $161 \pm 74$ & $3 / 3$ & $\mathrm{nd}$ & $\mathrm{nd}$ \\
Polygonum persicaria & $135 \pm 61$ & $3 / 3$ & $\mathrm{nd}$ & $0 / 3$ & $171 \pm 25$ & $3 / 3$ & $0 / 1$ \\
Veronica persica & $301 \pm 58 *$ & $4 / 5$ & $196 \pm 55$ & $4 / 5$ & $\mathrm{nd}$ & & $0 / 5$ & $52 \pm 32$ \\
Viola arvensis & $<\mathrm{LOQ}$ & $4 / 5$ & $185 \pm 132$ & $3 / 3$ & $\mathrm{nd}$ & & $0 / 1$ & $24 \pm 22 *$ \\
Zea mays & $112 \pm 87$ & $4 / 4$ & $171 \pm 6$ & $4 / 4$ & $165 \pm 17$ & $3 / 3$ & $61 \pm 27$ & $3 / 5$ \\
\hline
\end{tabular}

Samples with values less than LOQ were considered as positive with the quantity equal LOQ/2

LOQ for $F$. avenaceum, $F$. culmorum, $F$. graminearum and $F$. proliferatum, respectively: $50 \mathrm{pg} \mathrm{mg}^{-1}, 150 \mathrm{pg} \mathrm{mg}^{-1}$, $150 \mathrm{pg} \mathrm{mg}^{-1}$ and $16.7 \mathrm{pg} \mathrm{mg}^{-1}$

Abbreviations: P: number of positive samples; R: number of replications; nd: not detected; *: new hosts for the relevant Fusarium species 


\section{Determination of Mycotoxins Content}

The content of mycotoxins was measured for the common weeds of maize fields. The results are summarized in Table 5. Trichothecenes, fumonisins and also zearalenone were not detected in any of the weeds sampled, whereas occurrence of beauvericin and enniatins was common. High incidence rates of contamination for toxins, beauvericin and enniatins were observed in some of the weed plant samples, while others contained low or no toxin. For example, regarding to Chenopodium album, only one plant sample showed high level $\left(>5 \mathrm{mg} \mathrm{kg}^{-1}\right.$ ) of enniatins and four samples out of 30 were contaminated with high amount of beauvericin (Fig. 7). As it is presented in Table 4, high values (up to $66 \mathrm{mg} \mathrm{kg}^{-1}$ ) of beauvericin were recorded in some of the plant samples belonging to Matricaria inodora and Chenopodium album. Similarly, potentially harmful levels (up to $24 \mathrm{mg} \mathrm{kg}^{-1}$ ) of enniatins were observed in Chenopodium album and Elymus repens. The relationship between fungal biomass and mycotoxin content was investigated. There was no apparent correlation between enniatins content and fungal biomass determined with all enniatins-producing species tested ( $F$. avenaceum, $F$. poae, $F$. proliferatum, and $F$. tricinctum). No clear trend was found for beauvericin, as well.

Tabel 5. An overview of mycotoxins concentration in common weeds of maize fields

\begin{tabular}{|c|c|c|c|c|c|c|}
\hline \multirow[t]{2}{*}{ Weed species } & \multicolumn{2}{|c|}{$\begin{array}{c}\% \text { of positive } \\
\text { samples }\end{array}$} & \multicolumn{2}{|c|}{$\begin{array}{c}\text { Median of positive } \\
\text { samples }\left(\mathrm{ng} \mathrm{g}^{-1}\right)\end{array}$} & \multicolumn{2}{|c|}{ Max value $\left(\mathrm{ng} \mathrm{g}^{-1}\right)$} \\
\hline & BEA & Enns & BEA & Enns & BEA & Enns \\
\hline Chenopodium album & 93 & 100 & 174 & 67 & 45,000 & 24,000 \\
\hline Echinochloa crus-galli & 91 & 100 & 55 & 116 & 5,700 & 4,900 \\
\hline Galium aparine & 87 & 88 & 79 & 16 & 190 & 230 \\
\hline Matricaria inodora & 93 & 71 & 5 & 15 & 66,000 & 68 \\
\hline Polygonum aviculare & 100 & 89 & 12 & 68 & 1,400 & 1,500 \\
\hline Polygonum convolvulus & 100 & 92 & 54 & 67 & 750 & 4,200 \\
\hline Viola arvensis & 64 & 93 & 27 & 158 & 530 & 4,500 \\
\hline
\end{tabular}

Only the weed species which had more than 8 plant samples are shown.

Half of the LOQ was considered as value for the samples containing toxin lower than LOQ.

For all mycotoxins, the amount of LOQ and LOD were $10 \mathrm{ng} \mathrm{g}^{-1}$ and $3 \mathrm{ng} \mathrm{g}^{-1}$, respectively.

Abbreviations: BEA: beauvericin; Enns: enniatins 

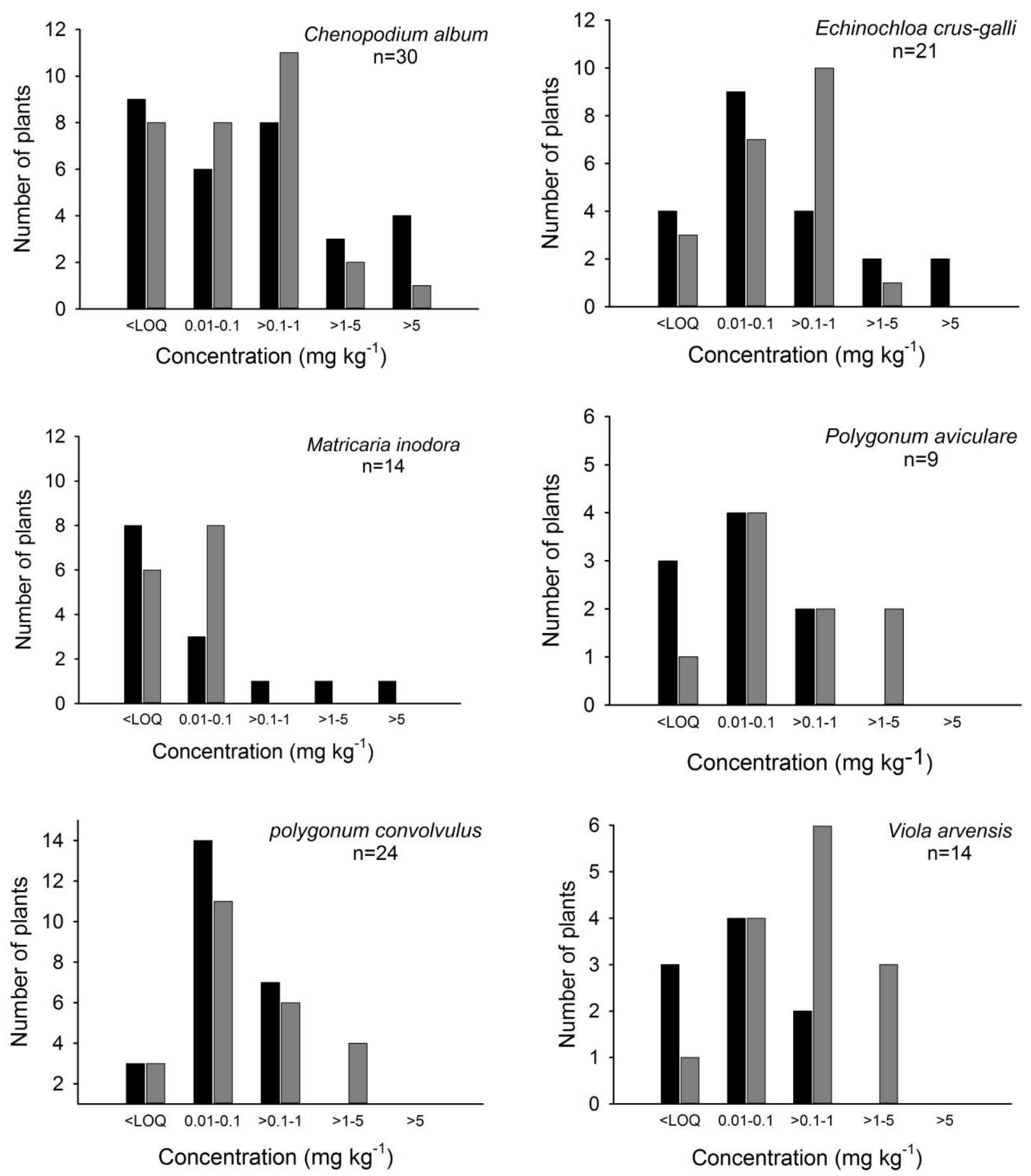

Fig. 7. Concentration of beauvericin and enniatins in common weed species of maize fields. Black bars and gray bars show beauvericin and enniatins concentrations, respectively. n: total number of plant samples tested. 


\section{Discussion}

A high biodiversity of Fusarium species associated with maize diseases are demonstrated. In this research, the qPCR assay successfully detected eight species of Fusarium in weeds sampled from maize farms. Morphological and molecular characteristics also confirmed the presence of eight different species, whereas $F$. equiseti and $F$. avenaceum were predominant and most frequently found in common weeds of the maize fields. This finding triggers the preliminary assumption that these two species are the most abundant Fusarium in the northern parts of Germany which may help to incidence of maize Fusarium diseases. Different reports confirm $F$. avenaceum as a common species associated with cereals in Europe while F. equiseti has less frequently (Logrieco et al., 2002; Yli-Mattila, 2010; Kosiak et al., 2003). Environmental and agronomic factors affect the occurrence of $F$. avenaceum on cereals (Gäfenhan et al., 2013). F. tricinctum which is another important species in cereals of Northern Europe (Yli-Mattila, 2010) was detected in $18 \%$ of total assessed weed samples. Regarding to F. graminearum described as the most important Fusarium in Central and Northern Europe, although the reports show replacement of this species with F. culmorum (Yli-Mattila, 2010), our study revealed a higher incidence of $F$. culmorum (18\%) in weeds than $F$. graminearum (8\%). We could not recover $F$. poae and $F$. subglutinans which were detected in very low frequency (3\% and $1 \%$, respectively) by qPCR detection. F. oxysporum has been demonstrated from maize and other cereal crops as a less common species (Logrieco et al., 2002; Kosiak et al., 2003). In our sampling this species was isolated from most common weed plants. $F$. venenatum which has been sporadically recovered from maize tissues (Logrieco et al., 2002) was isolated from six different weed species. Therefore, the biodiversity of Fusarium of weeds sampled was as high as reported in maize fields. In addition, prevalence of $F$. avenaceum and $F$. equiseti on almost all common weeds studied indicates that these two species are more competitive Fusarium for weed colonization compared to the main Fusarium of cereals such as $F$. graminearum. As we expected, $F$. verticillioides was not detected in any of the weeds sampled. $F$. verticillioides is a serious problem of maize production in southern parts of Germany, while our samples had been collected from the north and eastern-north. Further work, thus, is needed to find the role of weeds in survival of this species as well as in fumonisin production. The frequent detection of Fusarium spp. on weed plants raised the importance of their role in the survival of Fusarium fungus. 
The diversity of Fusarium species was similar in two farming types. Comparsion of Fusarium population in two different cultivation systems indicated a higher incidence of Fusarium spp., not necessarily significant, among organic fields except $F$. avenaceum, F. culmorum and F. tricinctum. The comparison of fungal biomass for six Fusarium species (out of eight) revealed no significant difference in aggressiveness of the fungi in two corn cropping systems. However, there was a statistical difference in fungal biomass of $F$. equiseti and F. tricinctum among two different farming types. F. equiseti had a higher level of biomass in ecological fields while $F$. tricinctum was more aggressive in conventional farms. Lack of fungicide application for the control management of Fusarium maize pathogens in both cropping systems have been likely leaded to the similar Fusarium diversity in addition to equal fungal biomass. According to Nutz \& Karlovsky (unpublished) there is no significant difference between conventional and organic farming in occurrence of fusarium ear rot and level of fungal biomass. They demonstrated variety levels of infection in two cultivation methods.

Weed plants sampled from maize fields did not show any disease symptoms what was obviously evidenced in inoculation experiments in the greenhouse. Furthermore, the Fusarium strains were recovered from surface sterilized weed segments in both field and greenhouse samples. This issue confirmed that the isolates have originated from inner parts of the contaminated weeds. Symptomless colonization of weed plants has been observed by several Fusarium spp. (Haware \& Nene, 1982; Clark and Watson 1983; Jenkinson \& Parry, 1994; Postic et al., 2012; Altinok, 2013). Lack of visible symptoms on the weed plants and their re-isolation would suggest that the infection of these hosts by Fusarium species could be endophytic.

In this study, weeds were clearly shown to harbor different species of Fusarium. To our knowledge, some of the weed species demonstrated in this study (Table 4) are new alternative hosts and have not been reported for the relevant Fusarium species. Our results increased the possible role of weeds in the survival of fungus and production of primary inoculum in maize fields. In the absence of susceptible host plants, Fusarium spp. can survive in weeds as an alternative hosts and increase the inoculum potential for infecting the main crop during the growing season. This is much more expected for the species such as $F$. poae or F. subglutinans which are not able to survive saprotrophically on crop debris by producing resting spores (Jenkinson \& Parry, 1994). Although plant residues produce the main source of 
inoculum in maize fields (Cotten \& Munkvold, 1998), different studies also show survival of Fusarium species on non-host plants such as wild plants and weeds (Jenkinson \& Parry, 1994; Inch \& Gilbert, 2003; Pereyra \& Dill-Macky, 2008; Postic et al., 2012; Altinok, 2013). As a result, for determination of the relative importance of weeds as a source of inoculum, the pathogenicity of isolated Fusarium should be compared to that isolates obtained from maize.

High frequency of Fusarium spp. was detected in Echinochloa crus-galli, Polygonum convolvulus, and Chenopodium album based on the qPCR assay. These plants were the main weed species reported from maize fields sampled (Westerman \& Gerowitt, 2012). The study also pointed out very low incidence of Fusarium infection in some weed species. For example, the only Fusarium species detected in Cirsium arvense L., Sinapis arvensis L., Alopecurus myosuroides (L.) Huds. and Euphorbia helioscopia L. were F. proliferatum, F, equiseti, F. culmorum and F. equiseti, respectively. Furthermore, in several weed species such as Sonchus asper L., Anchusa arvensis L., Papaver rhoeas L., Solanum nigrum L., Geranium dissectum L., Lolium sp. and Erysimum cheirathoides L. no Fusarium infection was observed. Number of relevant weed samples was not enough for resulting. Thus, the relative importance of the same above mentioned weeds as Fusarium hosts or inoculum source in maize fields cannot be determined from this work.

DNA sequences of genes such as TEF-1 $\alpha$ have been widely used for supporting morphological traits of Fusarium species (Yli-Mattila et al., 2002; Harrow et al., 2010; Geiser et al., 2004; Hsuan et al., 2011). In the present study, molecular investigation based on the TEF-1 $\alpha$ gene leaded to more precise identification of Fusarium isolates. The isolates that were grouped morphologically as F. equiseti were placed in FIESC according to the closest match of BLAST search analysis using Fusarium-ID database. A high level of genetic diversity has been observed in FIESC (O'Donnell et al., 2009a). This species complex with two clades (Incarnatum and Equiseti) has been included 62 sub-clades in each one to eight isolates are introduced. Currently reports have revealed 28 different genetic lineages in FIESC while Latin binomials were applied with confidence to only three of the species and others were identified with the English numerals (O'Donnell et al., 2009a). In our work, 22 isolates which have morphologically been identified as F. equiseti showed a high identity to the sub-clades of FIESC 14-a, FIESC 12-a, and FIESC 5-f (Supplemental Table 2). FIESC 14-a has been named $F$. equiseti while the next two 
sub-clades have still no Latin name (O'Donnell et al., 2009a). The percentage of similarity of the isolates belonged to FIESC ranged from 99.06-99.84\%. The possible reasons for not perfect matching can be the occurrence of allelic variant, the existence of a new species, no sequence representative in the database or poorly defining of the query sequence. In some cases, all known isolates of a pathogen have identical TEF- $1 \alpha$ sequence; but variation among TEF- $1 \alpha$ alleles within some species may vary (Geiser et al., 2004). Similarly, the isolates morphologically identified as F. oxysporum placed in three different sub-clades of FOSC. Fusarium-ID database introduce 256 sub-caldes in this Fusarium complex. Based on the sequencing homology, strain RD61 was identified as a member of FOSC6; but molecular phylogenetic analysis grouped it in a distinct branch close to FOSC6. More investigation with other DNA sequences or mycotoxin profile is necessary for finding the exact place of this strain in FOSC.

Furthermore, based on the morphological assessment strain RD99 was identified as $F$. graminearum; but it was placed in a distinct branch close to $F$. graminearum. The TEF-1 $\alpha$ sequence of this strain indicated $99.68 \%$ identity with $F$. boothii NRRL29105. F. boothii $(=F$. graminearum, lineage 3$)$ was formerly described as one of the nine species lineages within the $F$. graminearum clade. These two species are morphologically similar, but have slightly different conidia. Recently, thirteen species lineage of $F$. graminearum clade have been supported through the genealogical concordance and phylogenetic analysis of DNA sequences of nuclear genes (O'Donnell et al., 2000, 2004, 2008; Starkey et al., 2007).

According to the morphological characters (orange color sporodochia and pyriform microconidia) and the results of species-specific qPCR assay the strains RD22, RD32, RD95 and RD98 were identified as $F$. avenaceum. In UPGMA dendrogram, constructed with TEF-1 $\alpha$ sequences from $F$. avenaceum and closely related species, the reference strains of F. arthrosporioides did not form completely separated group (Fig. 4). They were nested within $F$. avenaceum strains. The previous studies with the combined IGS and $\beta$-tubulin sequences data could not distinguish $F$. avenaceum and $F$. arthrosporioides strains to form separate groups (Yli-Mattila et al., 2002). However, investigations based on the ATP Citrate Lyase (acl1) and TEF- $1 \alpha$ gene sequences were able to form a distinct lineage for $F$. arthrosporioides in the F. avenaceum main clade (Gräfenhan et al., 2013). 
Common weeds were assessed for the main toxin contents by HPLC-MS/MS. Lack of trichothecenes, zearalenone and fumonisin contamination in weed samples containing their producers, made the assumption that these fungi are not active for toxin production in wild host plants. We suppose that the production of toxins by some Fusarium strains may be affected by inappropriate environmental factors. Uhlig et al. (2007) demonstrated that field situations in Northern Europe are not favor for moniliformin production while enniatins are frequently detected in cereal grains. On the other hand, poor performance of Fusarium pathogens such as F. graminearum on weeds (Akinsanmi et al., 2007), may explain the lack of symptoms and mycotoxin production on these alternative hosts. In this study, DON and NIV were not detected in weed samples highly contaminated with $F$. equiseti. There are controversial reports regarding DON and NIV production by F. equiseti strains (Kosiak et al., 2005; Marín et al., 2012). Therefore, based on our knowledge of weeds, this question is still remained that whether $F$. equiseti strains harbored in weeds have potential contribution for rising of contamination risk of the DON and NIV in cereal grains.

Whereas, F. equiseti and F. avenaceum were found in $49 \%$ and $35 \%$ of all samples, respectively, beauvericin and enniatins content were also determined in weed samples. The results indicated that weeds were contaminated with beauvericin at the levels ranging from $65621 \mathrm{ng} \mathrm{g}^{-1}$ to $5 \mathrm{ng} \mathrm{g}^{-1}$ plant tissues. Beauvericin as a toxic contaminant has been reported from maize ears infected with Fusarium pathogen (Logrieco et al., 1993; Bottalico et al., 1995; Ritieni et al., 1997; Logrieco et al., 1995; Yli-Mattila, 2010). The values for enniatins contamination were in the range of $24236 \mathrm{ng} \mathrm{g}^{-1}$ to $5 \mathrm{ng} \mathrm{g}^{-1}$. Previous analytical surveys have indicated the contamination of cereal grains by enniatins resulting of $F$. avenaceum. Single weed samples showed extremely high level of toxins. There was no significant correlation between mycotoxin level and Fusarium DNA. High level of fungal DNA in some beauvericin/enniatin-free samples or beauvericin/enniatin-low samples revealed that some strains of fungal producers were not able to yield relevant toxins. On the other hand, high contamination of both toxins with low levels of fungal genomic DNA can be explained by the presence of other Fusarium species such as F. acuminatum, $F$. sambucinum, $F$. venenatum which are able to produce related toxins.

In summary, the present results demonstrat the frequent occurrence of Fusarium species in weed plants. Large number of recovered Fusarium spp. can support the role of weeds as 
symptomless hosts for Fusarim species. The possible importance of weeds in increasing of the pressure of primary inoculum in maize fields raises the risk of toxin contamination in cereal grains. Although the main toxins were not detected in weed samples, the significance of Fusarium strains, harbored in weeds, for mycotoxin production in primary host plants should not be disregarded. These findings indicate that weed management in maize fileds would aim to reduce Fusarium inoculum and assist in the control of Fusarium maize diseases.

\section{Acknowledgements}

We acknowledge Dr. Barbara Edler who kindy helped us during the preparation of weed plants for inoculation tests in the greenhouse.

\section{Authors' Contributions}

In this study, the weed samples were collected and identified by Prof. Dr. Bärbel Gerowitt and Dr. Horst-Henning Steinmann. The mycotoxin experiments were carried out by Dr. Katharina Döll. 


\section{Literature Cited}

- Abbas, H. K., and Boyette, C. D. 1992. Phytotoxicity of fumonisin B1 on weeds and crop species. Weed Technology 6:548-552.

- Abbas, H. K., Boyette, C. D., Hogland, F. E., and Vesonder, R. F. 1991. Bioherbicidal potential of Fusarium moniliforme and its phytotoxin. Weed Sci. 39:673-677.

- Adejumo, T. O., Hettwer, U., and Karlovsky, P. 2007a. Occurrence of Fusarium species and trichothecenes in Nigerian maize. Int. J. Food Microbiol. 116:350-357.

- Adejumo, T. O., Hettwer, U., and Karlovsky, P. 2007b. Survey of maize from south western Nigeria for zearalenone, fumonisin B1, alpha- and beta- zearalenols and enniatins produced by Fusarium species. Food Add. Contam. 24:993-1000.

- Akinsanmi, O. A., Chakraborty, S., Backhouse, D., and Simpfendorfer, S. 2007. Passage through alternative hosts changes the fitness of Fusarium graminearum and Fusarium pseudograminearum. Environ. Microbiol. 9:512-520.

- Altinok, H. H. 2013. Fusarium species isolated from common weeds in eggplant fields and symptomless hosts of Fusarium oxysporum f. sp. melongenae in Turkey. J. Phytopathol. 161:335-340.

- Bai, G. H., and Shaner, G. 1996. Variation in Fusarium graminearum and cultivar resistance to wheat scab. Plant Dis. 80:975-979.

- Baayen, R. P., O'Donnell, K., Bonants, P. J. M., Cigelnik, E., Kroon, L. P. N. M., Roebroeck, E. J. A., and Waalwijk, C. 2000. Gene genealogies and AFLP analyses in the Fusarium oxysporum complex identify monophyletic and nonmonophyletic formae speciales causing wilt and rot disease. Phytopathology 90:891-900.

- Balmas, V., Migheli, Q., Scherm, B., and Garau, P. 2010. Multilocus phylogenetics show high levels of endemic fusaria inhabiting Sardinian soils (Tyrrhenian Islands). Mycologia 102:803-812.

- Bottalico, A., Logrieco, A., Ritieni, A., Moretti, A., Randazzo, G., and Corda, P. 1995. Beauvericin and fumonisin B1 in preharvest Fusarium moniliforme maize ear rot in Sardinia. Food Addit. Contam. 12:599-607.

- Boyette, C. D., and Walker, H. L. 1985. Factors influencing biocontrol of Velvetleaf (Abutilon theopbrasti) and Prickly Sida (Sida spinosa) with Fusarium lateritium. Weed Sci. 33:209-211. 
- Brandfass, C., and Karlovsky, P. 2008. Upscaled CTAB-based DNA extraction and real-time PCR assays for Fusarium culmorum and $F$. graminearum DNA in plant material with reduced sampling error. Int. J. Mol. Sci. 9:2306-2321.

- Castanares, E., Stenglein, S. A., Dinolfo, M. I., and Moreno, M. V. 2011. Fusarium tricinctum associated with head blight on wheat in Argentina. Plant Dis. 95:496.

- Cerkauskas, R. F., Dhingra, O. D., Sinclair, J. B., and Asmus, G. 1983. Amaranthus spinosus, Leonotis nepetaefolia, and Leonurus sibiricus: New hosts of Phomopsis spp. in Brazil. Plant Dis. 67:821-824.

- Clark, C. A., and Watson, B. 1983. Susceptibility of weed species of Convolvulaceae to root-infecting pathogens of sweet potato. Plant Dis. 67:907-909.

- Cotten, T. K., and Munkvold, G. P. 1998. Survival of Fusarium moniliforme, $F$. proliferatum, and $F$. subglutinans in maize stalk residue. Phytopathology 88:550-555.

- Dill-Macky, R., and Jones, R. K. 2000. The effect of previous crop residues and tillage on fusarium head blight of wheat. Plant Dis. 84:71-76.

- Dorn, B., Forrer, H. R., Schürch, S., and Vogelgsang, S. 2009. Fusarium species complex on maize in Switzerland: occurrence, prevalence, impact and mycotoxins in commercial hybrids under natural infection. Eur. J. Plant Pathol. 125:51-61.

- Fandohan, P., Hell, K., Marasas, W. F. O., and Wingfield, M. J. 2003. Infection of maize by Fusarium species and contamination with fumonisin in Africa. Afr. J. Biotechnol. 2:570-579.

- Garrett, S. D. 1960. Inoculum potential. In Plant Pathology. An Advanced Treatise. Vol. 3 (ed. J. G. Horsfall \& A. E. Dismond), p. 23-56. Academic press: New York.

- Geiser, D. M., Jime'nez-Gasco, M. D. M., Kang, S., Makalowska, I., Veeraraghavan, N., Ward, T. J., Zhang, N., Kuldau, G. A., and O'Donnell, K. 2004. FUSARIUM-ID v. 1.0: A DNA sequence database for identifying Fusarium. Eur. J. Plant Pathol. 110:473-479.

- Glenn, A. E. 2007. Mycotoxigenic Fusarium species in animal feed. Anim. Feed Sci. Tech. 137:213-240.

- Gordon, W. L. 1959. The occurrence of Fusarium species in Canada. VI. Taxonomic and geographic distribution of Fusarium species on plants, insects and fungi. Can. J. Botany 37:257-290. 
- Gräfenhan, T., Patrick, S. K., Roscoe, M., Trelka, R., Gaba, D., Chan, J. M., McKendry, T., Clear, R. M., and Tittlemier, S. A. 2013. Fusarium damage in cereal grains from western Canada. Phylogenetic analysis of moniliformin-producing Fusarium species and their natural occurrence in mycotoxin-contaminated. J. Agric. Food Chem. 61:5425-5437.

- Harrow, S. A., Farrokhi-Nejad, R., Pitman, A. R., Scott, I. A. W., Bentley, A., Hide, C., and Cromey, M. G. 2010. Characterization of New Zealand Fusarium populations using a polyphasic approach differentiates the Fusarium avenaceum/ F. acuminatum/ F. tricinctum species complex in cereal and grassland systems. Fungal Biol. 114:293-311.

- Haware, M. P., and Nene, Y. L. 1982. Symptomless carriers of the chickpea wilt Fusarium. Plant Dis. 66:250-251.

- Helbig, J. B., and Carroll, A. B. 1984. Dicotyledonous weeds as a source of Fusarium oxysporum pathogenic on soybean. Plant Dis. 68:694-696.

- Hornunga, R. W., and Reeda, L. D. 1990. Estimation of average concentration in presence of nondetectable values. Applied Occupational and Environmental Hygiene 5:46-51.

- Hsuan, H. M., Salleh, B., and Zakaria, L. 2011. Molecular identification of Fusarium species in Gibberella fujikuroi species complex from rice, sugarcane and maize from Peninsular Malaysia. Int. J. Mol. Sci. 12:6722-6732.

- Inch, S., and Gilbert, J. 2003. The incidence of Fusarium species recovered from inflorescences of wild grasses in southern Manitoba. Can. J. Plant Pathol. 25:379-383.

- Jenkinson, P., and Parry, D. W. 1994. Isolation of Fusarium species from common broad-leaved weeds and their pathogenicity to winter wheat. Mycol. Res. 98:776-780.

- Kosiak, E. B., Holst-Jensen, A., Rundberget, T., González-Jaén, M. T., and Torp, M. 2005. Morphological, chemical and molecular differentiation of Fusarium equiseti isolated from Norwegian cereals. Int. J. Food Microbiol. 99:195-206.

- Kosiak, B., Torp, M., Skjerve, E., and Thrane, U. 2003. The prevalence and distribution of Fusarium species in Norwegian cereals: a survey. Acta Agr. Scand. (Section B- Soil and Plant Science) 53:168-176.

- Kristensen, R., Torp, M., Kosiak, B., and Holst-Jensen, A. 2005. Phylogeny and toxigenic potential is correlated in Fusarium species as revealed by partial translation elongation factor 1 alpha gene sequences. Mycol. Res. 109:173-186. 
- Leslie, J. F., and Summerell, B. A. 2006. The Fusarium Laboratory Manual. Blackwell Publishing. 388 pp.

- Logrieco, A., Mulè, G., Moretti, A., and Bottalico, A. 2002. Toxigenic Fusarium species and mycotoxins associated with maize ear rot in Europe. Eur. J. Plant Pathol. 108: 597-609.

- Logrieco, A., Moretti, A., Ritieni, A., Bottalico, A., and Corda, P. 1995. Occurrence and toxigenicity of Fusarium proliferatum from preharvest maize ear rot, and associated mycotoxins, in Italy. Plant Dis. 79:727-731.

- Logrieco, A., Moretti, A., Ritieni, A., Chelkowski, J., Altomare, C., Bottalico, A., and Randazzos, G. 1993. Natural occurrence of beauvericin in preharvest Fusarium subglutinans infected corn ears in Poland. J. Agric. Food. Chem. 41:2149-2152.

- Maiorano, A., Blandino, M., Reyneri. A., and Vanara, F. 2008. Effects of maize residues on the Fusarium spp. infection and deoxynivalenol (DON) contamination of wheat grain. Crop Protection 27:182-188.

- Marín, P., Moretti, A., Ritieni, A., Jurado, M., Vázquez, C., and González-Jaén, M. T. 2012. Phylogenetic analyses and toxigenic profiles of Fusarium equiseti and Fusarium acuminatum isolated from cereals from Southern Europe. Food Microbiol. 31:229-237.

- Minerdi, D. Moretti, M., Gilardi, G., Barberio, C., Gullino, M. L., and Garibaldi, A. 2008. Bacterial ectosymbionts and virulence silencing in a Fusarium oxysporum strain. Environ. Microbiol. 10: 1725-1741.

- Munkvold, G. P. 2003. Epidemiology of Fusarium diseases and their mycotoxins in maize ears. Eur. J. Plant Pathol. 109:705-713.

- Naef, A., and De'fago, G. 2006. Population structure of plant-pathogenic Fusarium species in overwintered stalk residues from Bt-transformed and non-transformed maize crops. Eur. J. Plant Pathol. 116:129-143.

- Nalim, F. A., Elmer, W. H., McGovern, R. J., and Geiser, D. M. 2009. Multilocus Phylogenetic diversity of Fusarium avenaceum pathogenic on Lisianthus. Phytopathology 99:462-468.

- Nelson, P. E., Toussoun, T. A., and Marasas, W. F. O. 1983. Fusarium species: An Illustrated Manual for Identification. Pennsylvania State University Press, University Park. 193 pp. 
- Niessen, L., Gräfenhan, T., and Vogel, R. F. 2012. ATP citrate lyase 1 (acll) gene-based loop-mediated amplification assay for the detection of the Fusarium tricinctum species complex in pure cultures and in cereal samples. Int. J. Food Microbiol. 158:171-185.

- Nirenberg, H. I. 1976. Untersuchungen über die morphologische und biologische Differenzierung in der Fusarium Sektion Liseola. Mitt. Biol. Bund. Land-Forst. (Berlin-1. Dahlem) 169:1-117.

- Nutz, S., Döll, K., and Karlovsky, P. 2011. Determination of the LOQ in real-time PCR by receiver operating characteristic curve analysis: application to qPCR assays for Fusarium verticillioides and $F$. proliferatum. Anal. Bioanal. Chem. 401:717-726.

- O'Donnell, K., Humber, R. A., Geiser, D. M., Kang, S., Park, B., Robert, V. A., Crous, P. W., Johnston, P. R., Aoki, T., Rooney, A. P., and Rehner, S. A. 2012. Phylogenetic diversity of insecticolous fusaria inferred from multilocus DNA sequence data and their molecular identification via FUSARIUM-ID and Fusarium MLST. Mycologia 104: 427-445.

- O'Donnell, K., Sutton, D. A., Rinaldi, M. G., Gueidan, C., Crous, P. W., and D. M. Geiser. 2009a. Novel multilocus sequence typing scheme reveals high genetic diversity of human pathogenic members of the Fusarium incarnatum- $F$. equiseti and F. chlamydosporum species complexes within the united states. J. Clin. Microbiol. 47:3851-3861.

- O'Donnell, K., Gueidan, C., Sink, S., Johnston, P. R., Crous, P. W., Glenn, A., Riley, R., Zitomer, N. C., Colyer, P., Waalwijk, C., van der Lee, T., Moretti, A., Kang, S., Kim, H. S., Geiser, D. M., Juba, J. H., Baayen, R. P., Cromey, M. G., Bithell, S., Sutton, D. A., Skovgaard, K., Ploetz, R., Kistler, H. C., Elliott, M., Davis, M., and Sarver, B. A. J. 2009b. A two-locus DNA sequence database for typing plant and human pathogens within the Fusarium oxysporum species complex. Fungal Genet. Biol. 46:936-948.

- O'Donnell, K., Ward, T. J., Aberra, D., Kistler, H. C., Aoki, T., Orwig, N., Kimura, M., Bjørnstad, A., and Klemsdal, S. S. 2008. Multilocus genotyping and molecular phylogenetics resolve a novel head blight pathogen within the Fusarium graminearum species complex from Ethiopia. Fungal Genet. Biol. 45:1514-1522.

- O'Donnell, K., Ward, T. J., Geiser, D. M., Kistler, H. C., and Aoki, T. 2004. Genealogical concordance between the mating type locus and seven other nuclear genes supports formal recognition of nine phylogenetically distinct species within the Fusarium graminearum clade. Fungal Genet. Biol. 41:600-623. 
- O'Donnell, K., Nirenberg, H. I., Aoki, T., and Cigelink, E. 2000. A multigene phylogeny of the Gibberella fujikuroi species complex: Detection of additional phylogenetically distinct species. Mycoscience 41:61-78.

- O'Donnell, K., Kistler, H. C., Cigelnik, E., and Ploetz, R. C. 1998. Multiple evolutionary origins of the fungus causing Panama disease of banana: Concordant evidence from nuclear and mitochondrial gene genealogies. Proceedings of the National Academy of Sciences of the United States of America 95:2044-2049.

- Parry, D. W., Jenkinson, P., and McLeod, L. 1995. Fusarium ear blight (scab) in small grain cereals- a review. Plant Pathol. 44:207-238.

- Pereyra, S. A., and Dill-Macky, R. 2008. Colonization of the residues of diverse plant species by Gibberella zeae and their contribution to fusarium head blight inoculum. Plant Dis. 92:800-807.

- Placinta, C. M., D'Mello, J. P. F., and Macdonald, A. M. C. 1999. A review of worldwide contamination of cereal grains and animal feed with Fusarium mycotoxins. Anim. Feed Sci. Technol. 78:21-37.

- Postic, J., Cosic, J., Vrandecic, K., Jurkovic, D., Saleh, A. A., and Leslie, J. F. 2012. Diversity of Fusarium species isolated from weeds and plant debris in Croatia. J. Phytopathol. 160:76-81.

- Ritieni, A., Moretti, A., Logrieco, A., Bottalico, A., Randazzo, G., Monti, S. M., Ferracane, R., and Fogliano, V. 1997. Occurrence of fusaproliferin, fumonisin B1, and beauvericin in maize from Italy. J. Agric. Food. Chem. 45:4011-4016.

- Roy, K. W. 1982. Cercospora kikuchii and other pigmented species: cultural and reproductive characteristics and pathogenicity to soybean. Can. J. Plant Pathol. 4: 226-232.

- Roy, K. W., Miller, W. A., and McLean, K. S. 1994. Survey of pathogenic genera on fungi on foliage of weeds in Mississippi. Can. J. Plant Pathol. 16:25-29.

- Schaafsma, A. W., Tamburic-Ilinic, L., Miller, J. D., and Hooker, D. C. 2001. Agronomic considerations for reducing deoxynivalenol in wheat grain. Can. J. Plant Pathol. 23: 279-285.

- Starkey, D. E., Ward, T. J., Aoki, T., Gale, L. R., Kistler, H. C., Geiser, D. M., Suga, H., To'th, B., Varga, J., and O'Donnell, K. 2007. Global molecular surveillance reveals 
novel fusarium head blight species and trichothecene toxin diversity. Fungal Genet. Biol. 44:1191-1204.

- Sutton, J. C. 1982. Epidemiology of wheat head blight and maize ear rot caused by Fusarium graminearum. Can. J. Plant Pathol. 4:195-209.

- Teich, A. H., and Nelson, k. 1984. Survey of fusarium head blight and possible effects of cultural practices in wheat fields in Lambton County in 1983. Can. Plant Dis. Surv. 64:11-13.

- Uhlig, S., Jestoi, M., and Parikka, P. 2007. Fusarium avenaceum-The North European situation. Int. J. Food Microbiol.119:17-24.

- Ward, T. J., Clear, R. M., Rooney, A. P., O'Donnell, K., Gaba, D., Patrick, S., Starkey, D. E., Gilbert, J., Geiser, D. M., and Nowicki, T. W. 2008. An adaptive evolutionary shift in fusarium head blight pathogen populations is driving the rapid spread of more toxigenic Fusarium graminearum in North America. Fungal Genet. Biol. 45:473-484.

- Westerman, P. R., and Gerowitt, B. 2012. Probability of maize biomass contamination with weed seeds. J. Plant Dis. Protect. 11:68-73.

- Yli-Mattila, T. 2010. Ecology and evolution of toxigenic Fusarium species in cereals in Northern Europe and Asia. J. Plant Pathol. 92:7-18.

- Yli-Mattila, T., Paavanen-Huhtala, S., Bulat, S. A., Alekhina, I. A., and Nirenberg, H. I. 2002. Molecular, morphological and phylogenetic analysis of the Fusarium avenaceum/ F. arthrosporioides/ F. tricinctum species complex- a polyphasic approach. Mycol. Res. 106:655-669. 
Supplemental Table 1. Discription of Fusarium accessions for TEF-1 $\alpha$ sequence used in this study

\begin{tabular}{|c|c|c|c|}
\hline Accession No. & Strain & Species & Reference \\
\hline JF496585 & H2RA.033 & F. acuminatum & Marín et al., 2012 \\
\hline JF740857 & NRRL52789 & F. acuminatum & O'Donnell et al., 2012 \\
\hline КС999531 & S4B-10-15 & F. acuminatum & Gräfenhan et al., 2013 \\
\hline JX397826 & BBA:67701 & F. arthrosporioides & Niessen et al., 2012 \\
\hline КС999488 & BBA:64134 & F. arthrosporioides & Gräfenhan et al., 2013 \\
\hline AJ543533 & VI01199 & F. avenaceum & Kristensen et al., 2005 \\
\hline FJ154734 & R-3053 & F. avenaceum & Nalim et al., 2009 \\
\hline КС999540 & S7A-10-15 & F. avenaceum & Gräfenhan et al., 2013 \\
\hline EF428733 & NRRL34698 & F. culmorum & Ward et al., 2008 \\
\hline GU250560 & NRRL46661 & F. culmorum & Balmas et al., 2010 \\
\hline \multirow[t]{11}{*}{ JF740860 } & NRRL52792 & F. culmorum & O'Donnell et al., 2012 \\
\hline & NRRL6548 & FIESC $^{a} 12-a^{b}$ & O'Donnell et al., 2009a \\
\hline & NRRL26921 & FIESC 12-a & O'Donnell et al., 2009a \\
\hline & NRRL31011 & FIESC $12-\mathrm{a}$ & O'Donnell et al., 2009a \\
\hline & NRRL34002 & FIESC $22-\mathrm{a}$ & O'Donnell et al., 2009a \\
\hline & NRRL34010 & FIESC $15-\mathrm{c}$ & O'Donnell et al., 2009a \\
\hline & NRRL34059 & FIESC $16-\mathrm{c}$ & O'Donnell et al., 2009a \\
\hline & NRRL36136 & FIESC $14-\mathrm{a}$ & O'Donnell et al., 2009a \\
\hline & NRRL36321 & FIESC $14-\mathrm{a}$ & O'Donnell et al., 2009a \\
\hline & NRRL36466 & FIESC $14-\mathrm{a}$ & O'Donnell et al., 2009a \\
\hline & NRRL45997 & FIESC 5-f & O'Donnell et al., 2009a \\
\hline AJ543574 & VI02440 & F. flocciferum & Kristensen et al., 2005 \\
\hline КС999484 & F-424 & F. flocciferum & Gräfenhan et al., 2013 \\
\hline КС999485 & F5-89 & $F$. flocciferum & Gräfenhan et al., 2013 \\
\hline AJ543579 & VI01020 & F. graminearum & Kristensen et al., 2005 \\
\hline AJ543591 & VI01177 & F. graminearum & Kristensen et al., 2005 \\
\hline AJ543595 & VI01182 & F. graminearum & Kristensen et al., 2005 \\
\hline FJ985267 & NRRL22534 & F. oxysporum f.sp. apii & O'Donnell et al., 2009b \\
\hline AF246846 & NRRL26993 & F. oxysporum f.sp. gladioli race lit & Baayen et al., 2000 \\
\hline AF246856 & NRRL28359 & F. oxysporum & Baayen et al., 2000 \\
\hline \multirow[t]{3}{*}{ AF246874 } & NRRL28918 & F. oxysporum f.sp. gladioli & Baayen et al., 2000 \\
\hline & NRRL36263 & F. oxysporum f.sp. gladioli & \\
\hline & NRRL36278 & F. oxysporum & \\
\hline \multirow[t]{2}{*}{ FJ985372 } & NRRL38296 & F. oxysporum f.sp. betae & O'Donnell et al., 2009b \\
\hline & NRRL40182 & F. oxysporum & \\
\hline KC808223 & NRRL62546 & $F$. proliferatum & O'Donnell et al., 2013, unpublished \\
\hline KC808226 & NRRL54994 & F. proliferatum & O'Donnell et al., 2013, unpublished \\
\hline AF160280 & NRRL22944 & F. proliferatum & O'Donnell et al., 2000 \\
\hline FJ740866 ${ }^{c}$ & NRRL52798 & F. solani & O'Donnell et al., 2012 \\
\hline AJ543607 & VI01184 & F. torulosum & Kristensen et al., 2005 \\
\hline AJ543615 & VI01424 & F. torulosum & Kristensen et al., 2005 \\
\hline AJ543616 & VI01194 & F. torulosum & Kristensen et al., 2005 \\
\hline HQ214681 & TTAz1a & F. tricinctum & Castanares et al., 2011 \\
\hline JX397872 & DAOM:235659 & F. tricinctum & Niessen et al., 2012 \\
\hline AJ543630 & VI01423 & F. tricinctum & Kristensen et al., 2005 \\
\hline AJ543631 & VI01412 & F. venenatum & Kristensen et al., 2005 \\
\hline AJ543634 & VI01176 & F. venenatum & Kristensen et al., 2005 \\
\hline AJ543635 & VI01179 & F. venenatum & Kristensen et al., 2005 \\
\hline
\end{tabular}

a. Fusarium incarnatum-equiseti species complex

${ }^{\text {b. }}$ English numeral identify species and small letters identify unique haplotypes within each species

c. Sequence of $F$. solani FJ740866 was used to root the phylogeny (Fig. 4) 
Supplemental Table 2. Species identity of 62 Fusarium isolates based on morphological characters and TEF-1 $\alpha$ sequences

\begin{tabular}{|c|c|c|c|c|c|c|c|c|}
\hline Isolate & $\begin{array}{c}\text { GenBank } \\
\text { accession } \\
\text { No. }\end{array}$ & Fusarium spp. & Host & $\begin{array}{l}\text { Location in } \\
\text { Germany }\end{array}$ & Year & $\begin{array}{l}\text { Accessions for the first three } \\
\text { matched hits in Fusarium-ID } \\
\text { database }\end{array}$ & Related Fusarium spp. & $\begin{array}{c}\text { Similarity } \\
(\%)^{\mathrm{a}}\end{array}$ \\
\hline \multirow[t]{2}{*}{ RD22 } & KJ652275 & F. avenaceum & Polygonum convolvulus & Koblentz & 2010 & NRRL31101 & F. avenaceum & 98.16 \\
\hline & & & & & & NRRL25472 & Fusarium sp cf. acuminatum & 97.23 \\
\hline \multirow{3}{*}{ RD32 } & & & & & & NRRL20682 & F. negundis & 95.14 \\
\hline & KJ652276 & F. avenaceum & Chenopodium album & Dummers-torf & 2010 & NRRL31101 & F. avenaceum & 99.23 \\
\hline & & & & & & NRRL25472 & Fusarium sp cf. acuminatum & 97.38 \\
\hline \multirow{3}{*}{ RD95 } & & & & & & NRRL20682 & F. negundis & 95.88 \\
\hline & KJ652277 & F. avenaceum & Chenopodium album & Niex & 2010 & NRRL31101 & $F$. avenaceum & 99.38 \\
\hline & & & & & & NRRL25472 & Fusarium sp cf. acuminatum & 97.53 \\
\hline \multirow{3}{*}{ RD98 } & & & & & & NRRL20682 & F. negundis & 95.72 \\
\hline & KJ652278 & F. avenaceum & Chenopodium album & Kremlin & 2010 & NRRL31101 & F. avenaceum & 99.07 \\
\hline & & & & & & NRRL25472 & Fusarium sp cf. acuminatum & 97.23 \\
\hline \multirow{3}{*}{ RD100 } & & & & & & NRRL20682 & F. negundis & 95.72 \\
\hline & KJ652269 & F. culmorum & Chenopodium album & Niex & 2010 & NRRL3288 & F. culmorum & 99.83 \\
\hline & & & & & & NRRL25475 & F. culmorum & 99.83 \\
\hline \multirow{4}{*}{ RD102 } & & & & & & NRRL25475 & F. culmorum & 99.83 \\
\hline & KJ652270 & F. culmorum & Polygonum convolvulus & Püggen & 2010 & NRRL3288 & F. culmorum & 99.83 \\
\hline & & & & & & NRRL25475 & F. culmorum & 99.83 \\
\hline & & & & & & NRRL25475 & F. culmorum & 99.83 \\
\hline \multirow[t]{3}{*}{ RD105 } & KJ652271 & F. culmorum & Polygonum convolvulus & Niex & 2010 & NRRL3288 & F. culmorum & 99.83 \\
\hline & & & & & & NRRL25475 & F. culmorum & 99.83 \\
\hline & & & & & & NRRL25475 & F. culmorum & 99.83 \\
\hline \multirow[t]{3}{*}{ RD12 } & KJ652292 & F. equiseti & Chenopodium album & Niex & 2010 & NRRL36466 & FIESC $^{b} 14-a^{c}$ & 99.84 \\
\hline & & & & & & NRRL36321 & FIESC $14-\mathrm{a}$ & 99.84 \\
\hline & & & & & & NRRL36136 & FIESC 14-a & 99.84 \\
\hline \multirow[t]{3}{*}{ RD13 } & KJ652293 & F. equiseti & Chenopodium album & Püggen & 2010 & NRRL36466 & FIESC 14-a & 99.84 \\
\hline & & & & & & NRRL36321 & FIESC 14-a & 99.84 \\
\hline & & & & & & NRRL36136 & FIESC 14-a & 99.84 \\
\hline \multirow[t]{3}{*}{ RD14 } & KJ652294 & F. equiseti & Chenopodium album & Püggen & 2010 & NRRL36466 & FIESC 14-a & 99.84 \\
\hline & & & & & & NRRL36321 & FIESC 14-a & 99.84 \\
\hline & & & & & & NRRL36136 & FIESC 14-a & 99.84 \\
\hline \multirow[t]{2}{*}{ RD34 } & KJ652295 & F. equiseti & Elymus repens & Göttingen & 2011 & NRRL36466 & FIESC 14-a & 99.53 \\
\hline & & & & & & NRRL36321 & FIESC 14-a & 99.53 \\
\hline
\end{tabular}


Supplemental Table 2: continued

\begin{tabular}{|c|c|c|c|c|c|c|c|c|}
\hline Isolate & $\begin{array}{l}\text { GenBank } \\
\text { accession } \\
\text { No. }\end{array}$ & Fusarium spp. & Host & $\begin{array}{l}\text { Location in } \\
\text { Germany }\end{array}$ & Year & $\begin{array}{l}\text { Accessions for the first three } \\
\text { matched hits in Fusarium-ID } \\
\text { database }\end{array}$ & Related Fusarium spp. & $\begin{array}{c}\text { Similarity } \\
(\%)^{\mathrm{a}}\end{array}$ \\
\hline \multirow{4}{*}{ RD35 } & \multirow{4}{*}{ KJ652296 } & \multirow{4}{*}{ F. equiseti } & \multirow{4}{*}{ Elymus repens } & \multirow{4}{*}{ Rusch-Raduhn } & \multirow{3}{*}{2010} & NRRL36136 & FIESC 14-a & 99.53 \\
\hline & & & & & & NRRL36466 & FIESC 14-a & 99.53 \\
\hline & & & & & & NRRL36321 & FIESC 14-a & 99.53 \\
\hline & & & & & & NRRL36136 & FIESC 14-a & 99.53 \\
\hline \multirow[t]{3}{*}{ RD39 } & \multirow[t]{3}{*}{ KJ652297 } & \multirow[t]{3}{*}{ F. equiseti } & \multirow[t]{3}{*}{ Chenopodium album } & \multirow[t]{3}{*}{ Dummers-torf } & \multirow[t]{3}{*}{2010} & NRRL36466 & FIESC 14-a & 99.84 \\
\hline & & & & & & NRRL36321 & FIESC 14-a & 99.84 \\
\hline & & & & & & NRRL36136 & FIESC $14-\mathrm{a}$ & 99.84 \\
\hline \multirow[t]{3}{*}{ RD40 } & \multirow[t]{3}{*}{ KJ652298 } & \multirow[t]{3}{*}{ F. equiseti } & \multirow[t]{3}{*}{ Amaranthus retroflexus } & \multirow[t]{3}{*}{ Göttingen } & \multirow[t]{3}{*}{2011} & NRRL36466 & FIESC 14-a & 99.68 \\
\hline & & & & & & NRRL36321 & FIESC 14-a & 99.68 \\
\hline & & & & & & NRRL36136 & FIESC $14-\mathrm{a}$ & 99.68 \\
\hline \multirow[t]{3}{*}{ RD41 } & \multirow[t]{3}{*}{ KJ652299 } & \multirow[t]{3}{*}{ F. equiseti } & \multirow[t]{3}{*}{ Polygonum convolvulus } & \multirow[t]{3}{*}{ Koblentz } & \multirow[t]{3}{*}{2010} & NRRL36466 & FIESC 14-a & 99.84 \\
\hline & & & & & & NRRL36321 & FIESC 14-a & 99.84 \\
\hline & & & & & & NRRL36136 & FIESC 14-a & 99.84 \\
\hline \multirow[t]{3}{*}{ RD42 } & \multirow[t]{3}{*}{ KJ652300 } & \multirow[t]{3}{*}{ F. equiseti } & Chenopodium album & Sallahn & 2010 & NRRL36466 & FIESC 14-a & 99.84 \\
\hline & & & & & & NRRL36321 & FIESC 14-a & 99.84 \\
\hline & & & & & & NRRL36136 & FIESC 14-a & 99.84 \\
\hline RD44 & KJ652301 & F. equiseti & Amaranthus retroflexus & Göttingen & 2011 & NRRL36466 & FIESC 14-a & 99.68 \\
\hline & & & & & & NRRL36321 & FIESC 14-a & 99.68 \\
\hline & & & & & & NRRL36136 & FIESC $14-\mathrm{a}$ & 99.68 \\
\hline RD45 & KJ652302 & F. equiseti & Chenopodium album & Sallahn & 2010 & NRRL36466 & FIESC 14-a & 99.84 \\
\hline & & & & & & NRRL36321 & FIESC 14-a & 99.84 \\
\hline & & & & & & NRRL36136 & FIESC 14-a & 99.84 \\
\hline RD48 & KJ652303 & Fusarium sp. & Echinochloa crus-galli & Püggen & 2010 & NRRL31011 & FIESC $12-\mathrm{a}$ & 99.84 \\
\hline & & & & & & NRRL26921 & FIESC $12-\mathrm{a}$ & 99.84 \\
\hline & & & & & & NRRL6548 & FIESC $12-\mathrm{a}$ & 99.84 \\
\hline RD49 & KJ652304 & F. equiseti & Echinochloa crus-galli & Püggen & 2010 & NRRL36466 & FIESC $14-\mathrm{a}$ & 99.84 \\
\hline & & & & & & NRRL36321 & FIESC 14-a & 99.84 \\
\hline & & & & & & NRRL36136 & FIESC 14-a & 99.84 \\
\hline RD63 & KJ652305 & F. equiseti & Polygonum convolvulus & Püggen & 2010 & NRRL36466 & FIESC 14-a & 99.68 \\
\hline & & & & & & NRRL36321 & FIESC 14-a & 99.68 \\
\hline & & & & & & NRRL36136 & FIESC $14-\mathrm{a}$ & 99.68 \\
\hline RD69 & KJ652306 & Fusarium sp. & Polygonum persicaria & Rusch-Raduhn & 2010 & NRRL31011 & FIESC $12-\mathrm{a}$ & 99.84 \\
\hline & & & & & & NRRL26921 & FIESC $12-\mathrm{a}$ & 99.84 \\
\hline & & & & & & NRRL6548 & FIESC $12-\mathrm{a}$ & 99.84 \\
\hline
\end{tabular}


Supplemental Table 2: continued

\begin{tabular}{|c|c|c|c|c|c|c|c|c|}
\hline Isolate & $\begin{array}{c}\text { GenBank } \\
\text { accession } \\
\text { No. }\end{array}$ & Fusarium spp. & Host & $\begin{array}{l}\text { Location in } \\
\text { Germany }\end{array}$ & Year & $\begin{array}{l}\text { Accessions for the first three } \\
\text { matched hits in Fusarium-ID } \\
\text { database }\end{array}$ & Related Fusarium spp. & $\begin{array}{c}\text { Similarity } \\
(\%)^{\mathrm{a}}\end{array}$ \\
\hline \multirow[t]{3}{*}{$\overline{R D 72}$} & KJ652307 & F. equiseti & Veronica $\mathrm{sp}$. & Niex & 2010 & NRRL36466 & FIESC 14-a & 99.06 \\
\hline & & & & & & NRRL36321 & FIESC 14-a & 99.06 \\
\hline & & & & & & NRRL36136 & FIESC 14-a & 99.06 \\
\hline \multirow[t]{3}{*}{ RD75 } & KJ652308 & F. equiseti & Veronica sp. & Niex & 2010 & NRRL36466 & FIESC 14-a & 99.84 \\
\hline & & & & & & NRRL36321 & FIESC 14-a & 99.84 \\
\hline & & & & & & NRRL36136 & FIESC 14-a & 99.84 \\
\hline \multirow[t]{3}{*}{ RD76 } & KJ652309 & Fusarium sp. & Veronica sp. & Sallahn & 2010 & NRRL45997 & FIESC 5-f & 99.68 \\
\hline & & & & & & NRRL45995 & FIESC 5-b & 99.37 \\
\hline & & & & & & NRRL34037 & FIESC 5-b & 99.37 \\
\hline \multirow[t]{3}{*}{ RD77 } & KJ652310 & F. equiseti & Veronica sp. & Sallahn & 2010 & NRRL36466 & FIESC 14-a & 99.84 \\
\hline & & & & & & NRRL36321 & FIESC $14-\mathrm{a}$ & 99.84 \\
\hline & & & & & & NRRL36136 & FIESC 14-a & 99.84 \\
\hline \multirow[t]{3}{*}{ RD78 } & KJ652311 & F. equiseti & Veronica sp. & Püggen & 2010 & NRRL36466 & FIESC 14-a & 99.84 \\
\hline & & & & & & NRRL36321 & FIESC 14-a & 99.84 \\
\hline & & & & & & NRRL36136 & FIESC 14-a & 99.84 \\
\hline \multirow[t]{3}{*}{ RD80 } & KJ652312 & F. equiseti & Polygonum convolvulus & Niex & 2010 & NRRL36466 & FIESC $14-\mathrm{a}$ & 99.21 \\
\hline & & & & & & NRRL36321 & FIESC 14-a & 99.21 \\
\hline & & & & & & NRRL36136 & FIESC $14-\mathrm{a}$ & 99.21 \\
\hline \multirow[t]{3}{*}{ RD86 } & KJ652313 & F. equiseti & Polygonum convolvulus & Püggen & 2010 & NRRL36466 & FIESC 14-a & 99.84 \\
\hline & & & & & & NRRL36321 & FIESC 14-a & 99.84 \\
\hline & & & & & & NRRL36136 & FIESC 14-a & 99.84 \\
\hline \multirow[t]{3}{*}{ RD92 } & KJ652267 & F. graminearum & Chenopodium album & Kremlin & 2010 & NRRL28336 & F. graminearum & 99.36 \\
\hline & & & & & & NRRL5883 & F. graminearum & 99.36 \\
\hline & & & & & & NRRL6394 & F. graminearum & 99.36 \\
\hline \multirow[t]{3}{*}{ RD99 } & KJ652268 & F. graminearum & Chenopodium album & Kremlin & 2010 & NRRL29105 & F. boothii & 99.68 \\
\hline & & & & & & NRRL26916 & F. boothii & 99.68 \\
\hline & & & & & & NRRL26916 & F. boothii & 99.68 \\
\hline \multirow[t]{3}{*}{ RD10 } & KJ652252 & F. oxysporum & Chenopodium album & Niex & 2010 & NRRL36263 & FOSC $^{\mathrm{d}} 94$ & 99.84 \\
\hline & & & & & & NRRL36227 & FOSC 94 & 99.84 \\
\hline & & & & & & NRRL28918 & F. oxysporum & 99.84 \\
\hline \multirow[t]{3}{*}{ RD11 } & KJ652253 & F. oxysporum & Chenopodium album & Sallahn & 2010 & NRRL36263 & FOSC 94 & 100 \\
\hline & & & & & & NRRL36227 & FOSC 94 & 100 \\
\hline & & & & & & NRRL28918 & F. oxysporum & 100 \\
\hline RD19 & KJ652254 & F. oxysporum & Chenopodium album & Dummers-torf & 2010 & NRRL38296 & F. oxysporum & 99.84 \\
\hline
\end{tabular}


Supplemental Table 2: continued

\begin{tabular}{|c|c|c|c|c|c|c|c|c|}
\hline Isolate & $\begin{array}{l}\text { GenBank } \\
\text { accession } \\
\text { No. }\end{array}$ & Fusarium spp. & Host & $\begin{array}{l}\text { Location in } \\
\text { Germany }\end{array}$ & Year & $\begin{array}{l}\text { Accessions for the first three } \\
\text { matched hits in Fusarium-ID } \\
\text { database }\end{array}$ & Related Fusarium spp. & $\begin{array}{c}\text { Similarity } \\
(\%)^{\mathrm{a}}\end{array}$ \\
\hline \multirow{5}{*}{ RD20 } & \multirow{5}{*}{ KJ652255 } & \multirow{5}{*}{ F. oxysporum } & \multirow{5}{*}{ Polygonum convolvulus } & \multirow{5}{*}{ Niex } & \multirow{5}{*}{2010} & NRRL38291 & FOSC 180 & 99.84 \\
\hline & & & & & & NRRL36408 & FOSC 164 & 99.84 \\
\hline & & & & & & NRRL36278 & FOSC 6 & 99.84 \\
\hline & & & & & & NRRL22534 & FOSC 6 & 99.84 \\
\hline & & & & & & NRRL38474 & FOSC 209 & 99.84 \\
\hline \multirow[t]{3}{*}{ RD36 } & \multirow{3}{*}{ KJ652256 } & \multirow[t]{3}{*}{ F. oxysporum } & \multirow[t]{2}{*}{ Chenopodium album } & \multirow[t]{2}{*}{ Göttingen } & \multirow[t]{2}{*}{2011} & NRRL38296 & F. oxysporum & 99.84 \\
\hline & & & & & & NRRL38291 & FOSC 180 & 99.84 \\
\hline & & & \multirow{4}{*}{ Stellaria media } & \multirow{3}{*}{ Kremlin } & \multirow{3}{*}{2010} & NRRL36408 & FOSC 164 & 99.84 \\
\hline \multirow[t]{3}{*}{ RD54 } & \multirow[t]{3}{*}{ KJ652257 } & \multirow[t]{3}{*}{ F. oxysporum } & & & & NRRL36278 & FOSC 6 & 99.84 \\
\hline & & & & & & NRRL22534 & FOSC 6 & 99.84 \\
\hline & & & & & & NRRL38474 & FOSC 209 & 99.84 \\
\hline \multirow[t]{3}{*}{ RD57 } & \multirow[t]{3}{*}{ KJ652258 } & \multirow[t]{3}{*}{ F. oxysporum } & \multirow{3}{*}{ Echinochloa crus-galli } & \multirow[t]{3}{*}{ Kremlin } & \multirow[t]{2}{*}{2010} & NRRL36278 & FOSC 6 & 99.84 \\
\hline & & & & & & NRRL22534 & FOSC 6 & 99.84 \\
\hline & & & & & & NRRL38474 & FOSC 209 & 99.84 \\
\hline \multirow[t]{3}{*}{ RD59 } & \multirow[t]{3}{*}{ KJ652259 } & \multirow[t]{3}{*}{ F. oxysporum } & Elymus repens & Niendorf & 2010 & NRRL36278 & FOSC 6 & 99.84 \\
\hline & & & & & & NRRL22534 & FOSC 6 & 99.84 \\
\hline & & & & & & NRRL38474 & FOSC 209 & 99.84 \\
\hline RD61 & KJ652260 & F. oxysporum & Echinochloa crus-galli & Sallahn & 2010 & NRRL36278 & FOSC 6 & 99.84 \\
\hline & & & & & & NRRL22534 & FOSC 6 & 99.84 \\
\hline & & & & & & NRRL38474 & FOSC 209 & 99.84 \\
\hline RD64 & KJ652261 & F. oxysporum & Echinochloa crus-galli & Dummers-torf & 2010 & NRRL40182 & FOSC 99 & 99.84 \\
\hline & & & & & & NRRL38476 & FOSC 160 & 99.84 \\
\hline & & & & & & NRRL36364 & FOSC 160 & 99.84 \\
\hline RD67 & KJ652262 & F. oxysporum & Polygonum convolvulus & Püggen & 2010 & NRRL36278 & FOSC 6 & 99.84 \\
\hline & & & & & & NRRL22534 & FOSC 6 & 99.84 \\
\hline & & & & & & NRRL38474 & FOSC 209 & 99.84 \\
\hline RD70 & KJ652263 & F. oxysporum & Polygonum persicaria & Rusch-Raduhn & 2010 & NRRL40182 & FOSC 99 & 99.69 \\
\hline & & & & & & NRRL38476 & FOSC 160 & 99.69 \\
\hline & & & & & & NRRL36364 & FOSC 160 & 99.69 \\
\hline RD79 & KJ652264 & F. oxysporum & Polygonum convolvulus & Püggen & 2010 & NRRL36263 & FOSC 94 & 99.84 \\
\hline & & & & & & NRRL36227 & FOSC 94 & 99.84 \\
\hline & & & & & & NRRL28918 & F. oxysporum & 99.84 \\
\hline RD82 & KJ652265 & F. oxysporum & Chenopodium album & Kremlin & 2010 & NRRL38296 & F. oxysporum & 99.84 \\
\hline & & & & & & NRRL38291 & FOSC 180 & 99.84 \\
\hline
\end{tabular}


Supplemental Table 2: continued

\begin{tabular}{|c|c|c|c|c|c|c|c|c|}
\hline Isolate & $\begin{array}{l}\text { GenBank } \\
\text { accession } \\
\text { No. }\end{array}$ & Fusarium spp. & Host & $\begin{array}{c}\text { Location in } \\
\text { Germany }\end{array}$ & Year & $\begin{array}{l}\text { Accessions for the first three } \\
\text { matched hits in Fusarium-ID } \\
\text { database }\end{array}$ & Related Fusarium spp. & $\begin{array}{c}\text { Similarity } \\
(\%)^{\mathrm{a}}\end{array}$ \\
\hline & & & & & & NRRL36408 & FOSC 164 & 99.84 \\
\hline \multirow[t]{3}{*}{ RD94 } & KJ652266 & F. proliferatum & Polygonum convolvulus & Püggen & 2010 & Zm16 (CSIRO Entomology) & F. proliferatum & 99.84 \\
\hline & & & & & & Zm62 (CSIRO Entomology) & F. proliferatum & 99.84 \\
\hline & & & & & & Zm54 (CSIRO Entomology) & F. proliferatum & 99.69 \\
\hline \multirow[t]{3}{*}{ RD30 } & KJ652272 & F. tricinctum & Amaranthus retroflexus & Göttingen & 2011 & NRRL25481 & Fusarium sp cf. tricinctum & 99.68 \\
\hline & & & & & & NRRL20682 & Fusarium negundis & 97.72 \\
\hline & & & & & & NRRL36147 & FTSC $^{\mathrm{e}} 2-\mathrm{a}$ & 97.65 \\
\hline \multirow[t]{3}{*}{ RD31 } & KJ652273 & F. tricinctum & Chenopodium album & Göttingen & 2011 & NRRL25481 & Fusarium sp cf. tricinctum & 99.68 \\
\hline & & & & & & NRRL20682 & Fusarium negundis & 97.70 \\
\hline & & & & & & NRRL36147 & FTSC 2-a & 97.65 \\
\hline \multirow[t]{3}{*}{ RD33 } & KJ652274 & F. tricinctum & Chenopodium album & Göttingen & 2011 & NRRL25481 & Fusarium sp cf. tricinctum & 99.52 \\
\hline & & & & & & NRRL20682 & Fusarium negundis & 95.56 \\
\hline & & & & & & NRRL36147 & FTSC 2-a & 97.50 \\
\hline \multirow[t]{3}{*}{ RD15 } & KJ652279 & F. venenatum & Amaranthus retroflexus & Dummers-torf & 2010 & NRRL22196 & F. venenatum & 98.86 \\
\hline & & & & & & NRRL13394 & Fusarium sp cf. tumidum & 93.79 \\
\hline & & & & & & NRRL13392 & Fusarium sp cf. robustum & 92.38 \\
\hline \multirow[t]{3}{*}{ RD16 } & KJ652280 & $F$. venenatum & Echinochloa crus-galli & Sallahn & 2010 & NRRL22196 & F. venenatum & 99.83 \\
\hline & & & & & & NRRL13394 & Fusarium sp cf. tumidum & 93.09 \\
\hline & & & & & & NRRL13392 & Fusarium sp cf. robustum & 92.89 \\
\hline \multirow[t]{3}{*}{ RD17 } & KJ652281 & F. venenatum & Echinochloa crus-galli & Püggen & 2010 & NRRL22196 & F. venenatum & 99.83 \\
\hline & & & & & & NRRL13394 & Fusarium sp cf. tumidum & 93.09 \\
\hline & & & & & & NRRL13392 & Fusarium sp cf. robustum & 92.89 \\
\hline \multirow[t]{3}{*}{ RD18 } & KJ652282 & $F$. venenatum & Amaranthus retroflexus & Göttingen & 2011 & NRRL22196 & F. venenatum & 100 \\
\hline & & & & & & NRRL13394 & Fusarium sp cf. tumidum & 93.23 \\
\hline & & & & & & NRRL13392 & Fusarium sp cf. robustum & 93.05 \\
\hline \multirow[t]{3}{*}{ RD23 } & KJ652283 & F. venenatum & Amaranthus retroflexus & Niex & 2010 & NRRL22196 & F. venenatum & 100 \\
\hline & & & & & & NRRL13394 & Fusarium sp cf. tumidum & 93.28 \\
\hline & & & & & & NRRL13392 & Fusarium sp cf. robustum & 93.06 \\
\hline \multirow[t]{3}{*}{ RD24 } & KJ652284 & F. venenatum & Chenopodium album & Kremlin & 2010 & NRRL22196 & F. venenatum & 99.83 \\
\hline & & & & & & NRRL13394 & Fusarium sp cf. tumidum & 93.12 \\
\hline & & & & & & NRRL13392 & Fusarium sp cf. robustum & 92.89 \\
\hline \multirow[t]{3}{*}{ RD26 } & KJ652285 & F. venenatum & Agropyron repens & Rusch-Raduhn & 2010 & NRRL22196 & F. venenatum & 99.83 \\
\hline & & & & & & NRRL13394 & Fusarium sp cf. tumidum & 93.12 \\
\hline & & & & & & NRRL13392 & Fusarium sp cf. robustum & 92.89 \\
\hline
\end{tabular}


Supplemental Table 2: continued

\begin{tabular}{|c|c|c|c|c|c|c|c|c|}
\hline Isolate & $\begin{array}{c}\text { GenBank } \\
\text { accession } \\
\text { No. } \\
\end{array}$ & Fusarium spp. & Host & $\begin{array}{c}\text { Location in } \\
\text { Germany }\end{array}$ & Year & $\begin{array}{l}\text { Accessions for the first three } \\
\text { matched hits in Fusarium-ID } \\
\text { database }\end{array}$ & Related Fusarium spp. & $\begin{array}{c}\text { Similarity } \\
(\%)^{\mathrm{a}}\end{array}$ \\
\hline \multirow[t]{3}{*}{ RD27 } & KJ652286 & F. venenatum & Chenopodium album & Dummers-torf & 2010 & NRRL22196 & F. venenatum & 100 \\
\hline & & & & & & NRRL13394 & Fusarium sp cf. tumidum & 93.24 \\
\hline & & & & & & NRRL13392 & Fusarium sp cf. robustum & 93.05 \\
\hline \multirow[t]{3}{*}{ RD37 } & KJ652287 & F. venenatum & Amaranthus retroflexus & Niex & 2010 & NRRL22196 & $F$. venenatum & 98.87 \\
\hline & & & & & & NRRL13392 & Fusarium sp cf. robustum & 92.43 \\
\hline & & & & & & NRRL13394 & Fusarium sp cf. tumidum & 92.62 \\
\hline \multirow[t]{3}{*}{ RD38 } & KJ652288 & F. venenatum & Amaranthus retroflexus & Niex & 2010 & NRRL22196 & F. venenatum & 98.87 \\
\hline & & & & & & NRRL13392 & Fusarium sp cf. robustum & 92.44 \\
\hline & & & & & & NRRL13394 & Fusarium sp cf. tumidum & 92.64 \\
\hline \multirow[t]{3}{*}{ RD50 } & KJ652289 & F. venenatum & Echinochloa crus-galli & Göttingen & 2011 & NRRL22196 & $F$. venenatum & 99.83 \\
\hline & & & & & & NRRL13394 & Fusarium sp cf. tumidum & 93.11 \\
\hline & & & & & & NRRL13392 & Fusarium sp cf. robustum & 92.89 \\
\hline \multirow[t]{3}{*}{ RD53 } & KJ652290 & F. venenatum & Chenopodium album & Püggen & 2010 & NRRL22196 & F. venenatum & 99.19 \\
\hline & & & & & & NRRL13394 & Fusarium sp cf. tumidum & 93.00 \\
\hline & & & & & & NRRL13392 & Fusarium sp cf. robustum & 92.91 \\
\hline \multirow[t]{3}{*}{ RD90 } & KJ652291 & F. venenatum & Chenopodium album & Püggen & 2010 & NRRL22196 & F. venenatum & 99.83 \\
\hline & & & & & & NRRL13394 & Fusarium sp cf. tumidum & 93.11 \\
\hline & & & & & & NRRL13392 & Fusarium sp cf. robustum & 92.89 \\
\hline
\end{tabular}

a. Nucleotide sequences of the gene encoding TEF-1 $\alpha$ was compared with homologous sequences retrieved from Fusarium-ID database

b. Fusarium incarnatum-equiseti species complex

c. English numeral identify species and small letters identify unique haplotypes within each species

d. Fusarium oxysporum species complex

e. Fusarium tricinctum species complex 


\title{
Chapter 4
}

\section{Aggressiveness of Fusarium verticillioides Strains Differing in Ability to Produce Fumonisin in Maize, Sorghum, Rice, and Beetroot Seedlings}

\author{
Raana Dastjerdi and Petr Karlovsky \\ Molecular Phytopathology and Mycotoxin Research, Georg-August-University Göttingen, Grisebachstrasse 6, \\ 37077 Göttingen, Germany \\ Corresponding author: P. Karlovsky; E-mail address: pkarlov@gwdg.de
}

\begin{abstract}
Two fumonisin-nonproducing strains of Fusarium verticillioides (fum 1-3 and fum 1-4) and their progenitors (FUM 1-1) were tested for aggressiveness toward different plant species including maize, sorghum, rice and beetroot seedlings grown under greenhouse conditions. None of the plants showed obvious disease symptoms following root inoculation. The quantity of species-specific fungal biomass was measured by real-time PCR. No significant $(P=0.05)$ differences in colonization of tissues were detected between each wild type and the relevant mutant. F. verticillioides was not detected in any of the non-inoculated control plants. The fungus could transfer from the roots to the first two internodes/leaves of maize, rice/beetroot, regardless of fumonisin production. The symptomless systemic transmission rate, however, was low for sorghum. This phenomenon could be explained by different host preferences of biological species of Gibberella fujikuroi. The results indicate that in our system, fumonisin production was not required as a virulence factor for $F$. verticillioides to colonize the maize, rice and beetroot tissues.
\end{abstract}

Additional keywords: maize, Fusarium verticillioides, fumonisins 


\section{Introduction}

Fumonisins are polyketide mycotoxins that contaminate commercial maize-based human foodstuffs and animal feeds worldwide. Although number species of Fusarium, including F. anthophilum, F. fujikuroi, F. nygamai, F. oxysporum and F. proliferatum produce fumonisins, one species of particular concern is F. verticillioides (Sacc.) Nirenberg (syn. F. moniliforme Scheld.), teleomorph Gibberella fujikuroi (syn. G. moniliformis Wineland) (Munkvold \& Desjardins, 1997). This fungus is a common ear rot pathogen of maize (Zea mays) and can also infect maize stalks and roots without any visible symptoms of disease (Nelson et al., 1993; Munkvold \& Desjardins, 1997). Latent infections of maize stalk for extended periods of time have been demonstrated (Munkvold et al., 1997). F. verticillioides reduces yield and quality of contaminated kernels and also produces mycotoxins such as fumonisins. Since the discovery of fumonisins (Bezuidenhout et al., 1988), these toxins have been studied due to the presence of sphingolipid metabolism at the cellular level (Wang et al., 1991) and subsequently the impairment of animal health (Nelson et al., 1993). Fumonisin-contaminated maize causes various animal mycotoxicoses including leucoencephalomalacia in horses, pulmonary edema and hepatic syndrome in pigs, poor performance in poultry, liver cancer in rats and alteration in hepatic and immune function in cattle (reviewed in Logrieco et al., 2002). Studies have also indicated an epidemiological correlation between human esophageal cancer and consumption of fumonisincontaminated maize (Marasas, 1995). In plants, toxicity of fumonisins is associated with inhibition of Acyl CoA-dependent ceramide synthase (Williams et al., 2006). More than 10 fumonisins have been characterized, of which fumonisin B1 (FB1) is the most abundant in naturally contaminated maize. Other B-series fumonisin homologues including FB2, FB3 and FB4 make up 10-20\% of the total fumonisins in infected maize (Nelson et al., 1993). The fumonisin biosynthetic (FUM) gene cluster includes 16 genes (Brown et al., 2007). According genetic studies, four closely linked loci, fum1, fum2, fum3 and fum4 have been identified as being responsible in fumonisin biosynthesis (Desjardins et al., 1992, 1996). The lack of the correct gene at the fuml locus blocks fumonisin production, while strains defective at fum2 produce FB2, but not FB1 or FB3. Similarly, changes at fum3 could stop FB1 and FB2, but not FB3 (Desjardins et al., 1992, 1996). 
There is growing evidence of the occurrence of FB1 in maize all over the world, including Europe (reviewed in Logrieco et al., 2002). In southern European countries such as Italy, F. verticillioides is the most frequently isolated fungus from infected maize and high levels of FB1 have been reported (reviewed in Logrieco et al., 2002). F. proliferatum as another source of FB1 production has been found with $F$. verticillioides in southern Europe (Logrieco et al., 1995; Bottalico et al., 1995). In contrast, the levels of FB1 in central and north-eastern European areas such as Germany had been significantly lower (Usleber et al., 1994). Furthermore, F. verticillioides is well-known pathogen on a variety of plants such as wheat, barley, soybean (Castella et al., 1999), sorghum (da Silva et al., 2000; dos Reis et al., 2010), rice (Bhargava et al., 1979; Cartwright et al., 1995; Kushiro et al., 2008; Maheshwar et al., 2009; Tansakul et al., 2012) and banana (Glenn et al., 2008).

Toxicity of fumonisins to plants and animals has been clearly demonstrated (Lamprecht et al., 1994), but there are controversial reports regarding the potential function of fumonisins in virulence on maize. Some indirect evidence indicates that fumonisins may play a role in maize seedling diseases caused by $F$. verticillioides. Fumonisins have similar structure to AAL toxins, which are responsible for pathogenicity of Alternaria alternata on tomato cultivars (Gilchrist, 1998). AAL toxin-nonproducing strains were not able to provide leaf necrosis on susceptible tomato cultivars (Akamatsu et al., 1997). Other studies have been shown decreasing shoot and root length as well as leaf necrosis symptoms of maize and tomato seedlings while exposed to low concentrations of purified fumonisins (Gilchrist et al., 1992; Lamprecht et al., 1994). Although Desjardins et al. (1995) reported the importance of fumonisin production in virulence on maize seedlings; they mentioned that fumonisin production is not necessary or sufficient to cause maize blight disease. On the other hand, the greenhouse results of Jardine \& Leslie (1999) showed a fumonisin-nonproducing natural variant could infect the mature maize plants with the same aggressiveness as the fumonisin producing strain, and caused stalk rot. Fumonisin bioavailability to maize roots has been shown to cause a reduction in stalk weight and root mass and increased leaf lesions (Williams et al., 2006). These findings have supported the importance of fumonisins in plant pathogenesis. Recently, studies have shown that the expression of foliar maize diseases is associated with fumonisin production, and this toxin can contribute to all aspects of $F$. verticillioides maize seedling diseases (Williams et al., 2007; Glenn et al., 2008). 
In relation to maize ear rot, Desjardins \& Plattner (2000) employed three different natural FB1-nonproducing strains and compared them with fumonisin-producing (FB1, FB2, FB3) strains under field conditions. Both groups of the strains had the same capability to produce maize ear rot. The studies conducted with natural variants were improved by generating isogenic fumonisin non-producing mutants. Using these identical strains, which differ only in a fumonisin production gene, helped to demonstrate the importance of fumonisins as a virulence factor for F. verticillioides on maize (Desjardins et al., 2002). The results with two independent fumonisin non-producing (fuml-3 and fum1-4) mutants in field tests indicated that fumonisins are not necessary to cause maize ear infection by $F$. verticillioides (Desjardins et al., 2002).

On the basis of these observations, it has been proposed that the biological function of fumonisins regarding their possible role in maize ear rot is still not completely clear (Munkvold, 2003). Fumonisins may have no real function in virulence, which is a complex physiological process; however, it is possible to affect other host plants and enhance the pathogenicity (Proctor et al., 2002). This is what has been demonstrated for trichothecenes. These toxins are the virulence factor of Gibberella pulicaris (anamorph: F. sambucinum) and F. sporotrichioides on parsnip roots; but there is no known function for trichothecenes in the virulence on potato tubers (Desjardins et al., 1993). On the other hand, fumonisins could be responsible for other aspects of the ecology of $F$. verticillioides (Proctor et al., 2002).

In this study, we examined the biological function of fumonisins in the growth of F. verticillioides in maize and other possible hosts. We believed that maize silks/cobs may be a very special environment that only became available for $F$. verticillioides a couple of thousands years ago, which is too short to develop fumonisin biosynthesis. This means that fumonisin synthesis would be originated on hosts other than maize and in tissues other than silks/cobs. Therefore, we employed fumonisin-nonproducing strains as well as wild type strains to determine whether fumonisin production is a potential and general virulence factor for F. verticillioides on different plants such as sorghum, rice and beetroot as well as maize. Understanding the role of fumonisin in pathogenicity can help pathologists in finding a strategy to control cereal crop diseases and subsequently reduction of mycotoxin contamination. 


\section{Material and Methods}

\section{Fungal Strains and Inoculum Preparation}

Two mutants of $F$. verticillioides and their progenitor strains were obtained from Mycotoxin Research, National Center for Agricultural Utilization Research, United States Department of Agriculture-Agricultural Research Service (USDA-ARS), Peoria, USA. GFA2364 (Proctor et al., 1999) is a fumonisin non-producing mutant derived from virulent wild-type strain M-3125 (Proctor et al., 2002), which is representative for FB1, FB2, and FB3 producing strains. Another mutant used in this study was GFA2556, a fumonisin non-producing mutant (Desjardins et al., 2002) and its progenitor 109-R-7 (Desjardins et al., 1996) as a FB2-producing strain. Both M-3125 and 109-R-7 were designated as wild type FUM 1-1 alleles. This wild type functional allele was replaced with the mutant fum 1-3 allele to generate GFA2364. Mutant GFA2556 with mutant allele fum 1-4 was generated by gene disruption in 109-R-7.

Conidia from all four strains were produced for inoculum by growing the fungus on liquid mung bean media (Bai \& Shaner, 1996) at $25^{\circ} \mathrm{C}$ for 5-7 days. The cultures were filtered through sterile cheesecloth and centrifuged at $7300 \mathrm{~g}$ for $10 \mathrm{~min}$. The spores were re-dissolved in $15 \%$ (v/v) glycerol (Carl Roth, Karlsruhe, Germany) and the number of spores was counted with a Thoma Chamber $\left(0.0025 \mathrm{~mm}^{2}\right)$. The spore suspensions were stored at $-70^{\circ} \mathrm{C}$. Prior to inoculation, spores were checked for viability on PDA plates. The concentration of each conidial suspension was then determined and diluted to $1 \times 10^{6}$ spore $\mathrm{ml}^{-1}$ with sterile tap water. The inoculum contained $0.1 \%(\mathrm{v} / \mathrm{v})$ Tween ${ }^{\circledR} 20$ (Applichem, Darmstadt, Germany) as a surfactant. Spore suspensions were kept on ice during inoculation and homogenized well before using.

\section{Greenhouse Tests}

Mini maize cultivar 'Gaspe Flint landrace' (originally collected in Quebec, Canada, provided by Prof. Dr. J. Schirawski, Albrecht-von-Haller Institute for Plant Sciences, University of Göttingen, Germany), Rice genotype 'Taichung Sen 10 (TCS 10)' obtained from Africa Rice Center, Cotonou, Benin, Sorghum bicolor 'Tall Polish' cultivar (originating from Leibniz Institute of Plant Genetics and Crop Plant Research in Gatersleben, provided by Prof. Dr. J. Schirawski, Albrecht-von-Haller Institute for Plant Sciences, University of Göttingen, Germany), 
and Weiße Bete (Beetroot) cultivar 'Weißer Kegel' (Bio-Saatgut Gaby Krautkrämer, Armsheim) were used in this study. The seeds of beetroot, maize and sorghum were surface disinfected in $1 \%(\mathrm{v} / \mathrm{v})$ sodium hypochlorite $(\mathrm{NaClO})$ solution for $1 \mathrm{~min}$ and absence of Fusaium spp. propagules in or on the seeds was verified by plating a representative sample on potato dextrose agar (PDA) (Roth, Karlsruhe, Germany) prior to the greenhouse experiments. The seeds were then sown in plastic multi-pots containing sterile fine sand $(<2 \mathrm{~mm}$ granularity). Two to three seeds of each cultivar were planted per cavity and thinned to one plant when seedlings appeared. The multi-pots were maintained at $22^{\circ} \mathrm{C}$ and a relative humidity of $60 \%$ with alternating $12-\mathrm{h}$ light (mercury vapour lamps, 6600 lux at ear height) and dark periods. The rice seeds were placed on wet paper towel and incubated at $25^{\circ} \mathrm{C}$ at darkness. Germinated rice seeds were transferred to pots containing a mixture of sterile commercial plant substrate (Fruhstorfer Erde, Typ T25, HAWITA Group, Vechta, Germany), sand and compost (1: 1/2: 1) and placed at $30^{\circ} \mathrm{C}$ with $70-75 \%$ humidity. Two or three weeks after germination, all seedlings were inoculated with conidial spore suspension.

Root-dip inoculation method was employed by soaking the roots of individual plants in spore suspension for $30 \mathrm{~min}$. After inoculation, the seedlings were transferred to new pots $(9 \times 9$ $\times 9.5 \mathrm{~cm})$ with sterile mixed soil consisting of commercial plant substrate and sand (1:1). The plants were maintained under the same conditions as described above for each cultivar. Plants were irrigated with tap water as required. After one week of inoculation, the plants were supplemented (twice during the growth) with a 15-10-15 (N- P- K) soluble fertilizer. Rice seedlings were irrigated weekly with fertilizer containing N-P-K and Fe. Ten replicate pots were set up for each treatment. For rice, number of replications was ten with two plants per pot and the experiment was conducted two times. Control treatments were inoculated with autoclaved tap water mixed with adhesion detergent Tween ${ }^{\circledR} 20$. The plants were inspected at weekly intervals for symptoms. Seven to nine (for sorghum) weeks after inoculation, the plants were harvested and the roots were washed carefully under tap water. The sorghum, maize and rice plants were cut into three parts including roots, the first two or three internodes above the soil line and upper plant part and then placed separately in plastic bags. In the case of beetroot plants, they were divided into two parts: root and shoot. In order to quantify the fungal biomass in artificial 
inoculated plants and determine the function of fumonisins, the harvested plant materials were freeze dried and prepared for further experiments by real-time PCR (qPCR) assay.

\section{DNA Extraction and Determination of Matrix Effects}

Total genomic DNA was extracted by using 30-60 mg of fine powder plant material based on the CTAB method according Brandfass \& Karlovsky (2008). DNA quality and concentration was estimated by electrophoresis in $0.8 \%(\mathrm{w} / \mathrm{v})$ agarose gel (Cambrex, Rockland, ME, USA), prepared in TAE buffer (40 mM Tris, 1mM EDTA (ethylene diamine tetra acetic acid), $\mathrm{pH}$ set to 8.5) (both substances were obtained from Carl Roth, Karlsruhe, Germany). DNA was stained with ethidium bromide $\left(0.5 \mu \mathrm{g} \mathrm{ml}{ }^{-1}\right)$ (Applichem, Darmstadt, Germany) and visualized using a digital imaging system (VilberLourmat, Marne La Vallee, France).

For accurate quantification of fungal DNA in inoculated samples, DNA standards of F. verticillioides and DNA from plant samples should be amplified under identical conditions. Therefore, to perform the qPCR without matrix effects, the inhibitors were tested under a common technique. DNA from an uncontaminated sample of each plant cultivar was mixed in varying dilutions $(1: 25,1: 50,1: 100)$ with defined concentration of standard DNA, and amplification was then carried out by qPCR. In this way, we also run the uncontaminated DNA sample as well as DNA standard individually to be able to compare the results in different treatments. According to the threshold value $(\mathrm{Ct})$, the best dilution factor that could imitate matrix effects was chosen.

\section{Molecular Quantification of Fungal DNA}

A thermocycler $\left(\mathrm{CFX} 384^{\mathrm{TM}}\right.$ Real-Time System, C1000 ${ }^{\mathrm{TM}}$ Thermal Cycler, BioRad, USA) with 384-well microplates (Kisker Biotech GmbH, Steinfurt, Germany) was used for the qPCR analysis. F. verticillioides was assessed in inoculated samples based on a previously developed low-volume qPCR protocol (Dastjerdi et al., 2013, Chapter 2, unpublished). The Primer pairs VER 1 (CTTCCTGCGATGTTTCTCC) and VER 2 (AATTGGCCATTGGTATTATATATCTA) designed by Mule et al. (2004) were used to amplify a 578 bp fragment, specific for $F$. verticillioides. The reaction mixture consisted of reaction buffer $\left(16 \mathrm{mM}(\mathrm{NH} 4)_{2} \mathrm{SO}_{4} ; 67 \mathrm{mM}\right.$ Tris-HCl; $0.01 \%(\mathrm{v} / \mathrm{v})$ Tween-20, $\mathrm{pH} 8.8$ at $25^{\circ} \mathrm{C}$, 
Bioline, Lükenwalde, Germany), $0.1 \mathrm{mM}$ of each of the four deoxynucleoside triphosphates (dNTPs; Bioline, Lükenwalde, Germany), $2.5 \mathrm{mM} \mathrm{MgCl} 2,0.1 \mathrm{U}$ of $\mathrm{Taq}$ DNA polymerase (BIOTaq, Bioline, Lükenwalde, Germany), $0.3 \mu \mathrm{M}$ of each primer, 0.1x SYBR Green I (Invitrogen, Karlsruhe, Germany). The cycling conditions were as follows: 1 cycle of $2 \mathrm{~min}$ at $95^{\circ} \mathrm{C}, 34$ cycles of $30 \mathrm{~s}$ at $94^{\circ} \mathrm{C}$ (denaturalization), $30 \mathrm{~s}$ at $62.5^{\circ} \mathrm{C}$ (annealing), $40 \mathrm{~s}$ at $72^{\circ} \mathrm{C}$ (extension) and followed by a final extension cycle at $72^{\circ} \mathrm{C}$ for $5 \mathrm{~min}$. Fluorescent data were obtained during the annealing phase to construct a melting curve at the end of assay. The qPCR was completed by running a melting curve analysis. Quantity of fungal biomass was assessed as a parameter of fungal development.

\section{Data Processing and Statistical Analysis}

The software SigmaPlot 12.3 Notebook was used for statistical analysis. Non-parametric tests were performed when data distribution was not normal. The qPCR data were assessed to find the positive samples based on the melting temperature (Tm), starting quantity (SQ) and Ct value. The lowest DNA standard employed in qPCR assays was considered as the limit of quantification (LOQ). According to the qPCR data, the quantity of fungal biomass ( $\mathrm{pg} \mathrm{mg}^{-1}$ ) for the positive samples was calculated. DNA quantity for the samples containing values lower than LOQ was substituted as LOQ/2 (Hornunga \& Reeda, 1990). These samples had the right melting temperature and the logical $\mathrm{Ct}$ values.

\section{Results}

A common method was used to evaluate the influence of plant inhibitors on successful qPCR performance. The results indicated a significant effect for all plant extracts tested. The difference in $\mathrm{Ct}$ values between the standard reference DNA and the DNA from uncontaminated plant material was considered as an indicator to find the matrix effects. The results are presented in Table 1. High qPCR inhibition was seen in the root extracts; so that 100 dilution for maize and sorghum and 50 for beetroot samples were necessary to imitate matrix effects. Diluting to 1:25 $(\mathrm{v} / \mathrm{v})$ (for aboveground tissues of sorghum and beetroot) or 1:50 (v/v) (for aboveground maize parts) with double distilled water was preferred to reduce the $\mathrm{Ct}$ value to the same level as the standard-DNA. In the case of rice plant material, DNA dilution, even 100-fold, was insufficient for reduction of plant inhibitor effects. Adding $1 \mathrm{mg} \mathrm{ml}^{-1}$ bovine serum albumin (BSA) to the 
reaction mixture together with 1:50 dilution $(\mathrm{v} / \mathrm{v})$, could improve the qPCR amplification in DNA extracts of healthy plants mixed with standard-DNA and made the results comparable. Based on these results, all DNA samples were diluted with a suitable dilution factor and employed, then, for further real-time PCR assays.

Table 1. Determination of matrix effects in different plants studied

\begin{tabular}{llllll}
\hline \multirow{2}{*}{ Plant DNA sample } & \multicolumn{5}{c}{ Ct values derived from qPCR assay for : } \\
\cline { 2 - 6 } & Maize & Sorghum & Beetroot & Rice (without BSA) & Rice (with BSA) \\
\hline R (undiluted) & NA & NA & NA & NA & NA \\
R 1:25 & NA & NA & NA & NA & NA \\
R 1:50 & NA & NA & NA & NA & NA \\
R 1:100 & NA & NA & NA & NA & NA \\
LS (undiluted) & NA & NA & NA & NA & NA \\
LS 1:25 & NA & NA & NA & NA & NA \\
LS 1:50 & NA & NA & NA & NA & NA \\
LS 1:100 & NA & NA & NA & NA & NA \\
STD & 28.53 & 28.53 & 25.62 & 25.92 & 25.79 \\
STD + DNA R & NA & NA & NA & NA & 28.33 \\
STD + DNA R 1:25 & NA & NA & 27.93 & 28.80 & 26.80 \\
STD + DNA R 1:50 & 30.05 & 29.98 & $\mathbf{2 5 . 2 7}$ & 28.95 & $\mathbf{2 6 . 0 3}$ \\
STD + DNA R 1: 100 & $\mathbf{2 8 . 8 4}$ & $\mathbf{2 8 . 0 7}$ & 25.41 & 28.78 & 26.09 \\
STD + DNA LS & NA & 29.63 & 28.08 & 30.11 & 27.79 \\
STD + DNA LS 1:25 & 29.06 & $\mathbf{2 8 . 6 3}$ & $\mathbf{2 5 . 9 8}$ & 28.18 & 26.06 \\
STD + DNA LS 1:50 & $\mathbf{2 8 . 3 0}$ & 27.91 & 25.44 & 28.38 & $\mathbf{2 5 . 9 0}$ \\
STD + DNA LS 1:100 & 28.19 & 27.99 & --- & 28.12 & 26.08 \\
\hline
\end{tabular}

Bold letters are the $\mathrm{Ct}$ values related to the suitable dilution factor

Abbreviations: R: root; LS: leaf and stem (aboveground plant tissues); STD: standard DNA ( $p g \mu^{-1}$ ) which was 4.5 for maize, sorghum; 16.6 for beetroot and rice; BSA: bovine serum albumin; NA: not amplified

We compared the ability of two FUM 1-1 strains and the mutants derived from them (fum 1-3 and fum 1-4) to cause disease in maize, grain sorghum, beetroot and rice seedlings. None of the plants studied show any visible disease symptoms. Some necrosis spots were observed only on rice leaves, regardless of fumonisin or non-fumionisin production, which were not related to the fungus (Supplemental Fig. 1). F. verticillioides was not detected in any of these leaf samples. Lack of symptoms suggests that plant and fungus may coexist without obvious disease symptoms. Therefore, total fungal biomass was quantified by real-time PCR and it was used as an indicator of fungal aggressiveness. In all plants tested, no significant $(P=0.05)$ difference in aggressiveness was detected between each wild type and the relevant mutant. F. verticillioides was not detected in any of the control plants. The incidence of fungus for 10 
plant replicates of maize, sorghum, and beetroot also for 40 replicates of rice plants are presented in Fig. 1, 2, 4 and 3, respectively. Fungal transmission from roots to the first two internodes/leaves in maize and beetroot occurred following the root inoculation, but a low systemic infection rate was observed for the rice and sorghum cultivars. Lack of significant difference between fumonisin-producing strains and non-fumunisin producing strains in tissue colonization, therefore, supported the idea that fumonisin was not a virulent factor in our system.

\section{Discussion}

F. verticillioides is the most prevalent fungus associated with maize seedling diseases, ear rot and stalk rot (Logrieco et al., 2002; Srobarova et al., 2002). Fungus can colonize stalks without any visible disease symptoms (Kedera et al., 1992; Munkvold \& Carlton. 1997; Munkvold et al., 1997). The function of fumonisins, as the most widespread toxins reported from F. verticillioides strains, in virulence is still not completely identified. In this study, two fumonisin non-producing strains (fum 1-3 and fum 1-4) and their progenitors (fumonisinproducing) FUM 1-1 strains were employed to examine the possible role of toxin in the growth of the fungus in maize, grain sorghum, rice and beetroot seedlings. There was no relationship between fungal aggressiveness and fumonisin production in the plants studied.

Regarding the maize plants, movement of the fungus from the inoculated roots to the remainder of the plant parts occurred, regardless of whether the strain produced fumonisin or not. The rate of symptomless systemic colonization was lower above the second internodes in stalks. Munkvold et al. (1997) showed that restricted movement of fungus from maize seed or crown to higher internodes in stalk can limit systemic colonization of kernels. However, other studies provide evidence that systemic infection may contribute to the contamination of kernels by mycotoxins (Desjardins et al., 2002; Desjardins and Plattner, 2000). The possibility of systemic development of infection by $F$. verticillioides will be greater at higher temperatures (Williams \& Munkvold, 2008). There was no significant difference between fungal biomass of each wild type FUM 1-1 strain and the relevant mutant. Although high level of fungal biomass was observed in the first two stalk internodes, it was independent from fumonisin production. The GFA2364 and GFA2556 strains make relatively little, or no fumonisins in vitro (Desjardins et al., 2002), but in our experiments these two strains caused significant colonization of tissues at the same level of 

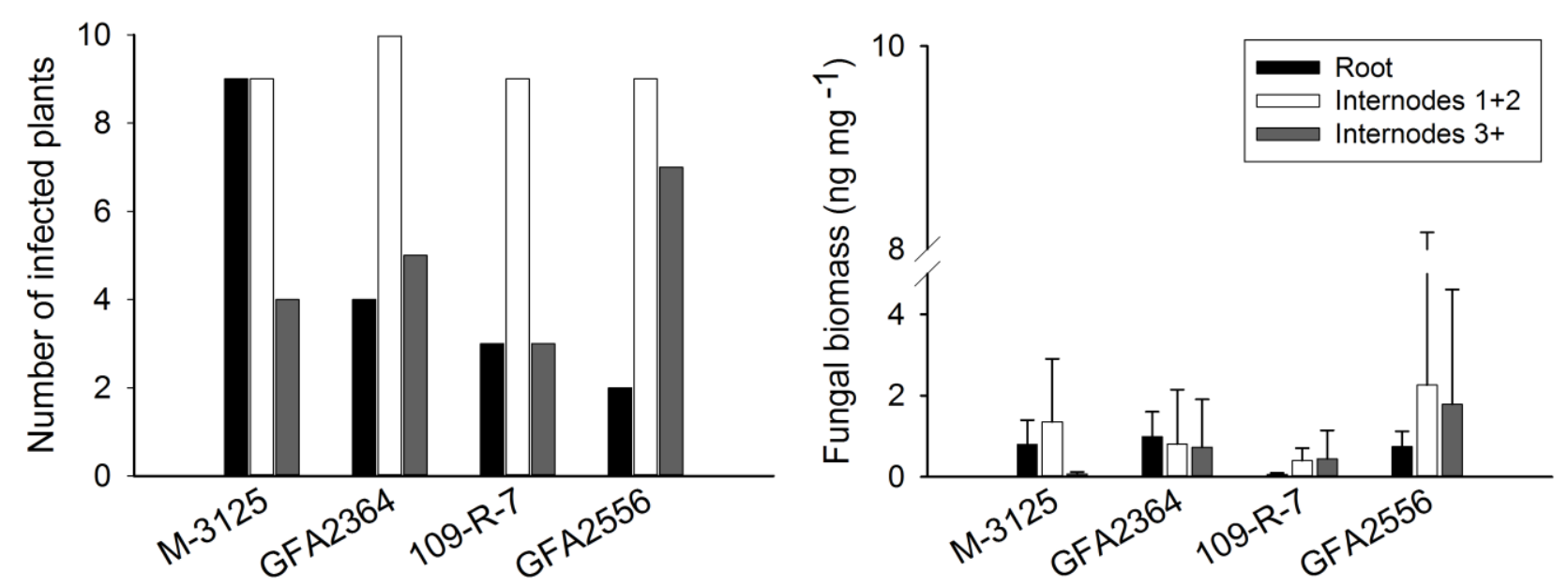

Fig. 1. Incidence of indicated strains of $F$. verticillioides on maize seedlings (left); mean amounts of fungal biomass in positive samples (right) inoculated in the greenhouse. Limit of quantification (LOQ) was set at $84.7 \mathrm{pg} \mathrm{mg}^{-1}$ for root samples and $50.8 \mathrm{pg} \mathrm{mg}^{-1}$ for upper parts of the plants. M-3125: FB1, FB2 \& FB3 producing; GFA2364: fumonisin non-producing; 109-R-7: FB2 producing; GFA2556: fumonisin non-producing.
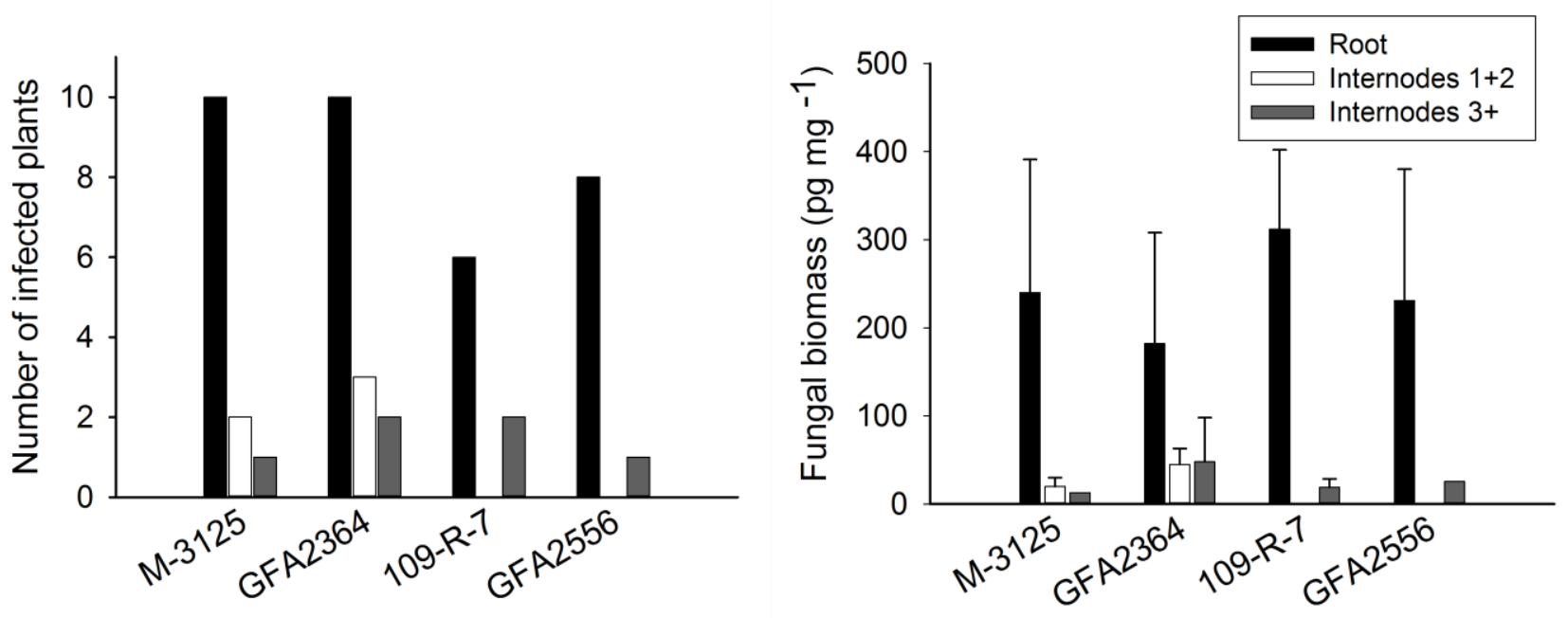

Fig. 2. Incidence of indicated strains of $F$. verticillioides on sorghum seedlings (left); mean amounts of fungal biomass in positive samples (right) inoculated in the greenhouse. Limit of quantification (LOQ) was set at $84.7 \mathrm{pg} \mathrm{mg}^{-1}$ for root samples and $25.4 \mathrm{pg} \mathrm{mg}^{-1}$ for upper parts of the plants. M-3125: FB1, FB2 \& FB3 producing; GFA2364: fumonisin non-producing; 109-R-7: FB2 producing; GFA2556: fumonisin non-producing. 

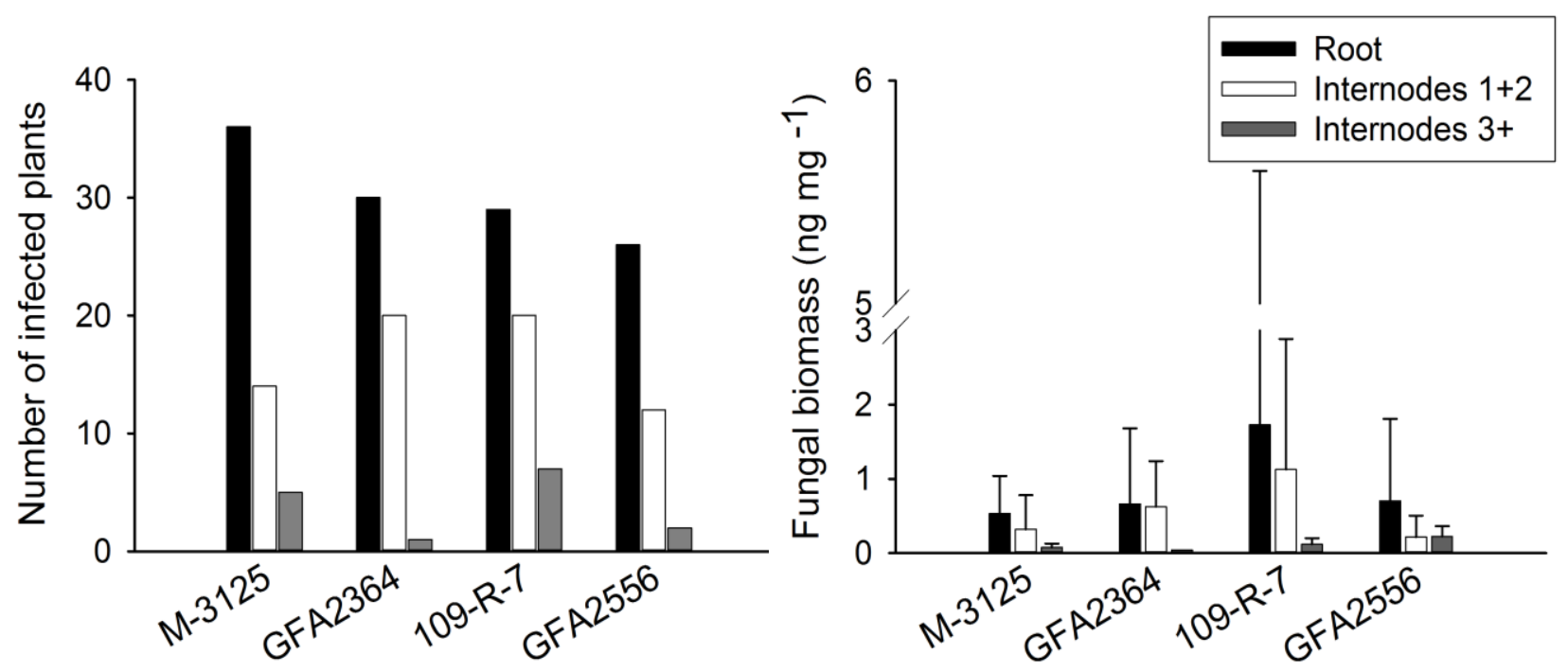

Fig. 3. Incidence of indicated strains of $F$. verticillioides on rice seedlings (left); mean amounts of fungal biomass in positive samples (right) inoculated in the greenhouse. Limit of quantification (LOQ) was set at $84.7 \mathrm{pg} \mathrm{mg}^{-1}$ for root samples and $42.3 \mathrm{pg} \mathrm{mg}^{-1}$ for upper parts of the plants. M-3125: FB1, FB2 \& FB3 producing; GFA2364: fumonisin non-producing; 109-R-7: FB2 producing; GFA2556: fumonisin non-producing.
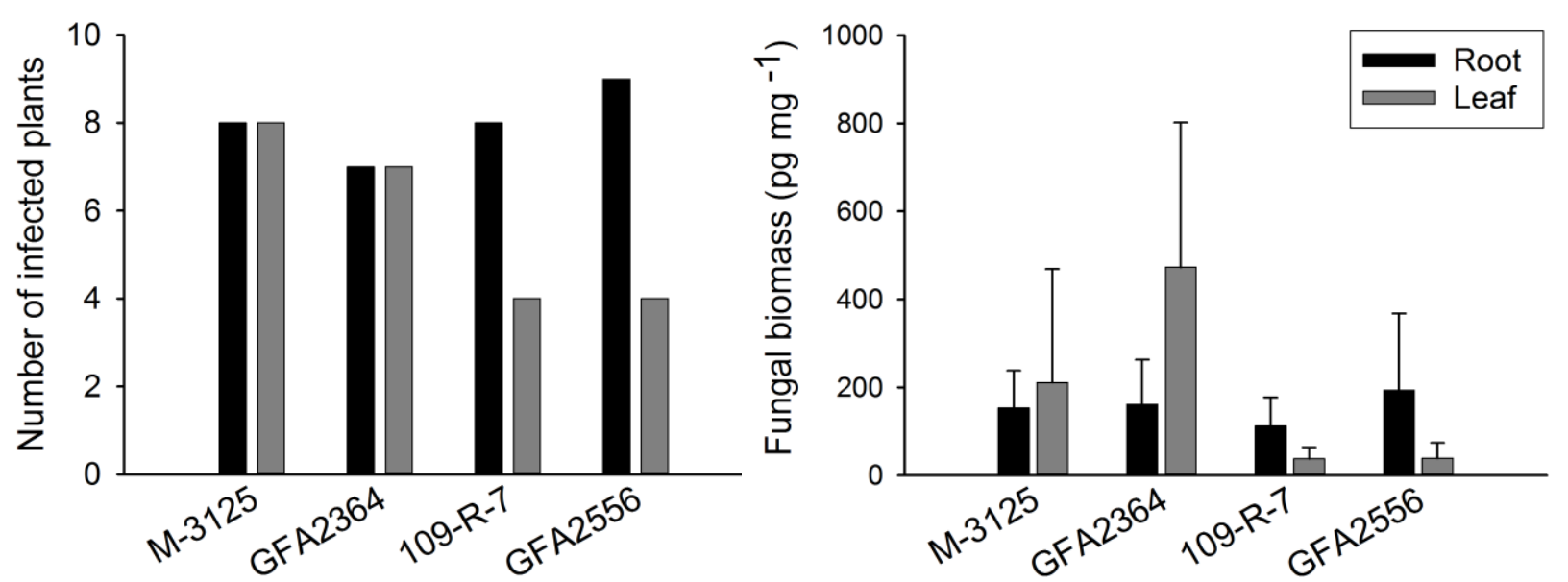

Fig. 4. Incidence of indicated strains of $F$. verticillioides on beetroot seedlings (left); mean amounts of fungal biomass in positive samples (right) inoculated in the greenhouse. Limit of quantification (LOQ) was set at $62.5 \mathrm{pg} \mathrm{mg}^{-1}$ for root samples and $31.3 \mathrm{pg} \mathrm{mg}^{-1}$ for leaf. M-3125: FB1, FB2 \& FB3 producing; GFA2364: fumonisin non-producing; 109-R-7: FB2 producing; GFA2556: fumonisin non-producing. 
fumonisin-producing strains. The results indicate that fumonisin production was not required for F. verticillioides to colonize the maize tissues following root inoculation.

In the case of sorghum, after root inoculation the fungus remained in the below ground tissues and fungal transmission did not occur. Only 20-30\% of the plants inoculated with the M-3125 strain and its mutant show the fungus in the first two internodes. This would be explained by host preference of biological species of G. fujikuroi in which mating population A (MPA) is predominant on maize while G. fujikuroi mating population F (MPF) can infect sorghum plants (Leslie et al., 1992). These differences may cause differences in the pathogenic potential of the strains (Leslie, 1991). The selection of suitable strains is, therefore, important in breeding programs (Jardine \& Leslie, 1999). It is also possible that the sorghum variety used in this study reacted to the fungus with a partial resistance response, whereby the pathogen was unable to spread through the plant. However, sorghum root colonization and lack of fungal movement to the upper parts of the plant suggest that $F$. verticillioides is able to survive in the roots of non-host plants when the main host is not available. This will clearly help to maintain fumonisin synthesis. We believe infection of maize silks or cobs may be a very special environment that only became available for the fungus a couple of thousands of years ago, which is a short time period to develop fumonisin biosynthesis. For millions of years previously, the fungus had infected roots or stems, living as endophyte. This means that fumonisin synthesis would be maintained by the selection pressure exerted on hosts other than maize and in tissues other than silks or cobs. The presence of fungus in upper internodes while it is absent in lower nodes (as was the case for two plants inoculated with 109-R-7 strain and one plant inoculated with GFA2556 strain) could be explained by spore splashing during the inoculation. Based on the data obtained from this work, it is not possible to make a conclusion with confidence regarding the function of fumonisin in pathogenicity on sorghum seedlings.

Although the fungus could have developed inside the young plants of rice and beetroot, the aggressiveness of wild type strains and their mutants to the rice or beetroot seedlings was not statistically different. Occurrence of fumonisins in rice plants has not been found as frequently as in maize, but more recently contamination of rice with FB1 and FB2 toxins has been reported (Kushiro et al., 2008; Maheshwar et al., 2009; Tansakul et al., 2012). The fungus has been demonstrated to causes panicle rot of rice (Bhargava et al., 1979). G. fujikuroi complex including 
MPA (anamorph, F. verticillioides), MPC (anamorph, F. fujikuroi) and MPD (anamorph, F. proliferatum) have been demonstrated in infected rice seeds (Desjardins et al., 2000). They show that some strains of G. fujikuroi MPD are capable of producing fumonisin as well as beauvericin and moniliformin; but not gibberellic acid, which has been reported in bakanae. The prevalence of MPD may be related to the role of this biological species in the complex symptoms of bakanae disease of rice (Desjardins et al., 2000). F. verticillioides causes seedling damping-off in sugar beet and has been reported as a pathogen which can produce symptoms similar to fusarium yellows (Hanson \& Hill, 2004; Drycott, 2006). In the present study, 15-20 days after inoculation some necrosis spots were observed on rice leaves. The spots were irregular, small, light brown in the center and dark brown at the margins in the initial stage. The necrotic lesions usually developed, joined together, made larger spots and extended along the length of the leaf. The spots were seen regardless of fumonisin or non-fumonisin producing strain tested. However, the qPCR assay could not detect the fungus in the leaf extracts. Control plants did not show any necrotic spots. Rice experiments were conducted twice (in summer 2012 and winter 2013) and the results were identical. Further assessments are, therefore, necessary to find the agent of these necrosis spots.

Potential plant inhibitors such as proteins, polyphenols, polysaccharides, secondary metabolites (Horne et al., 2004) are released during the DNA extraction process. These compounds in DNA extracts can affect the qPCR reactions. They prevent the amplification of target DNA, increase the $\mathrm{Ct}$ values or lead to reduction of overall efficiency and reproducibility of PCR and eventually may contribute to inaccurate results (Demeke \& Jenkins, 2010; Cankar et al., 2006). In this study, the effect of sample matrix properties on real-time PCR reactions was assessed for maize, sorghum, rice and beetroot tissues by adding standard reference DNA to the DNA of uncontaminated plant material. Initially experiments indicated a high potency of plant inhibitors, so that the qPCR assays were completely inhibited and no amplification was detected (Table 1). Dilution of DNA samples is a simple method to reduce the inhibitor concentration in plant extracts especially in samples involving complex matrices such as root extracts. On the other hand, for the samples with lower DNA concentration, a high DNA dilution factor may decrease PCR sensitivity (Demeke \& Jenkins, 2010). In this study, a dilution factor of 1:25 or 1:50 for the aboveground plant tissues and 1:100 for the root samples could decrease the PCR 
inhibition and the $\mathrm{Ct}$ values then reached to the same level of pure fungal DNA. In the case of rice plant tissues, although 100-fold dilution could generate PCR products, the Ct values were still far from the $\mathrm{Ct}$ expected for target molecules added to the reaction. More dilution was not possible due to decreasing qPCR sensitivity. BSA is a chemical which has been employed for deactivation of PCR inhibitors in various sample types and recently for plant materials as well (Wei et al., 2008; Plante et al., 2010). Adding this chemical directly into the PCR reactions was sufficient to enhance the qPCR results.

In this work, maize seedlings colonization with fumonisin non-producing strains and fumonisin-producing strains was similar. It is possible that such non-producing toxin strains can be used as biocontrol agents of maize fusarium diseases if they provide a substantial level of symptomless colonization in different maize plant tissues without causing any ear rot (Desjardins \& Plattner, 2000). In summary, the present results demonstrate that fumonisins may have a function in pathogenicity of $F$. verticillioides, but in our system, the ability to synthesize these toxins was not related to the fungal aggressiveness and fumonisins did not determine the pathogenicity of $F$. verticillioides pathogen.

\section{Acknowledgements}

We thank Prof. Dr. J. Schirawski (Albrecht-von-Haller Institute for Plant Sciences, University of Göttingen, Germany) for kindly providing the dwarf maize seeds and sorghum cultivar. We further thank Prof. Dr. R. H. Proctor (Mycotoxin Research, National Center for Agricultural Utilization Research, United States Department of Agriculture-Agricultural Research Service (USDA-ARS), Peoria, USA.) who kindly supplied the $F$. verticillioides strains. 


\section{Literature Cited}

- Akamatsu, H., Itoh, Y., Kodama, M., Otani, H., and Kohmoto, K. 1997. AAL-toxin-deficient mutants of Alternaria alternata tomatoa pathotype by restriction enzyme-mediated integration. Phytopathology 87:967-972.

- Bai, G. H., and Shaner, G. 1996. Variation in Fusarium graminearum and Cultivar Resistance to Wheat Scab. Plant Dis. 80:975-979.

- Bezuidenhout, S. C., Gelderblom, W. C. A., Gorst-Allman, C. P., Horak, R. M., Marasas, W. F. O., Spiteller, G., and Vleggaar, R. 1988. Structure elucidation of the fumonisins, mycotoxins from Fusarium moniliforme. J. Chem. Soc. Chem. Commun. 11:743-745.

- Bhargava, S. N., Shukla, D. N., Singh, N. K., and Singh, N. 1979. Fusarium moniliforme causing panicle rot of rice. Indian Phytopathology 31:367-369.

- Bottalico, A., Logrieco, A., Ritieni, A., Moretti, A., Randazzo, G., and Corda, P. 1995. Beauvericin and fumonisin B1 in preharvest Fusarium moniliforme maize ear rot in Sardinia. Food Addit. Contam. 12:599-607.

- Brown, D. W., Butchko, R. A. E., Busman, M., and Proctor, R. H. 2007. The Fusarium verticillioides FUM gene cluster encodes a $\mathrm{Zn}(\mathrm{II}) 2 \mathrm{Cys} 6$ protein that affect FUM gene expression and fumonisin production. Eukaryotic Cell 6:1210-1218.

- Cankar, K., Stebih, D., Dreo, T., Zel, J., and Gruden, K. 2006. Critical points of DNA quantification by real-time PCR effects of DNA extraction method and sample matrix on quantification of genetically modified organisms. BMC. Biotech. 6:37-51.

- Cartwright, R. D., Correll, J. C., and Crippen, D. L. 1995. Fusarium sheath rot of rice in Arkansas. (Abstr.) Phytopathology 85:1199.

- Castellá, G., Bragulat, M. R., and Cabañes, F. J. 1999. Surveillance of fumonisins in maize-based feeds and cereals from Spain. J. Agric. Food Chem. 47:4707-4710.

- da Silva, J. B., Pozzi, C. R., Mallozzi, M. A., Ortega, E. M., and Corrêa, B. 2000. Mycoflora and occurrence of aflatoxin B1 and fumonisin B1 during storage of Brazilian sorghum. J. Agric. Food Chem. 48:4352-4356.

- Demeke, T., and Jenkins, G. R. 2010. Influence of DNA extraction methods, PCR inhibitors and quantification methods on real-time PCR assay of biotechnology-derived traits. Anal. Bioanal. Chem. 396:1977-1990. 
- Desjardins, A. E., Munkvold, G. P., Plattner, R. D., and Proctor, R. H. 2002. FUM1- A gene required for fumonisin biosynthesis but not for maize ear rot and ear infection by Gibberella moniliformis in field tests. Mol. Plant-Microbe Interact. 15:1157-1164.

- Desjardins, A. E., Manandhar, H. K., Plattner, R. D., Manandhar, G. G., Poling, S. M., and Maragos, C. M. 2000. Fusarium species from Nepalese rice and production of mycotoxins and gibberellic acid by selected species. Appl. Environ. Microb. 66: 1020-1025.

- Desjardins, A. E., and Plattner, R. D. 2000. Fumonisin B1-nonproducing strains of Fusarium verticillioides cause maize (Zea mays) ear infection and ear rot. J. Agric. Food Chem. 48:5773-5780.

- Desjardins, A. E., Plattner, R. D., and Proctor, R. H. 1996. Linkage among genes responsible for fumonisin biosynthesis in Gibberella fujikuroi mating population A. Appl. Environ. Microb. 62:2571-2576.

- Desjardins, A. N., Plattner, R. D., Nelsen, T. C., and Leslie, J. F. 1995. Genetic analysis of fumonisin production and virulence of Gibberella fujikuroi mating population A (Fusarium moniliforme) on maize (Zea mays) seedlings. Appl. Environ. Microb. 61: 79-86.

- Desjardins, A. E., Hohn, T. M., and McCormick, S. P. 1993. Trichothecene biosynthesis in Fusarium species: chemistry, genetics, and significance. Microbiological Reviews 57:595-604.

- Desjardins, A. E., Plattner, R. D., Shackelford, D. D., Leslie, J. F., and Nelson, P. E. 1992. Heritability of fumonisin B1 production in Gibberella fujikuroi mating population A. Appl. Environ. Microb. 58:2799-2805.

- dos Reis, T. A., Zorzete, P., Pozzi, C. R., da Silva, V. N., Ortega, E., and Corr^ea, B. 2010. Mycoflora and fumonisin contamination in Brazilian sorghum from sowing to harvest. J. Sci. Food Agric. 90:1445-1451.

- Gilchrist, D. G. 1998. Programmed cell death in plant disease: the purpose and promise of cellular suicide. Annu. Rev. Phytopathol. 36:393-414.

- Gilchrist, D. G., Ward, B., Moussato, V., and Mirocha, C. J. 1992. Genetic and physiological response to fumonisin and AAL-toxin by intact tissue of a higher plant. Mycopathologia 117:57-64. 
- Glenn, A. E., Zitomer, N. C., Zimeri, A. M., Williams, L. D., Riley, R. T., and Proctor, R. H. 2008. Transformation-mediated complementation of a FUM gene cluster deletion in Fusarium verticillioides restores both fumonisin production and pathogenicity. Mol. Plant-Microbe Interact. 21:87-97.

- Hanson, L. E., and Hill, A. L. 2004. Fusarium species causing fusarium yellows of sugarbeet. J. Sugar Beet Res. 41:163-178.

- Horne, E. C., Kumpatla, S. P., Patterson, K. A., Gupta, M., and Thompson, S. A. 2004. Improved high-throughput sunflower and cotton genomic DNA extraction and PCR fidelity. Plant Mol. Biol. Rep. 22:83a-83i.

- Hornunga, R. W., and Reeda, L. D. 1990. Estimation of average concentration in presence of nondetectable values. Applied Occupational and Environmental Hygiene 5:46-51.

- Jardine, D. J., and Leslie, J. F. 1999. Aggressiveness to mature maize plants of Fusarium strains differing in ability to produce fumonisin. Plant Dis. 83:690-693.

- Kedera, C. J., Leslie, J. F., and Claflin, L. E. 1992. Systemic infection of corn by Fusarium moniliforme. (Abstr.) Phytopathology 82:1138.

- Kushiro, M., Nagata, R., Nakagawa, H., and Nagashima, H. 2008. Liquid chromatographic deletion of fumonisins in rice seeds. Rep. Nat'l. Food Res. Inst. 72: $37-44$.

- Lamprecht, S. C., Marasas, W. F. O., Alberts, J. F., Cawood, M. E., Gelderblom, W. C. A., Shephard, G. S., Thiel, P. G., and Calitz, F. J. 1994. Phytotoxicity of fumonisins and TA-toxin to corn and tomato. Phytopathology 84:383-391.

- Leslie, J. F., Plattner, R. D., Desjardins, A. E., and Klittich, C. J. R. 1992. Fumonisin B1 production by strains from different mating populations of Gibberella fujikuroi (Fusarium section Liseola). Phytopathology 82: 341-345.

- Leslie, J. F. 1991. Mating population in Gibberella fujikuroi (Fusarium section Liseola). Phytopathology 81:1058-1060.

- Logrieco, A., Mule, G., Moretti, A., and Bottalico, A. 2002. Toxigenic Fusarium species and mycotoxins associated with maize ear rot in Europe. Eur. J. Plant Pathol. 108: 597-609. 
- Logrieco, A., Moretti, A., Ritieni, A., Bottalico, A., and Corda, P. 1995. Occurrence and toxigenicity of Fusarium proliferatum from preharvest maize ear rot, and associated mycotoxins, in Italy. Plant Dis. 79:727-731.

- Maheshwar, P. K., Moharram, S. A., and Janardhana, G. R. 2009. Detection of fumonisin producing Fusarium verticillioides in paddy (Oryza sativa L.) using polymerase chain reaction (PCR). Braz. J. Microbiol. 40:134-138.

- Marasas, W. F. O. 1995. Fumonisins: their implications for human and animal health. Nat. Toxins. 3:193-198.

- Mul`e, G., Susca, G. S., and Moretti, A. 2004. A species-specific PCR assay based on the calmodulin partial gene for identification of Fusarium verticillioides, $F$. proliferatum and F. subglutinans. Eur. J. Plant Pathol. 110:495-502.

- Munkvold, G. P. 2003. Epidemiology of Fusarium diseases and their mycotoxins in maize ears. Eur. J. Plant Pathol. 109:705-713.

- Munkvold, G. P., and Carlton, W. M. 1997. Influence of inoculation method on systemic Fusarium moniliforme infection of maize plants grown from infected seeds. Plant Dis. 81:211-216.

- Munkvold, G. P., and Desjardins, A. E. 1997. Fumonisins in maize: can we reduce their occurrence. Plant Dis. 81:556-565.

- Munkvold, G. P., McGee, D. C., and Carlton, W. M. 1997. Importance of different pathways for maize kernel infection by Fusarium moniliforme. Phytopathology 87: 209-217.

- Nelson, P. E., Desjardins, A. E., and Plattner, R. D. 1993. Fumonisins, mycotoxins produced by Fusarium species: biology, chemistry, and significance. Annu. Rev. Phytopathol. 31:233-252.

- Plante, D., Be'langer, G., Leblanc, D., Ward, P., Houde, A., and Trottier, Y. L. 2010. The use of bovine serum albumin to improve the RT-qPCR detection of foodborne viruses rinsed from vegetable surfaces. Letters in Applied Microbiology 52:239-244.

- Proctor, R. H., Desjardins, A. E., McCormick, S. P., Plattner, R. D., Alexander, N. J., and Brown, D. W. 2002. Genetic analysis of the role of trichothecene and fumonisin mycotoxins in the virulence of Fusarium. Eur. J. Plant Pathol. 108: 691-698. 
- Proctor, R. H., Desjardins, A. E., Plattner, R. D., and Hohn, T. 1999. A polyketide synthase gene required for biosynthesis of fumonisin mycotoxins in Gibberella fujikuroi mating population A. Fungal. Genet. Biol. 27:100-112.

- Srobarova, A., Moretti, A., Ferracane, R., Ritieni, A., and Logrieco, A. 2002. Toxigenic Fusarium species of Liseola section in pre-harvest maize ear rot, and associated mycotoxins in Slovakia. Eur. J. Plant Pathol. 108:299-306.

- Tansakul, N., Limsuwan, S., and Trongvanichnam, K. 2012. Fumonisin monitoring in Thai red cargo rice by reversed-phase high-performance liquid chromatography with electrospray ionization ion trap mass spectrometry. Int. Food Res. J. 19:1561-1566.

- Usleber, E., Straka, M., and Terplan, G. 1994. Enzyme immunoassay for fumonisin B1 applied to corn-based food. J. Agric. Food Chem. 42:1392-1396.

- Wang, E., Norred, W. P., Bacon, C. W., Riley, R. T., and Merrill, Jr, A. H. 1991. Inhibition of sphingolipid biosynthesis by fumonisins. Implications for diseases associated with Fusarium moniliforme. J. Biol. Chem. 266:14486-14490.

- Williams, L. D., and Munkvold, G. P. 2008. Systemic infection by Fusarium verticillioides in maize plants grown under three temperature regimes. Plant Dis. 92:1695-1700.

- Williams, L. D., Glenn, A. E., Zimeri, A. M., Bacon, C. W., Smith, M. A., and Riley, R. T. 2007. Fumonisin disruption of ceramide biosynthesis in maize roots and the effects on plant development and Fusarium verticillioides-induced seedling disease. J. Agric. Food Chem. 55:2937-2946.

- Williams, L. D., Glenn, A. E., Bacon, C. W., Smith, M. A., and Riley, R. T. 2006. Fumonisin production and bioavailability to maize seedlings grown from seeds inoculated with Fusarium verticillioides and grown in natural soils. J. Agric. Food Chem. 54:5694-5700.

- Wei, T., Lu, G., and Clover, G. 2008. Novel approaches to mitigate primer interaction and eliminate inhibitors in multiplex PCR, demonstrated using an assay for detection of three strawberry viruses. J. Virol. Methods. 151:132-139. 


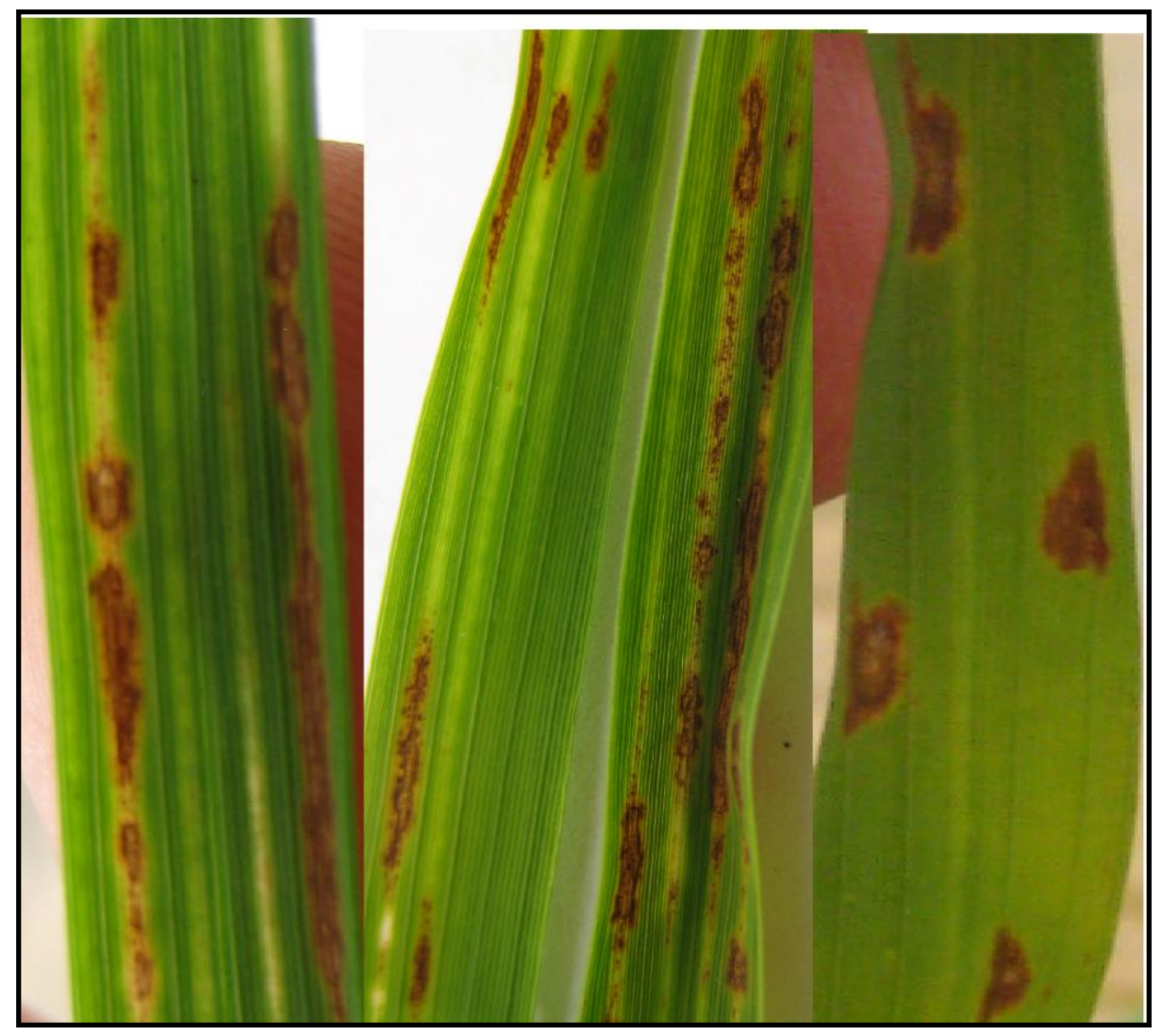

Supplemental Fig. 1. Leaf necrotic spots on inoculated rice plants in the greenhouse 


\section{Chapter 5}

\section{General Discussion}

Phytopathogenic fungi of the genus Fusarium are distributed worldwide and cause economically serious diseases in strategic cereals (Jurado et al., 2005). Additionally, some species are able to produce significant quantities of mycotoxins such as trichothecenes, fumonisins, enniatins, zearalenone and beauvericin (Logrieco et al., 2002). Owing to the positive correlation between fungal biomass and mycotoxin content (Waalwijk et al., 2004; Schnerr et al., 2002; Yli-Mattila et al., 2008), one possible method of predicting mycotoxin contamination is the quantification of fungal biomass in infected plant tissues. Among several quantification methods, using the well-known real-time PCR (qPCR) technique is growing. In this study, we developed a real-time PCR assay for quantification of the nine most important Fusarium pathogens of maize and small-grain cereals in 384-well microplates and in a total volume of $4 \mu 1$. The method is suitable for fast and cost-effective analysis of a large number of samples in a short time. The qPCR assay for all nine species utilizes the same thermocycler profile and, therefore, can be performed in the same microplate.

In spite of availability of thermocyclers with 384-well blocks, most of the published qPCR assays are set for screening only one target DNA in each assay and the protocols still work in a total volume of 15 to $25 \mu \mathrm{l}$. Similarly, the qPCR conditions were set up in our laboratory for F. culmorum, F. graminearum, F. proliferatum, and F. verticillioides (Brandfass \& Karlovsky, 2006; Nutz et al., 2011). The protocols, however, did not work well when the total volume was decreased to $4 \mu \mathrm{l}$ reactions. A second peak prior to specific melting point resulted in issues for the qPCR melting curve, especially in low DNA concentrations. Modification of thermal parameters (mostly annealing and elongation steps) and re-optimization of PCR reagents for each Fusarium spp. enhanced the qPCR assay and the wide shape peaks disappeared.

The PCR efficiency, one of the most important qPCR parameters, is defined as the amount of amplified template DNA during one cycle. Correct determination of this parameter is necessary while the PCR data are used for the quantitative purposes (Rebrikov \& Trofimov, 2006). In present optimized multi-species qPCR protocol, the PCR efficiency ranged from $81 \%$ 
(F. verticillioides) to $120 \%$ (F. equiseti). In this work, sensitivity which is the crucial factor for interpretation of the qPCR results was defined as the lowest standard DNA that was able to be amplified at the expected melting temperature in at least seven out of eight replicates. Based on this definition, sensitivity trials showed a detection limit of $0.05 \mathrm{pg} \mu \mathrm{l}^{-1}$ of standard DNA for

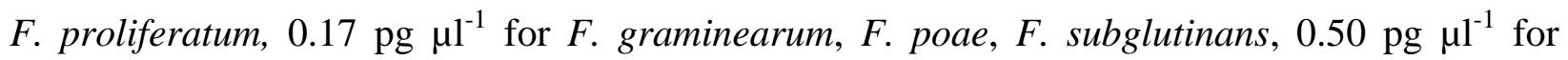
F. avenaceum, F. culmorum, F. tricinctum and $1.52 \mathrm{pg}_{\mu 1^{-1}}$ for $F$. equiseti, $F$. verticillioides. The developed multi-species qPCR assay did not show a delicate sensitivity for the last two Fusarium species. Therefore, in order to quantify these species while low amounts of fungal biomass are present in plant materials, it is suggested to follow the single species qPCR protocol developed in the present research. For both species, thus, sensitivity will be improved to $0.50 \mathrm{pg}^{-1}$ in a background free of plant tissues and other contaminants. In summary, both single and multi-species qPCR methods developed in this project are suitable for quick, cost-effective and high-throughput quantification of the nine Fusarium spp. in plant material.

Inhibitors have been reported as a challenge for the successful detection and reliable quantification of fungal biomass in plant tissues. Efficiency and sensitivity of qPCR assay will be affected by the inhibitors present in DNA extracts. Developed high sensitive qPCR protocols, therefore, maybe could not generate reliable data when a set of DNA extracts containing considerable inhibitors are used (Gao et al., 2004; Demeke \& Jenkins., 2010). Potential plant inhibitors such as proteins, polyphenols, polysaccharides, secondary metabolites (Horne et al., 2004), as well as components of DNA isolation buffers (Rossen et al., 1992) influence the qPCR reaction and cause a reduction in efficiency (Gao et al., 2004). In some cases, samples with strong matrix properties are able to completely block PCR amplification and result in a false negative reaction. Significant PCR inhibition is demonstrated from soil and root DNA extracts (Braid et al., 2003; Gao et al., 2004; Van de Graaf et al., 2003) in addition to DNA from senescing plant material (Turner et al., 1998). In this investigation, the DNA extracts obtained from different parts of maize, sorghum, rice and beetroot indicated different matrix effects. Similarity between the PCR efficiency of unknown samples and standard reference material is a prerequisite to determine the accurate quantity of fungal biomass (Cankar et al., 2006). For this purpose, diluting DNA is a simple way to overcome the qPCR inhibition. A dilution factor of 25 , 50 or 100 fold could decrease the threshold values $(\mathrm{Ct})$ to the same level of the reference DNA 
standard and enhanced the qPCR efficiency. One hundred times dilution was not sufficient for the DNA of the rice plants. Since a lower DNA concentration could decrease the PCR sensitivity, $1 \mathrm{mg} \mathrm{ml}^{-1}$ bovine serum albumin (BSA) was directly added to the PCR reaction mixture. This chemical has been successfully employed for deactivation of PCR inhibitors (Wei et al., 2008; Plante et al., 2010).

Both developed qPCR protocols were successfully applied for detecting the nine Fusarium spp. in weeds sampled from maize fields. These species are known as the most common Fusarium associated with maize diseases. The qPCR analysis revealed that 201 weed samples out of 294 were infected with at least one Fusarium species. Sometimes more than one species of Fusarium were detected in individual sample. Weeds have been demonstrated to be reservoirs of potential fungal pathogens. They serve as alternative hosts for several species of Fusarium, usually when the economically important host plants are not present (Helbig \& Carroll, 1984; Jenkinson \& Parry, 1994; Postic et al., 2012; Altinok, 2013). In this study, 36 weed species in the maize fields had been colonized with ten species of Fusarium. The rate of infection was high for $F$. equiseti (49\%) and $F$. avenaceum (34.7\%). F. avenaceum is well-known as a common species associated with cereals in Europe, while $F$. equiseti has less frequently (Logrieco et al., 2002; Yli-Mattila, 2010; Kosiak et al., 2003). F. culmorum and $F$. tricinctum indicated the same infection ratio (18\%). It was followed by $F$. proliferatum (11\%) and $F$. graminearum (8\%). F. poae and $F$. subglutinans were detected at very low frequencies (3\% and $1 \%$, respectively). In isolation experiments, $F$. oxysporum and $F$. venenatum were also recovered from weed samples in addition to other species.

The present study identified some of the weed species as new hosts for each Fusarium spp. tested in the greenhouse (see Chapter 3, Table 4). The frequent screening of Fusarium on common weeds (by qPCR or isolation on selective medium culture) increased their possible role in the survival of fungus. The previous studies have indicated that plant residues are the main inoculum source of Fusarium diseases (Cotten \& Munkvold, 1998). Other works have also demonstrated survival of Fusarium spp. on non-host plants such as weeds (Jenkinson \& Parry, 1994; Inch \& Gilbert, 2003; Postic et al., 2012; Altinok, 2013). Therefore, weeds as a harbor for Fusarium have the potential to provide an inoculum reservoir for the infection of main crop during the growing season. In this work, high incidence of Fusarium spp. occurred in 
Echinochloa crus-galli, Polygonum convolvulus and Chenopodium album which have been reported as the main weed species from maize farms (Westerman \& Gerowitt, 2012). Prevalence of $F$. avenaceum and $F$. equiseti on almost all common weed species studied (see Chapter 3, Table 2) may indicate that these Fusarium are more competitive species for colonization of weeds compared to the main cereal fusaria such as $F$. graminearum.

In this work, weeds were symptomless carriers of Fusarium spp. No obvious disease symptoms were observed on weeds assayed from the maize fields and also after inoculation in the greenhouse conditions. This finding is in agreement with others (Haware \& Nene, 1982; Clark \& Watson, 1983; Helbig \& Carroll, 1984; Jenkinson \& Parry, 1994; Postic et al., 2012; Altinok, 2013). Akinsanmi et al. (2007) reported that the pathogenic fitness of Fusarium pathogens was significantly reduced during passage through alternative hosts, while their fertility on the primary host increased. Other reports show only less aggressive isolates could attack weeds (Helbig \& Carroll, 1984). The above reasons may explain the symptomless infection of the weeds. On the other hand, Fusarium strains were recovered from surface sterilized roots and stems of weeds in both field and artificially inoculated samples. Successful infection of weed tissues in addition to the lack of symptoms on weeds suggested that the infection of weeds by Fusarium spp. could be endophytic.

Common weeds were assessed for the main toxic secondary metabolites by HPLC-MS/MS. All samples tested were negative (below the LOD of $3 \mathrm{ng} \mathrm{g}^{-1}$ ) for contamination of trichothecenes, zearalenone and fumonisins, even the samples containing the related producers. As it is mentioned above, poor performance of Fusarium strains on alternative hosts (Akinsanmi et al., 2007) may explain the lack of symptoms and mycotoxin production. Another possibility is field conditions that did not favor mycotoxin production. In contrast, high levels of beauvericin and enniatins were detected in the samples contaminated with $F$. equiseti and F. avenaceum. Enniatins were measured most often at high levels (up to $24 \mathrm{mg} \mathrm{kg}^{-1}$ ) in Chenopodium album, Elymus repens and Polygonum aviculare. Concentration of beauvericin in some weed species, such as Matricaria inodora, ranged from 0.0 to $65.6 \mathrm{mg} \mathrm{kg}^{-1}$. However, there was no correlation between mycotoxin content and fungal biomass. Contamination of cereal grains by enniatins, resulting from $F$. avenaceum, and the natural occurrence of beauvericin in maize ears has been reported (Logrieco et al., 1993; Bottalico et al., 1995; Ritieni 
et al., 1997; Logrieco et al., 1995; Yli-Mattila, 2010). In summary, although the main cereal toxins were not found in the weed samples tested, the significance of toxin production in the main host should not be disregarded.

There are limits on the use of morphological characters for identification of Fusarium spp. These limitations increase when differentiation is within members belonging to a species complex with highly similar morphology. In recent years, molecular techniques based mostly on DNA sequencing of genes have supported morphological identification of Fusarium species (Yli-Mattila et al., 2002; Harrow et al., 2010; Geiser et al., 2004; Hsuan et al., 2011). Nucleotide sequencing of genes is performed particularly in informative parts of genome such as translation elongation factor 1-alpha (TEF-1 $\alpha$ ). In this work, typical Fusarium structures were utilized to identify the recovered isolates according to Leslie \& Summerell (2006). Molecular information obtained from the DNA sequence of TEF-1 $\alpha$ and phylogenetic analysis were then employed to confirm the morphological identification and probably distinguish closely related strains. The isolates morphologically identified as F. equiseti, were placed in the Fusarium incarnatumequiseti species complex (FIESC) according to the closest match of BLAST search analysis using the Fusarium-ID database (Geiser et al., 2004). The results show they belong to three sub-clades of FIESC, only one of which has been called $F$. equiseti, and the next two sub-clades still have no latin name (O'Donnell et al., 2009a). Fusarium oxysporum species complex (FOSC) also comprises different sub-clades (O'Donnell et al., 2009b). Members of FOSC are ubiquitous soil borne pathogens and have been demonstrated from maize and other cereals to be a less common species (Logrieco et al., 2002; Kosiak et al., 2003). In this study, although closely related species to $F$. avenaceum such as $F$. torulosum, $F$. flocciferum and $F$. accuminatum formed different clades in the constructed UPGMA dendrogram, the reference strains of $F$. arthrosporioides, however, fell in the $F$. avenaceum clade. These two species ( $F$. avenaceum, F. arthrosporioides) are morphologically very similar. They are distinguished by lack of orange sporodochia in F. arthrosporioides after growing on SNA (Synthetic Nutrient Agar) medium in darkness (Yli-Mattila et al., 2002). A combined DNA sequence data is necessary to be able to distinguish these two species. The ATP Citrate Lyase (acl1) sequence together with the TEF-1 $\alpha$ gene could make a distinct lineage for $F$. arthrosporioides in the main clade of $F$. avenaceum (Gräfenhan et al., 2013). 
F. verticillioides, as the most important maize pathogen, is able to cause a wide range of symptoms, from asymptomatic infection to severe rotting and wilting. The fungus can colonize maize stalks with no obvious disease symptoms (Kedera et al., 1992; Bacon \& Hinton, 1996; Munkvold et al., 1997; Logrieco et al., 2002; Srobarova et al., 2002). This species was not detected in any of the weed samples. Furthermore, we could not recover it from different weed samples. Therefore, the importance of weeds as a possible source of $F$. verticillioides inoculum in maize fields remains still unknown. Additional studies need to be performed to evaluate if weed plants can serve as an alternative host for $F$. verticillioides in maize fields. Further weed sampling from maize fields of Italy and southern belt of Germany, where the fungus is a serious problem, has been carried out and the experiments are running in our group. We hope the results help us to find out if weed plants harbor $F$. verticillioides in maize fields and whether they can increase the infection pressure locally. The answer may also be helpful for finding the biological role of fumonisins in the growth of fungus in the host plants other than maize. We believe the fumonisin synthesis has been maintained by natural selection on weeds (or hosts other than maize) and in plant tissues other than silk/cobs (such as roots) for millions of years.

Fumonisins are polyketide mycotoxins produced by several species of Fusarium among which $F$. verticillioides is well-known as a main producer (Munkvold \& Desjardins, 1997). The biological role of fumonisins in virulence of $F$. verticillioides has been an eristic issue. In this study, two fumonisin non-producing strains (fum 1-3 and fum 1-4) and their progenitor (fumonisin-producing) FUM 1-1 strains were employed to determine the potential role of toxins in the growth of the fungus in maize, grain sorghum, rice and beetroot seedlings. The results of this study confirmed the previous reports (Kedera et al., 1992; Bacon \& Hinton, 1996; Munkvold et al., 1997) that $F$. verticillioides can infect maize plants without causing symptoms. Systemic movement of fungus within the root inoculated plants was detected by qPCR. Transmission of the fungus from roots to the first two internodes in maize plants occurred regardless of toxin production. Our experiments show that the infection through the roots has been an effective pathway for developing fungus within the plant. However, the rate of symptomless systemic colonization decreased after the second internode. This restricted movement of fungus may limit the infection of kernels. Williams \& Munkvold (2008) indicated that the systemic development of $F$. verticillioides could be increased in high temperatures. Movement of the fungus appeared 
to be limited in sorghum plants. Only in $20-30 \%$ of inoculated plants with the M-3125 strain or its mutant, GFA2364, the fungus was detectable in the first two internodes. Host preference of the biological species of Gibberella fujikuroi has been demonstrated (Leslie et al., 1992) and it could explain the lack of movement of fungus in sorghum plants. Another possibility would be the partial resistance of the sorghum variety which was utilized in this study. The relative distribution of the fungus in rice and beetroot seedlings was similar to maize plants. The quantified fugal biomass was considered as a marker to show the aggressiveness of the fungus. No infection was detected in control plants inoculated with sterile water. There was no significant difference $(P=0.05)$ between fumonisin-producing strains and fumonisin non-producing strains in colonization of plant tissues. The high level of fungal biomass was detected in roots and also in the first two internodes of the maize stalks; but it was independent of fumonisins production. Based on the results in our system, fumonisins have no role in fungal growth of $F$. verticillioides in maize, rice and beetroot seedlings and the aggressiveness of fungus was independent of toxin production. 


\section{Literature Cited}

- Akinsanmi, O. A., Chakraborty, S., Backhouse, D., and Simpfendorfer, S. 2007. Passage through alternative hosts changes the fitness of Fusarium graminearum and Fusarium pseudograminearum. Environ. Microbiol. 9:512-520.

- Altinok, H. H. 2013. Fusarium species isolated from common weeds in eggplant fields and symptomless hosts of Fusarium oxysporum f. sp. melongenae in Turkey. J. Phytopathol. 161:335-340.

- Bacon, C. W., and Hinton, D. M. 1996. Symptomless endophytic colonization of maize by Fusarium moniliforme. Can. J. Bot. 74:1195-1202.

- Bottalico, A., Logrieco, A., Ritieni, A., Moretti, A., Randazzo, G., and Corda, P. 1995. Beauvericin and fumonisin B1 in preharvest Fusarium moniliforme maize ear rot in Sardinia. Food Addit. Contam. 12:599-607.

- Braid, M. D., Daniels, M. L., and Kitts, C. L. 2003. Removal of PCR inhibitors from soil DNA from chemical flocculation. J. Microbiol. Meth. 52:389-393.

- Brandfass, C., and Karlovsky, P. 2006. Simultaneous detection of Fusarium culmorum and $F$. graminearum in plant material by duplex PCR with melting curve analysis. BMC Microbiol. 6 (4). Available from: http://www.biomedcentral.com/1471-2180/6/4 : URL. DOI.

- Cankar, K., Stebih, D., Dreo, T., Zel, J., and Gruden, K. 2006. Critical points of DNA quantification by real-time PCR effects of DNA extraction method and sample matrix on quantification of genetically modified organisms. BMC. Biotech. 6:37-51.

- Clark, C. A., and Watson, B. 1983. Susceptibility of weed species of Convolvulaceae to root-infecting pathogens of sweet potato. Plant Dis. 67:907-909.

- Cotten, T. K., and Munkvold, G. p. 1998. Survival of Fusarium moniliforme, $F$. proliferatum and F. subglutinans in maize stalk residue. Phytopathology 88:550-555.

- Demeke, T., and Jenkins, G. R. 2010. Influence of DNA extraction methods, PCR inhibitors and quantification methods on real-time PCR assay of biotechnology-derived traits. Anal. Bioanal. Chem. 396:1977-1990.

- Gao, X., Jackson, T. A., Lambert, K. N., Li, S., Hartman, G. L., and Niblack, T. L. 2004. Detection and quantification of Fusarium solani f.sp. glycines in soybean roots with real-time quantitative polymerase chain reaction. Plant Dis. 88:1372-1380. 
- Geiser, D. M., Jime'nez-Gasco, M. D. M., Kang, S., Makalowska, I., Veeraraghavan, N., Ward, T. J., Zhang, N., Kuldau, G. A., and O'Donnell, K. 2004. FUSARIUM-ID v. 1.0: A DNA sequence database for identifying Fusarium. Eur. J. Plant Pathol. 110:473-479.

- Gräfenhan, T., Patrick, S. K., Roscoe, M., Trelka, R., Gaba, D., Chan, J. M., McKendry, T., Clear, M., and Tittlemier, S. A. 2013. Fusarium damage in cereal grains from western Canada. Phylogenetic analysis of moniliformin-producing Fusarium species and their natural occurrence in mycotoxin- contaminated. J. Agric. Food Chem. 61:5425-5437.

- Harrow, S. A., Farrokhi-Nejad, R., Pitman, A. R., Scott, I. A. W., Bentley, A., Hide, C., and Cromey, M. G. 2010. Characterization of New Zealand Fusarium populations using a polyphasic approach differentiates the Fusarium avenaceum/ F. acuminatum/ F. tricinctum species complex in cereal and grassland systems. Fungal Biol. 114:293-311.

- Haware, M. P., and Nene, Y. L. 1982. Symptomless carriers of the chickpea wilt Fusarium. Plant Dis. 66:250-251.

- Helbig, J. B., and Carroll, A. B. 1984. Dicotyledonous weeds as a source of Fusarium oxysporum pathogenic on soybean. Plant Dis. 68:694-696.

- Horne, E. C., Kumpatla, S. P., Ptterson, K. A., Gupta, M., and Thompson, S. A. Improved high-throughput sunflower and cotton genomic DNA extraction and PCR fidelity. Plant Mol. Biol, Rep. 22:83a-83i.

- Hsuan, H. M., Salleh, B., and Zakaria, L. 2011. Molecular identification of Fusarium species in Gibberella fujikuroi species complex from rice, sugarcane and maize from Peninsular Malaysia. Int. J. Mol. Sci. 12:6722-6732.

- Inch, S., and Gilbert, J. 2003. The incidence of Fusarium species recovered from inflorescences of wild grasses in southern Manitoba. Can. J. Plant Pathol. 25:379-383.

- Jenkinson, P., and Parry, D. W. 1994. Isolation of Fusarium species from common broad-leaved weeds and their pathogenicity to winter wheat. Mycol. Res. 98:776-780.

- Jurado, M., Vazquez, C., Patino, B., and González-Jaén, M. T. 2005. PCR detection assays for the trichothecene-producing species Fusarium graminearum, Fusarium culmorum, Fusarium poae, Fusarium equiseti and Fusarium sporotrichioides. Syst. Appl. Microbiol. 28:562-568.

- Kedera, C. J., Leslie, J. F., and Claflin, L. E. 1992. Systemic infection of corn by Fusarium moniliforme. (Abstr.) Phytopathology 82:1138. 
- Kosiak, B., Torp, M., Skjerve, E., and Thrane, U. 2003. The prevalence and distribution of Fusarium species in Norwegian cereals: a survey. Acta Agr. Scand. (Section B- Soil and Plant Science) 53:168-176.

- Leslie, J. F., and Summerell, B. A. 2006. The Fusarium Laboratory Manual. Blackwell Publishing. 388 pp.

- Leslie, J. F., Plattner, R. D., Desjardins, A. E., and Klittich, C. J. R. 1992. Fumonisin B1 production by strains from different mating populations of Gibberella fujikuroi (Fusarium section Liseola). Phytopathology (Abstr.) 82: 34145.

- Logrieco, A., Mule, G., Moretti, A., and Bottalico, A. 2002. Toxigenic Fusarium species and mycotoxins associated with maize ear rot in Europe. Eur. J. Plant Pathol. 108: 597-609.

- Logrieco, A., Moretti, A., Ritieni, A., Bottalico, A., and Corda, P. 1995. Occurrence and toxigenicity of Fusarium proliferatum from preharvest maize ear rot, and associated mycotoxins, in Italy. Plant Dis. 79:727-731.

- Logrieco, A., Moretti, A., Ritieni, A., Chelkowski, J., Altomare, C., Bottalico, A., and Randazzos, G. 1993. Natural occurrence of beauvericin in preharvest Fusarium subglutinans infected corn ears in Poland. J. Agric. Food. Chem. 41:2149-2152.

- Munkvold, G. P., and Desjardins, A. E. 1997. Fumonisins in maize: can we reduce their occurrence. Plant Dis. 81:556-565.

- Munkvold, G. P., McGee, D. C., and Carlton, W. M. 1997. Importance of different pathways for maize kernel infection by Fusarium moniliforme. Phytopathology 87: 209-217.

- Nutz, S., Döll, K., and Karlovsky, P. 2011. Determination of the LOQ in real-time PCR by receiver operating characteristic curve analysis: application to qPCR assays for Fusarium verticillioides and F. proliferatum. Anal. Bioanal. Chem. 401:717-726.

- O'Donnell, K., Sutton, D. A., Crous, P. W., Rinaldi, M. G., and Geiser, D. M. 2009a. Novel multilocus sequence typing scheme reveals high genetic diversity of human pathogenic members of the Fusarium incarnatum- $F$. equiseti and $F$. chlamydosporum species complexes within the united states. J. Clin. Microbiol. 47:3851-3861.

- O'Donnell, K., Gueidan, C., Sink, S., Johnston, P. R., Crous, P. W., Glenn, A., Riley, R., Zitomer, N. C., Colyer, P., Waalwijk, C., Lee, T., Moretti, A., Kang, S., Kim, H. S., Geiser, D. M., Juba, J. H., Baayen, R. P., Cromey, M. G., Bithell, S., Sutton, D. A., 
Skovgaard, K., loetz, R., Corby Kistler, H., Elliott, M., Davis, M., and Sarver, B. A. 2009b. A two-locus DNA sequence database for typing plant and human pathogens within the Fusarium oxysporum species complex. Fungal Genet. Biol. 46:936-948.

- Plante, D., Belanger, G., Leblanc, D., Ward, P., Houde, A., and Trottier, Y. L. 2010. The use of bovine serum albumin to improve the RT-qPCR detection of foodborne viruses rinsed from vegetable surfaces. Letters in Applied Microbiology 52:239-244.

- Postic, J., Cosic, J., Vrandecic, K., Jurkovic, D., Saleh, A. A., and Leslie, J. F. 2012. Diversity of Fusarium species isolated from weeds and plant debris in Croatia. J. Phytopathol. 160:76-81.

- Rebrikov, D. V., and Yu. Trofimov, D. 2006. Real-time PCR: a review of approaches to data analysis. Appl. Biochem. Microbiol. 42:520-528.

- Ritieni, A., Moretti, A., Logrieco, A., Bottalico, A., Randazzo, G., Monti, S. M., Ferracane, R., and Fogliano, V. 1997. Occurrence of fusaproliferin, fumonisin B1, and beauvericin in maize from Italy. J. Agric. Food. Chem. 45:4011-4016.

- Rossen, L., Norskov, P., Holmstrom, K., and Rasmussen, F. 1992. Inhibition of PCR by components of food samples, microbial diagnostic assays and DNA-extraction solutions. Int. J. Food Microbiol. 17:37-45.

- Schnerr, H., Vogel, R. F., and Niessen, L. 2002. Correlation between DNA of trichothecene-producing Fusarium species and deoxynivalenol concentrations in wheat-samples. Lett. Appl. Microbiol. 35:121-125.

- Srobarova, A., Moretti, A., Ferracane, R., Ritieni, A., and Logrieco, A. 2002. Toxigenic Fusarium species of Liseola section in preharvest maize ear rot, and associated mycotoxins in Slovakia. Eur. J. Plant Pathol. 108:299-306.

- Turner, A. S., Lees, A. K., Rezanoor, H. N., and Nicholson, P. 1998. Refinement of PCR-detection of Fusarium avenaceum and evidence from DNA marker studies for phonetic relatedness to Fusarium tricinctum. Plant Pathol. 47:278-288.

- Van de Graaf, P., Lees, A. K., Cullen, D. W., and Duncan, J. M. 2003. Detection and quantification of Spongospora subterranea in soil, water and plant tissue samples using real-time PCR. Eur. J. Plant Pathol. 109:589-597.

- Waalwijk, C., van der Heide, R., de Vries, I., van der Lee, T., Schoen, C., Costrel-de Corainville, G., Häuser-Hahn, I., Kastelein, P., Köhl, J., Lonnet, P., Demarquet, T., and 
Kema, G. H. J. 2004. Quantitative detection of Fusarium species in wheat using TaqMan. Eur. J. Plant Pathol. 110:481-494.

- Wei, T., Lu, G., and Clover, G. 2008. Novel approaches to mitigate primer interaction and eliminate inhibitors in multiplex PCR, demonstrated using an assay for detection of three strawberry viruses. J. Virol. Methods. 151:132-139.

- Westerman, P. R., and Gerowitt, B. 2012. Probability of maize biomass contamination with weed seeds. J. Plant Dis. Protect. 11:68-73.

- Williams, L. D., and Munkvold, G. P. 2008. Systemic infection by Fusarium verticillioides in maize plants grown under three temperature regimes. Plant Dis. 92:1695-1700.

- Yli-Mattila, T. 2010. Ecology and evolution of toxigenic Fusarium species in cereals in northern Europe and Asia. J. Plant Pathol. 92:7-18.

- Yli-Mattila, T., Paavanen-Huhtala, S., Jestoi, M., Parikka, P., Hietaniemi, V., Gagkaeva, T., Sarlin, T., Haikara, A., Laaksonen, S., and Rizzo, A. 2008. Real-time PCR detection and quantification of Fusarium poae, F. graminearum, F. sporotrichioides and F. langsethiae in cereal grains in Finland and Russia. Archives of Phytopathology and Plant Protection 41:243-260.

- Yli-Mattila, T., Paavanen-Huhtala, S., Bulat, S. A., Alekhina, I. A., and Nirenberg, H. I. 2002. Molecular, morphological and phylogenetic analysis of the Fusarium avenaceum/ F. arthrosporioides/ F. tricinctum species complex- a polyphasic approach. Mycol. Res. 106:655-669. 


\section{Summary}

Fusarium is a large and complex genus, comprises important pathogens most of which are able to produce mycotoxins. Maize is a host of several Fusarium species that cause ear rot, kernel rot, stalk rot and also seedling blight. Fusarium contamination of kernels and maize products had always been a serious concern. Owing to the positive correlation between fungal biomass and mycotoxin content, quantification of fungal DNA in plant materials would be considered as an initial fast and cost-effective mean to evaluate the risk of grain contamination. Several quantification methods are well-known of which real-time PCR (qPCR) has been used as an effective tool for species-specific quantification of fungal biomass in plant tissues. The method mostly relies on standard thermocyclers (96-well or 384-well blocks) with a separate run for each template and usually set in total reaction volume of 15 to $25 \mu 1$. In this investigation, we developed a multi-species qPCR assay for simultaneous quantification of genomic DNA of the nine Fusarium species with 384-well microplates in a total volume of $4 \mu \mathrm{l}$. The sensitivity of the method ranged from $0.05-1.52$ pg DNA per reaction, and the repeatability ranged from $0.81 \%$ to $1.71 \%$ RSD.

Developed low volume qPCR assay was successfully employed for the analysis of weed plants to the infection of nine Fusarium spp. The main objectives were determination the role of weeds in the survival of maize fusarium pathogens and assessment of their ability for producing of the main mycotoxins. The Real-time PCR detected eight Fusarium species in 201 weed samples representing 36 weed species, collected from maize fields. The highest frequency was observed for F. equiseti (49\%) and F. avenaceum (34.7\%). Similar diversity of Fusarium spp. was observed in both conventional and organic farming systems. Isolation of Fusarium strains from 12 common weed species were carried out, the strains were identified based on the morphological characters and then identification was confirmed by using the translation elongation factor 1 -alpha (TEF-1 $\alpha$ ) gene sequence. The recovery rate was high for $F$. equiseti $(32.7 \%)$ and $F$. avenaceum (21\%). None of the field samples as well as weed plants tested in inoculation studies show obvious symptoms of Fusarium infection. Re-isolation of the strains from artificially inoculated plants confirmed the endophytic infection of weeds by Fusarium spp. The present study reports five new alternative hosts for Fusarium species in maize fields. High 
incidence rate of beauvericin and enniatins contamination was obtained in weed samples while trichothecenes, fumonisins and zearalenone were not detected in any of the weeds studied.

Although toxicity of fumonisins to plants and field animals has been clearly demonstrated, the function of this toxin, however, in virulence of $F$. verticillioides toward maize plants is still unknown. In present study, virulence of two non-fumonisins producing strains (fum 1-3 and fum 1-4) and their progenitors (FUM 1-1) was assessed on different plants including maize, sorghum, rice and beetroot seedlings grown under greenhouse conditions. The quantity of fungal biomass in plant tissues was considered as an indicator of fungal aggressiveness and it was measured by the developed low volume qPCR protocol. There was no significant $(P=0.05)$ differences between each wild type and the relevant mutant for colonization of plant tissues. In inoculated maize, rice and beetroot seedlings, systemic fungal infection was observed from roots to the aboveground parts; but rate of systemic transmission was low in sorghum plants. Although our results are not enough to make a final conclusion of fumonisin function in virulence of $F$. verticillioides on rice and sorghum seedlings, however, the results show diseases incidence was independent of fumonisins production in maize seedlings. In our system, therefore, fumonisins had no role as a pathogenicity factor. 


\section{Acknowledgements}

I would like to deeply thank my great supervisor Prof. Dr. Petr Karlovsky for giving me the opportunity to complete this work in his group. My sincere gratitude is for his scientific guidance and also for giving me the chance to gain extraordinary experiences by working on side projects along my study. Working in his group enriched my life experiences, as well.

I am very grateful to have Dr. Horst-Henning Steinmann and Prof. Dr. Andreas von Tiedemann as my Ph. D. committee members.

Many friendly people of Karlovsky lab helped me scientifically or morally to be able to do this work. I am indebted to Heike Rollwage, Ruth Pilot and Patricia Bartoschek for their advices and technical support. They always were beside me and shared good moments with me. Special gratitude to Dr. Katharina Döll for her friendship, constant support, numerous scientific advices and positive thinking even during difficult moments. I am extremely grateful to Andrea Breitkopf, Jacqueline Moser and Daniel Kretzschmar for technical assistance. It was a great honour to be with all of you during my Ph. D. study; and Special thanks to Yi Kuang, Somayyeh Sedaghatjoo, Nahid Shafiei, my friends, and all Ph. D. students who made my moments more enjoyable in Germany.

I would like to get this opportunity to say thank to all the administrative staff of molecular phytopathology and mycotoxin research department for a good working atmosphere, especially to Mrs. Evelin Kistner, Mr Thomas Oesterreich and Mr Siegfried Opolka. They kindly accompanied me on this research project.

So many thanks to Seed and Plant Improvement Research Institute (SPII) authorities, in Iran, especially Dr. R. Chokan and Dr. D. Hassani that authorized me for the highest level of my education.

I want to express my deepest thank to Dr. Seyed Mostafa Pirseyedi, my colleague, for his fruitfull scientific discussions and valuable suggestions.

I owe my gratitude to all my friends in Iran, especially Mrs. Sima Damyar for encouragements and great emotional support during my $\mathrm{Ph}$. D. study. 
Ultimately, love and thanks to my parents who sacrificed everything to give me the most and best education possible. They taught me to stand up against the problems and compromise with life. Now, I am honoered to show them the beautiful world where that they have let me be a part of. I am grateful to my lovely sister, Roya, who always supported me to follow my dreams; and many thanks to my brothers, Hamid, Majid and Vahid. I am proud of you. During the last three years, I had very nice and happy moments through "ooVoo" with my cute nephew, Ali, and my sweet niece, Baran, who were new members of our family when I started my Ph. D. Hope, someday, when they read their names in my dissertation be reassured of my love to themselves.

You, all, made my dreams come true. Thanks !, and Here, I am excited for the future...

Raana Dastjerdi

19 March, 2014, Gättingen, Germany 


\section{Curriculum Vitae}

\section{Personal information}

Name:

Raana Dastjerdi

Born:

Ghazvin, Iran

E-mail

raana_dastjerdi@yahoo.com

\section{Academic Education}

From 03/2011

International Ph. D. Program for Agricultural Sciences, Molecular Phytopathology and Mycotoxin Research Unit, Division of Plant Pathology and Plant Protection, GeorgAugust-University Göttingen, Germany

09/1999-02/2002

Master Program in Agricultural Sciences, Field: Plant Pathology, Ferdowsi University of Mashhad, Iran. Master thesis: "Investigation on genetic diversity in population of Fusarium oxysporum from sugar beet in Khorasan using vegetative compatibility groups (VCG) and RAPD molecular marker"

09/1993-07/1997

Bachelor Program in Agricultural Engineering, Field: Plant Protection, Ferdowsi University of Mashhad, Iran. Bachelor thesis: "Biological control and applying of PGPR in plant diseases management"

\section{Work Experience}

Since $05 / 2002$

Faculty member and research leader of Horticulture Crops Research Department, Seed and Plant Improvement Research Institute (SPII), Tehran-Karaj, Iran 


\section{Publications}

\section{Publications During the Ph. D. Study}

- Dastjerdi, R., Döll, K., Gerowitt, B., Steinmann, H. H., and Karlovsky, P. 2013. Fusarium species and mycotoxins in weed plants. $35^{\text {th }}$ Mycotoxin Workshop. Ghent, Beljium.

- Thirumalai, A. E., Dastjerdi, R., Döll, K., Venkatachalam, A., Karlovsky, P., and Suryannarayanan, T. S. 2013. Mycotoxins of endophytic Fusarium mangiferae and F. pallidoroseum from betel leaves (Piper betle L.). $35^{\text {th }}$ Mycotoxin Workshop. Ghent, Beljium.

\section{Other Publications}

\section{Journal Publications}

- Damyar, S., Hassani, D., Dastjerdi, R., Hajnajari, H., Zeinanloo, A. A., and Fallahi, E. 2007. Evaluation of Iranian native apple cultivars and genotypes. Journal of Food, Agriculture and Environment 5(3\&4):207-211.

- Dastjerdi, R., and Damyar, S. 2010. Evaluation of relative resistance in eleven apple rootstocks to crown rot caused by Phytophthora cactorum. Seed and Plant Improvement Journal 26(3): 297-311.

- Dastjerdi, R., Falahati-Rastegar, M., and Jafarpour, B. 2003. Identification of Fusarium species associated with sugar beet root in Khorasan province and investigation of the pathogenicity of Fusarium oxysporum. Iranian Journal of Sugar Beet 18 (2):143-154.

- Dastjerdi, R., and Hassani, D. 2009. Response of 11 walnut cultivars and genotypes to Gnomonia leptostyla. Seed and Plant Improvement Journal 25(3):433-449.

- Dastjerdi, R., Hassani, D., and Javan-Nikkhah, M. 2009. Study on some characteristics, assessment of Pathogenicity and diversity in Gnomonia leptostyla isolates casual agent of walnut anthracnose in Iran. Iranian Journal of Plant Pathology 45(1):61-73.

- Dastjerdi, R., Mozafari, J., Falahati-Rastegar, M., and Jafarpour, B. 2006. Population diversity of Fusarium oxysporum associated with sugar beet in Khorasan based on vegetative compatibility groups (VCGs). Agricultural Sciences and Technology Journal (Ferdowsi University of Mashhad, Iran) 20(2):78-91.

- Dastjerdi, R., Mozafari, J., Falahati-Rastegar, M., and Jafarpour, B. 2004. RAPD Analysis of genetic diversity within and among vegetative compatibility groups (VCGs) of Fusarium oxysporum f. sp. betae in sugar beet fields of Khorasan, Iran. Applied Entomology and Phytopathology 72(1):1-19. 
- Hassani, D., Atefi, J., Haghjooyan, R., Dastjerdi, R., Keshavarzi, M., Mozaffari, M. R., Soleimani, A., Rahmanian, A. R., Nematzadeh, F., and Malmir. A. 2012. Jamal, a new persian walnut cultivar for moderate-cold area of Iran. Seed and Plant Improvement Journal 28(3):525-527.

- Hassani, D., Atefi, J., Haghjooyan, R., Dastjerdi, R., Keshavarzi, M., Mozaffari, M. R., Soleimani, A., Rahmanian, A. R., Nematzadeh, F., and Malmir. A. 2012. Damavand, a new persian walnut cultivar as a pollinizer for Iranian walnut cultivars and genotypes. Seed and Plant Improvement Journal 28(3):529-531.

\section{Presentations and Posters}

- Damyar, S., Dastjerdi, R., and Hassani, D. 2009. Determination of the best harvesting time for Braeburn, Gala and Fuji apple cultivars in Iran. $6^{\text {th }}$ International Postharvest Symposium. Antalya, Turkey. p: 227.

- Damyar, S., Keshavarzi, M., Hassani, D., Dastjerdi, R., and samie, N. 2007. Non chemichal control of superfacial scald in apple cultivar Red Delicious (Full Text). International Scientific Conference. Minsk, Belarus. 128-131.

- Dastjerdi, R., Damyar, S., and Farhadnejad, A. 2008. Evaluation of apple vegetative rootstocks for resistance to Phytophthora cactorum. $18^{\text {th }}$ Iranian Plant Protection Congress. Hamedan, Iran.

- Dastjerdi, R., and Hassani, D. 2010. Study of walnut anthracnose and determination of pathogenicity diversity in Gnomonia leptostyla isolates in greenhouse. $19^{\text {th }}$ Iranian Plant Protection Congress. Tehran, Iran.

- Dastjerdi, R., and Hassani, D. 2010. Survy on reaction of thirteen walnut cultivars and genotypes to black spot in greenhouse. $19^{\text {th }}$ Iranian Plant Protection Congress. Tehran, Iran.

- Dastjerdi, R., Hassani, D., Javan-Nikkhah, M., Farhadnejad, A., and Salahi, S. 2008. Evaluation of some walnut cultivars and genotypes for relative resistance to anthracnose. $18^{\text {th }}$ Iranian Plant Protection Congress. Hamedan, Iran.

- Salahi, S., Javan-Nikkhah, M., Zad, J., Hassani, D., Dastjerdi, R., and Jamshidi, S. 2006. Geographical distribution and determining of some traits of Gnomonia leptostyla isolates on walnut trees in East Azarbaijan. 17 ${ }^{\text {th }}$ Iranian Plant Protection Congress. Tehran, Iran.

- Saman, S.M., Mozafari, J., Abasi moghadam, A., Vaezi, S., and Dastjerdi, R. 2010. Evaluation for resistance to Fusarium oxysporum f. sp. lentil in the lentil collection of National Plant Gene-Bank of Iran. $19^{\text {th }}$ Iranian Plant Protection Congress. Tehran, Iran. 